\title{
Un-Natural Histories: The Specimen as Site of Knowledge Production in Contemporary Art
}

Helen Gregory, The University of Western Ontario

Supervisor: Dr. Bridget Elliott, The University of Western Ontario

A thesis submitted in partial fulfillment of the requirements for the Doctor of Philosophy degree in Art and Visual Culture

(c) Helen Gregory 2016

Follow this and additional works at: https://ir.lib.uwo.ca/etd

Part of the Contemporary Art Commons

\section{Recommended Citation}

Gregory, Helen, "Un-Natural Histories: The Specimen as Site of Knowledge Production in Contemporary Art" (2016). Electronic Thesis and Dissertation Repository. 3694.

https://ir.lib.uwo.ca/etd/3694

This Dissertation/Thesis is brought to you for free and open access by Scholarship@Western. It has been accepted for inclusion in Electronic Thesis and Dissertation Repository by an authorized administrator of Scholarship@Western. For more information, please contact wlswadmin@uwo.ca. 


\begin{abstract}
One of the primary functions of museums is the preservation and deployment of knowledge as articulated through collected artifacts. In the case of natural history museums, these collections consist largely of preserved specimens that, despite being natural in origin, all share the marks of the human hand as a result of the processes of preservation and display. Such processes engender a fusion of nature and culture: the transformation of nature into objects of material culture. Given the challenges that arise from shifting definitions of what constitutes a natural history specimen in an age when life is being re-defined and reconfigured, and living matter is treated as a mutable and expressive substance, I question how our perception of the "order of life" has been impacted by recent developments in genetic manipulation, tissue engineering, and DNA taxonomy. I extend the discussion of the impact of the human hand on natural objects to include the practices of contemporary artists whose practices borrow heavily from museum technologies, such as taxidermy, wet preservation, field research, scientific illustration, and bioartists whose practices use biotechnology to investigate the shifting relationship between living organisms and taxonomy. I ask how the work of artists who are addressing these classificatory shifts can illuminate how we understand such changes. How can the work of artists using biotechnology be positioned in relation to artists who use more traditional practices to address similar issues? How is the discipline of the natural history museum implicated in these practices? I focus on the hierarchical nature of knowledge in art and science, the changing use of language in classification, systems of preservation and display, and mutations and hybrid organisms, to suggest that natural history as a discipline, can be viewed as a mediating factor between the museum, on the one hand, and both scientific and art practices on the other. The specimen therefore functions as a site of knowledge production that merges both the museological impulses of preservation and conservation with the scientific/laboratory-based impulses of experimentation and alteration.
\end{abstract}

\title{
Keywords
}

Natural History, Taxidermy, Bioart, Art-science Collaboration, Museum Studies, Natural History Collections, Natural History Specimens, Taxonomy, Cabinet of Curiosities, Chimera, Genetic Manipulation, Tissue Culture 


\section{Acknowledgments}

I have finally arrived at the end of a journey that I didn't think that I would ever have the opportunity to begin, let alone finish. I certainly would not have succeeded without significant help along the way. I would like to thank Dr. Jennifer Dyer of Memorial University who provided a great of deal help and encouragement when I initially began to consider undertaking my $\mathrm{PhD}$, and who went above and beyond the call of duty in her role as my academic advisor. Once I arrived at Western, I had the immediate pleasure of encountering the wonderful and supportive department, including both staff and faculty. I would like to thank Paula Dias and Marlene Jones in particular for always being both helpful and extremely kind to me. Any attempt to acknowledge all of the faculty members who have offered support and advice along the way make it obvious in how many capacities I have benefitted from their time and efforts, from helping me to decide which side of the fence to fall on - studio or art history - to the reading of my initial prospectus. Deserving of particular gratitude in this regard are Patrick Mahon, Dr. John Hatch, Dr. Sarah Bassnett, Dr. Joy James and Dr. Kirsty Robertson.

I would like to thank the members of my examining committee for having graciously offered their time to read this dissertation, including (again) Dr. John Hatch and Dr. Kirsty Robertson, Dr. Joshua Schuster, and especially Dr. Nigel Rothfels for his words of encouragement over the past three years and for travelling to attend my defense.

I would like to extend my great appreciation to all of the artists who granted permission for the reproduction of their work in this dissertation, and who have taken the time to provide input, especially Oron Catts of Tissue Culture and Art Project who has proven to be exceptionally helpful and extremely generous with his time and resources, Richard Pell of the Center for PostNatural History, Marta de Menezes, Cornelia HesseHonegger, and Gemma Anderson with whom I had such stimulating conversations following our panel session together at the University Art Association of Canada Conference in 2014. I would like to thank Dr. Elizabeth Stephens for offering feedback on a very early draft of chapter two of this dissertation. 
I offer my deepest gratitude to Dr. Bridget Elliott and Dr. Tony Purdy who, although they held different roles throughout this process, deserve equal thanks. As my supervisor, Bridget not only provided excellent and pragmatic feedback as I have pushed my way through course work, minor comprehensive exams, major comprehensive exams, the prospectus, and finally this dissertation, but also offered no small amount of emotional support. I would like to thank Tony for having sufficient faith in me to suggest the coauthored paper that led to my first journal publication. I would particularly like to acknowledge the effort put in during the final stages of preparing to submit my dissertation. Bridget and Tony, I'm so profoundly grateful for the many ways in which you have both supported me, it is almost impossible to put it into words.

Finally I would like to thank my support system of family and friends, near and far, who have offered encouragement, empathy, and occasional sustenance. Michelle, thank you for being such a great friend. It's amazing how something as simple as a plate of dinner offered when I was falling apart under the stress of deadlines could leave such a lasting impression. To my parents, thank you for a lifetime of encouragement and teaching me to believe in myself. And to Mark, who has borne the brunt of my stress through my MPhil, a major exhibition of paintings, and now my PhD...thanks for standing by me throughout it all. I am grateful that I didn't have to do it alone. Special thanks also go to William and Morris who have been by my side the whole time, often literally.

Of course, despite the many sources of emotional and intellectual support that I have received, I would not have been able to complete this $\mathrm{PhD}$ without adequate funding. I would like to gratefully acknowledge the generous financial support of the Social Sciences and Humanities Research Council of Canada, the Department of Visual Arts, and the Faculty of Arts and Humanities. This support has allowed me the opportunity to travel for research, to speak at international conferences, and to make invaluable professional connections, all of which have made completing my $\mathrm{PhD}$ a rich and rewarding experience. 


\section{Table of Contents}

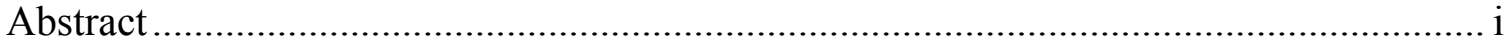

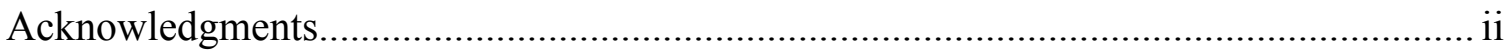

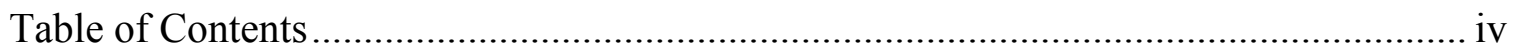

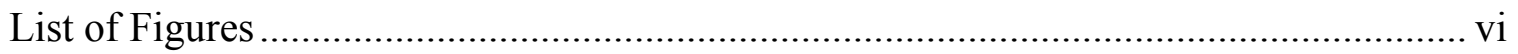

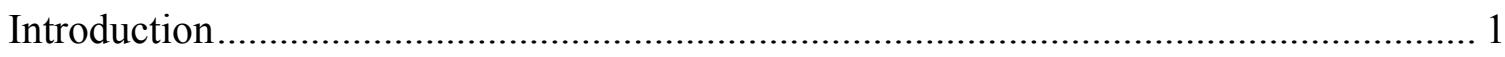

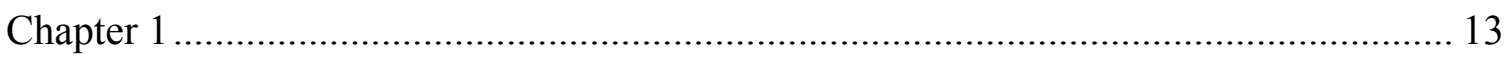

1 Fieldwork, Laboratories, and the Construction of Knowledge ................................ 13

1.1 The Spaces of Knowledge ...................................................................... 13

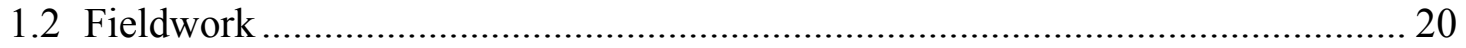

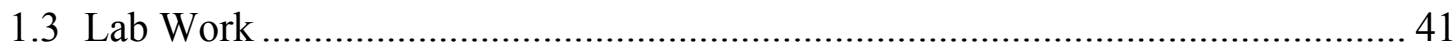

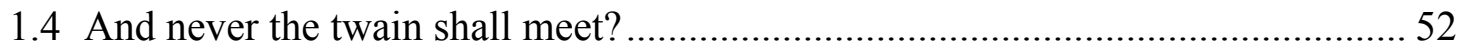

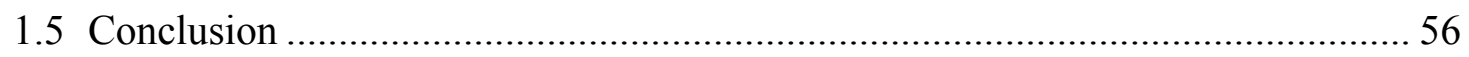

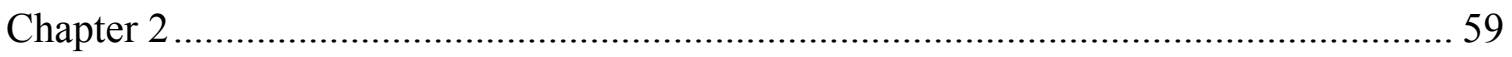

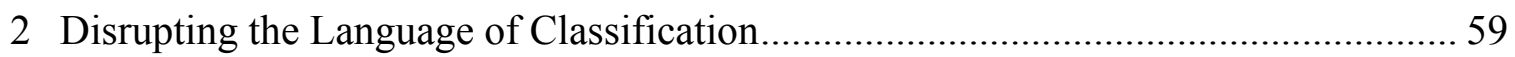

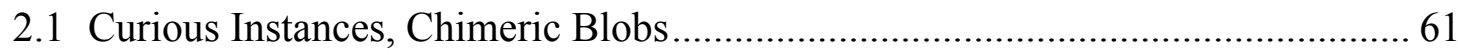

2.2 Fragments of Language, Fragments of Life.................................................... 73

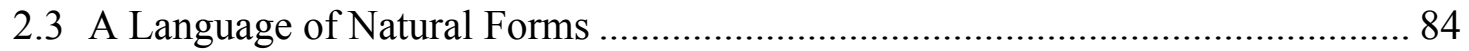

2.4 DNA Barcoding as an Imperfect Taxonomy …....................................... 88

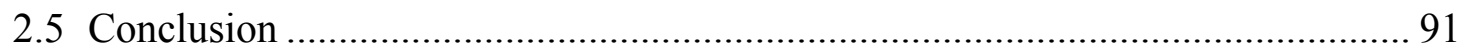

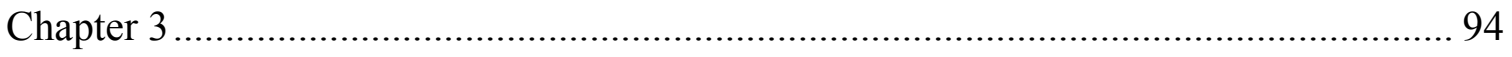

3 Of Vitrines and Bioreactors: Museums and Methods of Preservation and Display .... 94

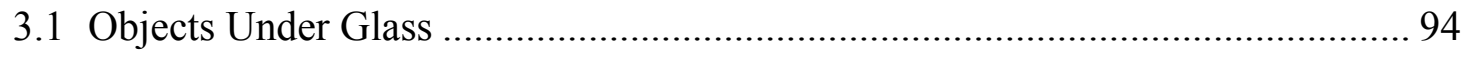

3.2 Taxidermy: the Preserved Animal Body .................................................. 99

3.3 In the Belly of a Whale: Fiona Tan's Depot ................................................ 110 
3.4 Mark Dion's Curious Specimens ................................................................. 116

3.5 Exhibiting the Postnatural Specimen................................................................. 128

3.6 The Bioreactor as Vitrine ................................................................................ 138

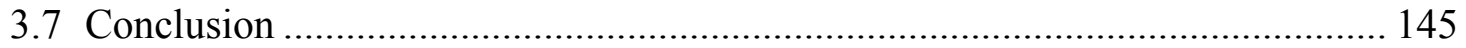

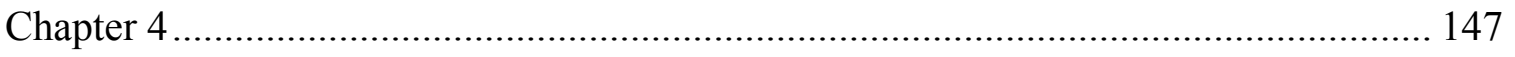

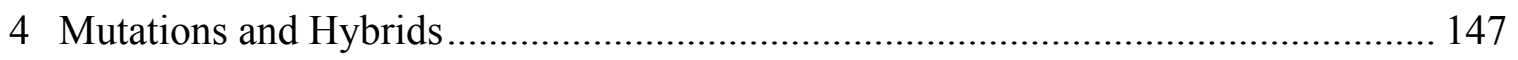

4.1 Making Sense of Monsters................................................................................ 147

4.2 Taxidermic Hybrid Constructions........................................................................ 152

4.3 Bioart and the Recombinant Life Form ........................................................... 160

4.4 Human/ Non-Human Hybrids........................................................................... 179

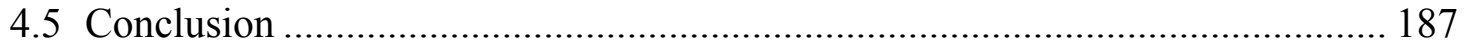

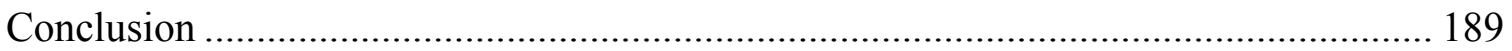

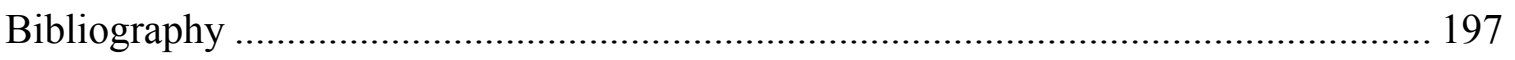

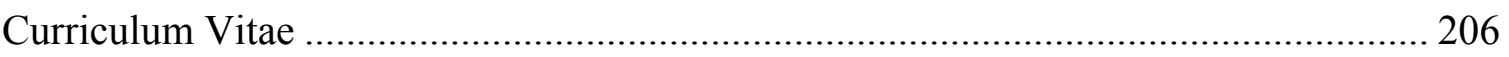




\section{List of Figures}

\section{Chapter 1}

Figure 1.1: Brandon Ballengée, Malamp Drawing 024, 1996-98.

Figure 0.1.2: Brandon Ballengée, Malamp DFA 23: Khárôn, 2001/07...................24

Figure 1.3: Brandon Ballengée, Malamp Reliqueries (installation), 2001-ongoing. .25

Figure 1.4: Cornelia Hesse-Honegger, Garden Bug Rhaphigaster nebulosa, 1991. Insect found in Küssaberg, Germany, about ten kilometers east of the nuclear power plant at Leibstadt.

Figure 1.5: Mark Dion, Systema Metropolis Fieldwork 1, 2007, Natural History Museum, London.

Figure 1.6: Mark Dion, Systema Metropolis Fieldwork 2, 2007, Natural History Museum, London. .38

Figure 1.7: Mark Dion, Systema Metropolis Fieldwork 3, 2007, Natural History Museum, London

Figure 1.8: Mark Dion, Systema Metropolis Fieldwork 4, 2007, Natural History Museum, London

Figure 1.9: Tissue Culture and Art Project, Lab-grown "steak" from Disembodied Cuisine, 2003

Figure 1.10: Tissue Culture and Art, Disembodied Cuisine (installation), 2003.............44

Figure 1.11: Marta de Menezes, Nature?, 1999....................................48

Figure 1.12: Marta de Menezes, Nature? (installation), 1999..........................50

Figure 1.13: Dorothy Cross, Medusae (film still), 2003..............................54 


\section{Chapter 2}

Figure 2.1: Tissue Culture and Art Project, NoArk, 2007...........................62

Figure 2.2: Tissue Culture and Art Project, NoArk (detail), 2007......................63

Figure 2.3: Tissue Culture and Art Project, Odd Neolifism 2010.......................69

Figure 2.4: Tissue Culture and Art Project, Odd Neolifism (detail), 2010..................70

Figure 2.5: Gemma Anderson, Isomorphology, 2012-2013........................85

Figure 2.6: Gemma Anderson, Hexagonal Forms, 2012.............................. 86

\section{Chapter 3}

Figure 3.1: Snæbjörnsdóttir/Wilson, nanoq: flat out and bluesome (2004) installation featuring 10 polar bear specimens, Spike Island Bristol, UK

Figure 3.2: Snæbjörnsdóttir/Wilson, Somerset from the photographic archive, nanoq: flat out and bluesome (2004) Lambda print. ... 103

Figure 3.3: Snæbjörnsdóttir/Wilson, Worcester from the photographic archive, nanoq: flat

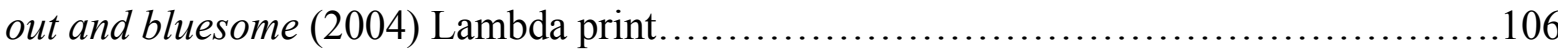

Figure 3.4: Fiona Tan, Depot, 2015, Baltic Centre for the Arts, Gateshead, UK............112

Figure 3.5: Fiona Tan, Leviathan (screened in conjunction with Depot), 2015...........114

Figure 3.6: Mark Dion, Oceanomania, 2011, Oceanographic Museum of Monaco.........118

Figure 3.7: Mark Dion, Davy Jones Locker, 2011, Nouveau Musée National de Monaco...120

Figure 3.8: Mark Dion, Neukom Vivarium, 2006, Olympic Sculpture Park, Seattle.........122

Figure 3.9: Mark Dion, Neukom Vivarium, 2006, Olympic Sculpture Park, Seattle.........123

Figure 3.10: Center For PostNatural History, Pittsburgh 
Figure 3.11: BioSteel ${ }^{\mathrm{TM}}$ Goat, Center for PostNatural History, Pittsburgh.

Figure 3.12: Richard Pell, Atomic Age Rodents, 2011, Center for PostNatural History, Pittsburgh.

Figure 3.13: Center for PostNatural History, Knock-out Mice, (installation detail)

Figure 3.14: Tissue Culture and Art Project, Tissue Culture and (Art)ificial Wombs or SemiLiving Worry Dolls, 2000 141

Figure 3.15: Tissue Culture and Art Project, The "feeding ritual" (tissue cultures are provided with necessary nutrients).

\section{Chapter 4}

Figure 4.1: Deborah Sengl, The Lioness - As Predator - Disenguises Her Desired Prey, 2004. 155

Figure 4.2: Idiots, Ophelia, 2005 156

Figure 4.3: Idiots, Geologische Vondst II, 2012. 157

Figure 4.4: Idiots, This Seat is Taken, 2007. .158

Figure 4.5: Eduardo Kac, GFP Bunny, 2000

Figure 4.6: Eduardo Kac, The Eighth Day (view of biobot), 2000

Figure 4.7: Tissue Culture and Art Project, Pig Wings, 2000-02

Figure 4.8: Eduardo Kac, The Natural History of the Enigma (installation), 2009 .180

Figure 4.9: Eduardo Kac, The Natural History of the Enigma (detail: "Edunia"), 2009.....182

Figure 4.10: Art Objet orienté, Que le Cheval Vive en Moi (May the Horse Live in Me), 2011 


\section{Introduction}

As has been well established in recent scholarship, natural history specimens can be defined as a combination of nature and culture. They are objects removed from nature and re-contextualized in museum and university collections, and as a result of the processes required for their preservation and display they are transformed into objects of material culture. Many museums have also recently moved towards keeping parallel collections of DNA sourced from their historical collections, taking the act of transformation a step further. This thesis responds to the questions that arise from the subsequent shifting definitions of what constitutes a natural history specimen in a world where not only is the nature of museum collections changing, but life is being redefined and reconfigured, and living matter is treated as a mutable and expressive substance. How has our perception of the "order of nature" been impacted by recent developments in genetic manipulation, tissue engineering, and DNA taxonomy? The notion of the mutability of life is by no means the exclusive territory of those working in the natural sciences and biotechnology, but has also been embraced by artists working in various mediums ranging from traditional techniques of representation such as drawing and painting and the appropriation of museum technologies such as taxidermy and display, to the use of advanced biotechnological practices such as genetic modification and tissue culturing. How can the work of artists addressing these classificatory shifts illuminate how we understand them? How can the work of artists using biotechnology be positioned in relation to artists who use more traditional practices to address similar issues? How is the chronology of the natural history museum implicated in these practices?

For the purposes of this thesis, I have taken a relatively flexible view of natural history specimens, but confined my research to preserved matter derived from formerly living things, primarily animals and the tissues and cells derived from them, as well as insects and plants. I have excluded geological specimens, and human specimens with the exception of where the artist has integrated elements of their own body into their work. I have also limited my discussion of bioart practices - which is a much broader field than the one I present in this thesis - to projects that deal with material that could fall under the definition of natural history as delineated here. 
There is currently an extensive body of scholarship on the various fields that my research engages: museum studies, the history of museum collections, museum display practices, the history of taxonomy and classification including DNA taxonomy, as well as writings that focus on artists whose work involves interactions with either natural history museum collections, or with biological and biotechnological laboratory research. The means by which contemporary art takes up these intersecting discourses, specifically with regards to the relationship between bioart practices and more traditional art practices that focus on natural history, remains a relatively new area of exploration. In particular there is little that positions bioart within a discussion of the history of natural history.

Throughout this dissertation, I will be arguing that the aforementioned advances in biotechnology pertaining to genetic manipulation and tissue culturing have resulted in objects and organisms that are difficult to understand, classify, and preserve, from both a museological standpoint and within a broader cultural context. Although these advances represent potential benefit for humankind, they also recall moments from the past when knowledge of the natural world was expanding more rapidly than could be adequately comprehended. My argument finds its roots in the assumption that one of the primary functions of museums is the preservation and deployment of knowledge as articulated through collections of such objects. These collections have taken various forms over the past four centuries. Early constructs of museums were rooted in the palatial collections of treasures acquired by fifteenth-century Italian princes, sixteenth-century cabinets of curiosity, and seventeenth-century repositories of scientific thought and experimentation. ${ }^{1}$ Collections of artifacts and specimens have been accumulated and displayed in a quest to understand not only the world but also our position within it, and museums generally function as the repositories of such collections: objects and phenomena that have been removed from their original contexts and repositioned in a

\footnotetext{
1 The seventeenth century heralded the beginning of what Foucault termed the Classical episteme, which marked the advent of modern science including natural history. See Michel Foucault, The Order of Things: An archaeology of the human sciences, London and New York: Routledge, 2002, especially chapter 5 on "Classifying." Also, Eilean Hooper-Greenhill, Museums and the Shaping of Knowledge, London: Routledge, 1992, for further reading on structures of knowledge and power in early museums.
} 
hermetic world of seemingly infinite possibilities of recombination. ${ }^{2}$ In contrast to the fifteenth-century collections of art and artifacts whose primary aim was to display the prestige, power and wealth of the collector, there was a shift in emphasis in sixteenthcentury collections towards producing a private cabinet that juxtaposed objects against one another in order to reproduce a microcosmic vision of the world. Eilean HooperGreenhill argues that, "The fact that the world was interpreted in terms of allegory and symbol, and that this could be endlessly reinterpreted through reversibility and shifts in emphasis meant that each thing could be ordered and reordered as different classifications or different contexts of meaning or plays of sympathies were employed. ${ }^{33}$ Although the archetypal cabinet is generally portrayed as an undisciplined accumulation of unrelated objects randomly assembled, the mere fact that they were brought together suggests an attempt to gain knowledge about the world. According to Hooper-Greenhill, these cabinets were characterized by two possible functions: firstly, to represent a microcosm of the world, and secondly, both to demonstrate knowledge of that world and to establish the position of the ordering subject within it. ${ }^{4}$ These two objectives can be contradictory in nature in that the former recreates an existing order in the world, whereas the latter allows the ordering subject to create his or her own interpretation.

The shift away from the collection of predominantly man-made works of art as an index of the owner's power towards the later notion of a collection inclusive of objects drawn from nature as a means of discovering man's position within the natural order of the world is indicative of what Foucault described as an epistemological rupture between the Renaissance and the Classical age. ${ }^{5}$ As Hooper-Greenhill explains it,

Where, in the earlier period, man is subsumed within the hierarchized cosmology, and the world, the existent, is understood as an expression of the Creator-God, in

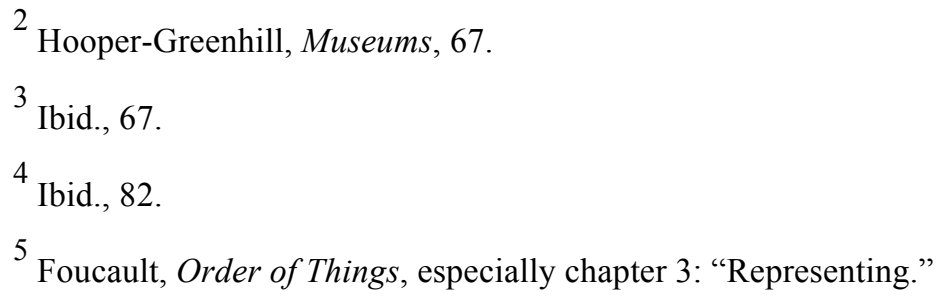


the later period the subject is struggling to find a way to represent the world as his own creation, part of which struggle represents the emergence of the subject $\operatorname{him} /$ herself. $^{6}$

Although it is perhaps an exaggeration to suggest that we currently live in a period of similar epistemic rupture, it is true that we are capable of creating new organisms and are effectively redefining our place as subjects within the shifting field that constitutes our natural world. The notion of the museum, if it can be loosely (although certainly not definitively) defined as a space in which collected objects are maintained and displayed with some level of curatorial intent, has evolved from being a private repository for objects of knowledge and power that could be ordered and reordered according to the whims of its owner, and has come to exist in a variety of spaces and to serve a diversity of purposes. The natural history museum in particular has come to function not only as a site of knowledge dissemination through the display of collected objects, but also as a venue for the creation of new knowledge through integrated research facilities.

When artists interact with scientific practices and museum collections, they not only engage the public in discourse surrounding scientific, technological, and aesthetic debates, they also highlight how we define ourselves both through research and through the resulting collections of material culture - and preserved specimens are indeed a form of material culture. The artifacts that have resulted from the history of scientific exploration are often placed in science and natural history museums for public viewing, yet the practices of exploration and experimentation that have revealed these objects generally take place behind the scenes in laboratories. Although science currently occupies the privileged position in society as the domain in which experimentation takes place, it can be argued that science is merely one mode of experimentation in a culture that thrives on this type of investigation. Science may have transformed our existence and our understanding of the world, but it is only one aspect of culture to have done so. Not only do artists practice within a contemporary visual culture that can be viewed as a

${ }^{6}$ Ibid., 84 
metaphorical laboratory space in which experiments in a broader sense occur, but many also engage in practices that straddle the line between scientific research and traditional studio practices. Contemporary art-science collaborations, for example, often result in research-based works of art that resemble science as much as they resemble art.

In addition to laboratory-based art practices that involve bioreactors, tissue cultures, and genetic manipulation in line with current biological research, there are also representational practices that have their roots in natural history illustration and taxidermy. On the one hand, for example, there are artists such as Eduardo Kac, who defines himself as a transgenic artist and whose practice routinely involves the manipulation of genetic material by transferring synthetic genes to an organism, by mutating an organism's own genes, or by transferring existing genetic material from one species into another to create a hybrid species. On the other hand, we have artists like Thomas Grünfeld, whose ongoing series Misfits uses the traditional technique of taxidermy to create combinatory organisms that owe as much to Bavarian folktales as they do genetic engineering.

It is the relationship between these two modes of scientific/aesthetic enquiry practices arising from scientific research and practices based on traditional forms of representation - that provides the framework for this thesis. I suggest that there is an affinity between the practices of particular bio-artists who are working with living organisms and artists whose practice involves the use of non-living matter, and I contend that the crux of that relationship can be found by investigating representations of the specimen. I also argue that natural history as a discipline, with its focus on the preserved specimen, can be viewed as a mediating factor between the museum, on the one hand, and both scientific and art practices on the other. Consequently, my focus is on the specimen as site of knowledge production that merges both the museological impulses of preservation and conservation with the scientific/laboratory-based impulses of experimentation and alteration. 
Derived from the Latin specere, meaning "to look," The Oxford English Dictionary variously defines the word specimen ${ }^{7}$ as: a means of discovering or finding out; an experiment; an example, instance, or illustration of something, from which the character of the whole may be inferred; a single thing selected or regarded as typical of its class; a part or piece of something taken as representative of the whole; an animal, plant, or mineral, a part or portion of some substance or organism, etc., serving as an example of the thing in question for purposes of investigation or scientific study. Such a definition implies acts of looking, discovering, observing and deducing, collecting and classifying, as well as drawing attention to the metonymic and synecdochic potential of the object itself. We might ask how these activities translate into certain contemporary art practices, spanning the spectrum from traditional forms of representation through taxidermy and the use of preserved organic materials to the use of biotechnology and living cellular tissues and matrices. If one can group much of this activity together using the common activity of nature mediated by the human hand, where does bio-art fit into this territory? Do we still classify this raw material as "nature" if the starting point is matter that exists merely at the cellular level? Or is it more easily classified as a purely human construct?

Further questions arise from the manner in which our understanding of natural history is complicated by advances in biotechnology, and subsequently foregrounded by the artists who appropriate them. Bioart collective Tissue Culture and Art Project, for example, has suggested that by working with such new and unprecedented technologies including tissue culturing, regenerative medicine, and genetic manipulation - scientists are creating new organisms that effectively disrupt established systems of classification and taxonomy. Further to this, they address the recent movement in natural history museums towards collecting the fragments of life, frozen tissue and DNA samples ostensibly capable of representing whole species. What do these fragments mean and how do they function in relation to the preserved specimens that are the mainstay of museum collections?

${ }^{7}$ http://www.oed.com.proxy1.lib.uwo.ca/view/Entry/186018?redirectedFrom=specimen 
Given that I am making strong connections to work performed in the laboratory and in the museum, I feel it necessary to justify the connection that I perceive between these two spaces. Here I would like to briefly turn to Foucault for a perspective on museums, natural history and heterotopic spaces. I suggest that Foucault's notion of the heterotopic space can be used in an analysis of these art-science practices, and while it has frequently been invoked in reference to the museum, I argue that it can similarly be applied to a discussion of the research laboratory. Foucault defines a heterotopia as a kind of enacted utopia, a space in which other real sites that can be found within a culture are "simultaneously represented, contested, and inverted." 8 They are spaces of difference that exist both in the world, yet slightly outside of it. Heterotopic spaces rely on some variation of the principles outlined by Foucault, including being capable of combining multiple incompatible sites within a single existing real place, and representing a totality of time through the continuous acquisition and juxtaposition of artifacts from different temporal moments. Consequently such a space is characterized by "the idea of accumulating everything, of establishing a sort of general archive, the will to enclose in one place all times, all epochs, all forms, all tastes, the idea of constituting a place of all times that is itself outside of time and inaccessible to its ravages." "9any laboratories, particularly those willing to host artist-researchers are affiliated with other larger institutions such as universities or museums, which in and of themselves can be described as places that are both removed from the world and also reflective upon it, and are also spaces characterized by numerous synchronous spatio-temporalities. Another principle of the heterotopia embodied by the laboratory is that of a system of opening and closing that makes the space both isolated and impenetrable. Foucault tells us that these spaces are not freely open to the public and to access them requires permission: for an artist to work in a laboratory space, they must prove that they have either the necessary practical knowledge or some sense of curiosity that might make collaboration mutually rewarding.

\footnotetext{
8 Michel Foucault, "Of Other Spaces,” Diacritics 16, No 1, (Spring 1986), 22-27.

9 Foucault, "Of Other Spaces," 26.
} 
The natural sciences have their origin in a period of epistemic rupture that Foucault traces back to the mid to late seventeenth century, starting with Johnston's publication of his Natural History of the Quadruped, when living things were no longer described according to the entire semantic network that connected them to the world, and began instead to be described mainly by their physical attributes: their anatomy, their form, their habits:

Natural history finds its locus in the gap that is now opened up between things and words - a silent gap, pure of all verbal sedimentation, and yet articulated according to the elements of representation, those same elements that without let or hindrance be named...natural history - and this is why it appeared at precisely this moment - is the space opened up in representation by an analysis which is anticipating the possibility of naming: it is the possibility of seeing what one will be able to say. ${ }^{10}$

Taking up the ramifications arising from this gap between object and language, Beth Lord argues contemporary museums cannot easily be described as heterotopic spaces according to Foucault's definition, as many are now more concerned with narrative and experience rather than the continued acquisition and juxtaposition of multi-temporal artifacts. She suggests (and I would argue that this also applies to the laboratory) that heterotopias should be regarded as a space of difference, the difference between objects and concepts, which she equates with curatorial interpretation - the relationship between things and the words used to describe them. ${ }^{11}$ Ultimately I suggest that it is in this gap between things and words as described by Foucault, or between objects and interpretation as described by Lord, where artists practicing at the intersection of art, natural science, and museology are able to do the work of representation, of finding and articulating the meaning that exists in the undefined area where these disciplines converge.

\footnotetext{
10 Michel Foucault, Order of Things, 141.

11 Beth Lord, "Foucault's Museum: Difference, Representation, and Genealogy," Museum and Society 4, Issue 1, (March 2006), 5.
} 
In order to determine how artists construct artistic knowledge in this field, I break my discussion down into four areas: the hierarchical nature of knowledge, the language of classification, cultures of preservation and display, and finally, mutations and hybrids. In Chapter one, Fieldwork, Laboratories and the Construction of Knowledge, I examine how hierarchies of knowledge persist not only between the disciplines of art and science but also between those who possess scientific knowledge through advanced education and the general public who may not. Artists working at the intersection of art and science are in a position to destabilize these hierarchies, and bridge the gap between the kinds of knowledge available to scientists and to the public. They are also in the position of taking a more socially critical stance with regards to advances in science and technology.

Drawing on Robert E. Kohler's suggestion that a binary relationship exists between the field and the laboratory, I examine how this affects artists who have worked within these spaces. I suggest that the field and the laboratory are associated with different types of research, and correspondingly lead to different types of art practice. Because of its past association with amateur naturalists, field research provides a somewhat more receptive space to those without a formal scientific background, although not in all cases. Brandon Ballengée blurs the line between artist and biologist, whereas Cornelia Hesse-Honegger, who has a background in scientific illustration, has performed extensive field research into radiation-induced mutations in true bugs, but has been heavily criticized by scientists for publishing her findings. The laboratory has traditionally been seen as an even more inaccessible space, available only to those with the required educational background. Tissue Culture and Art Project have much of the required specialist knowledge but regard themselves as artists, and use that status to pose critical questions surrounding the role of biotechnology in society. They have also set up workshops to bridge the gap between those who can access that knowledge and those who normally cannot. Marta de Menezes also works in laboratories but uses them as a space to pursue aesthetic questions. This binary is contrasted with two other models. Mark Dion embraces his dilettante status, and collaborates with scientists and museum staff in order to illuminate the role that institutions have in the formation of scientific knowledge. Artist Dorothy Cross and her zoologist brother Dr. Tom Cross, have worked together but without borrowing from each other's methodologies. Their research has the form of an "encounter" rather than 
collaboration, resulting in two parallel bodies of knowledge arising from a single investigation.

In Chapter Two, Disrupting the Language of Classification, I begin with the premise that natural history museums depend on systems of classification to articulate how nature is structured through relationships of predictability and similarity. Because every culture names and categorizes, these relationships are expressed through language. However, existing categories are being challenged by the proliferation of new kinds of organisms including hybridomas, genetically modified organisms, and organisms altered through tissue culturing, consequently creating unclassifiable creatures and a "crisis" of taxonomy. I suggest that this crisis calls for a new approach to taxonomy that has its roots in Francis Bacon's proposal for a natural language. I turn to the work of Tissue Culture and Art Project as well as Gemma Anderson, each of whom provides a different perspective on the subject of classification, and both of whose work I argue can be aligned with Bacon's ideas regarding classification through non-linguistic symbols that are isomorphic to the things they represent. Concurrent with the aforementioned biotechnological advances, museums have begun storing DNA samples and turning to DNA sequencing to identify organisms rather than using traditional morphological taxonomy. I argue that this turn towards technology in an attempt to preserve the past promises longevity of storage as well as speed and efficiency in identifying as yet unnamed specimens, while at the same time threatening the viability of traditional taxonomy and limiting the biographical potential of existing museum specimens.

Working from the premise that, in contemporary art, the bioreactor functions in much the same way as a traditional museum vitrine, in chapter three, Of Vitrines and Bioreactors: Museums and Methods of Preservation and Display, I argue that both of these structures act as a disciplinary barrier between the viewer and the enclosed objects while at the same time combining the contradictory positions of offering up a spectacle and acting as a means of preservation and protection. I use several case studies to illustrate how the vitrine or the bioreactor acts as a marker of difference that dictates to the viewer how enclosed objects, specimens, or cultured tissues must be observed. Natural history dioramas, for example create an illusion of a natural environment while at 
the same time obscuring the colonialist histories that led to the collection of the mounted animals. Bryndís Snaebjörnsdóttir and Mark Wilson, in the project nanoq: flat out and bluesome, explore the violent colonial legacy of taxidermic polar bears in both private and museum collections, and by recontextualizing them in a white cube style gallery space, reconnect the bears with their lost histories. Fiona Tan incorporates glass vitrines, filmed images of wet specimens, and a flatbed truck to invoke the absent body of a preserved whale in Depot, an installation that explores the relationship between hunting, science, spectacle, and preservation. Mark Dion plays on the history of the research laboratory as well as the greenhouse as both a method of display and a functioning microecosystem in Neukom Vivarium to draw attention to the fragility of the natural environment. The Center for PostNatural History channels Victorian display techniques including taxidermy, glass vitrines, and recessed display cases to present a collection of organisms that have been changed through either genetic modification or selective breeding. Tissue Culture and Art Project draw on the history of infant incubators to foreground the duty of care that they owe to the semi-living sculptures they display in bioreactors. In each of these examples, I argue that the viewer's assumptions regarding his or her relationship with the objects of nature contained within the glass structure, be it vitrine, greenhouse, or bioreactor, is unsettled through the use of that particular method of display.

Finally, in chapter four, Mutations and Hybrids, I suggest that the various "unclassifiable" objects that are discussed throughout the thesis, but particularly those in this chapter, can be regarded as the monsters and mirabilia of the modern age. Mirabilia is the term used to describe the miraculous objects created by sixteenth-century craftsmen who gilded and otherwise embellished natural objects such as coral and nautilus shells. Drawing on Rachel Poliquin's work on taxidermy, and W.J.T. Mitchell's “The Work of Art in the Age of Cybernetic Reproduction," I focus on three categories in which artists explore the mutable potential of organic material: taxidermic hybrid constructions, bioart and recombinant life forms, and human/non-human hybrids. I draw on case studies including Thomas Grünfeld, Deborah Sengl, and Idiots, all of whom combine different animal bodies using the techniques of taxidermy to create sculptures that reference both the history of chimeras and the advent of biotechnology. I contrast these traditional 
approaches to sculpture with bioartists Paul Perry, who has created hybridomas that combine his own cells with immortal cancer cells and Eduardo Kac, who creates transgenic art using living animals and treats DNA like an expressive text to be edited and embellished. Finally, I analyze the ethical implications of breaching the human/nonhuman divide in the performance by Art Objet orienté, May the Horse Live in Me, in which the artists obscure the boundaries of what it means to be human or animal by injecting horse serum into the body of Marion Laval-Jeantet. I conclude with the cautionary note that in as much as all of these projects can be regarded as contemporary mirabilia, the impulse that drives their creation is not beyond criticism. Objects once celebrated as nature's rarities have now become all too rare indeed. 


\section{Chapter 1}

\section{Fieldwork, Laboratories, and the Construction of Knowledge}

\subsection{The Spaces of Knowledge}

Between the eighteenth and nineteenth centuries, natural history underwent a transformation in which there was a shift in emphasis from the classification systems of plant and animal specimens to an increased interest in investigating organisms' interior structures and the functions of their physiological systems. Natural history was no longer an overarching field of investigation, but began to separate into various sub-disciplines focused on specific areas of research. As Dorinda Outram tells us, during this period, not only did natural history as a discipline begin to subdivide into specializations, the profession also underwent changes in terms of who performed the various types of research. ${ }^{1}$ Although biological data continued to be gathered by gentlemanly and gentlewomanly amateur naturalists working within an extensive network of learned clubs and societies, the discipline also began to see an increased emphasis on state-sanctioned research that took place in natural history museums.

Along with the separation of natural history into different areas of specialization, there was a concomitant division in the types of space in which that research took place. These spaces can be loosely divided into the exterior spaces of nature or "the field," and the interior spaces of museums and laboratories. Exterior spaces were primarily associated with concerns around taxonomy and systems of classification as well as with ecology and the natural environment. These exterior spaces also included zoos and gardens that were adjunct to the built space of the museum. Interior spaces such as the museum and the laboratory were the sites of research primarily based in experimentation. The separation between the two types of space came to carry different respective social

\footnotetext{
1 See Dorinda Outram, "New Spaces in Natural History," Cultures of Natural History, ed. N. Jardine, J.A. Secord, and E.C. Spary, (Cambridge and New York: Cambridge University Press, 1996), 249 -265.
} 
connotations that were the result, at least in part, of who was gathering and elucidating that new knowledge. Field research continued to carry associations with amateur naturalists, whereas the built space of the laboratory came to wield a greater scientific influence over the transmission of scientific knowledge that corresponded with the increased social capital of formally educated scientists. ${ }^{2}$ Because the built spaces of science have sometimes been accorded greater authority than external spaces such as botanical or zoological gardens, or even the natural environment in which scientists have done field research, this division continues to impact the credibility of knowledge borne through different types of experience. The resulting hierarchy of knowledge, in terms both of the spaces in which it has been constructed and of those who have performed the research, continues to impact how scientific information is perceived. This hierarchy exists not only within the various fields of science per se, but also in instances when scientific knowledge is the result of research performed by those from other fields. For the purposes of this dissertation, I will focus on how hierarchies of scientific knowledge persist between the disciplines of art and science, and have been destabilized by artists working in the intersections of the two specializations.

Robert E. Kohler argues that the rift between biology done in the field and biology done in the laboratory, as described by Outram, continues in contemporary scientific culture. Furthermore, he tells us, despite the relationship between the laboratory and the museum that was established during the nineteenth century, that connection has become far less tangible today. He asserts, "The objects of laboratory work are not at all like those of herbarium or museum collections; they may be acquired in the field but are not specimens and are often so transformed for the purpose of experiment as to be quite unlike anything in nature...Experimenters analyze and reveal causes and effects; field biologists more often describe, compare, name, classify, map. In fieldwork spatial and locational ways of knowing have equal standing with causal reasoning. ${ }^{33} \mathrm{He}$ also argues

\footnotetext{
2 Outram, "New Spaces," 249-250.

3 Robert H. Kohler, Landscapes and Labscapes: Exploring the Lab-Field Border in Biology, (Chicago: University of Chicago Press, 2002), 2.
} 
that different types of knowledge arise from the different types of investigation that occur in the two types of space. In the case of field research, place is not only where the research occurs, but is also part of the research. The site itself both influences and is a part of the results. Laboratories, on the other hand, are seen as neutral territory where experiments are performed, but do not influence or become part of the outcome of the experiment. ${ }^{4} \mathrm{~A}$ further differentiation is that field research involves various players, including citizen scientists, hunters, trappers, surveyors, prospectors, and other people with knowledge of the area. In contrast, it tends to be a very specific type of person, usually with a specific set of qualifications, who populates the laboratory: laboratories are generally not connected to other social worlds. ${ }^{5}$ I propose that these assertions are complicated, however, when we introduce artists into this binary model. When an artist works in the laboratory, for example, the space does indeed become connected to another social world and the laboratory becomes an important part of any artwork created there. Furthermore, the space is no longer neutral due to the artist's status as a foreigner in that space. The laboratory, under such circumstances, informs the research that the artist performs and becomes imbricated within the meaning of whatever the artist produces while working there. The presence of the artist in the laboratory also highlights issues surrounding the amateur versus the professional. Any perceived hierarchy of how new knowledge is created becomes increasingly evident when it is an artist who has carried out the research, as it calls into question who is qualified to gather and present certain types of information.

Although Kohler argues that the connection between the spaces of the laboratory and the museum is increasingly tenuous, many natural history museums do continue to engage in research and have laboratories to support it. Research that occurs in the context of the natural history museum also involves a significant field research component. The resulting knowledge that grows out of these two imbricated fields also informs the

\footnotetext{
${ }^{4}$ Kohler, Landscapes and Labscapes, 6. Ibid, 7.
} 
museum collection. Brita Brenna argues that there are two types of collections held in natural history museums, each with separate functions: those that are on display to the public and those that are held in storage for the purpose of research. Those used for education and public display have been prepared artistically and aesthetically for maximum visual impact. Those held for research fall into two sub-categories: type specimens that formed the basis of the morphological description of a species, and a more expansive serial collection of multiple specimens acquired to document the breadth of variation that might occur from one specimen to another within a single species. Brenna argues that these two types of collection, display and research, have historically possessed different corresponding ontologies:

In the display case nature emerged as already identified and known. In the storage room, nature would make room for uncertainty. In the first instance, the objects are stilled and frozen, whereas a working collection would be dynamic as curators moved objects in and out of the cases to work with them, or entered new objects into the museum. In the public department, the object is made singular; in the research department, the objects are turned into part of a series. ... Maybe we can deduce that the singular object would stand in for an idea of nature, whereas the working object would "be" nature. ${ }^{6}$

Here, Brenna establishes the argument that the natural history collection as a whole has two different sets of epistemological potential: the publicly exhibited collection is static, and embodies knowledge as a closed, fixed entity, whereas the research collection is characterized as dynamic, a catalyst to further exploration, and indicative of knowledge as an open-ended process. Collections of specimens that are visible to the public on display in museums consist of those that have been identified and about which there exists a body of knowledge that is understood as correct. She contrasts these with

\footnotetext{
6 Brita Brenna, "The Frames of Specimens: Glass Cases in Bergen Museum Around 1900," Animals on Display: The Creaturely in Museums, Zoos, and Natural History, ed. Liv Emma Thorsen, Karen A Rader, and Adam Dodd, (University Park, Pennsylvania: The Pennsylvania State University Press, 2013 ), 49.
} 
collections that form the basis of scientific research conducted behind the scenes at museums, which she perceives as the locus of ongoing research.

At first glance, Brenna's proposed binary feels antiquated and seemingly only holds true for certain older museums with a deeply rooted history and relatively unchanging permanent exhibitions. However, despite the fact that her argument fails to take into account the extent of the current movement in many museums towards creating interactive installations that overcome perceptions of the permanent collection as fixed and unvarying, there are aspects of what she says that continue to hold true. Many museums do indeed now change their exhibitions to reflect advances in what is known about organisms, and many exhibits are also becoming increasingly interactive in an attempt to engage the public in understanding the natural world. The Natural History Museum in London, England, despite its Victorian architecture and remaining vitrines filled with old specimens, is now an exercise in contrasting display techniques. The antique vitrines and dioramas that occupy the geology, birds, and mammal sections stand in stark contrast to the multiple video screens and immersive environments that make up the "Green Zone" built to raise awareness of current ecological issues. However, despite attempts to engage visitors in interactive installations, there continues to exist a palpable feeling of restricted access between what is exhibited and what is going on "behind the scenes at the museum." Nowhere is this more apparent than in the Cocoon, the architecturally stunning research center adjacent to the Natural History Museum built in conjunction with the 2009 bicentenary celebrations of Charles Darwin's birth. The Cocoon was built to provide research space to the 350 staff researchers and 8000 visiting researchers as well as to house collections of specimens. Although, as a visitor, one can access the Cocoon via an impressive glass elevator, when one arrives there is little to see beyond a few glass-fronted installations embedded in the smooth, white, intensely solid, curvilinear walls that make up the new structure. A few windows provide oblique glimpses into the laboratories, but the overwhelming feeling is that of separation between those who have access to the spaces of research and knowledge, and those who don't.

On the other hand, there are museums that are actively working towards breaking down the all too literal walls between spaces of knowledge generation and spaces of 
knowledge reception. One such museum is the Exploratorium in San Francisco, California, which relies on the embodied experience of the visitor for the success of its exhibits. According to Michelle Henning,

The Victorian glass case exhibits had placed the visitor as an observer, and the 1930s mechanical and chemical displays had positioned the visitor as an operator or user. But the Exploratorium incorporated the visitor into the exhibition, so that the visitor's body and mind become the subject and content. The emphasis on the visitor's own bodily experiences is connected to the view that the process of disseminating scientific knowledge should start with people's own everyday experiences....the aim is to dismantle hierarchies of knowledge and to level the relationship between visitor and museum, public and science. ${ }^{7}$

In addition to relying on the body of the viewer as the focal point of the museum experience, the Exploratorium also places a strong emphasis on art as a means to transmit scientific knowledge to the public. Not only has it hosted significant touring exhibitions that investigated the intersections of art and science, but it has also employed artists as members of their educational staff. One such artist was Julia Reodica, a bioartist who has a background in both art and nursing, and who was employed at the Exploratorium from 1998-2004. In her role as exhibition support in the Life Sciences section, Reodica worked with exhibitions that often involved the use of living organisms. Many of these exhibits required regularly scheduled dissection or removal of organs according to protocols agreed upon as humane and practiced by lab staff. These included, for example, dissections of live crayfish including the removal of the nerve cord. This was part of an exhibit that illustrated nerve cord reaction to outside stimuli controlled by the museum patron. According to Reodica, the "sacrifice" of the animal that was made for the sake of communicating information through the use of "live science" was necessary and remains

\footnotetext{
7 Michelle Henning, Museums, Media, and Cultural Theory (Maidenhead, Berkshire: Open University Press, 2006), 85.
} 
the best way to understand biological principles. ${ }^{8}$ She further states, "By making scientific principles accessible outside the laboratory, I hope my work can help another person construct their own opinions and conclusions through this unconventional forum." "Such interactions with "live science" as visitors experience at the Exploratorium undoubtedly help break down barriers to the accessibility of scientific knowledge to nonspecialists.

Although one cannot realistically compare hands-on dissection exhibits to the research being performed by trained scientists, the efforts of museums that attempt to bridge the gap between the two worlds are both admirable and important. I suggest that artists can play a vital role in assisting in the destabilization of the hierarchical nature of scientific knowledge not only in museums but also in the field research and in the laboratories that have generated the knowledge often translated into museum display. Just as two types of collections that have shifting meaning and purpose can exist within the museum, I believe that both field and laboratory can be the sites of different types of knowledge generation: pure, objective, scientific research as performed by scientists, and research performed by artists that result in more subjective interpretations and provide a different sort of knowledge in response to the same stimuli or methods used by scientists.

The notion that scientific research contributes to what is known about a given organism, and contributes to a more dynamic interpretation of that organism, is beyond question. I suggest that in addition to formal scientific research, what is known about the natural world becomes even more multifaceted with the integration of artistic research, and allows for more complex bodies of knowledge and experience. There is, of course, a marked difference between methodologies associated with scientific research and artistic research/practice in that the two disciplines elicit answers to different types of questions.

\footnotetext{
8 Julia Reodica, "Test Tube Gods and Microscopic Monsters," The Aesthetics of Care? The artistic, social and scientific implications of the use of biological/medical technologies for artistic purposes (Perth, Australia: SymbioticA, School of Anatomy and Human Biology, University of Western Australia, 2002), 48.

9 Reodica, "Test Tube Gods," 49.
} 
Art is not science, nor should it attempt to be so. Broadly, the sciences are concerned with questions of how, whereas the arts may be more concerned with questions of why or to what end. This also raises issues surrounding the status of the amateur versus the professional. Such a division is not necessarily negative in that the two perspectives allow for increased richness of interpretation of how we interact with the collected natural world. Brandon Ballengée has engaged in significant field research that has resulted both in an impressive body of artwork and in the publication of peer-reviewed scientific papers. Cornelia Hesse-Honegger has struggled with her ambiguous status as an artist with a background in scientific illustration, neither accepted fully as an artist due to the illustrative nature of her work, nor taken seriously by scientists because of her lack of formal scientific education. By contrast, Mark Dion, despite frequently interacting with scientists and museum professionals, embraces his amateur or "dilettante" status because he feels that his outsider status presents a more interesting set of potential perspectives and possibilities. Artists working in bioart such as Tissue Culture and Art Project and Marta de Menezes have extensive laboratory experience and have been able to work closely with bio-scientists, blurring the definition of what it means to "do science" and particularly in the case of Tissue Culture and Art Project - destabilizing established hierarchies of who is allowed to create certain types of knowledge. Artist Dorothy Cross and her zoologist brother Dr. Tom Cross present another model in which art and science come together to present two parallel streams of research around a single topic, mutually informing and enhancing one another but without crossing into one another's discipline.

\subsection{Fieldwork}

Fieldwork, by its nature, involves practical work performed by a researcher in the natural or social environment rather than in the laboratory with the aim of acquiring knowledge directly through firsthand observation. Brandon Ballengée is an artist who makes extensive use of field research to inform his mixed media installations that incorporate a variety of techniques including traditional painting and drawing, digital imaging, film, the exhibition of preserved animal specimens, and the alteration of vintage natural history illustrations. He employs a combined disciplinary, or transdisciplinary, approach to science, arguing that there is a great potential to reach a broader audience and raise 
awareness about ecological issues among non-specialists. ${ }^{10}$ Transdisciplinary research, which Ballengée defines as being characterized by "novel strategies and theoretical models for practices that move 'beyond' or 'across' disciplinary (specialist) boundaries" ${ }^{11}$ leads to the disrupting of organizational hierarchies and allows for a greater dialogue across different fields of specialization or levels of experience. In support of this idea, Ballengée employs a variation on the practice of citizen science, or scientific research that involves the participation of non-scientists in the gathering of data. This practice is not new and dates back centuries. During the Victorian era, for example, a strong interest in natural history transgressed boundaries of amateurism and professionalism as well as class and gender. ${ }^{12}$ The accumulation of natural history collections for both personal use and in the service of science was a common pastime. Currently, however, citizen science is less aligned with the hobbyism of the Victorian era, and more with the amassing of data for the purpose of conducting genuine scientific research. Because in some examples of citizen science it has been the case that participants merely collect data that is passed - without analysis - on to the scientists and thus maintains the elite status of the scientist, Ballengée has adopted a more democratic approach that he terms "participatory biology." He defines this as "primary research biological studies in which students, volunteers, or general members of the public are involved directly in the scientific methods of field and laboratory observations, monitoring experiments, aid in the establishment of experiments, data collection, or other tasks in field or laboratory settings." ${ }^{\text {13 }}$ That is to say, the volunteers are trained to participate in every aspect of both field research and laboratory investigation, and are not

\footnotetext{
${ }^{10}$ Ballengée outlines his position extensively and with great clarity in his doctoral thesis. See: Brandon Ballengée, "Ecological Understanding through Transdisciplinary Art and Participatory Biology" $(\mathrm{PhD}$ diss., University of Plymouth, 2014). natural history in late Victorian Yorkshire," Journal of the History of Biology 34 (2001): 115-47, and Kate Hill, "'He knows me...but not at the museum' Women, natural history collecting, and museums, 18801914," Narrating Objects, Collecting Stories: Essays in Honour of Professor Susan M. Pearce, ed. Sandra H. Dudley et al. (London: Routledge, 2012), 184-195.

13

Ballengée, "Ecological Understanding," 37.
} 
merely treated as providers of information with which they will have no further interaction.

Due to his focus on biological fieldwork as a form of research, Ballengée positions himself within a group of contemporary artists who have engaged in primary biological and ecological research as art practice, and who have generated tangible scientific knowledge. This includes artists such as Helen and Newton Harrison, Tissue Culture \& Art Project, and Cornelia Hesse-Honegger who have all worked as primary researchers but within a context different from traditional scientific research. In the case of each of the artists, as with Ballengée's work, new scientific knowledge has been achieved through hybrid art-science practices. I would also include Marta de Menezes (who will be discussed later in this chapter) in this group as her work has also generated new scientific knowledge, although there is a distinction between her work and that of Ballengée as a result of the differences in intentionality inherent to their practices. Although De Menezes utilized the laboratory technique of microcautery on butterfly pupae and achieved unexpected results that suggested further scientific experimentation, her own interest lay in treating the butterfly specimens as mutable material for the purpose of artistic expression. She performed neither primary research nor interventions into the pupae for the purpose of the advancement of scientific or ecological knowledge. Her intentions were aesthetic and conceptual. Ballengée, on the other hand performs field research, and both scientific knowledge and artistic output are the anticipated and intended results of the accumulated data. 
Ballengée's most significant body of work is the result of the long-term project, Malamp (2000-2011), a multi-phase exploration into the occurrence of mutated limbs in amphibians in various sites across southern Quebec in Canada and in Yorkshire in the United Kingdom. The catalyst for this project occurred in 1995 when a group of school

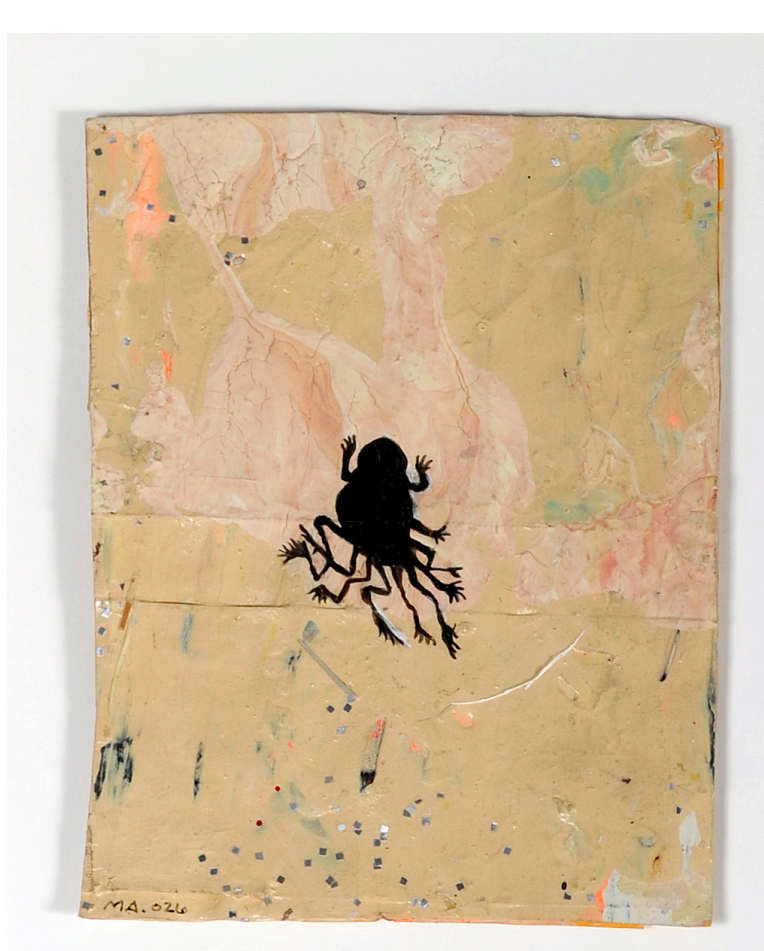

Figure 2.1: Brandon Ballengée, Malamp Drawing MA026, 1996-98. Image appears with permission from the artist. children in Minnesota found an unusually high number of deformed frogs while on a class field trip, and the discovery was covered in the media. Inspired and disturbed by this occurrence, Ballengée consequently visited numerous labs and wetlands between 1996 and 1999, where he interviewed scientists and created artworks about the deformed frogs. This body of work consisted of over three hundred portraits of individual specimens created on site using cigarette ash, leftover coffee, and local pond water on paper salvaged from older works. Although the resulting small watercolour-like paintings were traditional in form, the project led to an increased level of collaboration between Ballengée and a number of biologists. His practice began to shift from a conventional approach to art practice to something that increasingly resembled biological research. By 2000, he was working closely with Dr. Stanley K. Sessions with whom he went on to publish several scientific papers on the topic of underlying developmental explanations for malformations in anurans (frogs) and caudates (salamanders and newts).

As a consequence of working closely with biologists, Ballengée has incorporated techniques and tools more commonly aligned with biological preservation and scientific imaging than with the visual arts in the creation of the project. Malamp now consists of 
three distinct bodies of work. The photographic series Malamp Reliquaries (2001 present) was achieved by creating high resolution scans of severely deformed amphibians that had been chemically cleared and stained. Clearing and staining is a process by which the bones and cartilage of a specimen are coloured with vividly hued dyes while the

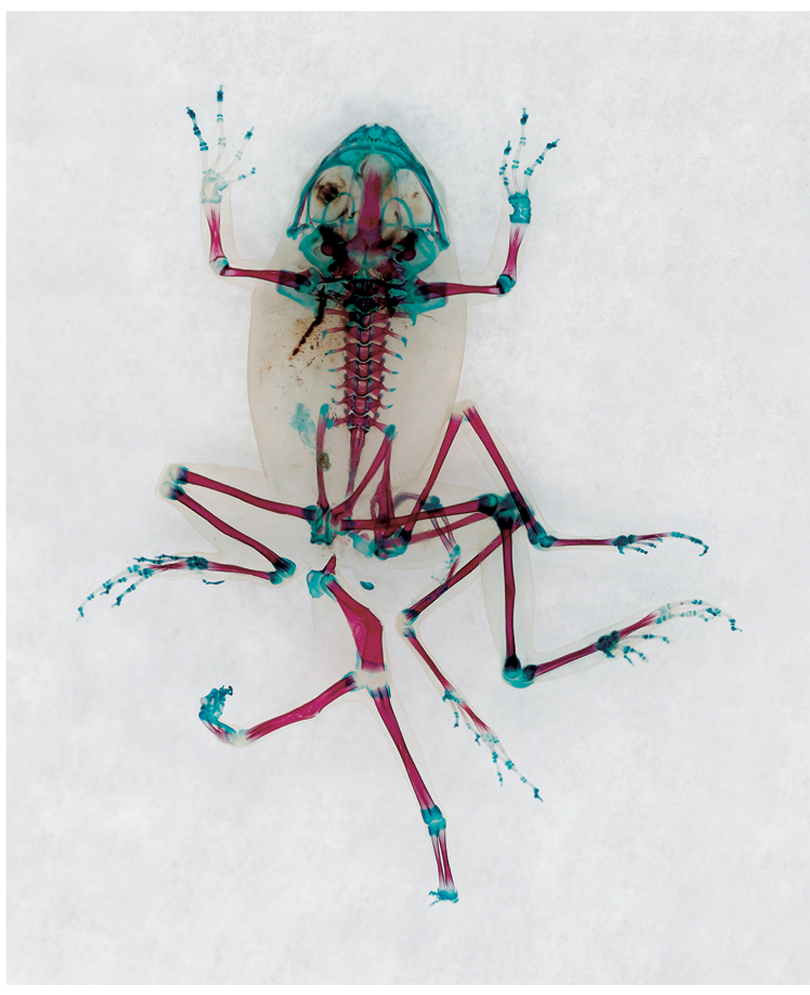

Figure 1.2: Brandon Ballengée, Malamp DFA 23: Khárôn, 2001/07, 2001. Image used with permission from the artist. surrounding tissues are chemically digested to achieve a state of transparency. This process results in a specimen in which the morphology is revealed and deformities and anomalies are thrown into sharp relief, but at the same time creates an object that is extremely beautiful. The resulting specimens are then scanned at high resolution to create very clear and detailed images that are enlarged and printed at the scale of a human child. By working at this scale, Ballengée's intention is to highlight the human/non-human relationship here, the fragile nature of the ecology inhabited by the amphibian and

perpetually influenced by humankind - as well as to create a bodily relationship between the amphibian and the viewer without straying into the realm of the monstrous. Ballangée states that although these works are akin to scientific illustration and are inspired by scientific research, they are not meant to be read as science. ${ }^{14}$ The large scale photographic work led to the creation of Styx (2007 - present), a sculptural work consisting of the actual cleared and stained specimens mounted in circular glass containers evocative of petri dishes and backlit within a display case. The specimens are

\footnotetext{
${ }^{14}$ Ballengée, “Ecological Understanding”, 110.
} 
tiny and require close observation by the viewer, creating an experience that is both curiously intimate yet evocative of detached scientific observation. The third element in the series is a video work entitled Un Requiem pour Flocons de Neige Blessés (20092011), in which a series of images of deformed toadlets superimposed over a background of laboratory grade cotton appear and disappear, slowly dissolving into one another. The images of malformed limbs become almost indistinguishable from one specimen to the next. Gathered from an area with a particularly high recurrence of deformations, each specimen is presented with a level of pathos that would be neither present nor relevant within systematic scientific observation.

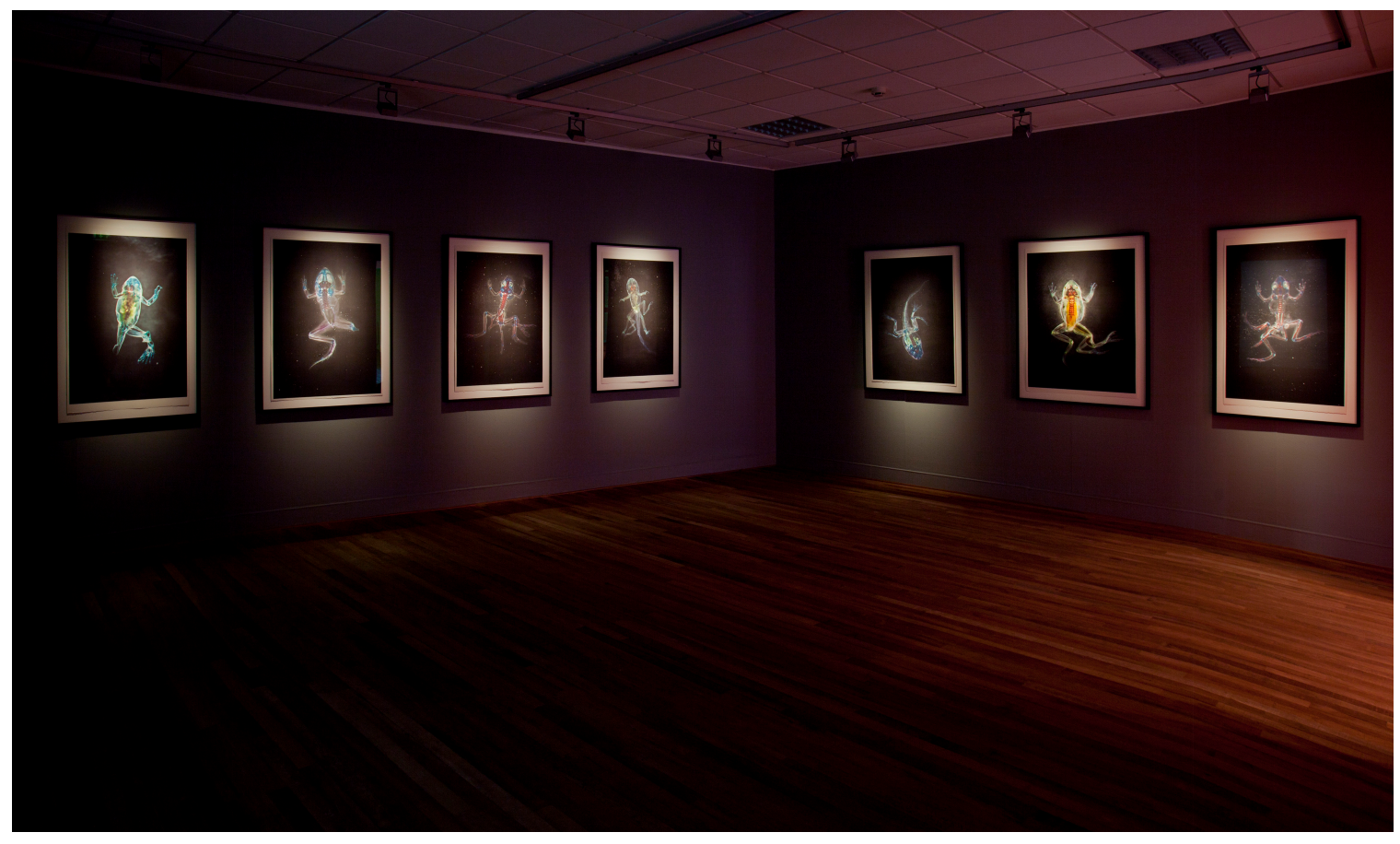

Figure 1.3: Brandon Ballengée, Malamp Reliqueries (installation), 2001-ongoing. Image used with permission from the artist.

According to Ballengée, the Malamp project was characterized by a cycle of transdisciplinary inquiry that resulted in what he called a "feedback loop,"15 meaning that the scientific research became the inspiration for and subject of his own works of art, but the creation of the artworks in turn led to previously unseen scientific observations and

\footnotetext{
15 Ballengée, “Ecological Understanding," 105.
} 
subsequent raising of questions that required scientific follow-up. For example, during the process of high resolution imaging of deformed toads that were later printed on a large scale as the series Malamp Reliquaries, it was observed that there was a lack of scar tissue in certain specimens. This became the catalyst for further laboratory studies on healing in developing anurans.

Across Ballengée's practice there is a strong focus on ecological concerns, not only in the Malamp project but in many of his other works, including the visually stunning installation Collapse, a pyramidal structure of wet-preserved specimens created in response to both the collapse of the world's fisheries and the impact of the Deep Water Horizon oil spill in the Gulf of Mexico. The installation is comprised of 26,162 preserved specimens in jars representing 370 species of aquatic specimens. There are also empty jars meant to represent species that are close to extinction. Ballengée's practice resonates, both in philosophy and methodology, with that of pioneering eco-artists Helen and Newton Harrison, whose early work was influenced by Rachel Carson's Silent Spring and reflected on the fragility of the world's ecosystems. In much the way Ballengée now works, the Newtons combined parallel modes of research including primary ecological field research with a concurrent visual art practice. One of the Newtons' most ambitious projects was The Lagoon Cycle (1974 - 1984), an offshoot of an earlier series The Survival Pieces (1970-1972), in which they exhibited food species such as lobsters and catfish in rubber-lined tanks with the intention of harvesting and eating them. ${ }^{16}$ For The Lagoon Cycle, the Harrisons similarly tackled the notions of sustainable farming and aquaculture by researching the life cycle of a Southeast Asian crab as a sustainable food source, using a combination of both scientific research methodologies and art practices. Supplementary to their field research, they created a "museum-lagoon" that consisted of work inspired by the ecosystem of a Sri Lankan estuary, including a 350-foot mural, maps, collages, performances, and poetry. By combining their research on existing aquaculture technology as well as on the habitat of Sri Lankan mud crabs, the Harrisons

\footnotetext{
16 Ballengée provides this project as a case study in his doctoral thesis. See Ballengée, "Ecological Understanding," 77-84.
} 
were able to develop an artificial lagoon in which they attempted to breed the crabs in captivity. Subsequent to a successful First Lagoon, the Harrisons received funding from the Scripps Institute of Oceanography to create Second Lagoon: Sea Grant, which was a more elaborate and accurate recreation of the mud crab's habitat. Improvements included altering water conditions to simulate seasonal weather conditions, and changing the specific gravity and nutrients in the water to encourage the crabs to mate. The Lagoon Cycle was recreated several more times, with each incarnation becoming increasingly elaborate. Gallery installations included fictional characters known as the Witness and the Lagoonmaker, who engaged in a conversation focusing on the increasing ambition of the Lagoonmaker as he envisions greater museum-lagoons. The Witness cautions the Lagoonmaker against the human hubris that comes from thinking that mankind is capable of improving on, or even emulating, nature. ${ }^{17}$

In Ballengée's estimation, The Lagoon Cycle was scientifically significant in that it developed a new understanding of a declining species of mud crab while increasing public awareness of disappearing mangrove ecosystems. In addition, he posits,

If nothing else, The Lagoon Cycle was revolutionary in being able to actually perform the scientific process, replicate ecosystems, and breed living organisms within the context of a work of art. Pragmatically, The Lagoon Cycle designed successful indoor enclosures for the Sri Lankan crab (Scylla serrate), where specimens survived up to 18 months and reproduced for the first time in captivity... Secondly, the work yielded the discovery that this species of crab has a 12-hour circadian rhythm that must be maintained for long-term survival in captivity: a new scientific insight. Thirdly, the research also revealed that this species of crabs could be successfully induced to breed by lowering the specific gravity of the water in the tank from 1.025 to 1.022 , which mimicked a natural lunar tide cycle. Finally, it proved that these crabs reacted differently to varied forms of artificial habitats and that social behaviors were driven through a

\footnotetext{
17 Note that the idea of human hubris and the environment is similarly addressed by Mark Dion in many of his works, but particularly in Neukom Vivarium, discussed elsewhere in this thesis.
} 
dominant-male social structure. All of these insights posited new knowledge to the field of research biology and were shared with the larger scientific community through a report published by the University of Hawaii. ${ }^{18}$

Here, we can observe that Ballengée has a highly analytical and pragmatic interest in transdisciplinary art practices, with equal focus placed on social value, aesthetics, and scientific outcomes. He takes a similar approach in his own practice, as is evidenced in the Malamp series. As previously discussed, Ballengée's process resulted not only in a body of work consisting of a series of digital images, a sculptural installation developed from the cleared and stained frog specimens, and a video work, but also in the social value that came about from involving volunteers in the gathering of specimens in the field, as well as in measurable scientific data through experimentation that lead to new information about the source of malformations in amphibians. In his participatory biology programs, Ballengée is a strong believer in the social and scientific value of involving non-specialist volunteers who, being familiar with the area already, have both a personal investment in their environment as well as local knowledge that an outsider would not possess. In his field investigations in both Yorkshire and southern Quebec, Ballengée trained his volunteers in data collection, handling specimens, amphibian observation techniques, post-experimental care of animals, analysis of results, and public dissemination through art or social media. Ballengée also encourages post-research reflection through creative means such as creative writing and visual art.

In both of these cases Ballengée set up a Public Bio-Art Laboratory, in the Yorkshire Sculpture Park and at the Société des Arts Technologiques in Montreal, Quebec, where they performed experimental simulations in which anuran larvae (tadpoles) were placed in tanks with aquatic predators. The results of the predation were observed, and systematically recorded. Any fatalities were removed and preserved, while non-fatalities were removed to another tank and allowed to mature for 120 days in order to observe the effect of predation on amphibian limb formation. Data was collected that

${ }^{18}$ Ballangée, "Ecological Understanding," 82. 
showed that predation was a major cause of traumatic injury to amphibians, and the findings were later published by Balengée and Dr. Stanley Sessions. ${ }^{19}$ Ballengée ultimately concludes that participatory biology programs, even those imbricated within transdiciplinary art practices and which include non-specialist volunteers, are able to generate relevant scientific insights into ecological phenomena. With regards to Ballengée's studio practice, his work as an artist has become seamlessly interwoven with his passions for biological research and social amelioration. It is apparent through his numerous co-authored publications with his collaborator Dr. Sessions that biological research can form the basis for both a thriving art practice and scientific advancement. That the articles have been published in peer reviewed scientific journals confirm that knowledge gained through transdisciplinary art practice can be accepted as a useful contribution to scientific research.

Like Ballengée, Cornelia Hesse-Honegger has also engaged in substantial field research as a vital part of her studio practice. Having trained as a scientific illustrator, Hesse-Honegger regards herself first and foremost as an artist. She is interested in visualization and the aesthetics that occur within her practice, both in a lab setting and in her own field research. She believes that an artist "does or should do research in the form of visualization. This means that while painting or even drawing the intricate designs presented in insects, I research in a visual sense as well as a scientific sense...After the picture or a series of pictures are finished, the analysis can start." ${ }^{20}$ For Hesse-Honegger, the processes of drawing and analysis are symbiotic - separate activities that are inextricably linked and that mutually strengthen each other. The act of drawing is itself a

\footnotetext{
${ }^{19}$ In the case of the amphibian limb deformations occurring in Minnesota that were the catalyst for Ballengée's project, the higher than acceptable occurrence of malformation was initially attributed to manmade causes. Although Dr. Sessions had suggested that the malformations were potentially attributable to tremetode parasites as early as 1990, Minnesota Environmental Protection Agency focused its efforts and investigations on the role of pesticides in the environment as the most likely cause. Over the past decade, a number of biologists have continued to pursue the hypothesis that the damaged limbs were the result of parasites and predation as sources of physical trauma to the developing limb buds, causing such deformations as missing or multiple limbs. The work that Ballengée has done, both independently through his participatory art practice as well as with Dr. Sessions has contributed to this ongoing dialogue.

${ }^{20}$ Giovanni Aloi and Cornelia Hesse-Honegger, "Cornelia Hesse-Honegger: Heteroptera," Antennae: The Journal of Nature in Visual Culture 11 (Autumn 2009), 32.
} 
form of research: it is through drawing that one learns to see and to commit visual knowledge to memory.

Hesse-Honegger has had a sustained fascination with the morphology of insects, and that of the true bug in particular. This aesthetic interest in combination with the illustrative work that she was doing in the lab led to a substantial period of research into genetic mutations occurring in true bugs found near the sites of nuclear power plants that

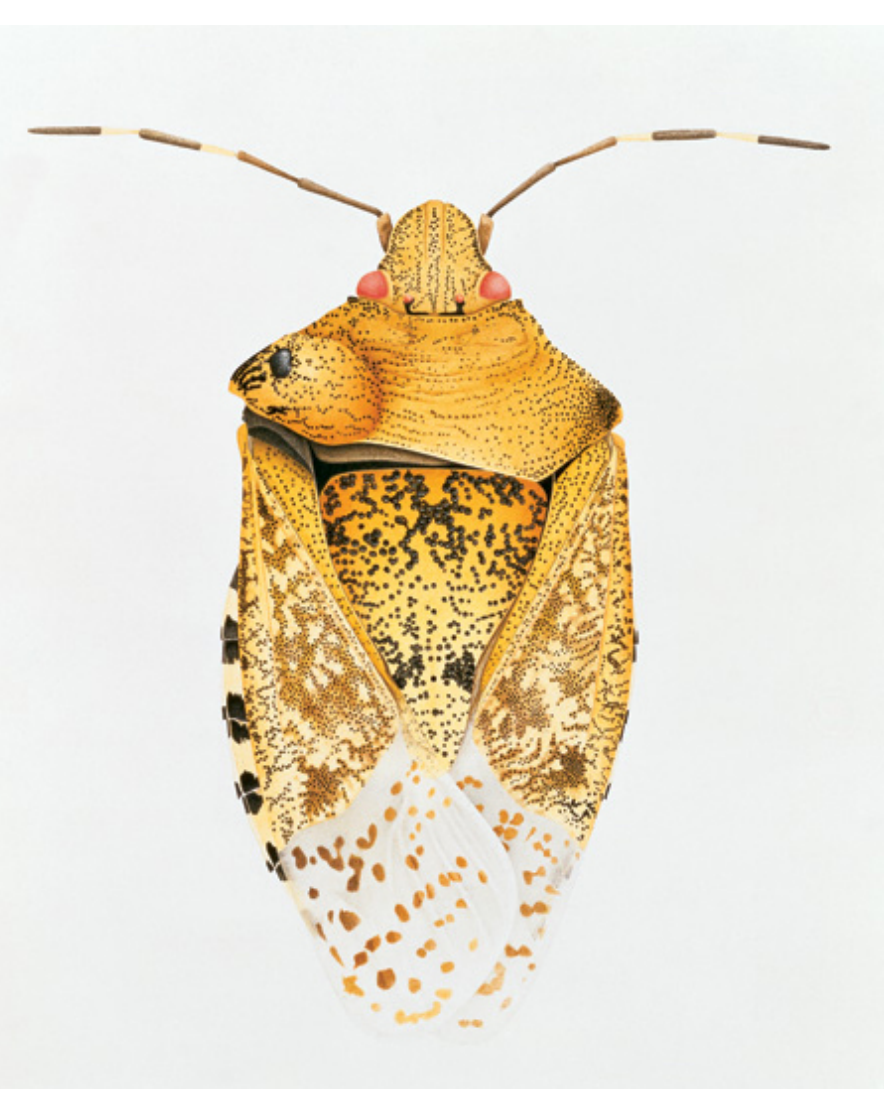

Figure 1.4: Cornelia Hesse-Honegger, Garden Bug Rhaphigaster nebulosa, 1991. Insect found in Küssaberg, Germany, about ten kilometers east of the nuclear power plant at Leibstadt. Image used with permission from the artist. continuously emit low doses of radioactivity. She was working at the Zoological Institute of the University of Zurich painting a series of drosophila that had mutated as a result of having been exposed to X-rays, when there was a catastrophic nuclear accident at the Chernobyl Nuclear Power Plant in the Ukraine. The disaster led to measurable levels of radiation not only in the Ukraine but also in a number of surrounding countries including Switzerland. HesseHonegger subsequently became interested in how nuclear fallout might be taken up by insects through the ingestion of plants

from the affected areas. She collected Drosophila melanogaster from a town called Rancate in Switzerland that was badly affected by the fallout from Chernobyl and began breeding them in her kitchen, documenting any changes. At the time scientists were saying that the level of radioactivity was not substantial enough to cause deformations of insects. Concerned that true bugs could suffer deformation as a result of nuclear radiation, Hesse-Honegger consulted a geneticist at the University of Zurich who told her 
that levels of radiation in Europe were too low to have an effect on Heteroptera. ${ }^{21}$ Nevertheless she decided to extend her own research to bug specimens collected from contaminated sites.

In 1988, Hesse-Honegger published the first of two cover stories in the Sunday magazine of the leading Swiss newspaper Tages-Anzeiger, under the headline "When Flies and Bugs Don't Look the Way They Should," in which she presented exquisite paintings of deformed leaf bugs and fruit flies collected from around Österfarnebo, Sweden and Ticino, Switzerland. The story outlines the methods by which she determined that, following the meltdown in Chernobyl, the site of the worst fallout was in eastern Sweden. When she began her research there, she found numerous plants with unusual growth patterns. She had already been concerned that bugs could potentially be affected by consuming fluids from the leaves and shoots of contaminated plants.

Although I was theoretically convinced that radioactivity affects nature, I could still not imagine what it would actually look like. Now these poor creatures were lying there under my microscope. I was shocked. It was as if someone had drawn back the curtain. Every day I discovered more damaged plants and bugs.

Sometimes I could hardly remember what the normal plant shapes looked like. ${ }^{22}$

The language that Hesse-Honegger uses to speak about her research, and the style in which she portrays deformed insect specimens belies her scientific background. Although her language remains personal and emotional, her drawing style nevertheless strives for scientific objectivity. Each insect is portrayed in a manner that is scientifically accurate, "realistic but not naturalistic...each painting is a portrait and each insect is a subject, a specific individual." 23 Her methodology is a combination of scientific observation and

\footnotetext{
21 Cornelia Hesse-Honegger and Peter Walliman, "Malformation of the True Bug (Heteroptera): a Phenotype Field Study on the Possible Influence of Artificial Low-Level Radioactivity," Chemistry and Biodiversity 5 (2008), 500.

22 Cornelia Hesse-Honegger, from Heteroptera: The Beautiful and the Other, or images of a Mutating World, quoted in Hugh Raffles, Insectopedia, (New York: Vintage Books, 2011), 29.

23 Raffles, Insectopedia, 29.
} 
artistic sensitivity. Hesse-Honegger describes how each specimen is examined, measured, analyzed, and documented within twelve hours of collection, prior to rigor mortis setting in. The bugs are "scrutinized individually, first from the ventral and then from the dorsal side...Morphological abnormalities in feelers, head (including trunk and eyes), thorax, scutellum, wings, abdomen, legs and feet were noted separately." 24 However, when she describes how the images are rendered, even within the context of a peer-reviewed scientific journal, her language makes a subtle shift:

Selected bugs were painted in watercolour, true to scale, by using the internal ruler (in $\mathrm{cm}$ ) in one of the oculars of the microscope. The insects were first drawn in with pencil, all details being exactly measured. When finished, the pencil drawing was transferred with the help of graphite paper to watercolour paper, and finally worked out with brush and paint. Thereby, I painted according to Paul Cezanne's "Color Perspective." There is no specific source of light and no shadow, allowing one to simulate the species-typical colours. ${ }^{25}$

The resulting images possess an extraordinary scientific accuracy combined with a sensitive touch resulting from her use of watercolour and graphite. The colours, while true to the original specimen, possess a luminosity inherent to the transparency of the medium. Depictions of mutations combine surfaces that oscillate between the suggestion of fragile wings, vulnerable thoraces, and hard carapaces. Her work embodies a clash in sensibilities: in addition to the scientific and the artistic combined within a single image, Hesse-Honegger has also had to contend with her own sensitivity to the capturing and chloroforming of thousands of insect specimens coupled with the knowledge that it is a necessary evil in order to raise awareness of the effects that nuclear radiation is having on the insect population. This paradox echoes the practice of killing in the name of conservation that enabled many museums to justify the putting to death of many perfectly healthy animals in order to create natural history dioramas. Hesse-Honegger now has a

\footnotetext{
${ }^{24}$ Hesse-Honegger and Walliman, "Malformation," 510.

${ }^{25}$ Ibid., 511.
} 
collection of 17,000 true bugs, cicada, and ladybird beetles, which she suggests is likely the only collection of insects from nuclear contaminated areas. This is the positive outcome to a scenario that had its origins in the doubt that scientists had surrounding her research. As Hesse-Honegger has informed me, "At the beginning I let them go but a biologist told me to keep them so they could be studied again by a 'real' scientist."26

Following the publication of her findings and the media stir that it provoked, Hesse-Honegger was highly criticized within the scientific community. After publishing her work Hesse-Honegger was shocked by the negative reaction: "I felt very insecure, not about my paintings or research but about the way I was treated: a single person against hundreds of scientists who had the 'truth' on their side and who considered themselves to be the only ones entitled to carry out official research."27 Following her publications in the Tages-Anzeiger and the resulting criticism from the scientific community, HesseHonegger showed a deformed cicada specimen to one of her former professors who, despite not having seen such deformities before, criticized her for publishing her findings and reminded her that although she may have worked with him in the past, the experience made her neither a scientist nor his peer. ${ }^{28}$ This exchange illustrates that although there are numerous artists who enjoy a certain level of autonomy while working in the lab with scientists, the perception of autonomy may in fact rely on a collaborative relationship in which the role of the scientist and that of the artist remain clearly defined. The relationship between Hesse-Honegger and the scientists with whom she has worked is reminiscent of the relationship described by Lorraine Daston and Peter Galison between Enlightenment era naturalists and the artists they employed. In striving to force artists to depict their visions of idealized natural specimens, naturalists exerted control over what the artists illustrated:

\footnotetext{
${ }^{26}$ Quote taken from correspondence between the author and Cornelia Hesse-Honegger, March 7, 2016.

27 Aloi and Hesse-Honegger, "Heteroptera," 34.

28 Raffles, Insectopedia, 27.
} 
Battles of wills, eyes, and status were joined when the naturalist peered over the shoulder of the artist, correcting every pen stroke... these collaborations aimed at a fusion of the head of the naturalist with the hand of the artist, in which the artist surrendered himself (or, often, herself) entirely to the will and judgment of the naturalist. This relationship of subordination to the point of possession or thought transference frequently exploited other forms of social subordination in order to render the artist as pliant as possible: the subordination of servant to master, of child to adult, of woman to man. ${ }^{29}$

The interaction between Hesse-Honegger and her former professor is indicative of the social hierarchy that continues to exist within the field of scientific research in which scientific knowledge and artistic knowledge are deemed unequal, ${ }^{30}$ suggesting that in some cases artists may only be taken seriously while engaging in forms of citizen science. Scientists have criticized Hesse-Honegger's methodology for not adequately controlling for alternative causal factors such as pesticides or parasites, or comparison of a baseline level of normal incidence of mutations. ${ }^{31}$ She has addressed such questions regarding her methodology, arguing that "there can be no reference habitat on a planet thoroughly polluted by fallout from aboveground testing and emissions from nuclear power plants," and also pointing out that she is documenting induced deformities rather than heritable mutations. ${ }^{32}$

Paradoxically, in an atmosphere of increased transdisciplinary research between the arts and sciences, Hesse-Honegger continues to struggle within an undefined area between the two disciplines. She has both invited the ire of the scientific community,

\footnotetext{
${ }^{29}$ Lorraine Daston and Peter Gal ison, Objectivity, (New York: Zone Books, 2007), 88.

${ }^{30}$ In response to the above quote from Daston and Galison, Hesse-Honegger tells me, "This happened to me every day. I call myself a 'maid' to the scientist. They corrected by half a line made with a pencil (width) but I also learned something." (Taken from correspondence between the author and HesseHonegger, March 7, 2016.)

${ }^{31}$ Raffles, Insectopedia 25.

32 Ibid, 34.
} 
which has refuted her findings, and struggled to gain acceptance in the art world. Her work has been relegated to curated exhibitions that focus on mutation or catastrophe, and beyond that she has had little success, a situation that she believes is the result of her work being perceived as scientific illustration. ${ }^{33}$ Hugh Raffles, however, suggests that Hesse-Honegger's slight distancing from the rigors of scientific testing frees her to align herself with environmental and cultural organizations, where her strengths are valued rather than questioned, and her lack of a formal scientific education is less problematic. ${ }^{34}$ Her credibility has however seen a significant boost with the publication of the coauthored paper in the peer-reviewed journal, Chemistry and Biodiversity. Although both Hesse-Honegger and Ballangée have both published peer-reviewed journal articles, it is noteworthy that in both cases they were co-authored with scientists, leading one to wonder whether either would have been accepted had they submitted as single authors, and raising doubts that there has been any destabilizing of established disciplinary boundaries. In Hesse-Honegger's case, she remains clearly aware of the contingent nature of her position, and states that Peter Walliman co-authored the paper with the intention of helping to establish her work within the scientific community. ${ }^{35}$ She does, however, also acknowledge that by being an artist and working on the fringes of the scientific community she is allowed the freedom to write what she pleases, which might not be the case if she were writing from within a scientific culture. ${ }^{36}$

Unlike Ballengée and Hesse-Honegger who straddle the line between artist and scientist, Mark Dion fully embraces his status as the amateur, or the dilettante. He has spoken widely on the notion that this status allows him to question and criticize the social and historical constructs that characterize the presentation of the natural sciences, and

\footnotetext{
33 Aloi and Hesse-Honegger, 36.

34 Raffles, Inscetopedia, 34.

35 Hesse-Honegger states that she even paid Walliman with one of her watercolours in gratitude for his contribution to the paper. Statement made in correspondence between the author and Hesse-Honnegger.

36 See later in this chapter where I echo these sentiments in the context of artists who work in labs and are free to make social commentary, unconstrained by factors such as research funding that may impact scientists.
} 
also that it allows him to make unique contributions to scientific discourse within the public sphere:

I am very interested in the figure of the dilettante, the amateur. Amateurs have made great contributions in science, but now we live in a time when there's such a radical degree of specialization that it's very difficult for professionals in physics or biology to be able to communicate to a general public... People disparage the amateur and the dilettante. We see the dilettante as a very negative thing. But the history of the dilettante societies was exactly the opposite; they were really collections of learned people who were pooling their knowledge and resources together into clubs. And I think the amateur really has made tremendous contributions. $^{37}$

In many of his projects, Dion has pooled his resources - knowledge and experience as a contemporary artist - with those who would be defined as experts in their field. In the installation Systema Metropolis (2007), commissioned by the Natural History Museum in London, UK to celebrate the $300^{\text {th }}$ birthday of Carl Linnaeus, Dion collaborated with museum scientists including soil specialists, botanists, entomologists, molecular biologists, and the curator of fish displays to create a multi-element installation that celebrated Linnaean taxonomy.

Systema Metropolis comprised an introduction to Linnaeus, and four "laboratories" in which Dion worked with scientists in view of the general public. Each of these laboratories contained the results of the fieldwork during which samples were gathered from various different sites around London. The introductory room showed the work and life of Linnaeus. His tools, books and specimen sheets were displayed to illustrate the thoughts and ideas of the man who contributed much not only to Dion's work but also to the ordering of human knowledge and understanding of the natural world. Following the introduction to Linnaeus, the first laboratory installation, Systema

\footnotetext{
${ }^{37}$ Mark Dion: Science and Aesthetics, http://www.art21.org/texts/mark-dion/interview-mark-dion-scienceand-aesthetics. See also, Lisa Graziose Corrin et al., Mark Dion, (London: Phaidon Press, 1997), 29.
} 
Metropolis Fieldwork 1, presented the results of an expedition during which Dion and several entomologists from the museum went to the gravestones of three significant individuals: Karl Marx, Thomas Huxley, and Emmeline Pankhurst.

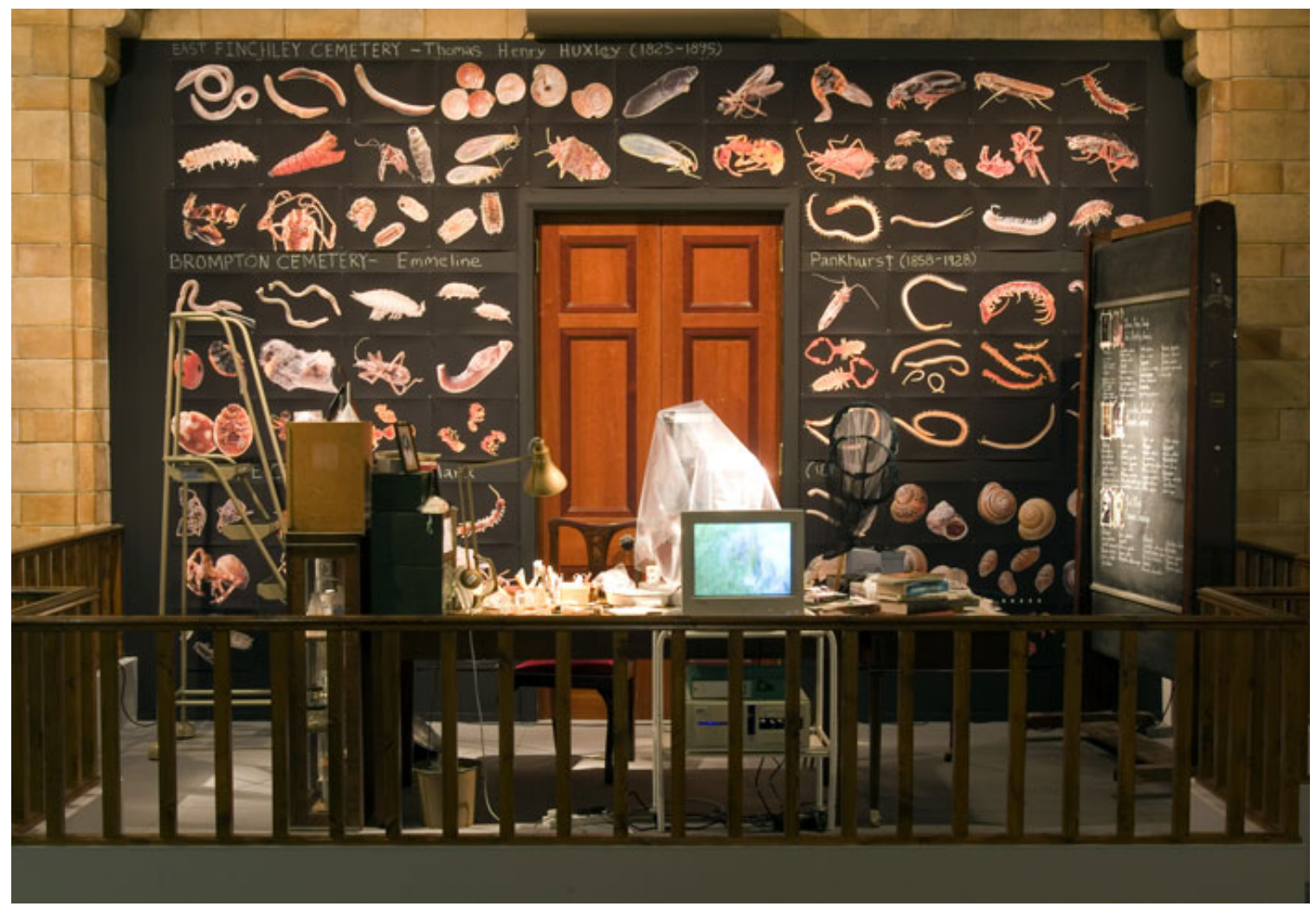

Figure 1.5: Mark Dion, Systema Metropolis Fieldwork 1, 2007, Natural History Museum, London. Image used with permission from the artist.

At each of the gravesites they collected different insects, preserved them in alcohol, and took them back to the lab at the museum to be identified. In Systema Metropolis Fieldwork 1 Dion creates a mock entomologist's laboratory, complete with the tools required for the identification of specimens. ${ }^{38}$ Illustrations of the specimens were displayed in a grid on the wall behind the desk, and although the grid suggested an ordered logic or taxonomy, Dion himself made no claims to the procedure being systematic.

38 Dion frequently uses the trope of "the tools of the trade" in many of his installations, creating mock workstations, including requisite tools, and any clothing that he might have worn when taking on his roles of amateur collector, archaeologist, or scientist. 


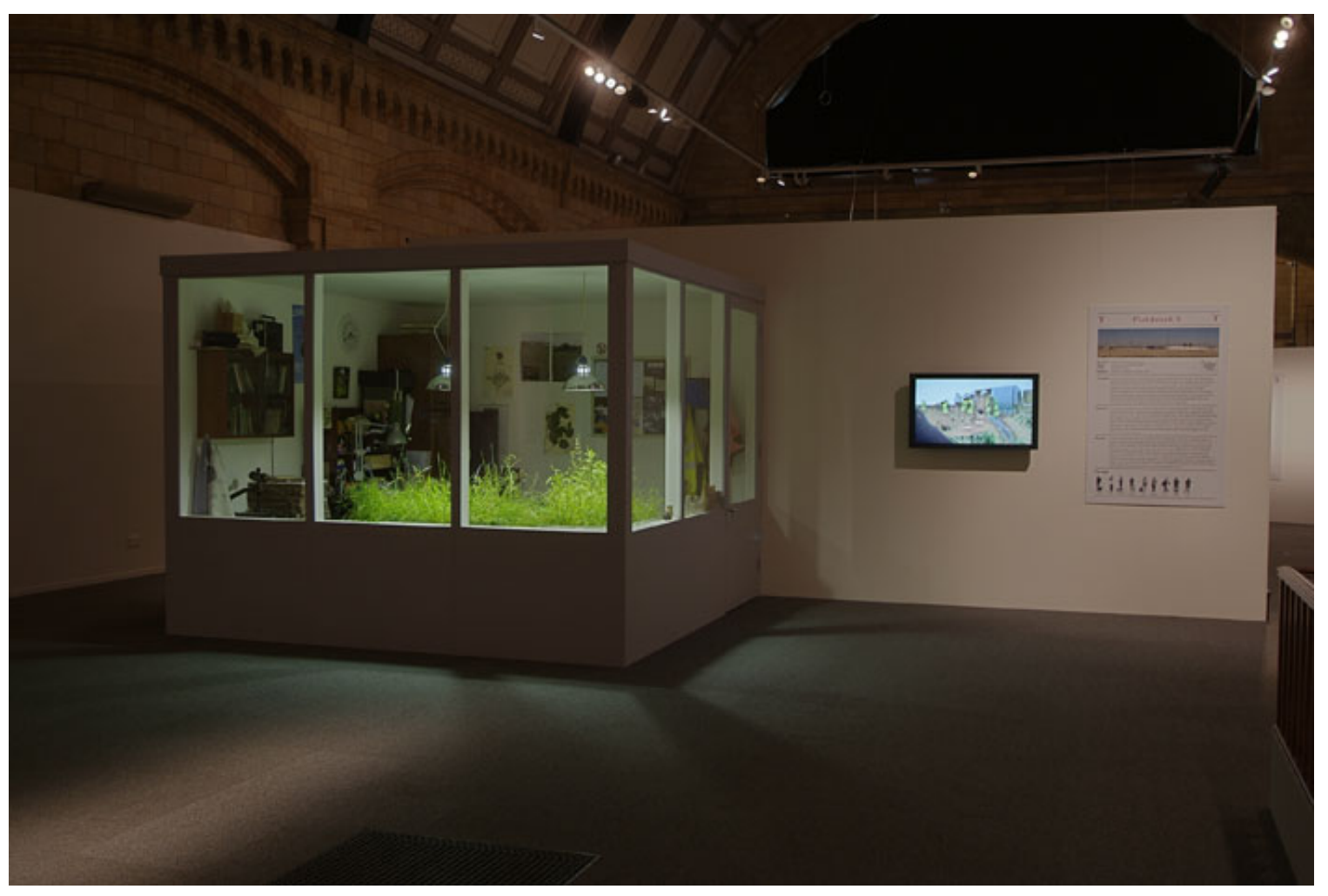

Figure 1.6: Mark Dion, Systema Metropolis Fieldwork 2, 2007, Natural History Museum, London. Image used with permission from the artist.

For the second laboratory Systema Metropolis Fieldwork 2, square sections of turf were gathered from two areas of the Olympic Park development, one from a disused football field and the other from the banks of the Lea River. All living organisms were collected, and the various types of grass that made up the samples were identified, catalogued, and preserved using the museums botanical presses. Sections of the living turf were installed under lights and exhibited along with the living insects in a recreated scientist's office, again simulating a workspace with all requisite tools and the clothing that would be worn in the field. The installation highlighted the difference in biodiversity between the sample from the football field, which contained two species of grass, and the patch of wild riverbank grass that had 25 different species. 


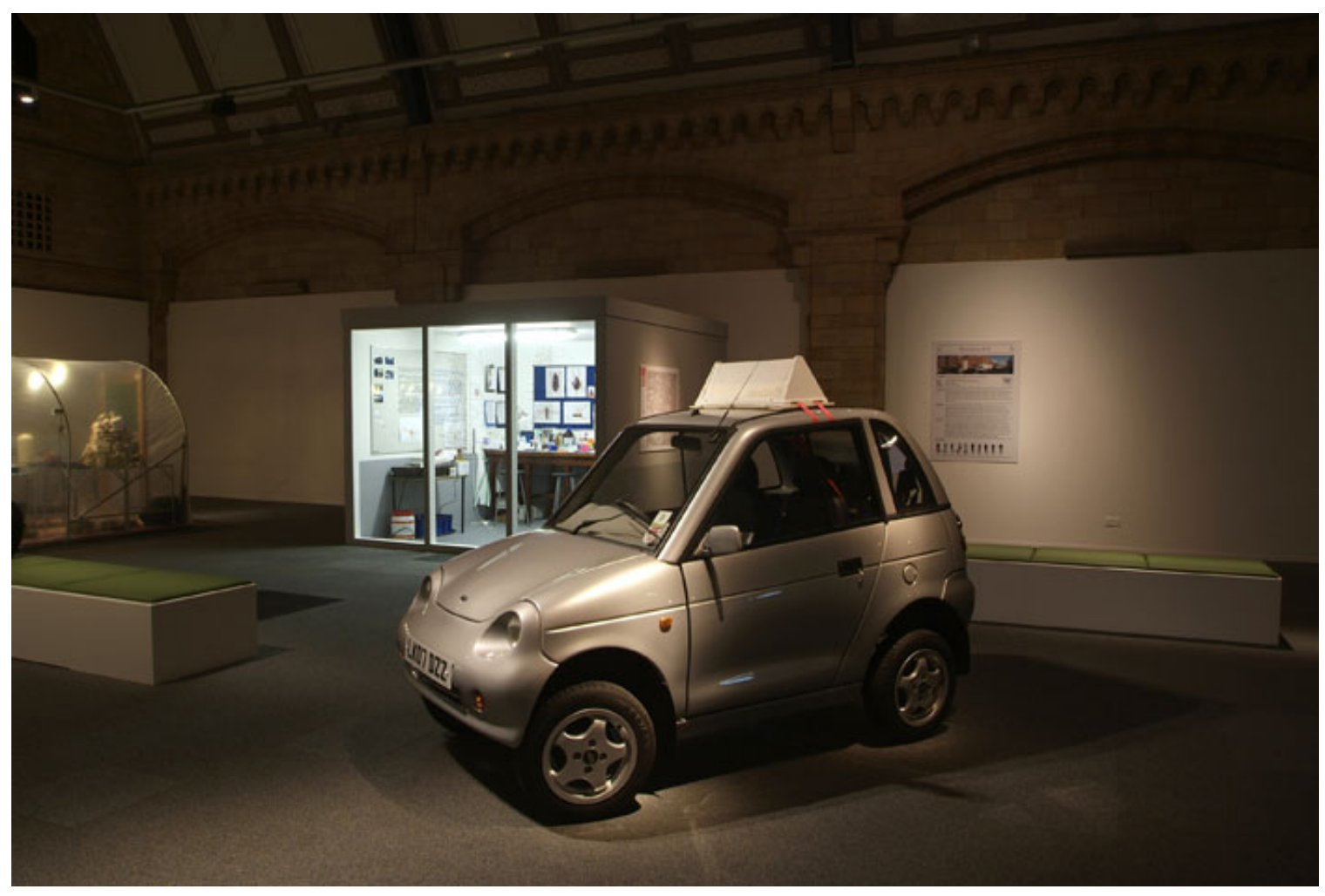

Figure 1.7: Mark Dion, Systema Metropolis Fieldwork 3, 2007, Natural History Museum, London. Image used with permission from the artist.

For the third fieldwork assignment (that serendipitously took place on Carl Linnaeus's birthday on May 23), Dion and his team of scientists gathered information on airborne biodiversity along a section of the A40, by driving an electric car (a G-wiz) that had a sticky flypaper screen attached to the roof as well as an insect net extended from the window. The car was driven at low speed in an attempt to gather insect samples. Although many of the insects gathered in the net were intact and suitable for identification according to their morphology, many others were squashed rendering it necessary to identify them through their DNA. Samples of the damaged specimens were fed through a molecular genetic sequencer in the lab set up in the gallery along with the car that was used to gather specimens. The use of the two methods of classification exposed the differences and tensions between contemporary DNA classification techniques and the more archaic - yet still vital - method of identification through visual study of a specimen's morphology and comparing it against specimens from the museum's reference collection. The tension between these two methods of identification arises from the fear that DNA taxonomy will add to an already looming crisis as fewer 
and fewer scientists are retained by museums to conduct morphological taxonomy, and will increase the possibility of obsolescence within the field.

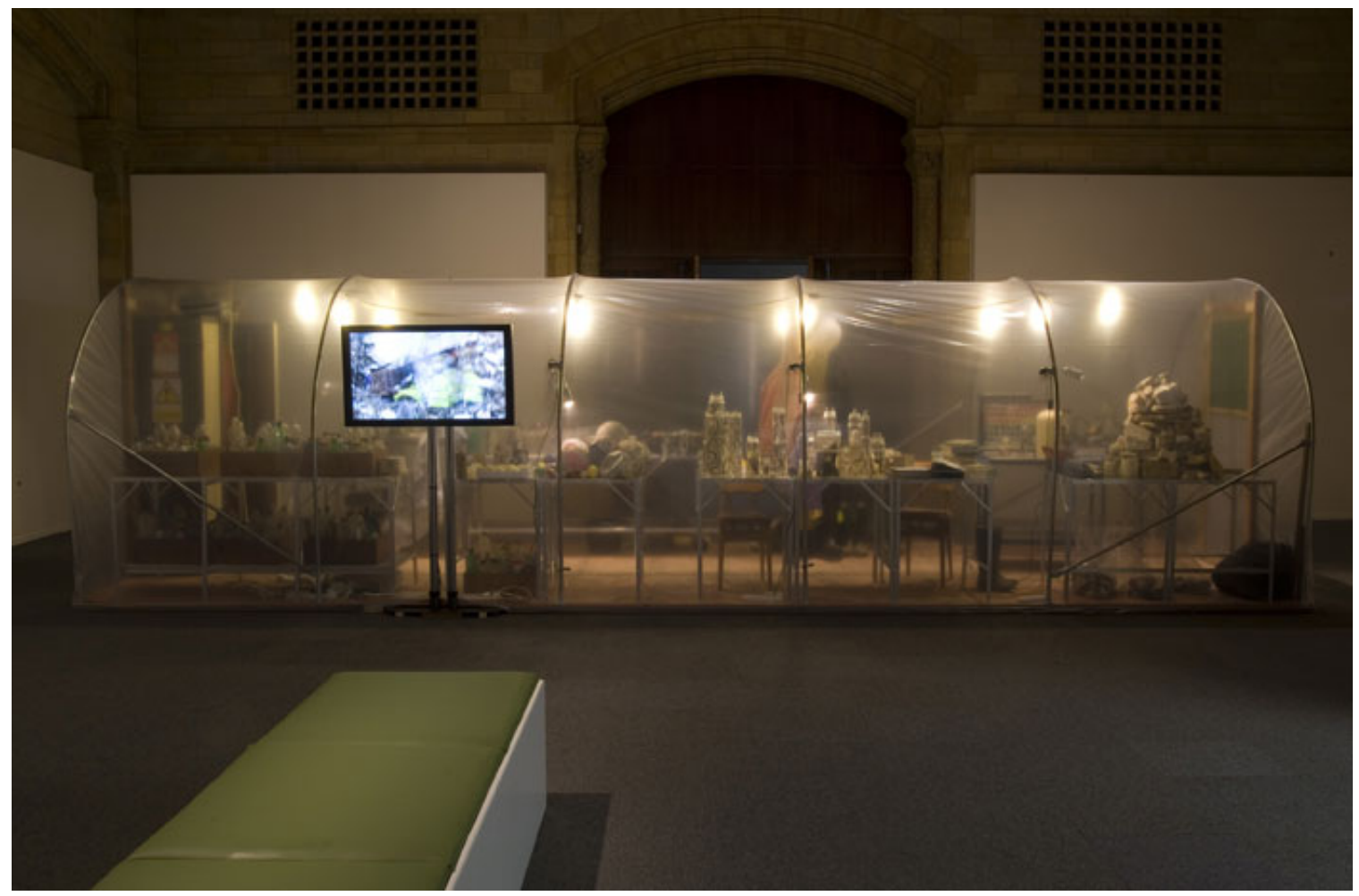

Figure 1.8: Mark Dion, Systema Metropolis Fieldwork 4, 2007, Natural History Museum, London. Image used with permission from the artist.

The final exhibit looked at two types of diversity: biodiversity and a sort of anthropological diversity that arises from human refuse. Dion and his team collected samples from underwater intake filters at the Kingsnorth power plant located on the river Thames using a trawl net, a seine net, and hand nets. Fish and other living things were thrown back after being identified but all other things, including a deflated football, a number of identical yellow plastic ducks, and many plastic bottles, were cleaned, sorted, and displayed in a polyurethane tunnel installed in the museum gallery. Dion used the system of organization that he has employed in numerous of his other installations, wherein man-made objects are subjected to a taxonomy reminiscent of - yet distinct from - how living organisms are classified. Objects were organized according to similarities of use, colour, material, or genealogy, rather than relations of morphology, resulting in collections of clay pipe stems, plastic bottle caps, pop cans, and pottery fragments. 
Although each fieldwork assignment was carried out in preparation for Dion's installation and functions as a performative element rather than as true field research from a scientific perspective, they were not without scientific value. As is reported on the Natural History Museum's blog, "It's not all science for art's sake. The Thames team found a seahorse, only the fifth ever reported in the river. Unexpected insect species were identified, including a parasitic wasp only recorded once before in London. And the project gave practicing scientists the chance to examine environments that they would normally ignore that are right on their own doorstep." 39 Despite the fact that Dion's field expeditions led to the unexpected find of a rare seahorse, his approach to fieldwork in general stands in contrast to that of Ballengée and Hesse-Honegger. By embracing his own self-proclaimed dilettantism, Dion investigates the structures that support institutionalized scientific knowledge without actually engaging in the scientific research itself, whereas for Ballengée and Hesse-Honegger, the fieldwork is a vital part of their process and potential scientific outcomes are as important as the resulting works of art.

\subsection{Lab Work}

In order for artists to work in laboratories they must become familiar with the techniques and protocols of the laboratory, in essence to learn its culture. This often results in work that, to the uninitiated, resembles science as much as it does art. Despite the blurring of disciplinary boundaries, however, those boundaries still remain. The case of in-vitro or lab-grown meat provides a particularly resonant case study that illustrates the continuing disconnect in the availability of specific bodies of scientific knowledge to artistic and scientific communities. On August 5, 2013, Dr. Mark Post, an instructor at Maastricht University who holds both a medical degree and a PhD in Pharmacology, unveiled what was claimed to be the world's first cultured beef-burger. The burger, consisting of labgrown cow muscle tissue mixed with egg, breadcrumbs, and beetroot, was launched at an event attended by two hundred journalists and academics where it was cooked by a chef and consumed by a panel of invited guests, including Mark Post, a food writer, and a

\footnotetext{
39 Mark Dion, Systema Metropolis, 15 June 2007, http://blogs.nature.com/london/2007/06/15/mark-dionsystema-metropolis
} 
nutritional researcher. ${ }^{40}$ Although widely hailed as the first lab-grown hamburger, this was by no means an accurate assessment. The first lab-cultured meat grown and consumed by humans had been made ten years earlier by a group of artists.

Tissue Culture and Art Project was founded in 1996 with the goal of exploring the use of tissue culture technologies for artistic purposes. They are the founders of SymbioticA, a lab located at the University of Western Australia, dedicated to enabling artists and researchers to creatively engage in wet biology practices. In their own practice, they are particularly interested in the creation of what they refer to as "semiliving entities." According to Tissue Culture and Art Project,

Semi-living entities are located on the fuzzy border between the living and the non-living, the grown and the constructed, the born and the manufactured, and the object/subject. They consist of living biological systems that are artificially designed and need human and/or technological intervention in their construction and maintenance. The semi-living rely on the nurturer/constructor to care for them; they are a new class of object-being that has both striking similarities to and important differences from other human artifacts such as constructed objects and selectively bred domestic plants and animals (both for pets and in husbandry). This new palette of manipulation is significantly linked to ethical concerns and emerging philosophical perplexities. ${ }^{41}$

\footnotetext{
40 See Alok Jha, "First lab-grown hamburger gets full marks for 'mouth feel,", The Guardian, August 6, 2013, https:/www.theguardian.com/science/2013/aug/05/world-first-synthetic-hamburger-mouth-feel, as well as http://culturedbeef.net/event/

41 Oron Catts and Ionat Zurr, "Ingestion/Disembodied Cuisine," Cabinet Magazine 16, (2004/2005), http://www.cabinetmagazine.org/issues/16/catts_zurr.php
} 
In their ongoing examination of humans' relationships with other life forms, Tissue Culture and Art Project turned their attention to one of the most common of interactions: that of the consumption of animals. While working in a laboratory at Harvard Medical School in 2000, Tissue Culture and Art Project attempted to create a

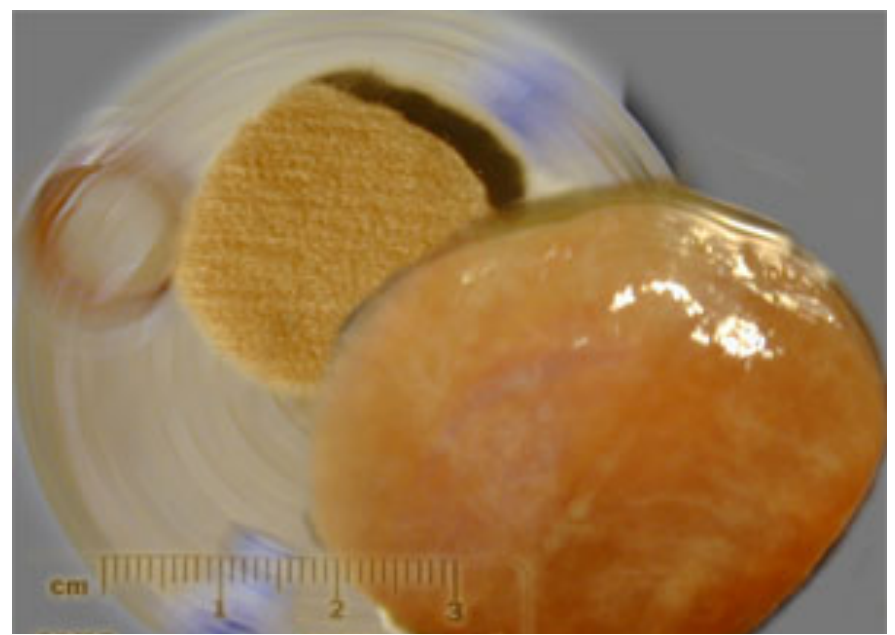

Figure 1.9: Tissue Culture and Art Project, Lab-grown "steak" from Disembodied Cuisine (2003). Image used with permission from the artists. "victimless" form of meat. They

grew their first steak from pre-natal sheep cells grown in a nutrient rich serum. Because of fears that the lab in which they were working could lose its license if they consumed the products of their experiment, it was decided that any meat grown would be consumed in another venue. In 2003, Tissue Culture and Art Project grew frog skeletal muscle tissue over

biodegradable/bio-absorbable polymer for the express purpose of human consumption. Cells were collected from a living animal that was otherwise not harmed for this project, seeded into a polymer substrate, and allowed to proliferate for three months in a bioreactor specially constructed within the gallery Le Lieu Unique in Nantes, France, in conjunction with the international biological art exhibition, "Art Biotech." This yielded a mere coin-sized blob, gelatinous in texture due to the fact that in order for muscle tissue to achieve a meat-like texture, it requires exercise. Tissue Culture and Art Project's exhibition, Disembodied Cuisine (2003), culminated in a performance during which the cultured frog "steak" was marinated in calvados, then fried in garlic and honey, both chosen for their antibacterial properties. 


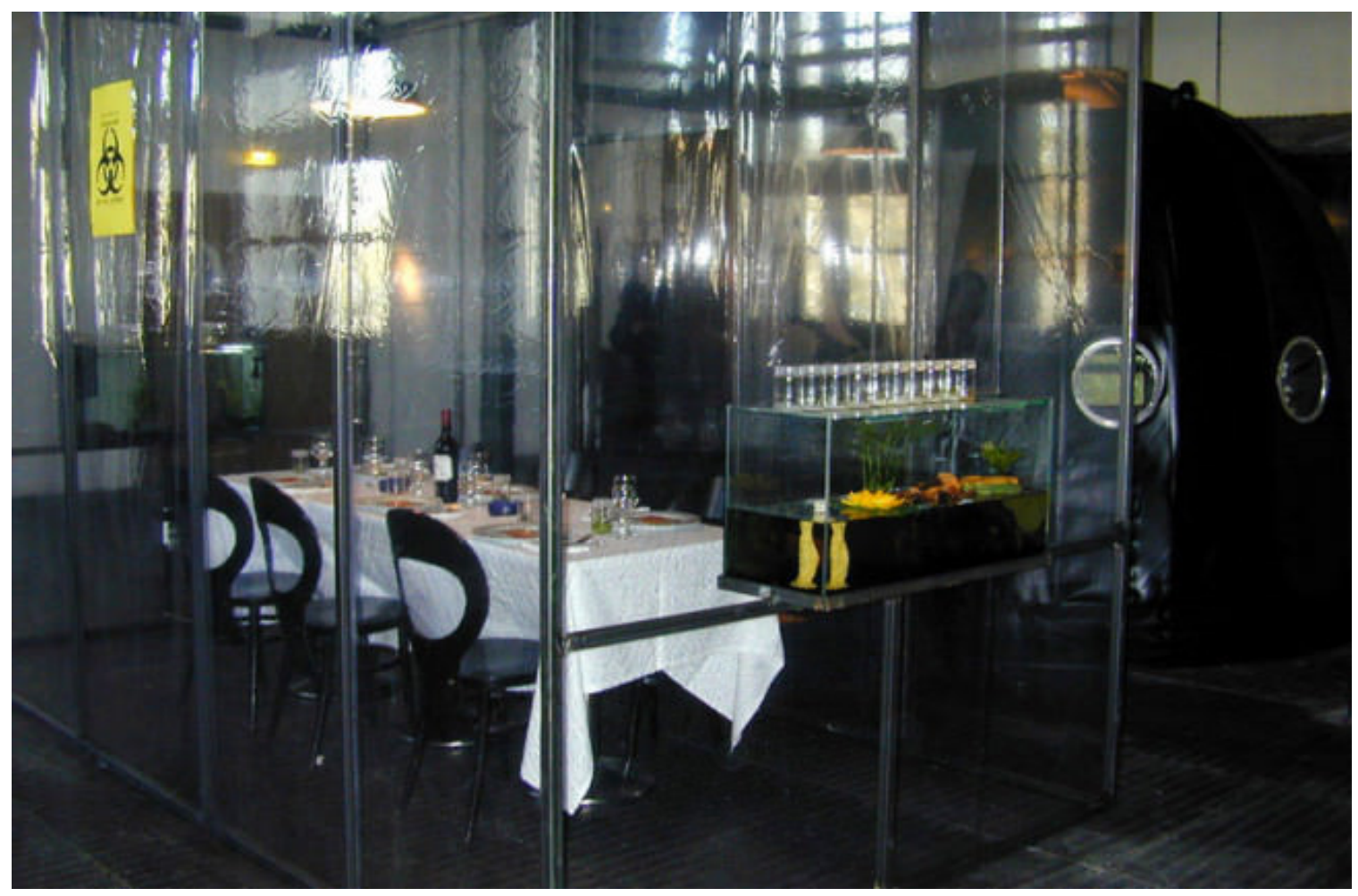

Figure 1.10: Tissue Culture and Art, Disembodied Cuisine (installation) 2003. Image used with permission from the artists.

Although it is worth noting that Mark Post did eventually admit that he was not the first to produce lab-grown meat, ${ }^{42}$ it nevertheless raises questions about how artists are perceived when advancing new scientific knowledge. As Elizabeth Stephens has pointed out, "The fact that the first laboratory-grown steak was produced and eaten in the context of experimental art is important, and not simply as a matter of historical record." ${ }^{43}$ Although Stephens focuses, at least in this instance, on how popular science

42 Charlotte Edwards, "Man vs Burger," Evening Standard, August 7, 2013, http://www.standard.co.uk/lifestyle/foodanddrink/man-vs-burger-8749749.html

43 See Elizabeth Stephens, "World's first Lab-grown burger? Don't forget the first semi-living steak," Science Alert, August 13, 2013, http://www.sciencealert.com/worlds-first-lab-grown-burger-dont-forgetthe-semi-living-steak 
relies on the history of spectacle in both the sciences and contemporary art, ${ }^{44}$ this event reflects the prioritization of scientific knowledge over artistic knowledge that is endemic across society.

Catts and Zurr have been outspoken with regards to the fact that artists working with new biological technologies enjoy the freedom to approach these technologies from a critical perspective in a way that many scientists cannot. They have written that they are free to "employ irony as an artistic and philosophical response to technological determinism. ${ }^{, 45}$ Further to this, they provide the example of Disembodied Cuisine, in which they "ironically offered the possibility of eating meat without killing animals, creating a victimless meat." Although this was written in 2008, and predates Mark Post's lab-grown burger by several years, it is relevant to observe that Catts and Zurr, because they operate from the position of artists, rather than privately sponsored scientists, are free to speak publicly and critically about the technologies they employ. They point out that current methods of tissue culture require the use of animal-derived products in substantial quantities in order to provide nutrients for the growth of the tissue. By their estimate, "growing around 10 grams of tissue will require serum from a whole calf $(500 \mathrm{ml})$, which is killed solely for the purpose of producing the serum. " it is quite evident that using current technologies provides a lab-grown meat that is by no means "victimless." In addition to the animals from which the tissues are initially sourced and the animal-derived ingredients that provide the nutrient media that nourishes the

\footnotetext{
${ }^{44}$ Commenting on Post's ability to mobilize private funding from Sergey Brin, the co-founder of Google, Stephens writes: "Rather than a Frankenburger, with its echoes of 19th century scientific experimentation, what we have here might best be understood as the world's first Googleburger: a hybrid of new technologies and new forms of flesh whose potential remains largely virtual, and whose significance is the product of spectacle as much as science. Indeed, given Post's acknowledgement that binding agents were added to the meat to make it look better and hold its shape, and the lack of reported independent scientific oversight of last Monday's event, we might usefully turn to consider the terms in which the scientific status of such spectacles are reported and understood." Ibid.

45

Oron Catts and Ionat Zurr, "The Ethics of Experiential Engagement with the Manipulation of Life," Tactical Biopolitics: Art, Activism, and Technoscience, edited by Beatriz De Costa and Kavita Philip, (Cambridge, Massachusetts and London, England: MIT Press, 2008), 131.

46

Catts and Zurr, “Ethics of Experiential Engagement," 133.
} 
tissues, the process also generates an enormous amount of waste in the form of plastic lab-ware, which has a lasting impact on the environment. ${ }^{47}$ Catts and Zurr argue that artists working in the lab with emergent technologies can be "a political act that goes beyond the democratization of the technology, to the act of breaking down dominant discourses, dogmas, and metaphors to reveal new understandings of life and the power structure that it operates within." 48

With the intention of democratizing access to the biological sciences, Catts has offered a series of one-week workshops in which they engage with people from various disciplines who have little or no lab experience but who share a common interest in art and biology. ${ }^{49}$ By exposing workshop participants to the tools and protocols of contemporary biology/biotechnology, Catts and Zurr provide participants with hands-on experience and knowledge. The goal of the workshops is to allow participants to engage with the issues of biotechnology from an informed and experiential basis with the aim of encouraging critical analysis, discussing ethical issues, and exploring cross-disciplinary issues in art. Throughout the course of the workshop, participants learn health and safety protocols, the basics of using a microscope, observation of bacteria and fungi, as well as proper handling, culturing, and identification techniques. They learn the basic techniques of DNA isolation, and how to insert Green Fluorescent Protein from a jellyfish gene into modified E. coli cells to create fluorescent bacteria. The workshop advances to introduce rudimentary tissue engineering using a piece of meat obtained from a butcher, and working with immortal cell lines derived from cancerous tissue. Finally, the participants are taken through a demonstration on tissue engineering and scaffold fabrication for the animal cell culture.

\footnotetext{
${ }^{47}$ Ibid. 138.

48 Ibid. 140.

49 See Oron Catts and Gary Cass, "Labs Shut Open: A Biotech Hands-on Workshop for Artists," Tactical Biopolitics: Art, Activism, and Technoscience, edited by Beatriz De Costa and Kavita Philip (Cambridge, Massachusetts and London, England: MIT Press, 2008), 143-156.
} 
Although the workshops are run in laboratories and the participants work with standard lab equipment, Tissue Culture and Art Project aim to provide information on how similar experiments could be achieved using comparatively low-tech materials and equipment readily available in a household kitchen or from the hardware store. Their aim is to develop an inexpensive tool kit so that artists interested in working with biology can pursue projects at home or in the studio. They hope that by making this type of research both accessible and affordable that it will lead to the democratization of knowledge in the field of biology and will open avenues of investigation that are currently available only to those who have privileged access through formal academic training. Catts summarizes the potential social value of such workshops,

The "us" and "them" feeling between the arts and sciences does exist, but this workshop may be a small step toward chipping away at these barriers. Successful art-science collaboration can be valuable for both parties only if they cooperate equally. We believe that the discussions and decisions emanating from such an alliance will have significant implications for interdisciplinary practice within arts and science. $^{50}$

One artist who has experienced consistently positive collaborative experiences while working with cooperative and enthusiastic scientists is Marta de Menezes, a Portuguese artist who works in research laboratories with the aim of investigating how new biological technologies can be use as an art medium. In 1999, de Menezes worked with evolutionary biologists in the Institute for Evolutionary Biology and Ecological Sciences at the University of Leiden to create her first biological artwork called Nature $?^{51}$ Despite now being regarded as a canonical work in the field of bioart, this project was the final work submitted during de Menezes' Master's degree in painting.

\footnotetext{
50 Cass and Catts, “Labs Shut Open," 155.

51 See Marta De Menezes, “The Artificial Natural: Manipulating Butterfly Wings for Artistic Purposes," Leonardo 36, No. 1 (2003), 29-32, and "The laboratory as Art Studio," The Aesthetics of Care? The artistic, social and scientific implications of the use of biological/medical technologies for artistic purpose, ed. Oron Catts, (Perth: SymbioticA, School of Anatomy and Human Biology, University of Western Australia, 2002), 53-58.
} 
The biologists were studying wing development in butterflies, and how external physical factors might influence the development of wing patterns in ways that did not affect their genetic make up and which would not be passed on to subsequent generations in order to account for variations within a species. ${ }^{52}$ They had discovered that during the pupal stage of the butterfly's life it is possible to interfere with the normal development of the wing patterns by using microcautery, passing a fine heated needle through the walls of the pupae, to damage regions of the wing and stimulate new patterns of development.

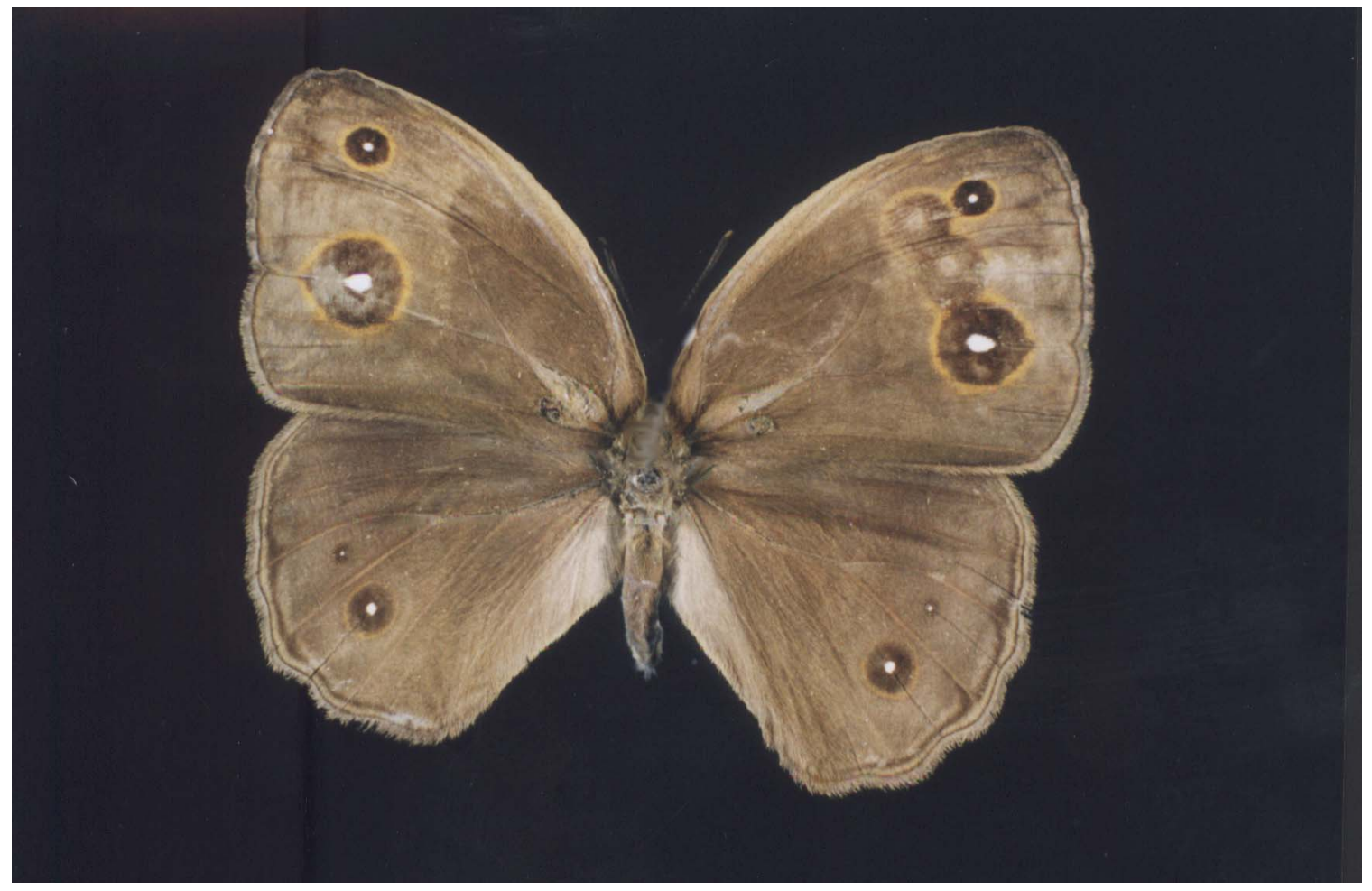

Figure 1.11: Marta de Menezes, Nature? (Bicyclus anynana), 1999. Image used with permission from the artist.

They had also found that it is possible to graft a portion of tissue from one position to another on the same wing or even onto that of another butterfly. In contrast to the scientists' purely pragmatic experiments, de Menezes uses the same techniques to explore the potential for manipulating the butterflies' wings in order to create temporal works of

\footnotetext{
52 Note the contrast between this type of interference (altering the phenotype without altering DNA) with the types of organisms that artist Richard Pell, discussed in Chapter 3, is concerned with (organisms that have been genetically altered in ways that are intentional and heritable).
} 
art. She stresses that she is not interested purely in beauty or aesthetics or in making something beautiful more beautiful, but in exploring the possibilities and constraints of the biological system, to create results that are not part of the evolutionary process. Of greater significance to the artist is the fact that these manipulated butterflies are something that have never before and will never again be seen in nature. They are works of art with the lifespan of a butterfly. For de Menezes, the alteration raises the question, "Is the altered butterfly artificial or not?" It has been manipulated by the human hand, but purely in a superficial way. The microcautery takes place in a very short window of time after the beginning of pupation when cells are forming, and the intervention merely interferes with chemical signals. The butterflies remain the same genetically and reproductively: any alterations would not be inherited by future generations.

Like the scientists, De Menezes only manipulates one side of the butterfly leaving one wing as it would occur in nature, as a kind of control. However, in contrast to the scientists who are interested only in the results of a single stimulus, De Menezes is free to combine multiple microcautery stimulations with the intention of creating more complex results. One of her manipulations of a Bicyclus anynana specimen resulted in a linear marking that was achieved by "piercing the pupal wing at several positions. Each of these microcauteries led to the development of an ectopic eyespot, but because they were applied at short distances from each other, the eyespots fused together in the resulting linear pattern." 53 In a Heliconius melpomene specimen, de Menezes, "changed the position of cells of the pupal wing by grafting epidermal tissue between two positions of the wing. By comparing with the non-manipulated side it is possible to see that the cells that would have become white became red in their new position just outside the red patch. The cells from the other grafted tissue matured into a black patch, as they would have done in the original location. This intriguing result raised questions that are being followed up by the scientists in Leiden." 54 In this instance, it was the experimentation by the artist that led to an unexpected discovery.

\footnotetext{
53 De Menezes, “Artificial Natural,” 30.

54 Ibid, 30.
} 


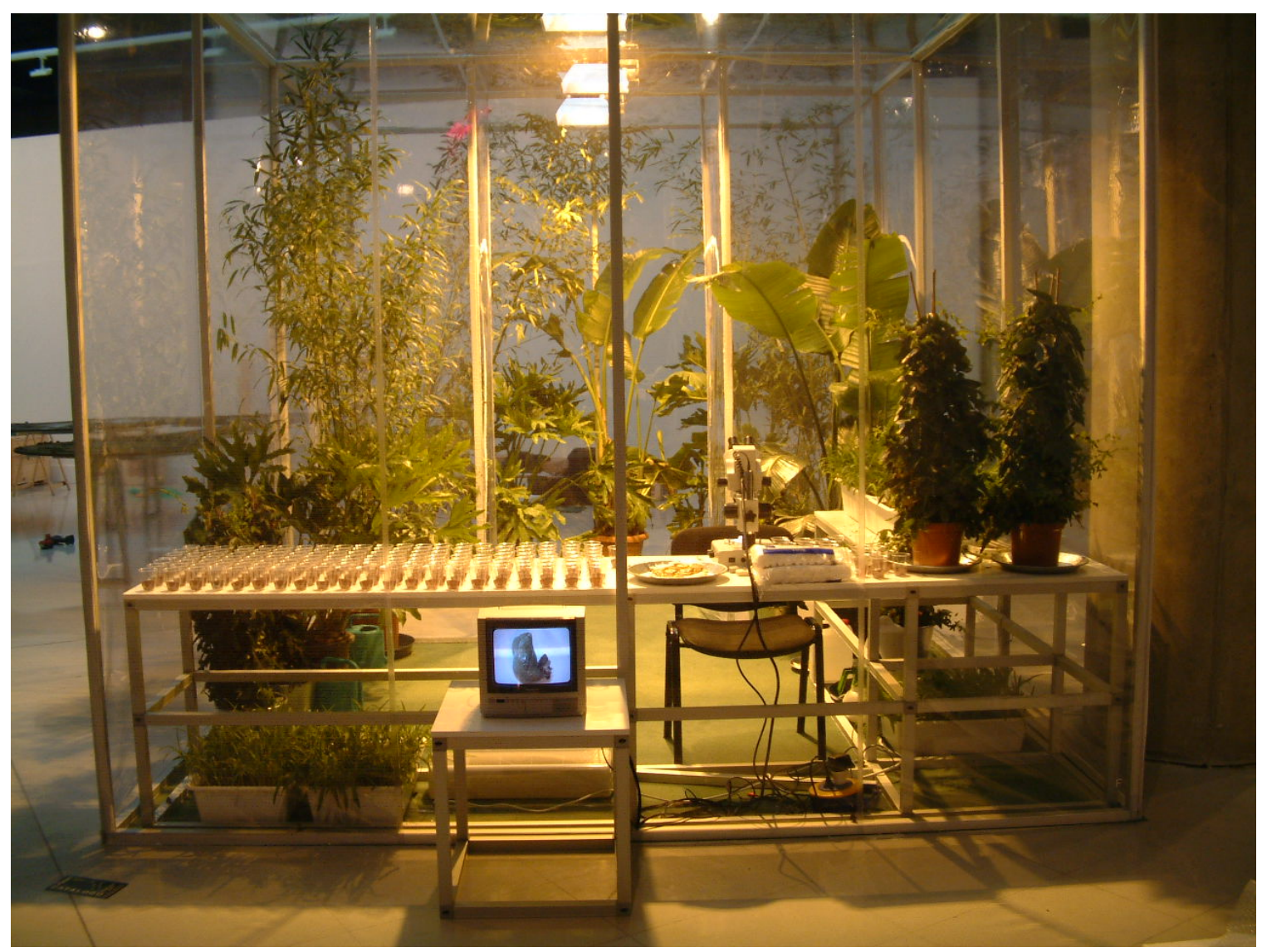

Figure 1.12: Marta de Menezes, Nature? (installation),1999. Image used with permission from the artist.

De Menezes exhibited the live butterflies in a purpose built greenhouse inside the Gallery at Ars Elecronica (2000). The greenhouse also contained plants, butterflies at all stages of development, and a microscope under which De Menezes publicly performed the microcauteries, and which was attached to an external monitor so that people could view how she made the alterations to the pupae. ${ }^{55}$ De Menezes is currently working on a new project that also involves the manipulation of a butterfly, but in this case it does involve genetic manipulation. The project, called Leda, is a play on taxonomic meaning. Here, de Menezes is inserting a human gene derived from fellow artist Melanitis Yiannis

55 Exhibition rights to this piece have since been purchased by Museo Extremeno e Iberoamericano de Arte Contemporáneo, in Badajoz, Spain, who are able to recreate the installation using the original greenhouse, but with trained staff who perform the microcauteries under microscopes. They have been given strict instructions on all stages of the exhibition, including how to source the butterflies and how to release them after the exhibition ends. 
into the genome of a butterfly that carries the same name: Leda melanitis, the Linnaean name of the Common Evening Brown butterfly.

When asked if she has ever encountered any sort of resistance arising from a perceived hierarchy of scientific knowledge over artistic knowledge, de Menezes replied that the scientists she had worked with had been very supportive. She acknowledges that in her earliest collaborations the scientists had not heard of the concept of artistic knowledge, as differentiated from scientific knowledge, but were "perfectly happy to acknowledge the field of art research and knowledge production." ${ }^{, 56}$ She also points out that when her experimentation on the butterflies in the piece Nature? led to unexpected results, the scientists encouraged her to publish a paper documenting her methods and results: "The lab in Leiden did get some unexpected results from my experiments and they were very encouraging in having me write a paper about the results and methods, but I was always going on to the next project and so I never wrote it. But not because they didn't want me to, they really did and would have helped me with it. So I would be the first author and name the collaborators and Paul Brakefield would have been the last name. ${ }^{, 57}$ Because De Menezes regards herself as an artist first and foremost, and does not prioritize publishing papers with her scientific collaborators within her art practice, she has since released her rights to the scientists so that they can proceed with research using her results or materials.

The symbiotic relationship that De Menezes enjoys with the scientists with whom she works contrasts with the paradigm of the $18^{\text {th }}$ century laid out by Daston and Galison, in which the hand of the artist is subservient to the mind of the scientist. In current interactions, the artist has some autonomy, although he or she often still depends on the scientists to share knowledge and facilities. With the increased interest in transdisciplinary research and art-science collaborations, however, more fine arts

\footnotetext{
${ }^{56}$ Correspondence between the author and Marta de Mendezes, February 16, 2016.

${ }^{57}$ Ibid.
} 
programs are establishing laboratory facilities for the purpose of artistic exploration of biotechnology.

\subsection{And never the twain shall meet?}

By working with the skill set required in the evolutionary biology lab, De Menezes essentially bridges the disciplinary schism between art and science practices. Rhonda Roland Shearer and Steven J. Gould argue that this split is arbitrary and has been naturalized by cultural forces that do not acknowledge the overlap between the two disciplines:

The contingent and largely arbitrary nature of disciplinary boundaries has unfortunately been reinforced, and even made to seem "natural," by our drive to construct dichotomies - with science versus art as perhaps the most widely accepted of all. Moreover, given our tendencies to clannishness and parochiality, this false division becomes magnified as the two, largely non-communicating, sides then develop distinct cultural traditions that evoke mutual stereotyping and even ridicule. $^{58}$

Lloyd Anderson takes issue with Shearer and Gould's suggestion that such boundaries might be subjective or socially constructed. He argues that although technologies mediate between art and science, it does not alter the fact that artists and scientists inhabit fundamentally different worlds. ${ }^{59}$ He argues that the former is individualistic, spontaneous, and aesthetically driven, while the latter relies on controlled conditions, repeatability and empirical data; although I suggest that this dichotomy is in itself a stereotype and, given the nature of certain art practices, no longer universally applicable. Anderson argues that both the arts and sciences have mind and skill sets that

\footnotetext{
58 Rhonda Roland Shearer and Stephen J. Gould, “Of Two Minds and One Nature,” Science 286, no. 5442, (5 November 1999), 1093.

59 See Lloyd Anderson, “On the Nature of Interactions," Artists in Labs: Networking in the Margins, ed, Jill Scott, (Vienna: Springer-Verlag / Wien, 2010), 23-33.
} 
are particular to each discipline and not interchangeable. Consequently, each discipline is populated by specialists within their respective fields, and when a practitioner of one discipline encroaches on the area of specialization of the other, the result is a type of dilettantism. This, Anderson argues, is a consequence of the internet age in which we have grown so used to having unfettered access to the technologies required by every field that it has created the illusion that any "generalist" can encroach on the skill set possessed by a specialist in another discipline as if no training or background was required. The trend towards interdisciplinarity has led to a watering down and a decrease in the appreciation of specialist knowledge. Because of this, Anderson cites Dorothy and Tom Cross's exhibition Medusae as a successful example of collaboration between an artist and a scientist. The joint effort resulted in two intertwined but disciplinarily discrete projects around a single theme, with the art serving to illustrate the science as well as to provide a humanist context to zoological research.

Dorothy Cross is an Irish artist who collaborated with her brother Tom, a professor of zoology at the University College Cork, on the project Medusae (2003), an interdisciplinary project that combined the Cross's mutual interest in jellyfish. Tom examined the biomechanics of the swimming patterns of Chironex fleckeri, the deadliest and fastest swimming species of jellyfish in the ocean, and Dorothy focused on the life of Maude Delap, an amateur naturalist who studied jellyfish in her home on Valentia Island, Ireland at the beginning of the twentieth century. Their research produced a body of moving images, including documentary footage of Chironix fleckeri, and two video works: Come Into the Garden Maude (2001) and Jellyfish Lake (2003). This footage was also combined to create the major output of the collaboration, the video Medusae (2003). 


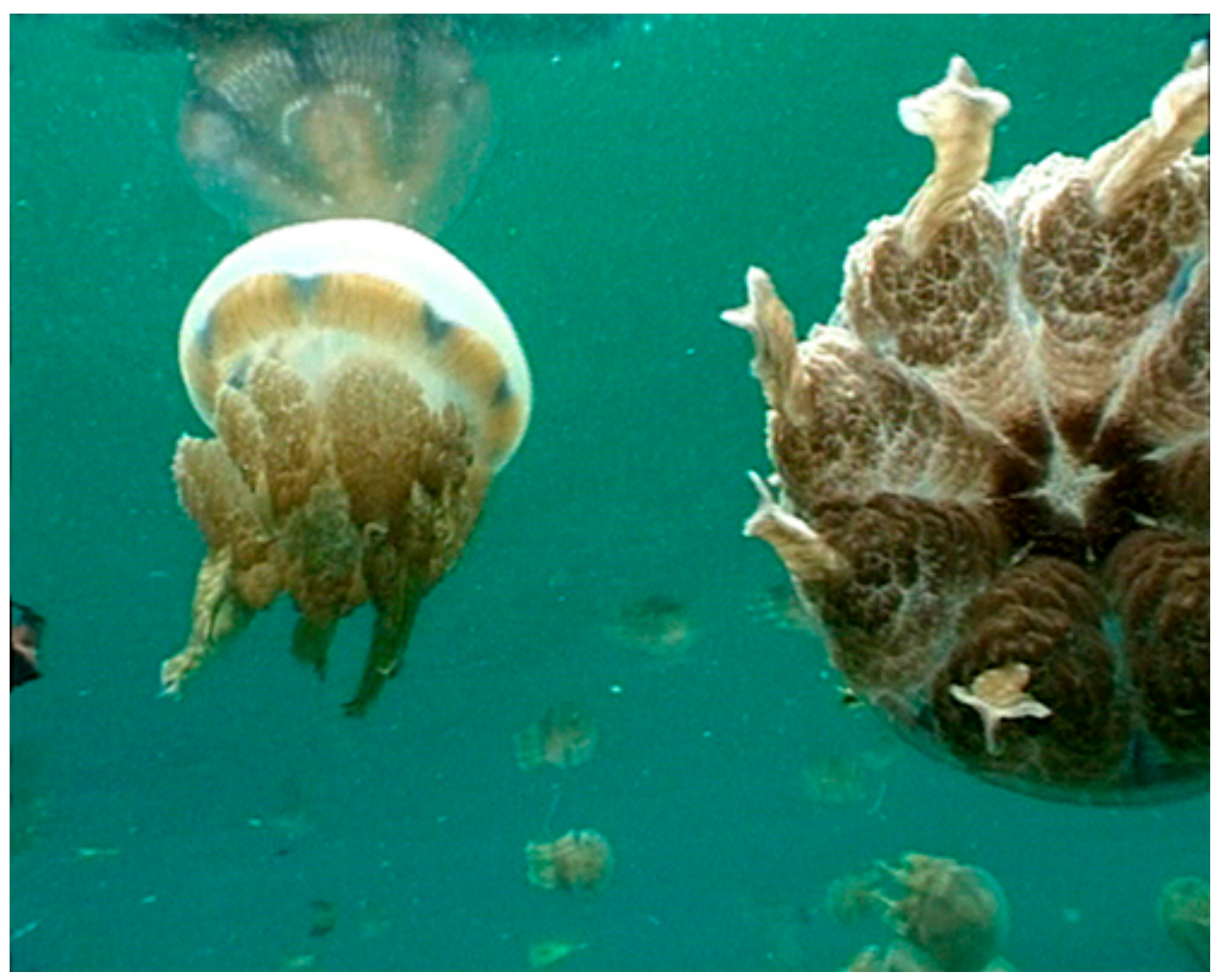

Figure 1.13: Dorothy Cross, Medusae (film still), 2003. Image used with permission from the artist.

The project combines Tom's scientific approach to the study of jellyfish biomechanics with Dorothy's more poetic weaving of narratives of Maude Delap's life as an amateur scientist with notions of longing and desire. Delap was an accomplished naturalist, who in 1902 succeeded in breeding jellyfish in her home with little equipment beyond glass bell jars, a significant accomplishment given the extreme difficulty of breeding jellyfish in captivity. She also maintained a lifelong correspondence with the Natural History Museum in Dublin, often providing them with unidentified and rare specimens that she had located and accompanying her donations with charming and witty letters. Delap's skills as a scientist are intermingled with the tale of her unrequited love for a British naturalist who had visited Valentia in 1898, and to whom Delap would fruitlessly send flowers every year. Dorothy Cross writes, 
Maude continued to write to Edward Browne until he died. She sent him a box of wild violets on his birthday every year all the way to Plymouth. He would refer fleetingly to this gift, generally followed by a list of instructions for her fieldwork. We know that Maude was offered a job at the University in Plymouth, but her father, the Minister, said, "No unmarried daughter of mine will leave this house." So she remained on the island and continued her independent research, later publishing several scientific papers on medusae. ${ }^{60}$

Unlike many art-science collaborations that are characterized by artists appropriating the methods and techniques of scientific practice and research so closely that they result in artwork that is barely distinguishable from scientific experiments, the Cross's collaboration follows the two streams of inquiry defined by their respective disciplines, which act in parallel to create two discrete but interrelated bodies of knowledge. Tom Cross's contribution to the Medusae project took the form of a body of scientific research into the biomechanics of swimming jellyfish through digital analysis of video sequences. Chironex jellyfish samples were collected in Australia then transported to a custom-built tank at Digital Dimensions Film Studio in Townsville, north of Queensland, where they were video recorded. Tom Cross writes that the footage

was run through graphics packages to identify nodes on seven readily apparent body locations. By using these superimposed coloured nodules on each frame, we could plot mathematically the position of a particular body part at any given time...The $\mathrm{x}$ and $\mathrm{y}$ coordinates were determined in each frame and then transferred to a spreadsheet for geometrical interpretation. Graphs based on the co-ordinates of these nodes during locomotion allowed numerical description of gait. $^{61}$

\footnotetext{
60 Dorothy Cross quoted in Marina Warner, Dorothy Cross, Tom Cross, "Medusae," Experiment: conversations in art and science, ed. Bergit Arends and Davina Thackara, (London: the Wellcome Trust, 2003), 30 .

61 Tom Cross quoted in Marina Warner, Dorothy Cross, Tom Cross, "Medusae," Experiment: conversations in art and science, ed. Bergit Arends and Davina Thackara, (London: the Wellcome Trust, 2003), 47-51.
} 
We can observe by comparing how the Crosses write about their own research contributions to the Medusae project that they each stay true to their own disciplinary methods and sensibilities. They ultimately conclude, "The stories of Maude and of jellyfish are still largely unknown. The work occurs at the point where both territories meet, like reflective opposites." ${ }^{~} 62$ They also admit that although their collaboration resulted in an engaging body of work, each of their methodologies remained uninfluenced by the other's. Dorothy continued with an art practice that cannot be seen as encroaching on scientific methodologies; likewise, Tom's research continued to be pure science. Medusae is not so much art-science collaboration as it is a dialogue between two disciplines. Dorothy and Tom Cross did not alter either their respective disciplinespecific methodologies or their modes of working, but created two discrete yet interrelated bodies of knowledge that demonstrated how different modes of exploration could be utilized to perform research on a single topic. Although I agree with Anderson's assessment that this collaboration is highly successful in that it resulted in an installation that was both visually stunning and metaphorically rich, I do contest his suggestion that it is sufficient for art to illustrate and humanize science. I feel that this approach does an injustice to works created by artists who engage in scientific practice in more than an illustrative or metaphorical capacity. In certain cases, artists have created bodies of work that not only illustrate and raise awareness of issues in scientific or ecological research, but also have resulted in a tangible expansion of scientific knowledge.

\subsection{Conclusion}

Perhaps at issue here is the notion of scientific objectivity. As Daston and Galison remind us, "To be objective is to aspire to knowledge that bears no trace of the knowerknowledge unmarked by prejudice or skill, fantasy or judgment, wishing or striving.

Objectivity is blind sight, seeing without inference, interpretation, or intelligence." ${ }^{\text {63 }}$ This invites the question of how we view the role of the artist vis-a-vis the scientist in the

\footnotetext{
62 Tom and Dorothy Cross, "Medusae," 60.

${ }^{63}$ Lorraine Daston and Peter Galison, Objectivity, (New York:Zone Books, 2007), 17.
} 
capacity of presenting knowledge. Siân Ede presents the two opposing archetypes of scientists and artists, reminding us that scientists are bound by the principles of the scientific method, driven to collect data through controlled experiments and presenting the demonstrated evidence through graphs devoid of emotion or opinion. On the other hand, Ede argues, artists today continue to be influenced by the Romanticist notion of the artist as divine messenger. "Romanticism opposed every tenet of the enlightenment: reason with emotion, objectivity with subjectivity, control with spontaneity, limitation with aspiration, empiricism with transcendentalism, society with the individual and order with rebellion., $" 64$

If we view it as the responsibility of the scientist to present information neutrally without judgment, and we regard it as the artist's role to interpret information and present it to us in a way that causes us to question aspects of our world or humanity, how do we respond to artists who are blurring the lines between those two positions by working within scientific disciplines? As Dr. Jonas Salk suggests in the introduction to Bruno Latour's Laboratory Life, if the public could understand how scientific knowledge is generated they would perhaps have a greater understanding of scientists and less fear of science, the social positions of scientists in societies would be clarified, and there would be an increased understanding of the substance of science and the creation of scientific knowledge ${ }^{65}$ In much the same way, artists who enter into collaborative projects with scientists are engaging in a sort of quasi-anthropological expedition, and given that the resulting work is often publically exhibited, they are able to translate scientific knowledge into cultural knowledge.

Although the notion of artists working in laboratories raises issues surrounding the amateur versus the expert and corresponding questions surrounding the validity of

\footnotetext{
${ }^{64}$ Siân Ede, “The Scientist's Mind: The Artist's Temperament," Strange and Charmed: Science and the Contemporary Visual Arts, ed. Sian Ede and A. S. Byatt (London: Calouste Gulbenkian Foundation, 2000), 35 .

${ }^{65}$ Bruno Latour and Steve Woolgar, Laboratory Life: The Construction of Scientific Facts, (Princeton, New Jersey: Princeton University Press, 1979), 13.
} 
different types of knowledge, such artists are also in the unique position of being able to work within a foreign discourse, like travellers or anthropologists, and are able to ask questions that the native inhabitants might not be in a position to pose. Perhaps the value of artists working from this position lies in their ability to present scientific information in a way that causes us to question how we understand such information, or the faith we place in science and scientific objectivity. Andrea Glauser suggests that one of the benefits of artists being in the laboratory (and by extension, I would argue, engaging in primary biological field research) is that they are in a position to ask questions without losing professional credibility. For example, Glauser states that for many scientists, addressing questions that are emotional or metaphysical is taboo, but artists are free to investigate these concepts. As a result, artists can be seen as a resource for overcoming certain sorts of restrictions that are intrinsic to the culture of the lab. However, this mentality suggests that art can be seen as providing a service to science by making scientific concepts more palatable and accessible to the general public. Artists not only mediate scientific and technological processes, but also humanize them. ${ }^{66}$ However, I argue that this does a disservice to artists' true social value when working in either the laboratory or the field. Tissue Culture and Art Project, for example, are affiliated with an academic institution, but as artists working in a lab made specifically for artists, they not indebted to private sponsorship and are free to criticize the socially or environmentally problematic aspects of the technology with which they engage. There is much to be gained when artists pursue the metaphysical or aesthetic end of the scientific spectrum, as was the case with Dorothy Cross's video work as complement to her brother's data, and there are significant social benefits to bridging the gap between scientists and lay people, as we have seen with Ballengée's eco-art interventions. But it is also vital that artists working with scientists are not merely viewed as acting in service to science, but are free to ask difficult and critical questions and to illuminate the negative aspects of new technologies.

\footnotetext{
66 See Andrea Glauser, "Formative Encounters: Laboratory Life and Artistic Practice," Artists in Labs: Networking in the Margins, ed, Jill Scott, (Vienna: Springer-Verlag / Wien, 2010), 12-22.
} 


\section{Chapter 2}

\section{Disrupting the Language of Classification}

Natural history specimens can be described as a meeting of nature and culture: nature mediated by the human hand. In an age when museums are storing and cataloguing genetic fragments meant to stand in for the whole specimen alongside collections of

nineteenth century taxidermy, the definition of what can be considered a natural history specimen is increasing in scope. Not only has our conception of what constitutes natural history specimens changed, but so has the language that we use to name and classify them. In this chapter, I will investigate the connection between the practices of artists who are working with either living organic material or the preserved animal body and the increasing mutability of what constitutes a natural history specimen. In 1989, Susan Leigh Star and James R. Greisemer introduced the term "boundary objects" to refer to objects that were "both adaptable to different viewpoints and robust enough to maintain identity across them." They described how scientific objects, including natural history specimens, have the ability to inhabit and fluidly move between multiple social worlds, particularly those of museum professionals and amateur collectors. With the current interest in applications of biological science to contemporary art, I suggest that this relational nexus can be extended to include contemporary artists whose practices focus on representations of natural history specimens - both artists working with museum collections and artists manipulating living specimens in the laboratory. These art-based interventions have highlighted how natural history specimens not only occupy an increasingly fluid social space, but have also been subjected to disruptions in the established classificatory systems that are applied to them, in terms of both our general understanding and the more specific taxonomic systems that situate specimens within an accepted natural order. 
In his work of popular science, Rob Dunn writes, "Every culture known names species, then groups them, then builds them into knowledge and stories." "He illustrates the different ways in which naming and knowledge can be constructed by providing the example of a research trip that he and his wife took to Cavinas, Bolivia. He contrasts his guide's methods of identification based on observation not only of the shape of the leaves and the texture of the bark but also of the presence of particular insects, with his own European predilection for identification through fruits and flowers as espoused by Linnaean taxonomy. Such different philosophies of classification are the result of cultural experience and language. His anecdote reminds us that, throughout mankind's existence, species have been named by individual cultures in their native language, with the result that a single given species might have multiple names in numerous languages. This led scientists to a need for a common language, a universal system of naming things so that they could be studied and discussed across different languages without fear of confusion or inconsistency. Here, I investigate the changing relationship of language to taxonomic classification by examining the potential of a contemporary re-visiting of an early seventeenth century model of language in the context of twenty-first century taxonomic concerns. First, using two installations by the bio-art collective Tissue Culture and Art Project as a case study, I will examine how multispecies semi-living lifeforms such as hybridomas and certain cell lines used in current biotechnical research have disrupted the systems of classification that have been in usage for the past two centuries. I will argue that Linnaean ideals of classification have been challenged by new classificatory systems applied to commercially available cell lines and that binomial methods of taxonomy have been replaced by numerical cataloguing. In addition, I will suggest that current groundbreaking approaches to DNA taxonomy, as manifested in the Barcoding of Life Database (BOLD), can be seen as a contemporary manifestation of Bacon's proposal for a natural language. I will then further develop this argument through an analysis of the work of Gemma Anderson, a UK-based artist who uses traditional drawing and engraving techniques to render the morphology of natural history specimens, and who has

\footnotetext{
${ }^{1}$ Rob Dunn, Every Living Thing, (New York, London, Toronto and Sydney: Smithsonian Books, HarperCollins, 2010), 11.
} 
subsequently created a symbolic language of shared forms that could be similarly described as fulfilling Bacon's description of a natural language.

Since the sixteenth century, collections of objects drawn from the natural world taking varying forms from cabinets of curiosity to natural history museums - have helped to shape our understanding of the natural world. Given the importance of language in communicating this knowledge, the relationship between language and classification has determined how we articulate the order of nature. During the eighteenth century, Carolus Linnaeus introduced a system of naming, classifying, and categorizing things using a binomial system of taxonomy. This system was largely based on observable relationships of similitude and predictability between organisms and it continues to be in common use. However, our current understanding of natural history has been complicated by the advent of new types of organisms created as a result of advances in biotechnology, as well as by the work of artists who draw attention to and disrupt our assumptions regarding what constitutes a living thing and how we subsequently choose to classify it. In addition to the increasing interest in applications of biotechnology to the visual arts, there has also been a concomitant return to working with materials and epistemologies that favor an earlier period, in which systems of classification were based on difference rather than similitude. These two trajectories have resulted in work that celebrates the curious, the freakish, and the anomalous in a manner that both acknowledges past practices and challenges potential future ramifications.

\subsection{Curious Instances, Chimeric Blobs}

Natural history collections have evolved over the past four centuries in response to changes in methods of classification, systems of display, and techniques of preservation. The cabinets of curiosity that characterized the fifteenth and sixteenth centuries gave rise in the seventeenth and eighteenth centuries to institutional collections, which often grew out of private collections bequeathed by individuals to universities. Ultimately, it was the golden age of the natural history museum during the nineteenth century that has largely continued to shape our perceptions of museums and the organization of knowledge to the 
present day. ${ }^{2}$ This evolving trajectory has garnered considerable attention recently in contemporary art. Perth-based bioart collective Tissue Culture and Art Project are known not only for their work using tissue culturing as a sculptural medium but also for

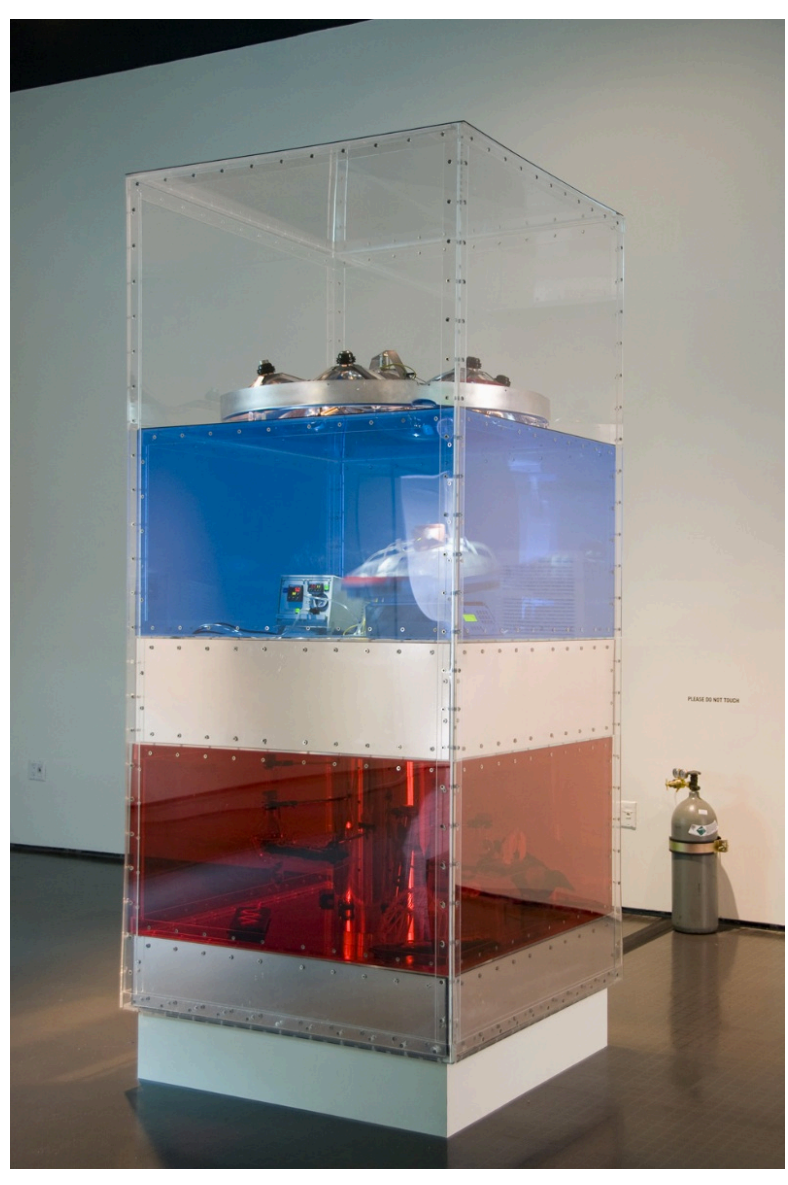

Figure 2.1: Tissue Culture and Art Project, NoArk, 2007. Image used with permission from the artists. questioning the socio-cultural impact that advances in new biotechnology have had on contemporary art and scientific thought, as well as on society more broadly. Although Tissue Culture and Art Project engages in a much wider field of investigation surrounding biological practices, of particular interest here are two installations that they created to explicitly address issues surrounding the history of scientific classification as it pertains to museums, and the potential impact that advances in biotechnology may have on how we perceive and classify life in the future. They suggest that, by working with new technologies, specifically those that form the basis for tissue culturing, regenerative medicine, and genetic manipulation, scientists are disrupting the established systems of classification and taxonomy that have been used to structure our current understanding of how organisms are ordered in nature. These scientists are, in effect, creating new "species" of organisms that cannot be inserted into the existing order. Such new organisms may also be referred

\footnotetext{
2 See Michael Hunter, “The Cabinet Institutionalized: The Royal Society's 'Repository' and its Background," in The Origins of Museums: The Cabinet of Curiosities in Sixteenth- and SeventeenthCentury Europe, ed. Oliver Impey and Arthur MacGregor (Oxford: Clarendon Press, 1985), 159-168 for a discussion of the institutional collection as an intermediate structure between cabinets of curiosity and public museums.
} 
to as "synthetic life," or life engineered from raw materials. In response to what they regard as "the taxonomical crisis that is presented by life forms created through biotechnology,"3 Tissue Culture and Art Project created the installations NoArk (2007) and Odd Neolifism (2010). ${ }^{4}$ NoArk has been exhibited several times with the elements arranged to suit the space in which it is installed. One incarnation comprises a freestanding transparent vessel that houses several preserved animal specimens, as well as a bioreactor. The vessel rotates on a turntable revealing shifting perspectives of the included life forms, both preserved dead animals and living cellular matter that requires a bioreactor to maintain its existence.

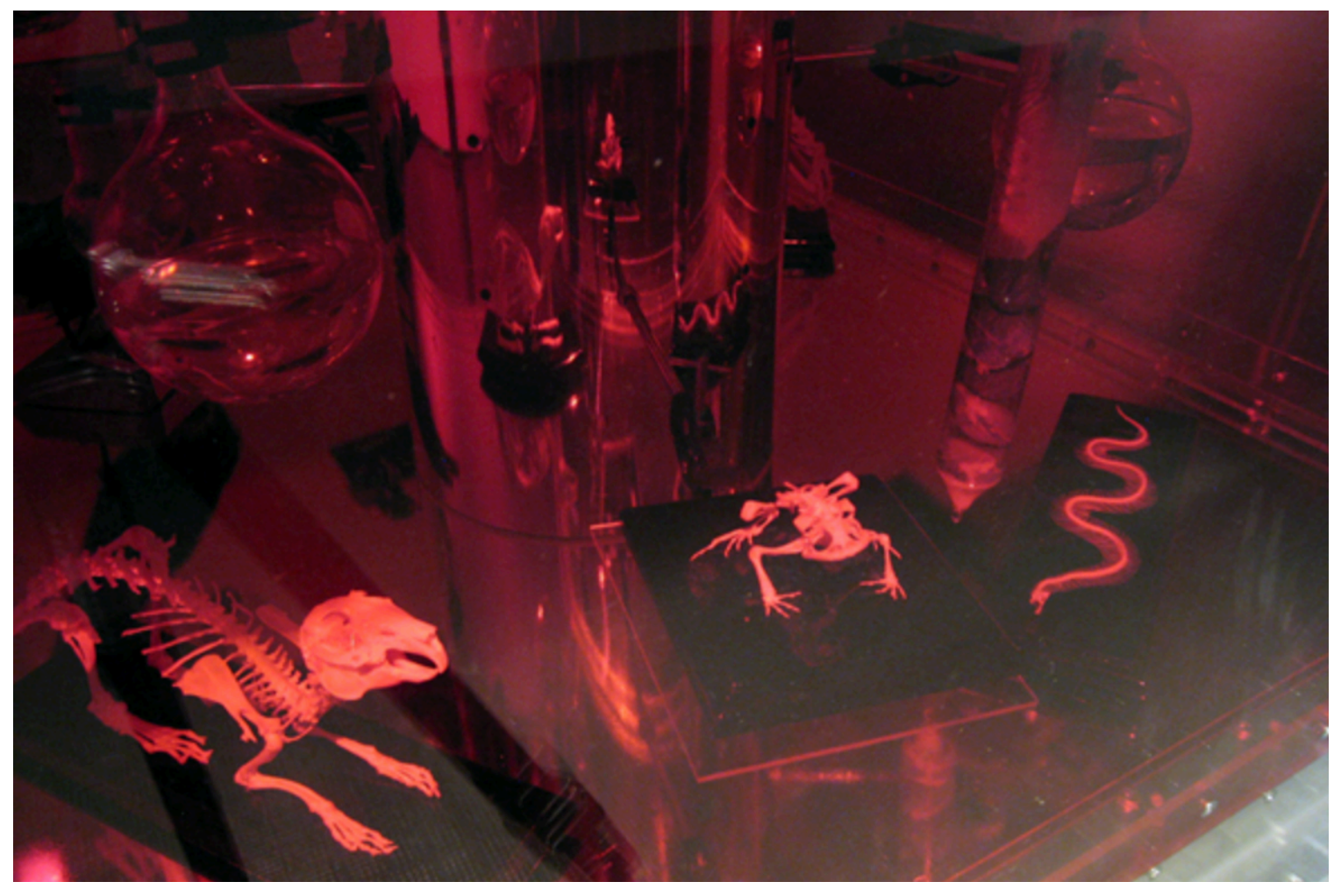

Figure 2.2: Tissue Culture and Art Project, NoArk (detail), 2007, Image used with permission from the artists.

\footnotetext{
3 “NoArk 2007", http://www.tca.uwa.edu.au/noark.html .

4 Tissue Culture and Art Project often exhibit their installations several times and in different venues, the various elements reconfigured to fit the space. As a result, the descriptions of NoArk and Odd Neolifism provided here may not conform exactly to every presentation of the work.
} 
In a later version of the installation, NoArk Revisited: Odd Neolifism, the elements were rearranged and placed inside vitrines set into a wall. In both cases, the specimens included several taxidermic animals, including a pig, a crow, a rabbit, a rat, and a twoheaded chick, as well as numerous wet specimens preserved in jars. The bioreactor serves as "a surrogate body to the collection of living fragments" collected from tissue banks, natural history museums, and laboratories. The cells of several different organisms were combined to create a "chimerical blob," an unclassifiable semi-living organism kept alive in a bioreactor. Tissue Culture art Art Project suggest that attempts to theorize this chimerical blob would have more in common with the seventeenth-century notion of the cabinet of curiosities, with its fraudulent mermaids created from fish and monkeys, than it would to currently used methods of classification. As Rachel Poliquin so eloquently tells us,

Spanning approximately a century and a half, from the mid sixteenth century to the early eighteenth, such cabinets are hemmed by two separate traditions of collecting, the one leading backwards in time to a world resonant with the power of relics, mystical visions, and ancient lore, the other pointing towards what would slowly germinate and sprout into the ordered, systematic fields of science, empirical observations, and facts. ${ }^{6}$

Although Poliquin's words specifically refer to the epistemology of the cabinet of curiosities, they could just as easily be applied to a reading of works by Tissue Culture and Art Project that address the history cabinets and freak shows as well as future implications of biotechnology. The new quasi life forms or "neo-organisms" that Tissue Culture and Art Project have created do not fit easily into the systematic order of nature as we have come to perceive it. For example, to create the "chimerical blob" included in NoArk, Tissue Culture and Art Project grew tissue over a polymer substrate using the

\footnotetext{
5 http://tcaproject.org/noark/ (accessed July 28, 2014)

${ }^{6}$ Rachel Poliquin, "Botched Animals and Enigmatic Beasts," in Curious Collectors, Collected Curiosities: An Interdisciplinary Study, ed. Janelle A. Schwatz and Nhora Lucía Serrano, (Cambridge: Cambridge Scholars Publishing, 2010), 43.
} 
McCoy cell line, a cell line identified by a number rather than by Linnaean taxonomic principles. This cell line is sold as being of human origin, and in 1965 scientists showed that the McCoy cell line did indeed come from human cells. ${ }^{7}$ However in subsequent years this widely disseminated cell line has been shown to be of mouse origin and in possession of marker chromosomes characteristic of strain L mouse fibroblasts. ${ }^{8}$ As a result, McCoy cells that are sold as human but may be mouse, can thus be perceived as a type of fraudulent chimera along the lines of the mermaids or basilisks that once populated cabinets of curiosities, consequently destabilizing our notions of a systematic method of classification. ${ }^{9}$

Catts and Zurr are only two of numerous artists who, in recent years, have made reference to the conceptual, aesthetic, and epistemological characteristics of the cabinet of curiosities as a construct in the history of classification. Consequently, it seems plausible to revisit scientific thought from the seventeenth century to ground an analysis of contemporary art that involves the notion of curiosity. I suggest that some of the writings of Francis Bacon, even at a distance of four centuries, provide a useful lens through which to examine current taxonomic practices, in particular to aid in a discussion of language used to describe paradoxical organisms that are simultaneously historical and contemporary and embody both the combinatory and the fragmentary. Bacon's writings

7 Marian Draganov, Marianna Murdjeva, and Teodora Michailova-Topalska, "McCoy and McCoy-plovdiv Cell Lines in Experimental And Diagnostic Practice - Past, Present, and Perspectives," Journal of Culture Collections 4, no. 1 (2005) 3-16.

8

http://www.fundacion.telefonica.com/es/at/vida/popUpPremiados/html/NoArk-en.html

(accessed November 12, 2013)

See Lorraine Daston and Katherine Park, Wonders and the Order of Nature 1150-1750 (New York: Zone Books, 1998), particularly chapter five, "Monsters: A Case Study," for a discussion of monsters, prodigies, and other creatures that defied categorization during the fifteenth and sixteenth centuries, and chapter six, "Strange Facts," for a discussion of Francis Bacon's bid to reform systems of classification to account for the anomalous and the monstrous; see also Harriet Ritvo, The Platypus and the Mermaid and Other Figments of the Classifying Imagination (Cambridge, Massachusetts: Harvard University Press, 1997), particularly chapter one, "The Point of Order," for an overview of the development of classificatory systems during the eighteenth and nineteenth centuries in light of the discovery of numerous new animals that defied existing paradigms of classification. 
may further help to establish a way of looking at how such organisms might be classified within existing constructs of the museum.

Museums of natural history have traditionally been charged with acting as repositories of knowledge and learning through the twin functions of maintaining collections of specimens and representing them to an audience in a way that reflects the understanding of the order of nature at a given moment in time. This raises the question of what to do with scientifically created hybrid organisms that are the result of advances in biotechnology. Confronted with presentations of the unclassifiable and the monstrous, we might ask how natural history museums can integrate these new organisms into the collection, or if they even should at all. Although these seemingly unclassifiable objects and organisms defy description in Linnaean terms, they can usefully be viewed through the lens of Francis Bacon's proposals for classification through difference.

Between the years 1605 and 1620, Francis Bacon instigated a program for the reform of natural history and natural philosophy in response to the need for a system of classification that would account for newly discovered and anomalous creatures that didn't fit into existing European experience. This arose from what Bacon perceived to be an inadequacy in Aristotelian logic, which was based on the assumption of a fixity and predictability in nature. As Foucault reminds us, until that period resemblance had been the prevailing from of structuring knowledge in western thought. During the seventeenth century, relationships based on similitude were displaced by systems of analysis based on identity and variations: "Similitude is no longer the form of knowledge but rather the occasion of error..." 10 As a result, "the entire episteme of Western culture found its fundamental arrangements modified. And, in particular, the empirical domain which sixteenth-century man saw as a complex of kinships, resemblances, and affinities, and in which language and things were endlessly interwoven - this whole vast field was to take

\footnotetext{
${ }^{10}$ Foucault, The Order of Things, 56.
} 
on a new configuration." ${ }^{11}$ The seventeenth century, Foucault tells us, was characterized by an epistemic shift in which thought would,

no longer consist in drawing things together, in setting out on a quest for everything that might reveal some sort of kinship, attraction, or secretly shared nature within them, but, on the contrary, in discriminating, that is, in establishing their identities, then the inevitability of the connections with all the successive degrees in a series, in this sense, discrimination imposes upon comparison the primary and fundamental investigation of difference. ${ }^{12}$

This epistemic shift, as Foucault calls it, was crystallized in Bacon's writings, both scientific and fictional. Bacon laid out his proposal for the reform of the study of natural phenomena in The New Organon; or True Directions Concerning the Interpretation Of Nature, published in 1620. In his plan for the instauration of science, he advocated for the identification and collection of monsters, or aberrations of nature, which were already popular in the collective consciousness of the time. "For we have to make a collection or particular natural history of all prodigies and monstrous births of nature: of everything in short that is in nature new, rare, and unusual. This must be done however with the strictest scrutiny, that fidelity may be ensured."14 Bacon regarded the collection of nature's aberrations as vital not only to the appreciation of preternatural deviations, but also to an increased understanding of more easily explained recurring phenomena. Following on this, Bacon suggested a method for the interpretation of nature that involved a movement back and forth between universal axioms and particulars. He developed an elaborate taxonomy based on a series of twenty-seven particulars, termed "Prerogative Instances" which he organized into tables. Bacon regarded five of these

${ }^{11}$ Foucault, Order of Things, 60.

12 Ibid., 61.

13 Katherine Park and Lorraine Daston, "Unnatural Conceptions: The Study of Monsters in Sixteenth- and Seventeenth-Century France and England,” Past \& Present 92, (August 1981), 20.

14 Francis Bacon, The New Organon, in The Works of Francis Bacon, Vol. IV, Ed. James Spedding, (London: Longman and Co., 1860), 169. 
instances as forming a cluster, which constituted the core of natural history, and were of primary importance because they served to "digest the matters that enter the understanding, and to correct the ill complexion of the understanding itself." 15 Instances Conformable or of Analogy were resemblances of form or physical parallels between things which were not necessarily related, and which created relationships of analogy between things in nature, for example, a looking glass and an eye, a bird's beak and an animal's teeth, or the branches and roots of a tree. Singular Instances were exceptional species within a genus, things that are only like themselves, or "seem to be out of the course and broken off from the order of nature. ${ }^{16}$ He provides examples such as "the magnet amongst stones or quicksilver amongst metals. ${ }^{17}$ Most significant for the purposes of my argument are Deviating and Bordering Instances. Deviating Instances were those things that could be classed as marvels or curiosities, aberrations in nature, monsters, prodigies, or vagaries that anticipated the wonders of art. Bordering Instances were "those which exhibit species of bodies that seem to be composed of two species, or to be rudiments between one species and another." ${ }^{\text {} 18}$ Bacon provides examples such as moss which he argued was somewhere between putrescence and a plant, or flying fish, which fell between fish and bird. Bacon also believed that "bi-formed fetuses" (or conjoined twins) were Bordering Instances, although he includes this in his list with little or no explanation as to his rationale. Instances of Power, also called Instances of the Wit or Hands of Man, were the wonders of art, which Bacon regarded as worthy of classification as they were indicative of man's desire to make nature subservient to his own wants. Bacon's quest to reform natural philosophy was born of a desire to construct a system of classification that was comprehensive enough to include, explain and classify both the ordinary and the extraordinary. He proposed a type of systematic empiricism utilizing a series of tables of agreement, difference, degree, and rejection among the

\footnotetext{
15 Bacon, New Organon, 173.

${ }^{16}$ Ibid., 168.

${ }^{17}$ Ibid.

${ }^{18}$ Ibid., 169.
} 
qualities of a thing. This system of classification was intended to produce knowledge of fundamental forms, which he called the "interpretation of nature."19

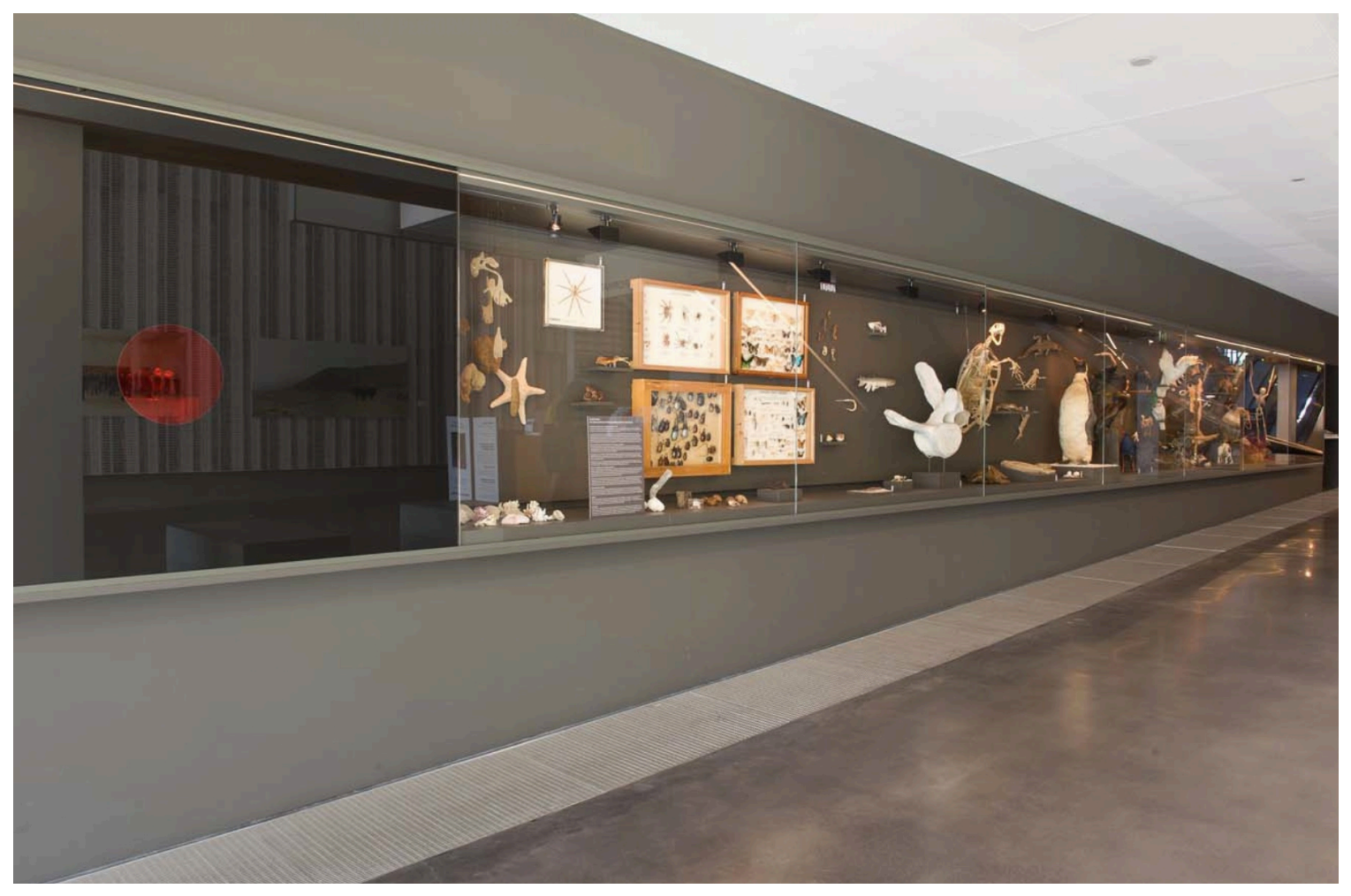

Figure 2.3: Tissue Culture and Art Project, Odd Neolifism, 2010. Image used with permission from the artists.

${ }^{19}$ In his work of utopian fiction, New Atlantis, Bacon wrote, "Lastly, we have three that raise the former discoveries by experiments into greater observations, axioms, and aphorisms. These we call Interpreters of Nature." In his description of the hierarchy of the scientific establishment in his fictional utopia of Bensalem, Bacon ranks all of the other levels of scientific investigators below the ranks of interpreters of nature, indicating his clear regard for the interpretation of nature as the most important element of the scientific process. 
A reinterpretation of what constitutes nature in our contemporary technoscientific world can be found in the organization of life forms in Tissue Culture and Art Project's installation Odd Neolifism (2010). This work extends the line of investigation

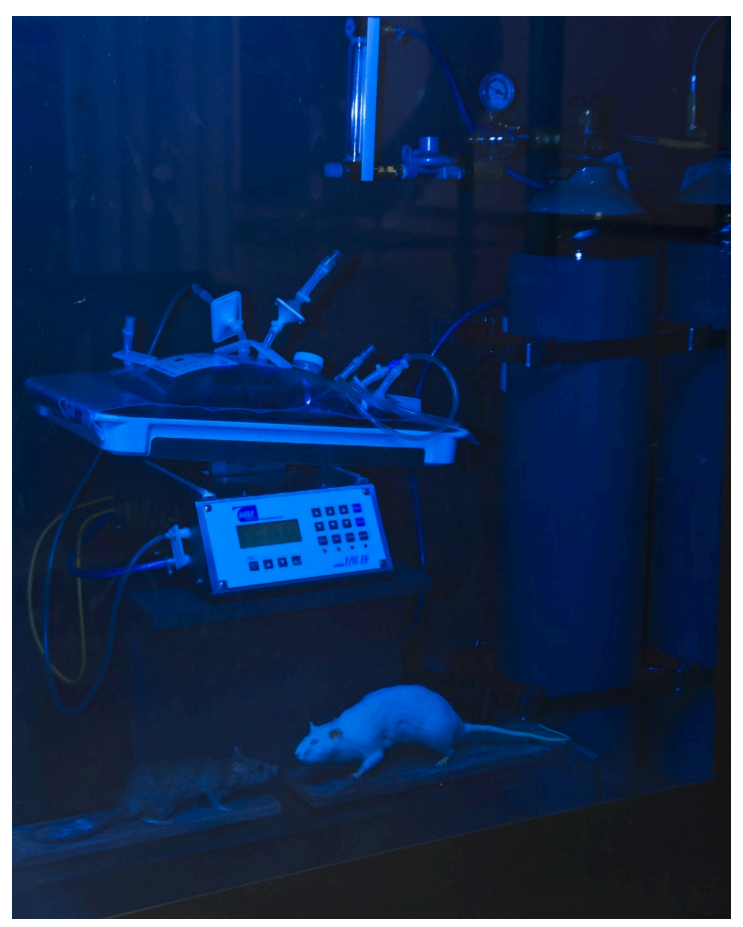

Figure 2.4: Tissue Culture and Art Project, NoArk (detail), 2010. Image used with permission from the artists. begun with NoArk and consists once again of specimens that are characterized by two types of preservation: dead animals that have been preserved through taxidermy, as well as wet specimens held in jars, in conjunction with live tissue cultures that are kept alive in a bio-reactor, all set into glass fronted vitrines embedded in the gallery walls. Moving along the installation, one encounters the two-headed chick that was previously observed in NoArk, illuminated by a red light, recalling the early history of museums as embodied by the cabinet of curiosities as well as the current movement towards altering nature through genetic manipulation. This taxidermic two-headed chick is the first of several examples to appear in this work of what Bacon might have regarded as a Bordering Instance, due to its conjoined nature. The two-headed chick is followed by collections of museum specimens displayed behind glass in a large case, moving from smaller organisms such as sponges, corals, and insects, through larger and more complex organisms: fish, turtles, lizards and snakes; numerous birds both large and small, mammals and marsupials (including the platypus, a challenge to classification once upon a time as it appears to be made of more than one animal, with its furry body, webbed feet, and duck-like bill), and ending with primates represented by a monkey skeleton and a glass skull, presumably intended to stand in for humans. The specimens appear as an approximate representation of the order of nature. A third vitrine, illuminated by a blue light, contains a pair of taxidermic rats and tissue cultures kept alive in a bioreactor. The moist gelatinous tissue 
culture could also be classified as an example of a bordering instance, both as a consequence its physical materiality - existing somewhere between liquid and solid - and its construction from the cells of multiple organisms.

The jelly-like blobs housed in the bioreactors of both NoArk and Odd Neolifism are monstrous in their resistance to the classification of either their material or species. Unique single organisms constructed from the tissue of several, they are simultaneously natural and man made, recalling Bacon's propositions regarding the relationship between the "nature erring" and "nature wrought," or curiosities and art. He divided natural history into the history "of nature in course, of nature erring or varying, and of nature altered or wrought" 20 , or the study of natural history (the natural), of curiosities and marvels (the preternatural - that which exists beyond the natural), and of art (the artificial or the manufactured). He believed that deviations in nature were reminiscent of the variability found in art, and that curiosities were the result of nature acting in anticipation of art:

[I]t is an easy passage from miracles of nature to miracles of art. For if nature be once detected in her deviation, and the reason thereof made evident, there will be little difficulty in leading her back by art to the point whither she strayed by accident. $^{21}$

As Park and Daston remind us, "Personification of nature permitted Bacon to straddle two explanatory divides ... the history of marvels bridged the traditionally opposed categories of nature and art."22 Correspondingly, Tissue Culture and Art Project's juxtaposition of natural history specimens, in particular aberrations such as the twoheaded chick or the seemingly freakish platypus, against the chimeric blob serves as a potent reminder of the relationship between "nature erring" and "nature wrought." By

\footnotetext{
20

Daston and Park, Wonders, 222.

21 Bacon, New Organon, 169.

22 Park and Daston, "Unnatural Conceptions," 44.
} 
virtue of the fact that the specimens that they present are all somehow preserved through human intervention, it can be argued that even the most commonplace of specimens, "nature in course," transgress categories and approximate "nature wrought." The chimeric blobs similarly straddle these two positions in that the cells are all extracted from naturally occurring organisms yet they have been combined in a way that is not natural in the strictest sense of the definition and they require human intervention in the form of a bioreactor to maintain their very existence.

Although I have steeped my analysis of NoArk and Odd Neolifism in the seventeenth-century writings of Francis Bacon, Tissue Culture and Art Project describe this work from a position that is critically reflective of the ramifications of advances in contemporary taxonomy. In a lecture given at The Sanctuary for Independent Media in Troy, New York, Oron Catts discussed the effects of DNA taxonomy on how we perceive specimens held in natural history museums. ${ }^{23}$ According to Catts, the natural history museum is where we learn about life, and it is there that we encounter idealized representations of animals in the form of taxidermy. Taxidermy cannot be confused with the original animal, he tells us, because the only part of it that is derived from the organism being represented is the hide. He argues that, within the space of the museum as in so many other aspects of society, we are now moving away from the privileging of this type of idealized form, and the knowledge we derive from it, to the privileging of genetic information. DNA and tissue samples are now being stored in cryogenic conditions and have begun to replace taxidermic specimens as a means of representing relationships between organisms. Neolifism is the fetishization of those "frozen bits that stand in for the animal," the fetishization of DNA as if it were sufficient to stand in for the animal. He speaks somewhat critically of the Frozen Ark Project, which has raised funds by offering the opportunity to sponsor DNA and tissue samples. Catts is concerned that DNA is presented as if it were all that would be required to resurrect a species if it disappeared and that such a suggestion encourages a dangerous mentality by implying that as long as

\footnotetext{
23 See Oron Catts, "Growing Neolifism," lecture at The Sanctuary for Independent Media in Troy NY, March 19, 2014, particulary between 35:00 and 41:00. https://www.youtube.com/watch?v=-9nu74yYQ34
} 
we can preserve the DNA of endangered species we don't need to be as diligent in our conservation attempts. He fears that the cryogenic storage of DNA can be perceived as an insurance policy against whatever perils we inflict on the environment, when in fact life is the result of a much more complicated structure than a mere DNA sample.

\subsection{Fragments of Language, Fragments of Life}

In addition to a more than glancing allusion to the cabinet of curiosities, Tissue Culture and Art Project here also make explicit reference to the recent movement in natural history museums towards collecting fragments of life, frozen cells capable of representing the genetic whole. They address both the meaning and function of these fragments in relation to traditional historical collections of the preserved specimens that continue to be the mainstay of museum collections as we currently think of them. This raises the question of how particular types of fragments might be perceived as fitting into taxonomy, not only cryogenically preserved specimens, but as yet uncollected specimens such as hybridomas that consist of cells from more than one species, or cancer cells used in medical study. In contrast to most cells that divide a finite number of times, cancer cells have been found to reproduce indefinitely and as such can be perceived as constituting a type of living organism that can live outside the body and be kept alive in the laboratory environment. An example of a hybridoma that has taken on almost mythical proportions within contemporary culture would be those cultured from the wellknown HeLa cell-line, originally derived from the cervical cancer cells of Henrietta Lacks. These cells are characterized by a tendency towards aggressive growth. They have been widely disseminated throughout the world and have shown a remarkable ability to grow rapidly, mutate, and even to contaminate the cell lines of other species.

Consequently, in 1991, Leigh Van Valen, an evolutionary biologist at the University of Chicago, argued that these cells constituted a separate species and named it according to Linnaean taxonomic rules: Helacyton gartleri.

By the early nineties, the little samples of Henrietta's cervix ... had given rise to many tons of other cells - all still known as HeLa, but all slightly different from one another, and from Henrietta. Because of this, Leigh Van Valen ... wrote, "We here propose, in all seriousness, that [HeLa cells] have become a separate 
species." Van Valen explained this idea years later, saying "HeLa cells are evolving separately from humans, and having separate evolution is really what species is all about." Since the species name Hela was already taken by a type of crab, the researchers proposed that the new HeLa cell species should be called Helacyton gartleri, which combined HeLa with cyton, which is Greek for "cell," and gartleri, in honour of Stanley Gartler, who'd dropped the "HeLa bomb" twenty-five years earlier. ${ }^{24}$

The proposed Linnaean name for the HeLa cell-line notwithstanding, Tissue Culture and Art Project observed the taxonomic peculiarities of many of the names given to the celllines purchased through tissue culture banks for use in growing their sculptures. They coined a term to describe their unique status, noting, "In tissue banks that provide scientists with cell lines, one starts to find all sorts of oddities: cells that have three different organisms as its origins, or fused cells of human and mouse origin, called hybridomas. These cells are only classified by catalogue numbers or by very odd names. This is neolife." 25 The use of the prefix "neo" incorporates both the concept of newness as well as the idea of modification that is intrinsic to these life forms as a result of human intervention and manipulation.

It might appear that the new or modified life forms or "neo-organisms" that are now being collected, classified, and catalogued in tissue banks, research institutes, and patent offices have little in common with the museums of natural history that have historically held the role of collecting and classifying nature. However, as I have argued, both NoArk and Odd NeoLifism actually exist within a historical continuum of taxonomic and collecting practices that has its roots in seventeenth-century cabinets of curiosity and Francis Bacon's proposal for scientific reform during that period, and also extends to current collecting practices that include initiatives surrounding the cryogenic storage of

\footnotetext{
24 Rebecca Skloot, The Immortal Life of Henrietta Lacks (New York: Crown Publishing Group, 2010) p. 215-216. Also see: Van Valen Leigh and M, Maiorana Virginia C, "HeLa, a new microbial species," Evolutionary Theory and Review 10, 1991, 71-74.

25 http://tcaproject.org/neolifism/ (Accessed July 28, 2014)
} 
DNA fragments. In response to Tissue Culture and Art Project's assertion that they are addressing the taxonomical crisis that is a consequence of the proliferation of these new engineered lifeforms, I argue that a model based on Francis Bacon's conception of a natural language reimagined through a contemporary taxonomical lens presents a novel way of looking at the dilemma brought about by neo-life.

Writing at the turn of the seventeenth century, Bacon was concerned with the rift between words and things that caused language to be an impediment to understanding. In the first section of The New Organon, entitled "Aphorisms Concerning The Interpretation of Nature and the Kingdom of Man," Bacon detailed a new system of logic based on axioms and inductive reasoning that he believed to be superior to Aristotelian logic, which was based on syllogisms and deductive reasoning. For Bacon, syllogism was an inadequate tool for arriving at the causes of natural phenomena. In order to ameliorate this, he proposed a systematic method which could compensate for the flaws that existed in man's senses and reasoning. The starting point for the Baconian method was the presupposition that there were certain biases or predispositions of the mind that were an impediment to progressing towards an understanding of natural phenomena and an interpretation of evidence. Bacon called these impediments "Idols" - Idols of the Tribe, Idols of the Cave, Idols of the Market Place, and Idols of the Theatre.

Idols of the Tribe were errors resulting from the human mind's tendency to perceive patterns and regularities not actually occurring in nature: "All perceptions as well as of the sense as of the mind are according to the measure of the individual and not according to the measure of the universe. ${ }^{26}$ Idols of the Cave were errors that resulted from the personal predilections and tendencies of the individual investigator: "For every one...has a cave or den of his own, which refracts and discolors the light of nature; owing either to his own proper and peculiar nature, or to his own education and conversation with others; or to the reading of books... ${ }^{27}$ Idols of the Market Place were errors that

\footnotetext{
${ }^{26}$ Bacon, New Organon, 54.

27 Ibid.
} 
arose as a result of language, of existing terminology and classifications that were already dominant within the discourse: "For it is by discourse that men associate; and words are imposed according to the apprehension of the vulgar. And therefore the ill and unfit choices of words wonderfully obstructs the understanding." 28 Finally, Idols of the Theatre were the consequence of accepting fallacious systems as explanations for natural processes: "The idols of the theatre are not innate, nor do they steal into the understanding secretly, but plainly impressed and received into the mind from the playbooks of philosophical systems and the perverted rules of demonstration." 29 Bacon regarded it as preferable to avoid these errors altogether than to attempt to correct them later.

The most detrimental to the interpretation of nature, and the most pertinent to discussions surrounding the challenges of contemporary taxonomy, were the Idols of the Marketplace, errors that arose as a result of language. Bacon argued that the language used to describe nature was inherently flawed, and even by turning to definitions for individual words, one would not be brought any closer to an understanding: "Yet even definitions cannot cure this evil in dealing with natural and material things; since the definitions themselves consist of words, and these words beget others: so that it is necessary to recur to individual instances, and those in due series and order." 30 It was the use of words themselves that stood in the way of a true understanding of nature. One of the ways that this impediment to understanding could be alleviated, according to Bacon, would be through the creation of a natural language, based in part on the idea of an Adamic language (the language spoken by Adam) ${ }^{31}$, which he described as "a pure

\footnotetext{
28 Ibid., 55. the beasts is true, that Adam's language was the first true God-given language, and is the innate, universal language of nature. For further explication of the impact of the idea of an Adamic language on seventeenthcentury thought see Michael Losonky, "Leibniz's Academic Language of Thought", Journal of the History of Philosophy, vol. 30, no. 4 (October 1992): 523-543, and Thomas C. Singer, "Hieroglyphs, Real
} 
knowledge of nature and universality, a knowledge by the light whereof man did give names unto other creatures in paradise, as they were brought before him, according to their proprieties." 32 Following on the essentialist notion that the fundamental characteristics of a thing could be reflected in its naming, Bacon suggested that such a natural language should be more isomorphic to the things that it was describing and should move away from language based on words towards one based on symbols. He was particularly interested in two categories of symbols capable of bypassing words altogether: Egyptian hieroglyphics, which he felt had some similitude to the things they signified and indicated the true meaning of things, and Chinese characters, which he believed represented neither letters nor words, but things and notions.

The idea that the essence of a thing could be reflected in its nomenclature, and consequently that nature should be described using a language that is somehow isomorphic to the thing that it represents brings me to the taxonomic requirements and present day storage techniques of a particular type of natural history specimen, specifically DNA samples. One of the most significant advances in collection storage at many natural history museums has been the recent move towards cryogenically preserving the DNA harvested from their collections of natural history specimens. It has long been acknowledged that many species are threatened with extinction, and equally detrimental is the possibility that species may disappear before they are identified. Consequently, various attempts are being made to preserve these new types of fragmentary specimens. The Frozen Ark Project, for example, is an initiative through the School of Biology at the University of Nottingham that aims to preserve the genetic material of threatened species before they become extinct. It is vital to preserve this information now, as the extinction of a species would result not only in the loss of that

Characters, and the Idea of Natural Language in English Seventeenth Century Thought", Journal of The History of Ideas, Vol. 50, No. 1 (1989): 49-70.

32 Francis Bacon, Advancement of Learning, in Essays, Advancement of Learning, New Atlantis, and Other Pieces, ed. Richard Foster Jones (New York: The Odyssey Press, 1937), 175. 
species but also the loss of the genetic material. In 2000, it was internationally recognized that a coordinated world effort would be required to bank DNA and cells from threatened species, which would furthermore require a database to record what species were housed in what collections. In 2004, the Frozen Ark Project was launched in response to this need for a database and to develop international links between institutions, many of which have collections of DNA samples but are not necessarily focused on endangered species.

DNA sequencing is useful not only as a method of cataloguing individual species, but it can also be used to reveal relationships between species that might have been previously unknown through traditional morphological analysis. A. G. Clarke suggests that, "It is within the realm of reasonable speculation that the fast progress of molecular biology will allow us, in the not-too-distant future, to construct artificial chromosomes from known genome sequences, insert them into 'generic eggs' and produce animals that have become extinct." 33 Furthermore, techniques are also being developed that would allow cells to be inserted into the embryos of another closely related species in order to potentially recreate extinct species. ${ }^{34}$ Such a process would result in an organism that might not be genetically chimeric, but nevertheless would echo the conceptual and historic overtones of constructed chimeric creatures, held in cabinets of curiosity. The Frozen Ark works with a consortium of different types of organizations: zoos, aquariums, universities, and museums, each of which contributes particular strengths to the endeavor. Zoos and aquariums, for example, are in the position of being able to house live examples of endangered animals, and have the veterinarians on staff to care for them. The biology departments of universities are where the majority of molecular biologists and conservation geneticists are engaged in conducting research. Museums, however, are of particular value in that many currently have the capacity to store the genetic material and have taxonomists who can identify new specimens. They also carry a certain amount of

\footnotetext{
33 A. G. Clarke, "The Frozen Ark Project: the role of zoos and aquariums in preserving the genetic material of threatened animals," International Zoo Yearbook 43 (2009): 224.

34 Clarke, "Frozen Zoo," 224.
} 
moral responsibility to house this new generation of specimens in much the same way they have housed historic collections: for the long duration.

The major collecting institutions, specifically museums and herbaria, have realized the importance of their collections to the future of molecular and genomic studies. Many of these institutions have expanded the traditional notions of collections to include storage of genetic material. As a result, the specimens used to harvest this material have come to have a value far beyond their original purpose. One of the most significant examples of this type of collection is the Ambrose Monell Cryo-Collection (AM-CC) at the American Museum of Natural History, which serves as a paradigm for modern genetic resource banking. Launched in May 2001, the cryo-collection will ultimately hold approximately 1 million frozen tissue samples. This contemporary collection of frozen specimens will exist in tandem with the traditional morphological specimens, including wet specimens, preserved plants, and taxidermic animals, that have been collected across history and are unfortunately subject to degradation over time. The ability to extract and preserve DNA from some of these specimens as well as from living examples will extend the utility of these collections in the future. "Unique and important biomaterials will be available to the scientific community in perpetuity. In this way the specimens themselves form databases, incorporating a massive body of information on distribution, seasonality, and so on."36 Museums have the twin roles of preserving the specimen as well as documenting and organizing it within a collection. The accuracy with which each specimen is identified is vital, because "nomenclatural assignments shape our fundamental perceptions of how the biological world is organized.

\footnotetext{
35 Hanner, Corthals and DeSalle argue that there is a symbiotic relationship between museum collections and genomic researchers in that some museum specimens were collected during a time characterized by a different paradigm of scientific inquiry in which preserving morphological accuracy was more important than preserving its biochemical components. These specimens are also subject to deterioration over time. Molecular biologists are able to supplement museum collections with their own collections of specimens gathered during genomic research in exchange for facilities that are able to house said collections well into the future. See, Robert Hanner, Angélique Corthals, and Rob DeSalle, "Biodiversity, Conservation, and Genetic Resources in Modern Museums and Herbarium Collections," Conservation Genetics in the Age of Genomics, ed. George Amato, Oliver Ryder, Howard Rosenblaum, and Rob DeSalle (New York: Columbia University Press, 2009), 114-123.

36

Hanner, Corthals, and DeSalle, "Biodiversity, Conservation, and Genetic Resources," as above, 118.
} 
Reference collections are essential for identification, as vouchers for the application of names, and as vouchers of species used in research projects." ${ }^{37}$ The AM-CC frozen tissue samples are organized using a relational database program called Freezerworks. The program generates a record of each specimen in the form of a unique barcode in which information has been encrypted. Each record contains the collection information (who collected it, where, when, and under what circumstances) that makes the specimen both scientifically and culturally useful, a physical description of the donor animal, and the precise position of the vial that contains the specimen within the collection's many freezers. Each vial is equipped with a cryo-resistant label that is printed with a numerical identifier and the barcode, allowing it to be quickly identified and accessed. ${ }^{38}$ The printed barcode can be electronically scanned to allow a researcher access to all of the information that it contains, and any activity surrounding each specimen (for example, the number of times it has been thawed, studied, and refrozen) becomes part of the database entry for that specimen.

Returning to Bacon's argument that language should be isomorphic to the thing it represents, I suggest that the ways in which these collections are catalogued do suggest a sort of isomorphism, or at the very least, there is a semiotic connection between the generated symbol and the thing that it stands in for. The Freezerworks database used by the Ambrose Monell Cryo-Collection does generate a symbol that refers to a particular specimen, largely unmediated by the fluidity or interpretability of language. Although the generation of the barcode is a highly mediated act that results in a man-made symbol and can hardly be regarded as God-given language, it is nevertheless a non-linguistic symbol that stands in for the thing that it represents. In this sense DNA barcodes can be paralleled to the hieroglyphs and real characters that inspired Bacon. What is particularly interesting about the barcodes generated by Freezerworks and the information that they contain is the way in which they encapsulate seventeenth-century thinking within a digital artifact. As Foucault reminds us, from the sixteenth century up until the middle of

\footnotetext{
37 Ibid., 117.

38 Ibid., 119.
} 
the seventeenth century, biology didn't exist as a discipline. Prior to a shift in focus towards the morphology of animals, the beginning of which Foucault attributes to Johnston's 1657 publication of a Natural History of Quadrupeds, knowledge was focused not only on physical description but also on the "history" of the animal, and encompassed all of the written lore that surrounded it.

To write the history of a plant or animal was as much a matter of describing its elements or organs as of describing the resemblances that could be found in it, the virtues that it was thought to possess, the legends and stories with which it had been involved, its place in heraldry, the medicaments that were concocted from its substance, the foods it provided, what the ancients recorded of it, and what travellers might have said of it. ${ }^{39}$

The barcodes at the Ambrose Monell Cryo-Collection contain more than mere genetic information about the specimens, they also contain collection information that in some cases may include anecdotal, almost narrative, information, as well as a description of the donor animal. This description is text based rather than image based, and consequently does not provide a morphology of the original specimen. In this way they might also be compared to early natural histories that described fictional or otherwise anecdotally observed creatures that populated early natural histories, such as Aldrovandi's History of Serpents and Dragons.

In recent years, there have been a number of competing attempts to archive genetic information in the face of the world's declining biodiversity. One project in particular provides an example in which an even stronger argument can be made that a generated barcode conforms to Bacon's notion of a universal language. Paul Hébert is leading a team of taxonomists, molecular biologists, and bioinformaticians at the Ontario Biodiversity Institute at the University of Guelph in an endeavor known as the Barcoding of Life Database (BOLD). According to Hébert, “a small fragment of any organism's DNA - a so-called micro-genome - could be translated into a digital artifact that would

39

Foucault, Order of Things, 140. 
look very similar to a conventional product barcode." ${ }^{40}$ The barcode is not generated from a random section of an organism's DNA, rather from "a rigorously standardized sequence of a minimum length and quality from an agreed-upon gene." 41 Hébert has proposed that such barcodes could be stored in a global library that would ultimately constitute a repository for the documentation and identification of every species on the planet, a lexicon constituted of barcodes standing in for the earth's flora and fauna. Similar to the cataloguing of the specimens held in the Ambrose Monell Cryo-Collection, the documentation requirements at BOLD include the species name, voucher data (catalogue number and the institution storing it), collection records (collector, date and location with GPS coordinates), as well as specific requirements for the collection of genetic data. The primary difference between the two systems of documentation is the nature of the barcode itself. At the AM-CC, the scannable barcode contains not only the genetic information but also all of the collection data relating to a specific specimen in the collection. On the other hand, the barcode utilized in the BOLD project is a document of a particular, standardized segment of the genome of the specimen. Consequently, the difference between the two types of barcode takes the form of a relationship between the universal and the particular. Hébert's barcodes are generated such that they contain a small amount of genetic information that identifies an entire species. Although the barcodes are linked through the database to a specific voucher specimen somewhere in the world, the barcode itself only contains the genetic information for the species, thereby standing in metonymically for all other examples of that species, representing the universal. The barcodes generated through the Freezerworks program at the AM-CC, on the other hand, contain the genetic information plus the scientific collection data referring to a specific specimen from the collection. Like the original specimen that can be said to stand in metonymically for its entire species from a museological standpoint, the barcode also contains the information that refers to a particular example.

\footnotetext{
40 Claire Waterton, Rebecca Ellis, and Brian Wynne, Barcoding Nature: Shifting Cultures of Taxonomy in an Age of Biodiversity Loss (London and New York: Routledge, 2014), p. 2.

Paul D. N. Hebert and T Ryan Gregory, "The Promise of DNA Barcoding for Taxonomy," Systematic Biology, 54, no. 5 (Oct., 2005): 853.
} 
The aspect of the barcodes generated through BOLD that make them potential examples of Bacon's conception of a natural language is the physical nature of the barcode itself. Bacon argued that symbols used in a natural language should be isomorphic to the thing that they represent, and the barcodes generated through BOLD, although they don't bear a physical resemblance to the morphology of the specimens to which they refer, do have a very real and direct physical relationship to the specimen on a molecular level. The BOLD barcodes consist of series of coloured stripes (green, red, black, and blue), each stripe referring to one of the four nucleotide bases that make up DNA: Adenine (A), Guanine (G), Thymine (T), and Cytosine (C). In this way, they create a pictorial symbol that stands in for the DNA of the specimen that it represents through a one-to-one relationship between the stripes and the nucleotide bases.

According to Hébert, there are several ways in which microgenomic identification systems such as DNA barcoding are preferable to traditional morphological taxonomy. First, both phenotypic plasticity and genetic variability in the characters employed for species recognition can lead to incorrect identifications. Second, this approach overlooks morphologically cryptic taxa, which are common in many groups. Third, since morphological keys are often effective only for a particular life stage or gender, many individuals cannot be identified. Finally, although modern interactive versions represent a major advance, the use of keys often demands such a high level of expertise that misdiagnoses are common. ${ }^{42}$

The barriers to correct identification are all the result of some misinterpretation of visible signs due to either variability within a species or failure to identify key markers of a species. The idea that specimens could be misidentified as a result of a misinterpretation of extant descriptive information recalls Bacon's argument that there are various idols or preconceptions that promote misinterpretation. If Hébert is correct DNA sequencing provides increased accuracy in identifying species and in determining

\footnotetext{
42 Paul D. N. Hébert, Alina Cywinska, Shelley L. Ball, and Jeremy R. deWard, "Biological Identification through DNA Barcodes," Biological Sciences 270, no. 1512 (Feb. 7, 2003), 313.
} 
how species are genetically related to one another, without the vagaries and misinterpretations that may result from human error.

\subsection{A Language of Natural Forms}

Although I have argued that the barcodes generated through genetic sequencing provide a possible example of a symbolic natural language akin to that prescribed by Francis Bacon, I would like to complicate this argument by looking at the work of Gemma Anderson, a UK-based artist whose practice has led her to develop a series of pictograms that could serve a similar function. However, in contrast to the techno-scientific nature of DNA sequencing, Anderson has arrived at her system through close visual observation of natural history specimens. Anderson has dedicated the majority of her art practice to working with natural history specimens in various museum and university collections. She connects the necessity for close observation during the process of drawing with knowing or understanding the specimens with which she works. As was stated in the previous chapter in relation to Cornelia Hesse-Honegger's work, drawing is a form of knowledge building. With regard to her own practice, Anderson says that the value in sustained periods of observation through drawing is that it allows her to make creative leaps and imaginative associations between forms as she seeks out parallels and relationships across multiple phylogenic kingdoms. This prolonged engagement with the morphology of specimens has led to the creation of a type of taxonomic system of Anderson's own devising, based on a set of symbols that reflect her observation of similarities between forms. This has resulted in the development of a project that she calls Isomorphology (2012-2013), ${ }^{43}$ in which she has developed a series of symbols that reflect recurring forms across the taxonomic kingdoms of animal, vegetable, and mineral. Anderson writes,

Because my interest spans zoological, mineralogical and botanical collections I spend a lot of time drawing specimens and observing form - which has led to an

\footnotetext{
43 Anderson coined the term isomorphology using the Greek words Isos, meaning same or equal, Morphe meaning form, and Logos, meaning study.
} 
awareness of the resemblances between species of separate kingdoms. As I worked, I became aware that there was no specific documentation of crosskingdom resemblances between the animal, the vegetable and the mineral. With further thought, I have realized that behind these resemblances are various forms and symmetries. These form the basis of 'Isomorphology' - a new term which I have coined. It is derived from 'Isomorphism'; a mathematical and biological concept. $^{44}$

The Isomorphology project consists of a series of thirteen symbols that Anderson has

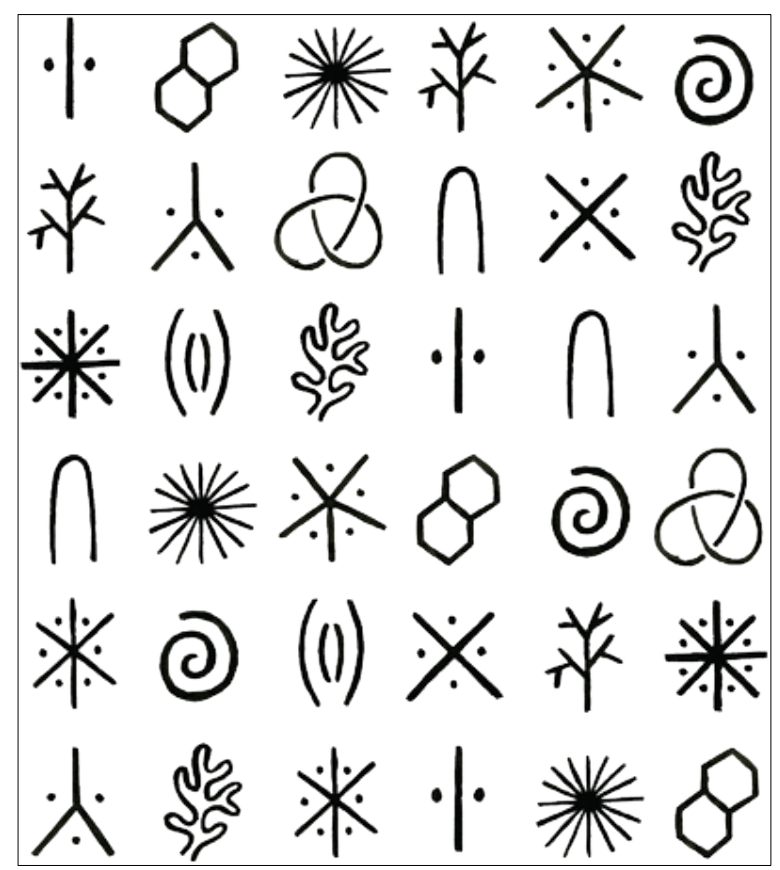

Figure 2.5: Gemma Anderson, Isomorphology, 20122013. Image used with permission from the artist. created, each an abstract representation of a different form or type of symmetry that recurs across different species in different kingdoms. She proposes it as an alternate system of classification that, "while connected to and derived from the observable...is a symbolic system and mode of abstraction. It can be understood as a visual language, which is coextensive with other modes of classification." ${ }^{45}$ What Anderson has created is a symbolic language used to aid in the identification of structural relationships that can be found across different types of species. These symbols

are based on recurring morphological forms, and in that sense are isomorphic to the things they represent. Anderson has unwittingly created something akin to Francis

\footnotetext{
44 Gemma Anderson, Isomorphology - Introduction, http://www.isomorphology.com/02introduction.html, Accessed December 9, 2014.

45 Gemma Anderson, Isomorphology - Is Isomorphology Scientific?, http://www.isomorphology.com/04iso-scientific.html Accessed December 9, 2014.
} 
Bacon's proposal for a natural language through the use of symbols that bear a similitude to the things they represent, as well as by implying relationships of classification between objects through physical likeness. ${ }^{46}$

To reiterate my earlier suggestion, DNA barcoding can be perceived as a natural language along the lines of what Bacon had proposed in that it generates an albeit highly

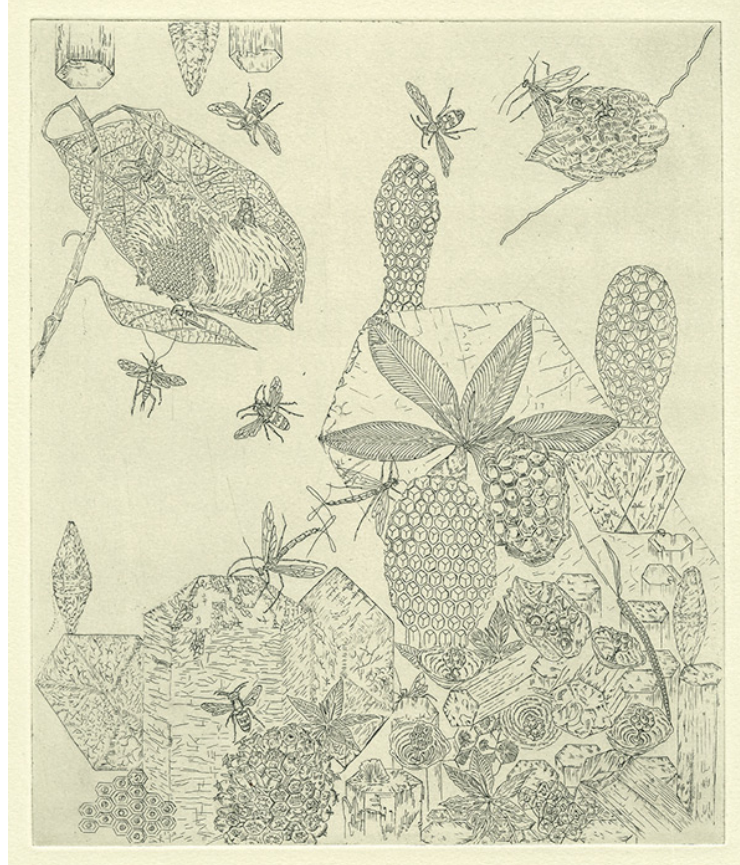

Figure 2.6: Gemma Anderson, Hexagonal Forms, 2012. Image used with permission from the artist. abstracted symbol that stands in for a specific species. Anderson's symbolic language presents another possible system. In contrast to DNA barcoding, which generates a symbol that corresponds to both a species in general and a particular specimen in a specific museum collection, Anderson's system of forms and symmetries describes morphologies in a much more generalized sense, which refer not to a single species or specimen but to a form that repeats across the phylogenic kingdoms. Isomorphologies includes the thirteen symbols (some repeated in the above image) as well as a series of engravings that Anderson completed while working with the Natural History Museum. Each engraving focuses on a single morphological form or symmetry and depicts several specimens across the animal, mineral, or vegetable kingdoms, all of which show evidence of the same symmetry in their morphological structure. For example, Anderson has identified four-fold symmetry

\footnotetext{
${ }^{46}$ It is perhaps noteworthy that Anderson had not read any of Francis Bacon's work on natural language at the time of creating the Isomorphology project. She only learned of the relationship between her project and Bacon's philosophical proposal when she and I presented together on a panel at the University Art Association of Canada Conference (October, 2014) in Toronto, in 2014, where I was presenting work from an earlier version of this chapter. The correspondence between our two presentations made for some very lively discussion, as prior to the conference I was not aware of her Isomorphology project either.
} 
as occurring in the wings of dragonflies, in the leaves of quatrefoil plants, and in the structure of the mineral andalusite. Hexagonal form is commonly observed in wasps' nests, the fruit of the Monstera deliciosa plant, and in the mineral basalt. Anderson creates her etchings by drawing directly onto an etching plate covered with hard ground and later etched in an acid bath. This process involves a combination of close observation, trained judgment, and abstraction. As Anderson describes it, "Concentrated observation within the act of drawing creates new perceptual knowledge. The morphology is observed in detail - activating the process of comparison. Each form observed joins a bank of knowledge in the observer's mind and each new drawing experience triggers a different formal memory stored in this bank." ${ }^{47}$ As quoted towards the end of the previous chapter, "To be objective is to aspire to knowledge that bears no trace of the knower - knowledge unmarked by prejudice or skill, fantasy or judgment, wishing or striving." ${ }^{48}$ Whereas an artist like Hesse-Honegger strives for scientific accuracy, Anderson's desire for accuracy is tempered by her whimsical sensibility. According to Daston and Galison, the representation of scientific imagery required "trained judgment," whereby scientists "stressed the necessity of seeing scientifically through an interpretive eye." 49 Despite her substantial exposure to techniques employed by biologists, Anderson's trained eye remains that of an artist, and the details that she selects and emphasizes in her drawings are less about conveying the details required to enable the identification of a specimen than they are about making visual connections across different forms.

\footnotetext{
47 Gemma Anderson, “The Drawing Process," http://www.isomorphology.com/05the-drawingprocess.html.

${ }^{48}$ Lorraine Daston and Peter Galison, Objectivity, (New York:Zone Books, 2007), 17.

49

Daston and Galison, Objectivity, 311.
} 


\subsection{DNA Barcoding as an Imperfect Taxonomy}

Anderson has worked closely with several taxonomists at the Natural History Museum in London where she has studied the morphology of various organisms. Thanks to this, she has been exposed to the endangered set of skills possessed by classically trained taxonomists who rely on an organism's morphology to determine classification. Because the ability to identify and depict a specimen using its morphology is seen as an endangered skill, the encroachment of DNA taxonomy can also be viewed as a detrimental technology, despite the advantages that it enjoys. The primary objection regarding DNA sequencing is that, although a database of DNA barcodes may prove a useful tool for identifying a found species, it does not actually describe the morphological characteristics of a species or minor variations that might occur within it. While Paul Hébert aims to develop a universal, democratic, and encyclopedic database, his detractors argue that barcodes are an inadequate means of capturing the intricacies required to document a species. Consequently, they argue that it is not a replacement for traditional taxonomy, and "the result will be at best a telephone book of life as opposed to an encyclopedia of life.",50

Anderson recently engaged in a project where she learned how to use a camera lucida device for the rendering of morphological drawings. The camera lucida is "a microscope mounted device that performs an optical superimposition of the object being viewed onto the drawing surface. Both object and drawing surface can be viewed simultaneously, as in a photographic double exposure, enabling the draftsman to trace the outlines of the microscopic object." ${ }^{, 51}$ This results in drawings that are both accurate and repeatable. Anderson claims that morphological drawing is the backbone of traditional morphological taxonomy in which living and extinct species are identified, described, classified, and named through a process of close study of their internal and external forms

\footnotetext{
50 Kipling W. Will, Brent D. Mishler, and Quentin D. Wheeler, "The Perils of DNA Barcoding and the Need for Integrative Taxonomy," Systematic Biology 54, no. 5 (Oct., 2005): 851.

Gemma Anderson, "Endangered: A Study of Morphological Drawing in Zoological Taxonomy," Leonardo 47, no. 3 (2014): 233.
} 
and structures. This practice is, however, falling into decline and is in grave danger of being eclipsed by newer taxonomic techniques and practices, including the use of scanning electron microscopes (SEMs) and DNA barcoding. As a result of her interactions with the taxonomists at the Natural History Museum in tandem with her own work with the camera lucida device, Anderson has come to appreciate the value of an extended period of observation of a specimen and the corresponding act of drawing as an observational practice. In addition to threatening a fragile field that is already in a state of crisis, another potential pitfall of DNA barcoding is that although it creates a digital symbol that identifies the specimen, it may result in a practice in which the specimens themselves remain unobserved with the level of exactitude that morphological drawing involves. Anderson fears that the process might eventually result in "a species being identified with a molecular formula or a number and without a binomial name., ${ }^{, 52}$

DNA taxonomy is useful in an age when traditional taxonomists are becoming increasingly rare, and it is recognized that a huge percentage of the world's biodiversity has likely not yet been identified, leading to concern that species may become extinct before they are named and classified. However, a turn to DNA sequencing as a form of nomenclature represents the potential for a significant loss. Speed and efficiency are gained at the cost of poetic description embedded in the act of naming. ${ }^{53}$ In other forms of taxonomy, such as Linnaean binomial taxonomy or in native folk taxonomies, names are chosen to communicate something of what is known about that organism, incorporating descriptive terms, or the names of scientists, or the circumstances of the organism's discovery. In replacing language with a symbol, perhaps we lose something of what is tacitly understood. Classifying a specimen based on its DNA rather than its morphology may generate a symbol that stands in for the specimen, but much of the specimen's narrative is lost.

\footnotetext{
52 Anderson, "Endangered," 237.

53 See Mary Slaughter, particularly chapter 3, "Nomenclature," in Universal Languages and Scientific Taxonomy in the Seventeenth Century (Cambridge: Cambridge University Press, 1982), in which she discusses taxonomy and the various descriptive ways in which language has been employed to classify things, from folk taxonomy to Linnaean binomial nomenclature.
} 
One of the most important features of morphological drawing is the way in which biologists are able to render specimens to highlight or draw attention to certain physical features, effectively guiding the viewer towards those characteristics that are more important than others as a means of identification. According to Anderson, morphological taxonomists use various means to suggest hierarchies of structure and form: one might use a dotted line in order to suggest that a feature is behind another, another uses a particular stippling technique to differentiate between membranous and harder surfaces. In this way, Anderson tells us, the biologist's trained eye combined with his or her drawing practice is "evidence that scientific objectivity can work in tandem with artistic subjectivity" ${ }^{, 54}$ in order to exercise trained judgment, as explained by Daston and Galison, to produce an interpreted piece of visual information.

DNA sequencing is an excellent method of taxonomy in situations where the morphology of an organism is not its primary defining characteristic, such as viruses or bacteria, or in the case of damaged or incomplete specimens. For example, as discussed in the previous chapter, DNA sequencing proved a valuable tool to identify the damaged insects gathered by Mark Dion by using sticky flypaper attached to the roof of an electric G-Wiz car for the installation Systema Metropolis. However, in the case of specimens where morphology is key to identification, DNA barcoding is not ideal. Other criticisms of DNA barcoding come from professionals in the field of museum studies, who address how this new approach to taxonomy affects the museum specimens used to generate some of the barcodes. Rebecca Ellis provides a critical perspective on the impact that current technology is having on classifying and preserving natural history museum specimens through the Barcoding of Life Database project. The initiative is global in scope in that it aims to provide barcoded genetic data on all species to anyone in the world. Although there are a number of satellite groups that are participating in the initiative by providing genetic information from their own collections of specimens, BOLD still relies in part on natural history museum collections to provide genetic material for sequencing. Ellis argues that "museum specimens, as scientific, epistemic

54 Anderson, “Endangered," 235. 
objects are sites of evolving and contested meaning as alternative approaches to the potential (classificatory and possibly commercial) value of DNA barcodes continue to be negotiated within the taxonomic community. As such they are sites of lively and everemerging forms of material culture in natural history museums as they speak for multiple natural orders. ${ }^{, 55}$ She bases this argument largely on the notion of object biography as discussed by Kopytoff, Appadurai, and Gosden and Knowles, ${ }^{56}$ all of whom argue that one of the ways that a museum object becomes valuable as a cultural object is through the associations it has had with collectors, as well as the historical trajectory that brought it to the museum collection. Furthermore, the focus on an organism's genetic make-up shifts the process of identification of a specimen away from the importance of a visual analysis that is so aligned with museum objects of almost all categories. Ellis maintains that museum specimens are in a constant state of interpretation and re-interpretation. By involving these specimens in BOLD, the evolving process of classification is brought to a standstill and the biographical trajectory that defines many museum specimens is similarly interrupted. These specimens will no longer be subject to an evolving history or a mutable body of interpretations; their potentiality has been radically limited. No longer part of a socially constructed identity, the specimens will be reduced to a genetic barcode. $^{57}$

\subsection{Conclusion}

Despite the fact that DNA barcoding is an imperfect method of taxonomy due to its privileging of genetic sequencing over morphology it nevertheless remains a useful tool for identifying many organisms quickly and efficiently. It is also a useful option for the classification of specimens that are not defined by their morphology. Hébert confirms

\footnotetext{
55 Rebecca Ellis, "Rethinking the Value of Biological Specimens: laboratories, museums, and the Barcoding of Life Initiative," Museum and Society 6 no. 2 (2008), 172.

56 See Igor Kopytoff, "The cultural biography of things: commoditization as process," The social life of things: Commodities in cultural perspective 68 (1986): 70-73, Arjun Appadurai, "Commodities and the politics of value," in Interpreting objects and collections (1994): 76-91, and Chris Gosden and Yvonne Marshall, "The cultural biography of objects," World archaeology 31, no. 2 (1999): 169-178.

57

Ellis, "Rethinking," 182.
} 
this, saying that the idea "has already gained broad acceptance among those working with the least morphologically tractable groups, such as viruses, bacteria and protists." Because of this, I suggest that it might provide a useful method for the classification of neo-life or other hybrid organisms that defy traditional taxonomy and do not require morphological descriptions to differentiate them from others. In the case of the chimerical blobs kept alive in the bioreactors of Tissue Culture and Art Project's installations, I cannot help but wonder what the relationship might be between these amorphous specimens and a barcode that documents the provenance of the tissues used to construct them. Perhaps blobs that cannot be described in words would be well represented by a strip of colours that describe their contents in a manner that does not rely on language.

I have perhaps taken an idea and pushed it beyond the realm of the sensible, yet I maintain that when a natural history specimen is reduced to a sample of DNA and then translated into a barcode that stands in for that specimen, containing not only genetic information common to any specimen of that species but also the collection information particular to that specific specimen, the process bears comparison with Francis Bacon's quest for a universal language. Slaughter suggests that the relationship between taxonomy and language in the seventeenth century stemmed from an inability of ordinary language to accommodate specialized knowledge. There were insufficient names to represent all the new kinds of organisms being discovered, which consequently required the creation of a new type of language. "As Foucault argued, classification was the episteme of the seventeenth century. The language which accompanies classification, the language of essential nomination, simply follows automatically." reached a stage where traditional verbal/alphabetic language-based taxonomy has become an insufficient, or perhaps merely an inefficient, form of nomenclature to describe the unclassifiable, as described in the work of TC\&A. I believe that this new form of nomenclature speaks to our biotechnical age, yet it also responds to Bacon's notion that

\footnotetext{
58 Hébert et al., "Biological Identifications," 313.

59 Slaughter, Universal Languages, 69.
} 
nomenclature should be more isomorphic to the thing that it describes, and that here language has been replaced by a barcode, a non-linguistic symbol that stands in for an entire body of information beyond a mere name of an object. However, I also concede that DNA barcoding, for all its efficiency, accuracy, and cost effectiveness, introduces another set of possible anxieties. It threatens to replace traditional approaches to taxonomy, potentially rendering observational skills obsolete and diminishing the more poetic aspects of the naming of things. Instead of adding to the richness of how we perceive life, it actually reduces it to a man-made generated symbol that diminishes the potential for future readings. As Catts warned, by reducing museum collections to cryogenically stored fragments, we run the risk of fetishizing DNA to the point of forgetting what it is that makes biodiversity so compelling in the first place. 


\section{Chapter 3}

\section{Of Vitrines and Bioreactors: Museums and Methods of Preservation and Display}

\subsection{Objects Under Glass}

Since the 1960s artists have frequently drawn upon the vitrine as a method of display, capitalizing on the history of its multiple uses, from museum display to church reliquary, and also on its role in science and medicine as a means of displaying specimens. James Putnam tells us "the vitrine functions as a means of protection both from the elements and the spectator, who is thus physically separated from its contents. Almost like a peepshow it seduces, concentrating, looking, staring at the untouchable and the unattainable." In the sciences, the use of the vitrine is also linked to methods of preservation, "to the need to keep a specimen in a still viewable, arrested state of being. The practice of preservation of museum exhibits by taxidermy, pickling, dehydration, etc. illuminates the desire to suspend time and stabilize the objects against decomposition."2

For centuries, the struggle to halt decay has presented a challenge to those collecting natural history specimens. Early collections of specimens and curiosities were not merely the results of a curiosity-driven desire for acquisition but were also a reflection of the wealth and power of the collector. As a result, the need to develop methods of preservation was driven as much by commerce as by scientific inquiry. In the seventeenth century, for example, the increased accumulation of commodities was reflected in an interest in the acquisition of unique objects brought back from all over the world. Over time, a trade in naturalia developed, and collectors began to keep inventories of their collections. The accumulation, preservation, warehousing, and cataloguing of these objects of knowledge was part of the creation of value for both merchants and

\footnotetext{
1 James Putnam, Art and Artifact: The Museum as Medium (New York: Thames \& Hudson, 2001), 15.

2 Ibid.
} 
naturalists, and continues to provide the basic structure of natural history collections. ${ }^{3}$ Tony Bennett tells us that these early collections were the domain of the wealthy rather than the subject of a wider public gaze, that they were "secreted in the studiolo of princes, or made accessible only to the limited gaze of high society in the cabinets des curieux of the aristocracy." ${ }^{4}$ By contrast, nineteenth-century museums epitomized the dual purpose of the vitrine by preserving and protecting their collections behind glass while opening them up for viewing by the wider general public. The display of nature behind glass is also associated with the contradictory practices of killing animal specimens in the name of scientific knowledge and re-presenting their bodies to illustrate the importance of the conservation of nature. Concurrent to the rise of the public museum during the nineteenth century was the increased proliferation of public fairs and sideshows, in which organisers attempted "to turn the amusement zone into an educational enterprise or at least to regulate the type of exhibit shown,"5 thereby conflating ideals of both the spectacular and the educational.

Brita Brenna argues that the shift in the display of specimens, curiosities, and artifacts from pre-enlightenment Kunstschrank to the Victorian use of glass vitrines had

\footnotetext{
${ }^{3}$ For a detailed discussion of the impact of preservation techniques on the trade of curiosities and naturalia, see Harold J. Cook, "Time's Bodies: Crafting the Preparation and Preservation of Naturalia." Merchants and Marvels: Commerce, Science, and Art in Early Modern Europe, Ed. Pamela H. Smith, and Paula Findlen (New York and London: Routledge, 2002), 223-247. Cook argues that in the $16^{\text {th }}$ century, most curiosity cabinets/collections of naturalia were based on dried specimens; as a result collectors could see the outer shape of things, their external forms but with a few exceptions, they could not see their inner structure. Animal parts could therefore only be studied at leisure if they were dried, for example in skeletal form. Anatomical studies could only be performed with rapidity, and often in cold temperatures, because of the imminent threat of putrefaction. There was consequently a great interest in finding ways to preserve things and prevent decay and putrefaction, so that they might be studied more easily. For both naturalists and merchants, the accumulation and preservation of things was in anticipation of later demand. The contents of many of the natural history and medical cabinets were ultimately sold for significant sums of money, and investing for the long term added value to one's transactions but required a struggle against the processes of decay.

4 Tony Bennett, “The Exhibitionary Complex," New Formations 4, (Spring 2008), 73.

5 Burton Benedict, quoted in Bennet, "Exhibitionary Complex," 87.
} 
both spatial and ontological effects on how the collection was perceived. ${ }^{6}$ The Kunstschrank, a cabinet with closed drawers, required that the viewer be shown the collection by the owner or caretaker of the collection, emphasizing the sense of control, power, and ownership of the collector. On the other hand, improvements in glass technology during the Victorian period meant that the space that housed a collection could provide a radically different experience. The use of large glass panes "made it possible to double the space of a collection, making an inside and an outside. They produced one space sealed off from the public, accessible only to the custodian or owner, and another for the visitor who could now enter the museum as part of an anonymous public, who did not have to relate personally to the caretaker of a collection." separation of the viewer from the object by a transparent pane of glass served to control how the viewer could move around within a space. Brenna argues that this was the legacy of a movement at the turn of the twentieth century that set out to discipline both museum visitors and museum nature. This movement made natural history museums into spaces where visitors could learn by reading rather than by touching or otherwise physically engaging with natural objects. The combination of accompanying text labels and glass cases that separated the viewer from the objects resulted in the objects being subordinated to the accompanying explanatory text. ${ }^{8}$ These natural history specimens became objects that could only be understood through observation and reading, in contrast to the haptic experience available to caretakers of the collection.

Although the preservation of specimens continues to be vital within contemporary natural history collections, the value of these collections no longer lies in their monetary

\footnotetext{
${ }^{6}$ Brenna traces the history of glass display cases in the context of a case study of the glass cases at the Bergen Museum. See Brita Brenna, "The Frames of Specimens: Glass Cases in Bergen Museum Around 1900," in Animals on Display: The Creaturely in Museums, Zoos, and Natural History, edited by Liv Emma Thorsen, Karen A Rader, and Adam Dodd (University Park, Pennsylvania: The Pennsylvania State University Press, 2013), 37-57, for an historical account of the cases, and Brita Brenna, "Nature and Texts in Glass Cases: the vitrine as a tool for textualizing nature," Nordic Journal of Technology Studies 3, no 1, 2014, 46-51, for a shorter account in which she argues that Victorian glass cases had the effect of reducing natural specimens to both readable text and illustration of text.

7 Brenna, "The Frames of Specimens," (as above), 40.

8 See Brenna, "Nature and Texts in Glass Cases," (as above).
} 
worth as a demonstration of princely power. Rather, value is entwined with the potential for knowledge embodied by a collection of objects and, as Brenna suggests, by the text that accompanies them as a means of interpretation. We can observe how lingering cultural and scientific values embodied by these "objects of knowledge" are being both embraced and challenged in the work of contemporary artists whose projects reference natural history collections and their methods of preservation and display. Here I will examine several projects that reflect the social and historical significance of preservation and display techniques commonly used in natural history museums with a particular emphasis on the role of glass structures as a means to reveal and protect their contents. Fiona Tan's installation Depot draws upon the scantily documented story of a giant whale carcass that formed the basis of an exhibition that toured through several towns in the United Kingdom during the 1950s. Mark Dion's massive exhibition Oceanomania draws upon Victorian methods of display to address the fragility of ocean ecosystems. Mark Wilson and Bryndís Snæbjörnsdóttir performed a survey of all of the taxidermied polar bear specimens in the United Kingdom, ultimately exhibiting as many of them as was feasible in a series of glass vitrines. I will contrast these seemingly direct appropriations of museum display techniques with projects such as Dion's Neukom Vivarium, which subverts tropes of museum display through the construction of a large glass structure that is at once greenhouse and vitrine, and which invites viewers to observe a macrocosmic specimen from both inside and outside. Paradoxically, it exudes a sense of suspended time while also maintaining the slow decomposition that occurs when a tree falls in the forest. Similarly subversive is Tissue Culture and Art Project's Semi-Living Worry Dolls, in which the importance of preservation, as embodied by an enacted ritual of caring for engineered tissue culture based sculptures, is countered with the necessary destruction of the cells at the end of an exhibition. Richard Pell's project, The Centre for Post-Natural History, draws upon traditional museum display techniques, including glass-fronted alcoves and taxidermy-filled vitrines to draw attention to organisms that have been overlooked or consciously ignored within the history of natural history museums. As such, Pell can be seen to be engaging in a type of institutional critique, even though it is neither his primary goal nor how he describes the project. 
Each of these artists either appropriates or subverts established conventions of museum display in order to influence how the viewer perceives the work. According to Svetlana Alpers, museums enforce a particular way of seeing. This is achieved by isolating objects, including works of art, natural history specimens, or ethnographic objects, from their original contexts and allowing the viewer to appreciate them for the visual interest that arises as a result of either that isolation or the re-contextualization into a series of other like or related cultural objects. ${ }^{9}$ What Alpers terms the "museum effect," or the transformation of an object, regardless of class, into an object of visual interest, can be traced back to the princely collections of the Renaissance, in which objects were acquired and arranged according to early taxonomies based on various similitudes. Remarkable within these collections was the particular class of objects that combined the work of nature and the work of the artist, which Alpers ties to the increasing interest of artists in depicting works of nature with absolute accuracy: "The visual interest accorded a flower or a shell in nature is challenged by the visual interest of the artist's representational craft. Providing paintings of rare flowers and shells for attentive looking in encyclopaedic collections was one way that artists were involved with museums from the start. ${ }^{10}$ By incorporating natural history specimens into their practices, contemporary artists are effectively creating bodies of work that blur the boundaries of the natural and the cultural or man-made, resulting in the type of attentive viewing focused on the art/objects that Alpers describes.

The isolation of objects for visual effect practiced by the artists discussed here is often achieved through the use of museum display techniques, in particular through the use of the glass vitrine. John C. Welchman echoes Alpers' description of the mode of seeing effected by museums in his outline of the characteristics of the vitrine, arguing that it is:

\footnotetext{
${ }^{9}$ See Svetlana Alpers, "The Museum as a Way of Seeing," in Exhibiting Cultures: The Poetics and Politics of Museum Display, ed. Ivan Karp and Steven D. Levine, (Washington and London: Smithsonian Institution Press, 1991), 25-32.

10 Alpers, "The Museum as a Way of Seeing," 26.
} 
first and foremost, a marker of difference. It separates the objects or things it contains from their contexts, puts them in relation with other objects, alike and dissimilar, and above all, perhaps, serves to reinforce both the intrinsic and aesthetic values of what it displays. At the same time the vitrine bears with it the proposition that the objects inside constitute a specific class of property. Vitrines, then, withhold things and a certain zone around them from common appropriation while at the same time encouraging viewers privileged to see according to a disciplined optic ordained by those who control the display. ${ }^{11}$

In short, vitrines used in museum displays not only isolate objects from any pre-existing contexts from which they were extracted, but also dictate to the viewer the parameters and circumstances in which the objects can be observed. I suggest that in addition to artists whose works draw upon conventions of museum display that mimic the form of the vitrine, there are also contemporary artists who utilize other types of glass structures that operate in a similar fashion not only to distance the contained objects from the viewers, but also to disrupt the ontological nature of the contained objects.

\subsection{Taxidermy: the Preserved Animal Body}

Natural history museums are the central mechanisms for the exhibition and consumption of natural knowledge in the form of collected natural artifacts and specimens. ${ }^{12}$ During the late nineteenth and early twentieth centuries, these collections were considerably enlarged through the activities of colonial trade expeditions, many of which included the collecting of specimens as part of their official duties. This resulted in a proliferation of

\footnotetext{
11 John C. Welchman, in Sculpture and the Vitrine, ed. John C. Welchman (Farnham Surrey: Ashgate Publishing, 2013), 2.

12 Porti Collection: Taxidermy, Photography and The Archetype of the Colonial Hunter in the Exhibition nanoq: flat out and bluesome," Museums, Marginality and the Mainstream, http://docslide.us/documents/museums-marginality-and-the-mainstream.html, and Helen Gregory and Anthony Purdy, "Present Signs, Dead Things: Indexical Authenticity and Taxidermy's Nonabsent Animal," Configurations 23, no. 1 (2015), 61-92.
} 
animals that were skinned and stuffed as both trophy mounts and museum specimens to be displayed in glass-fronted museum dioramas. Taxidermy was a widely used museum practice from the mid-nineteenth century until after 1920, when it declined as a legitimately perceived scientific profession. ${ }^{13}$ In the natural history museums of the nineteenth century, taxidermic dioramas revealed a culture preoccupied with freezing time and space. When animals were hunted in the wild, not only was the animal preserved but also the environment from which it was removed. Every plant from the piece of earth where the animal was killed was plotted and diagramed, so that it might be accurately reproduced and recreated at the destination museum. ${ }^{14}$ The idea of maintaining the spatiotemporal purity of a culture, or in this case an environment, is a common motif in contemporary anthropology and ethnography. ${ }^{15}$ There is an impulse to keep a culture unsullied by external cultural influences. Museum dioramas similarly preserve and display the illusion of a natural environment unharmed by human intervention. James Clifford argues that in addition to maintaining the purity of a culture through isolation, artifacts can also be detached both temporally and spatially from their origins and can acquire new value from being repositioned in the new context of an ethnographic collection, "Collecting - at least in the West, where time is generally thought to be linear and irreversible - implies rescue of phenomena from inevitable decay

\footnotetext{
${ }^{13}$ Susan Leigh Star tracks the shift from taxidermy as a "lower status auxiliary scientific craft, which strove for a time to be a full-fledged partner in science" to its eventual dismissal as a craft more appropriate to hobbyists by the 1970's. She argues that the decline in taxidermy is linked to the industrialization of science at the turn of the century, when research at academic institutions shifted its focus to industrial problems and expansion. She further asserts that, as modern science privileges objectivity over individual craft, skill, and tacit knowledge, there is little room for taxidermy, an undeniable mix of scientific observation and artistic interpretation. See, "Craft vs. Commodity, Mess vs. Transcendence: How the Right Tool Became the Wrong One in the Case of Taxidermy and Natural History," The Right Tools for the Job, ed. Adele E. Clarke and Joan H. Fujimura, Princeton, New Jersey: Princeton University Press, 1992. Significantly, recent years have been marked by a resurgence of interest in both historical and contemporary taxidermy.

${ }^{14}$ Star, as above, 259.

15 See James Clifford, “On Collecting Art and Culture," Predicament of Culture: Twentieth Century Ethnography, Literature, and Art (Cambridge: Harvard University Press, 1988) 215-52, for a discussion of Margaret Mead's account of the Mountain Arapesh. Mead was ultimately frustrated when members of the Arapesh left their own insular culture and were exposed to external cultural influences.
} 
or loss. The collection contains what 'deserves' to be kept, remembered or treasured."16 A diorama depicts a sanitized version of reality, devoid of the violence that would have been required for acquisition of the specimens. The animals have been removed from their geographical and temporal points of origin and preserved in a depiction of how we would want them to be remembered.

Although the means by which the specimens were collected is not evident in traditional museum dioramas, the reality of the colonial hunt for specimens remains a permanent specter. Ideal specimens were hunted, skinned, preserved, and eventually mounted in simulated environments half a world away from their points of origin in an attempt to capture a moment in time and space. The paradoxical notion that you had to destroy animals in order to preserve them derives from the desire to maintain a social or ecological system in a fixed and undefiled state of purity that could be appreciated and studied by future generations. As Henning contends, such destruction of nature in the name of salvaging nature is an underlying principle of museum dioramas, "where a living, healthy animal is sacrificed in order to enable its perfect reconstruction as a mannequin inhabiting its own skin, for the purposes of an exhibit intended to inspire in its audience a love of nature and desire to protect it." ${ }^{17}$ The irony was not lost on all contemporary observers. Frederic A. Lucas remarked in 1883, "Man is a great destroyer, and our wild animals, and especially the larger ones, are being rapidly civilized from the face of the earth. Sooner or later the time will come for many of them when their mounted forms preserved in our museums will be all to show they once existed." ${ }^{18}$ Today, museum dioramas come to us freighted with a complex history of carnage and seem curiously anachronistic.

\footnotetext{
16 Clifford, "On Collecting," 231.

17 Henning, "Skins of the Real," 140.

18 Quoted in Star, "Craft vs. Commodity," 279.
} 


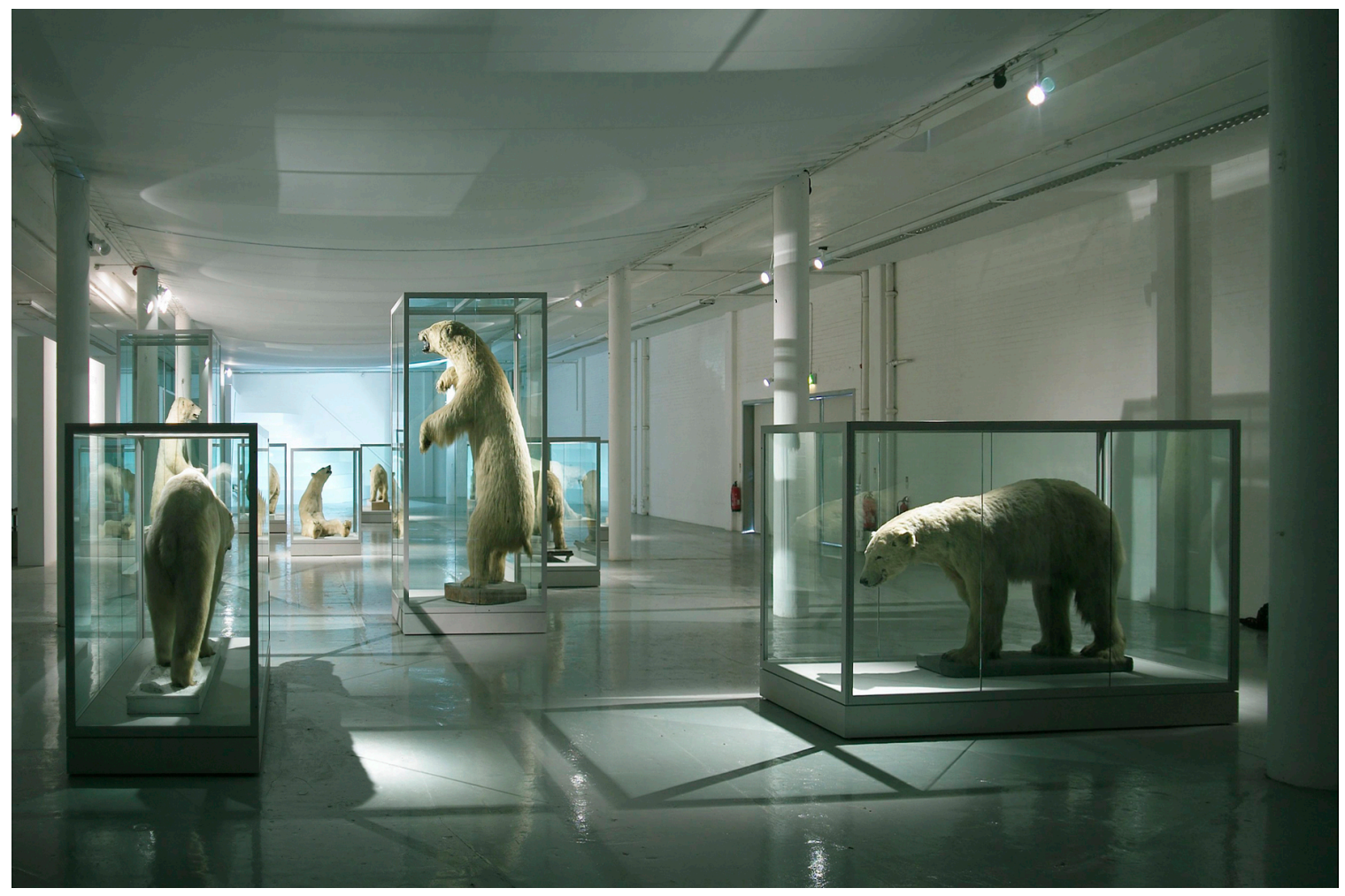

Figure 3.1: Snæbjörnsdóttir/Wilson, nanoq: flat out and bluesome (2004) installation - featuring 10 polar bear specimens, Spike Island Bristol, UK. Image used with permission from the artists.

The legacy of the historical practice of museum taxidermy is the focus of artists Bryndís Snaebjörnsdóttir and Mark Wilson's exhibition, nanoq: flat out and bluesome (2006), in which they attempted to locate and document the provenance of every taxidermied polar bear in Britain, with a view to bringing them together for display. Over the course of their research, Snaebjörnsdóttir and Wilson located thirty-four polar bears with a variety of histories, which were documented in a series of large-scale photographs depicting where they were found - in private homes, in museums, in storage, or undergoing restoration. The nanoq project not only documented the histories of the bears, but the legacies of the hunters who shot them and the expertise of the taxidermists who mounted them. The accompanying photographs were inscribed with text that explained the bears' varied histories, from being captured during scientific expeditions and eventually dying in a zoo, or hunted for sport and mounted and housed in stately homes, to acting as a mascot for a candy factory, or being kept behind the bar in a pub. Many of the specimens had been acquired by museums or private collections as the result of hunting or naturalist expeditions during the nineteenth century. Wilson and 
Snaebjörnsdóttir investigated the lost histories of these animals, many of which had been in storage or in private residences and no longer seemed to serve any clear purpose. Due to the current movement towards using technology to enhance user experience in museums, the use of preserved animal specimens has become increasingly associated with past museum practices. Displayed in dusty cases or wrapped in plastic and stored for decades, the polar bears had come to serve little didactic purpose in museum collections, while in domestic settings they functioned as a distant reminder of hunting expeditions, and now largely speak to the current penchant for using taxidermy as interior decorating.

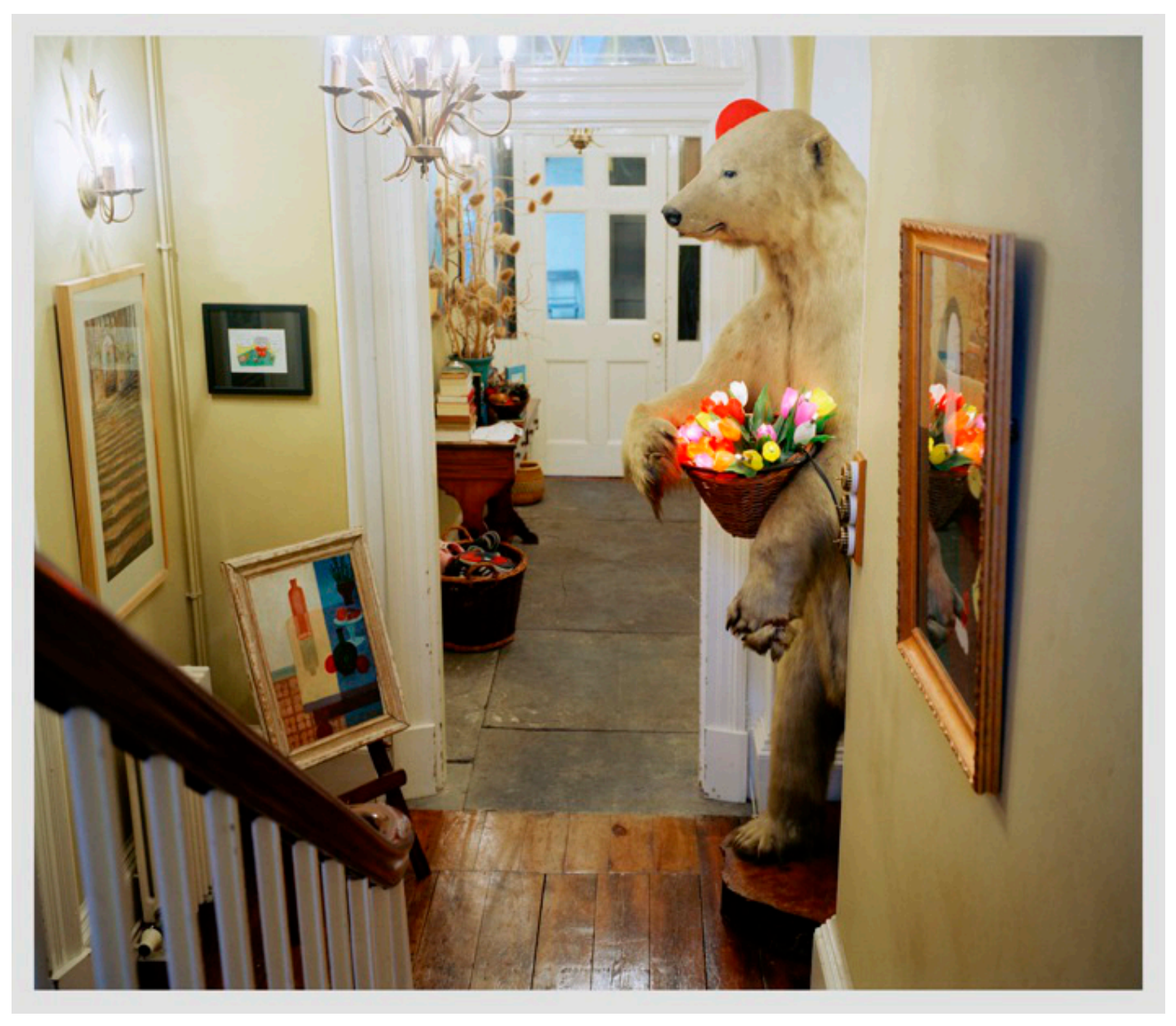

Figure 3.2: Snæbjörnsdóttir/Wilson, Somerset from the photographic archive, nanoq: flat out and bluesome (2004) Lambda print. Image used with permission from the artists.

Snæbjörnsdóttir and Wilson exhibit the polar bear specimens in tandem with two types of documentary photography: the large format contemporary photographs that they 
took to show the situations in which the bears were found, and historical photographs documenting the hunting and capturing of some of the bears featured in the exhibit. The artists' choice to exhibit the taxidermic polar bear specimens alongside documentary photography draws attention to the historical relationship of photography to sport hunting. Since the late 1850s, explorers, soldiers, and hunters used the camera to capture images of dead animals, not only to show the skill of the hunter, but also for the purpose of scientific documentation. As James R. Ryan tells us, "The colonial hunter was one of the most striking figures of the Victorian and Edwardian imperial landscape. Frequently pictured posed with a gun beside his recently killed prey, or surrounded by skins, tusks and other trophies of the expedition, the hunter is, to present-day eyes, the archetypal colonial figure." ${ }^{19}$ The act of big game hunting was deeply entrenched in both the Victorian belief in the authority of man over nature, as well as in the British imperialist project of geo-political expansion. Photographs of hunters standing over their slaughtered animals not only represented a conquest of the animal but also of the colonized nation itself, and consequently the animals became emblematic of a greater victory.

Michelle Henning writes, in the catalogue for nanoq: flat out and bluesome, "The tragedy of the polar bear is not just its hunting down, but also its sad resurrection as these taxidermy artifacts, and the indifference and forgetfulness associated with the places in which the artists find them. ${ }^{20}$ The forgetfulness is particularly evident in the bears that have been consigned to storage spaces. Not only have these bears been severed from their histories, no longer associated with the people, places or events surrounding their acquisition, they no longer even serve the didactic function of their visible counterparts. Ludmilla Jordanova examines the link between museums and the acquisition of knowledge, and the role that museum objects serve. She argues that there is an implicit idea that knowledge can be gained by looking at an object, that the object itself has been

\footnotetext{
19 James R. Ryan, Picturing Empire: Photography and the Visualization of the British Empire (London: Reaktion Books), 1997, 99.

20 Cultural Life of Polar Bears, Snæbjörnsdóttir/Wilson, [Exhibition catalogue], (Spike Island Gallery, Bristol: Black Dog Publishing, 2006), 138.
} 
positioned as the source of knowledge. ${ }^{21}$ This is particularly true in natural history museums due to the historically privileged position of looking and observation in the acquisition of knowledge within the sciences. She posits, "In order to gain knowledge from museums, viewers, whether they are aware of it or not, both reify the objects they examine, treating them as decontextualized commodities, and identify with them, allowing them to generate memories, associations, fantasies. ${ }^{22}$ Viewers assent to the authenticity of what they see, while recognizing its fabricated nature. In the context of the museum collection, the viewer creates fictions for the polar bears, likely imagining them in an authentic, pristine version of the artificial arctic habitat in which they have been presented. When specimens, such as the polar bears, are positioned in dioramas that create a simulacrum of their natural habitat, attention is distracted from their taxidermic and historical realities and viewers readily accept the fiction with which they are presented.

By recontextualizing the bears in a contemporary arts space, and accompanying them with documentary photography, the artists draw attention to both the taxidermic quality of the polar bears and as their historical legacies and contemporary positions. By reuniting the bears with their colonial pasts, Snæbjörnsdóttir and Wilson force us to confront the reality that the bears embody. Rachel Poliquin argues that "the postmodern animal is 'most productively thought of as an embodied thing,' and while it may take various forms - live animals or taxidermied creatures, either whole or disjointed, in installations, sculpture or performance - its essence is always most fully realized through an encounter or, more precisely, a confrontation with a viewer. ${ }^{, 23}$ Here Poliquin elaborates on Steve Baker's suggestion that the encounter is most profound when it takes place in a space shared between the animal and the human. Although it is a space

\footnotetext{
21 Ludmilla Jordanova, "Objects of Knowledge: A Historical Perspective on Museums," The New Museology, ed. Peter Vergo, (London: Reaktion Books, 1989), 23.

22 Jordanova, “Objects of Knowledge," 25.

23 Rachel Poliquin, "The Matter and Meaning of Museum Taxidermy," Museum and Society, Vol. 6, No. 2 (2008), 131 .
} 
characterized by unequal power relations, the natural history museum (and in the case of nanoq: flat out and bluesome, the contemporary art space) represents a space shared by both man and animal.

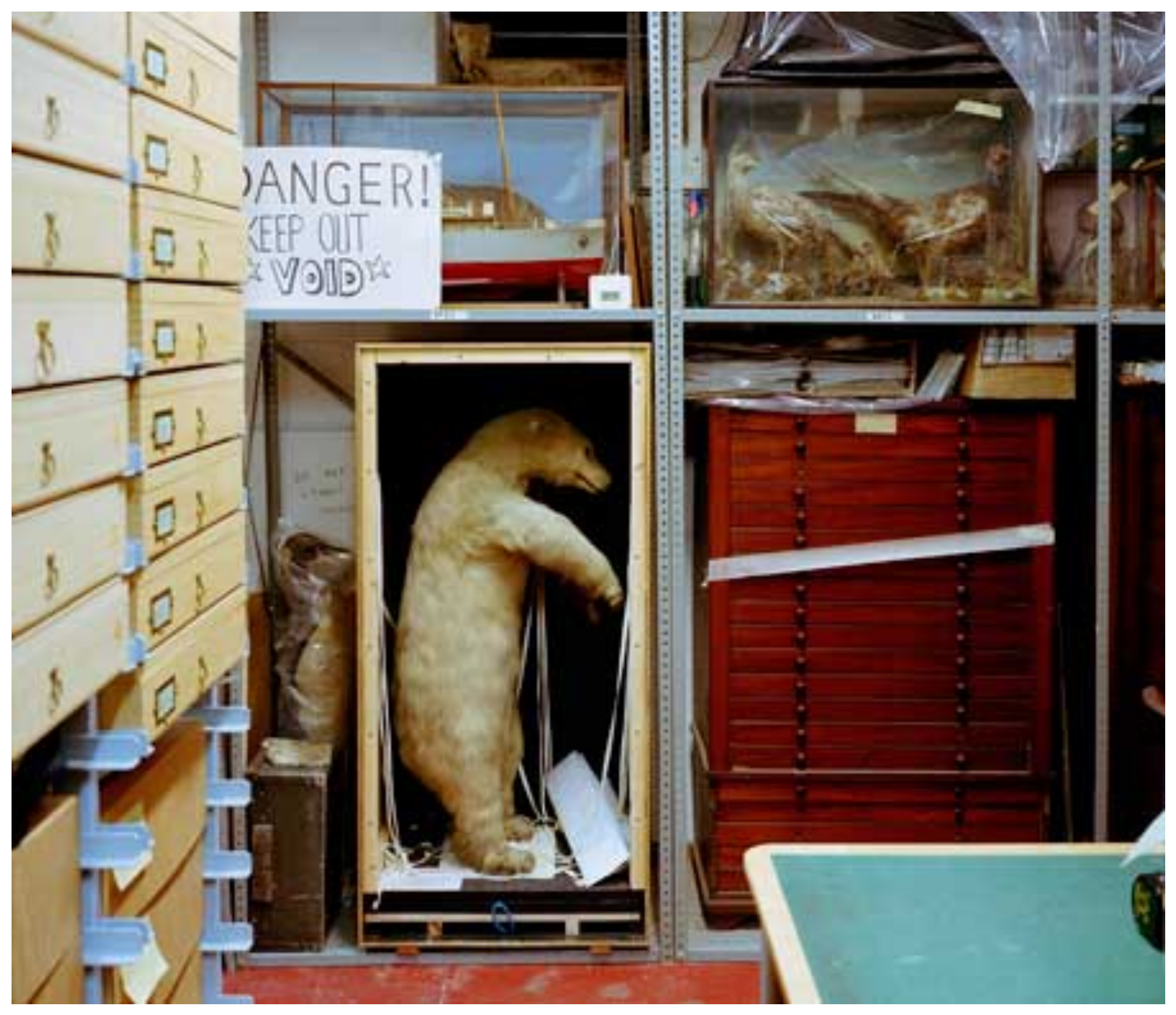

Figure 3.3: Snæbjörnsdóttir/Wilson, Worcester from the photographic archive, nanoq: flat out and bluesome (2004) Lambda print. Image used with permission from the artists.

It is precisely such an encounter between the gallery visitor and the polar bears in the nanoq exhibit that forces the viewer to acknowledge the history of museum specimens. According to Baker, "The postmodern animal is an awkward thing: its art and 
its animality do not sit easily together." 24 As a result of being presented in the guise of an art installation, the bears are imbued with yet another layer of meaning. Having been stripped of their museum contexts, the polar bears force the viewer to relinquish any fictitious narratives that they might have imagined. The encounter between human and taxidermic polar bear is informed by the artists' gesture, which illuminates the fact that not only were animals hunted in the name of heroism or science and later acquired by museum collections, but also that others were hunted specifically for the purpose of being taxidermied and placed in dioramas. Michelle Henning writes that living animals were "sacrificed in order to enable its perfect reconstruction as a mannequin inhabiting its own skin, for the purpose of an exhibit intended to inspire in its audience a love of nature and a desire to protect it.",25

While it was the hunter who was responsible for the killing of the animal, it was the taxidermist who was responsible for obliterating the reality that was the dead carcass, and infusing it with a semblance of life, blurring the line between object and subject. As a result of the taxidermist's art, Lucy Byatt asserts, “each specimen begins to take on a new identity. These are no longer polar bears - they are renewed objects representing polar bear-ness." 26 In addition to their "polar bear-ness", they also carry the semiotic weight of multiple meanings: they exemplify the blurred boundaries between subject and object; alive and dead; specimen and artifact; trophy, souvenir, and collection. Taxidermy possesses a complex matrix of cultural associations: on the one hand it brings to mind hunting trophies, and on the other, it is associated with the preservation of biological specimens in natural history collections. The polar bears featured in the nanoq project embody this duality, as almost all of them had been hunted in either the name of sport or science, or a combination of the two. The idea of hunting for the advancement of

\footnotetext{
24 Steve Baker, The Postmodern Animal (London: Reaktion Books, 2000), 52.

25 Henning, "Skins of the Real," 140.

${ }^{26}$ Lucy Byatt, nanoq: flat out and bluesome, A Cultural Life of Polar Bears, Snæbjörnsdóttir/Wilson, [Exhibition catalogue], (Spike Island Gallery, Bristol: Black Dog Publishing, 2006), 15.
} 
knowledge merely provided a thinly veiled disguise of virtue, obscuring the reality of a hunt that was equally an act of constructing the persona of the heroic hunter.

Snæbjörnsdóttir and Wilson's project alerts us to the fact that, in many cases, this legacy of colonial hunting expeditions has left the polar bears and other "exotic" taxidermic specimens in a state of institutional limbo. Contemporary museums rarely seek to expand their collections of taxidermy, and consequently it is becoming progressively obsolete as a didactic tool. Occasionally an animal will die a natural death and will be deemed worthy of preservation through taxidermy ${ }^{27}$ but for the purpose of public education, museums are increasingly relying on film, video, and interactive displays that accurately portray animals in their natural habitat without harming them. Michelle Henning argues that the increased use of film, video and new media in museums has been accompanied by a shift towards incorporating the museum visitor into the exhibit through interactivity. This has had the effect of changing the relationship between the body of the visitor and the museum exhibition. The emphasis has shifted away from the object as a source of embodied knowledge towards the experience of the viewer, which has consequently led to the visitor's body replacing the museum artifact as the thing that is examined within the display space. ${ }^{28}$ These experiential exhibits rely less on the authenticity and specific provenance of the individual objects than on their "corroborative power" to aid in the constructing of narratives. Such narrative based exhibits emphasize the coherence of a story and generalized truths over specific artifacts. ${ }^{29}$ The integration of new media has also changed the way that material artifacts function within the museum. The interactivity as performed by the museum visitor has shifted away from an engagement with the actual physical, material world towards an increased interaction with technology and representations of the world. The engagement

\footnotetext{
${ }^{27}$ Knut the polar bear achieved such celebrity in life that upon his death he was immediately taxidermied. For other examples of celebrity animals that had afterlives as taxidermied specimens, see The Afterlives of Animals. Ed. Samuel J. M. M. Alberti (Charlottesville and London: University of Virginia Press: 2011).

${ }^{28}$ Michelle Henning, Museums, Media, and Cultural Theory (Maidenhead, Berkshire: Open University Press: 2006), 83.

${ }^{29}$ Ibid. 91.
} 
with objects as sources of embodied knowledge has been displaced by representations of the objects. It is the movement away from the primacy of the object that has stripped taxidermic specimens of their didactic power. In many museums, one is as likely to learn about an animal through photographs or video as one is to encounter an actual preserved specimen, and consequently many taxidermic animals have been consigned to storage or disposed of altogether.

By removing the polar bears from their contexts of storage rooms, hallways, and museum vitrines, and resituating them in the white cube of a contemporary art space, Snæbjörnsdóttir and Wilson force the viewer to confront the polar bears, creating a bodily relationship beyond that of the traditional museum experience. As Steve Baker argues,

The literalism of the thing matters: its presence, its objecthood... it is an embodied thing, whose space includes and incorporates the viewer's body. Unable to quite contain itself, it creates something (a physical space, a situation), which comprises and binds the bodies of the viewer and the thing itself to form a new, awkward and explicitly non-modernist whole; only the viewer's presence completes the work. $^{30}$

In the exhibition nanoq: flat out and bluesome, the confrontation between the body of the viewer and the body of the polar bear creates an almost palpable physical and spiritual relationship. It connects the viewer to both the hunter and the hunted and elicits a visceral response that supersedes that of an interactive museum experience that privileges representations over authentic objects. The polar bears instigate a return to the primacy of the visual, and correspondingly of observation of an authentic object as a source of knowledge.

\footnotetext{
30 Baker, Postmodern Animal, 53.
} 


\subsection{In the Belly of a Whale: Fiona Tan's Depot}

The relationship between hunting, science, spectacle, and preservation is the subject of Fiona Tan's exhibition Depot (2015), commissioned by the Baltic Centre for the Arts in Gateshead, United Kingdom. Tan's installation consists of museum specimens, an enormous tarpaulin-covered truck, and accompanying video works inspired by the story of a fin whale specimen that during the 1950s was loaded onto the back of an enormous flatbed trailer, and toured around fairgrounds in the United Kingdom. "Jonah," as the whale came to be known, was one of three fin whales that had been captured off the coast of Norway in September 1952, and which were then taken on a nationwide tour in promotion of the whaling industry. ${ }^{31}$ In marked contrast to the acquisition practices of many natural history museums in which a specimen was hunted and preserved as an act of conservation and education, Jonah the whale was toured by Norwegians with the aim of promoting whaling during a period of post-war economic recovery, the whale specimen embarked on a twenty-five year tour of towns across Europe, Japan, and Africa, and over the years came to pass through the hands of various circus owners and showmen.

Despite being toured in the middle of the twentieth century, the techniques of preservation used to stay Jonah's putrefaction feel decidedly antiquated, recalling preservation techniques of centuries past. ${ }^{32}$ The whale's internal organs were removed, refrigeration units were placed inside the body cavities, and spectators were allowed to climb inside. According to a pamphlet that accompanied the exhibition,

\footnotetext{
31 John Chipperfield, “Jonah the giant blue whale still in one piece," Oxford Mail, May 14, 2007, http://www.oxfordmail.co.uk/news/community/memorylane/1395817.Jonah_the_giant_blue_whale_still_in _one_piece_/?ref=arc

${ }^{32}$ For historic precedent regarding methods of preservation through the acts of drying and replacing bodily fluids with waxes and preserving fluids, see Harold J. Cook, "Times Bodies" (as above) as well as Jonathan Simon, "The Theatre of Anatomy: The Anatomical Preparations of Honoré Fragonard", Eighteenth Century Studies 36, no.1 (2002) for a discussion of the techniques used by Honoré Fragonard to preserve flayed human bodies by injecting the bodily tissues with a mixture of wax and solvents.
} 
It is impossible to stuff a whale; it lacks the strong derm of other animals. A plaster cast would be equally impracticable on account of its excessive size and its brittleness. It was, therefore, decided to preserve it by means of an antiseptic fluid; for that purpose a 10 per cent formalin and water solution was selected of which high pressure injections were made in various parts of the body, Jonah absorbing no less than 2,200 gallons of it...The effect of formalin is to harden the flesh and blubber which become then, for a long period, immune against the noxious actions of microbes and mouldiness. The insides have been removed with the exception of the air-inflated lungs. The big bones of the skeleton, indispensible as supports for the immense carcass, were left in position. ${ }^{33}$

Images of "the whale Jonah" betray a wrinkled leathery looking animal that barely manages to maintain its "whaleness" yet still reads as obviously a whale. Despite predating the recent interest in preserved animal specimens in contemporary art by almost seventy years, the whale specimen embodies what Steve Baker refers to as "botched taxidermy." Baker coined the expression to refer to how the animal body has been treated by humans, and "to characterize those instances of recent art practice where things ... appear to have gone wrong with the animal, as it were, but where it still holds together." ${ }^{34} \mathrm{He}$ argues that the term might apply to taxidermy but that it could also refer to any imperfectly preserved body. It does, however, always refer to an instance where the body has been "botched" or gotten wrong in some way. Significantly, Baker further asserts that works of botched taxidermy refer to both the animal and the human, but need not necessarily be representations of either. ${ }^{35}$ Representations of the botched animal body function as a commentary on the relationship between the animal and the human that constructed it. In the case of Jonah the whale, the desiccated leviathan may well have

\footnotetext{
33 Quote taken from the brochure accompanying the 1952 Exhibition of Jonah the Whale, reproduced in Fiona Tan, Depot, (artist's book)

${ }^{34}$ Quote taken from Steve Baker, "Something's Gone Wrong Again," in Antennae 7, Autumn (2008), 4. Baker originally coined this term "botched taxidermy," however, in the book The Postmodern Animal, (London: Reaktion Books, 2000).

35

Baker, The Postmodern Animal, 75.
} 
been conceived as a way of drawing attention to and promoting the Norwegian whaling industry, but it acted in equal measure to fulfill the human desire to view the curious or the spectacular.

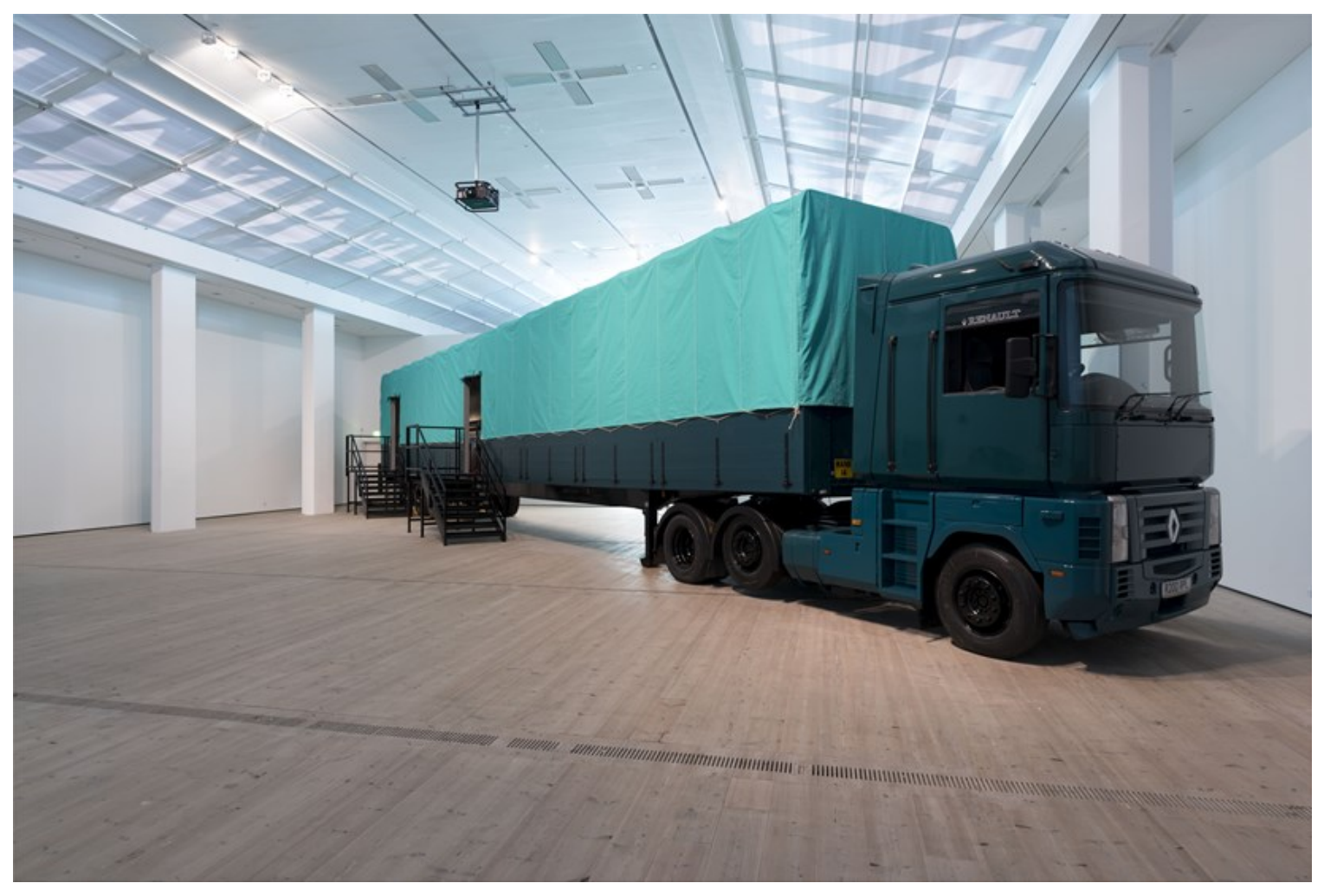

Figure 3.4: Fiona Tan, Depot, 2015. Image used with permission from the artist.

Despite its physical absence from Tan's Depot, Jonah the whale nevertheless inhabits the exhibition. The memory of the whale's body has been invoked through its absence, but also through evocative cinematic images of the whaling industry and natural history museums. Bringing to mind qualities of both the side-show and the cabinet of curiosities, Tan's installation recreates the truck that carried Jonah, covered with an ocean-coloured tarpaulin and emblazoned with large lettering proclaiming, "The Giant Whale Jonah - Caution - 76 Feet Long." However, instead of holding a partially rotten whale carcass, Tan's truck reveals a museum display filled with natural history objects that address our relationship with the ocean and its inhabitants. The truck functions as a gallery within the gallery, a museum in miniature containing a framed narwhal tusk that hangs on the wall and a traditional glass vitrine that holds glass sculptures of natural 
history specimens created by late nineteenth-century glassblowers, Leopold and Rudolph Blaschka. Inside the body of the truck, which arguably stands in for the body of the original whale-as-museum, Tan also shows a film of golden-hued images of museum specimens preserved in jars, complemented by a narrative voice-over that balances, according to art critic Laura Cummings,

an interior monologue concerning one man's lifelong passion for the undersea world with an equivalent narrative filmed in the amber twilight of a natural history museum. He remembers the long-ago past, a life spent searching for strange creatures beneath the waves, dreaming that he can breathe in this watery element; and the camera moves pensively among these creatures, suspended in glass vessels of formaldehyde. ${ }^{36}$

Screening alongside the massive truck is the film Leviathan, in which Tan splices together grainy black and white archival footage of a Newcastle whaling yard, where workers strip the skin from huge whales exposing the blubber beneath and allowing their steaming entrails to spill out. Newcastle, where the Baltic Centre for the Arts is located, was a major whaling port between 1752 and 1859. The juxtaposition of the images of industrial whaling and the collection of glass natural history objects serves to underscore the problematic relationship between the act of collecting natural history specimens and the act of hunting that allowed many early collections to exist.

\footnotetext{
${ }^{36}$ Laura Cummings, "Fiona Tan: Depot review - mementoes from the deep," The Guardian, July 19, 2015, http://www.theguardian.com/artanddesign/2015/jul/17/fiona-tan-depot-review-baltic-mementoes-from-thedeep.
} 


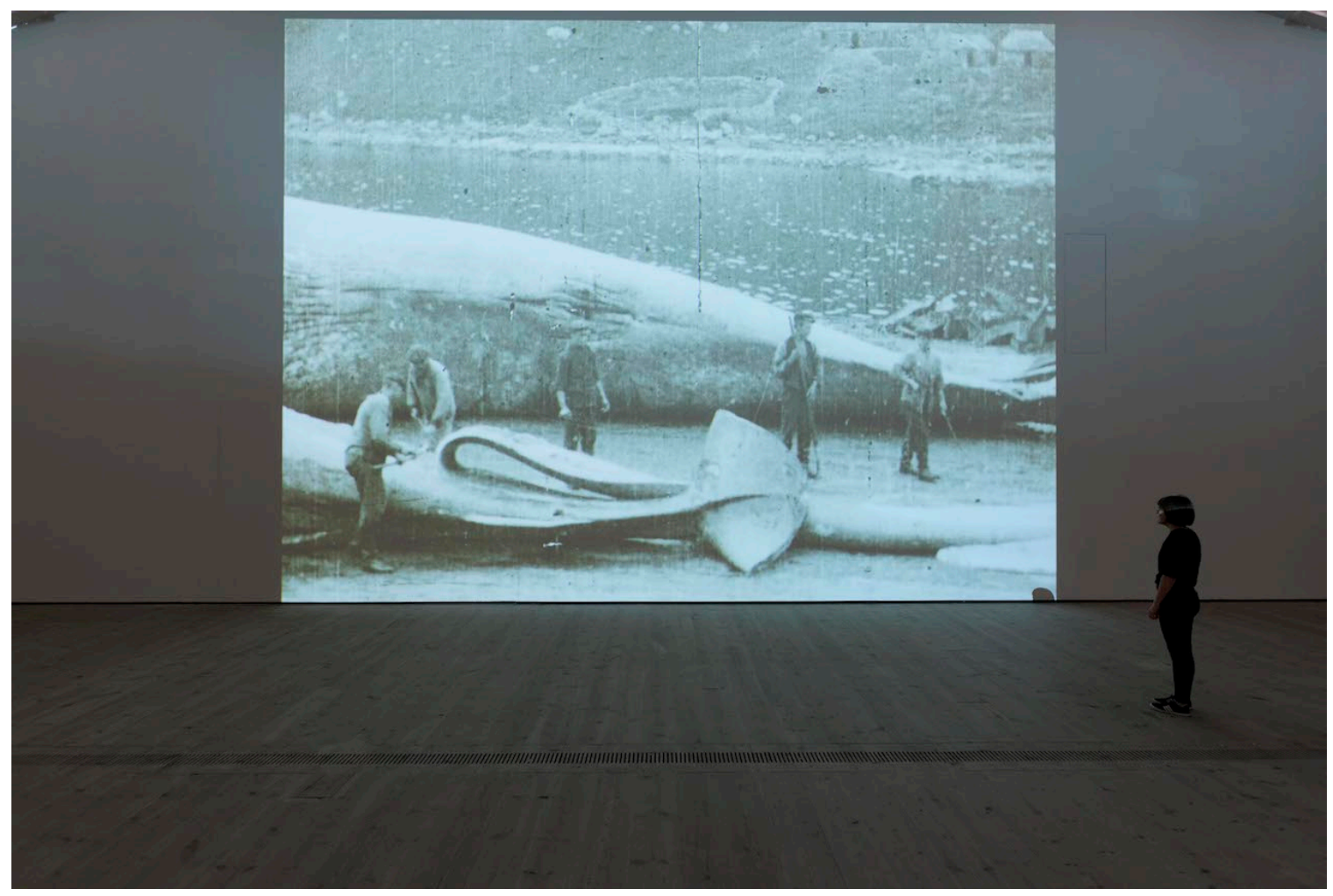

Figure 3.5: Fiona Tan, Leviathan (screened in conjunction with the installation Depot), 2015. Image used with permission from the artist.

Despite not having been acquired for a museum collection, the hunting of Jonah the whale recalls the colonialist tradition of hunting expeditions in the name of science and knowledge that justified the collection of animals for museum collections, an act that led to the preservation of a specimen for the conflated purposes of education and entertainment. This relationship has been widely examined in light of the recent escalation in interest in taxidermy in all its forms, from museum dioramas to hunting trophies to contemporary art. Although predating this recent trend, Donna Haraway's account of the racist, sexist, and hierarchical structures that underpinned the creation of the dioramas in the African hall at the American Museum of Natural History in the 1920s is still pertinent. Focusing in particular on the gorilla diorama created by Carl Akeley, Haraway outlines the perceived notion of the time that hunting an animal for a museum collection could be a means to raise awareness about the need for conservation of natural spaces. The killing of animals in the name of science was regarded as being for the greater good, and as being necessary for the preservation of nature. By mounting an ideal specimen within a diorama that presented a precise mimesis of its original natural 
environment, not only did the practice of taxidermy arrest the decay of the animal, it also halted time and maintained the specimen in a fixed moment of natural purity.

Haraway describes the dioramas as depicting "the moment of origin where nature and culture, private and public, profane and sacred meet - a moment of incarnation in an encounter of man and animal." 37 This encounter is twofold in that it encompasses both the moment when the museum visitor encounters the taxidermic animal and its accompanying constructed narrative, as well as the moment of encounter between the naturalist-hunter and the living animal, the moment of origin that sets the animal's fate. Similarly, spectators who viewed Jonah the whale would have encountered the embodied evidence of a hunt that had resulted in its own demise. Jonah existed for a purpose contradictory to that of preserved museum specimens: he was not preserved to promote conservation, but to promote the hunt itself. Unlike Tan's installation, which provides a clean environment from which to view a series of museum specimens, visitors who crawled inside the belly of a badly preserved fin whale would have had a shockingly visceral encounter more akin to a visit to a carnival side show than to a sanitized museum hall.

Although Depot can be examined in terms of its relation to colonialist collecting practices, Tan has also consciously made a connection to cabinets of curiosity through her use of the narwhal tusk, the crafted glass specimens, and images of preserved wet specimens. Consequently, it does not seem remiss to compare the text that accompanies Tan's exhibition to written material from the sixteenth century. Ancillary to Depot is a small artist's book of the same name. Created in lieu of a curatorial statement or comprehensive catalogue, Tan presents a document containing her research in the form of a poignant accumulation of old engravings of beached whales, examples of material culture portraying whales, and anecdotes that relate to the whaling industry, a history of whales' bodies used in popular exhibitions, and encounters between humans and whales.

\footnotetext{
37 Donna Haraway, "Teddy Bear Patriarchy: Taxidermy in the Garden of Eden, New York City, 1908-36," Primate Visions: Gender, Race, and Nature in the World of Modern Science (New York: Routledge, 1989), 29
} 
As a result of Tan's focus on the lore of the whale, her bookwork recalls the natural histories of various creatures published between sixteenth and mid-seventeenth centuries. As Foucault describes them, these histories contained, "the inextricable and completely unitary fabric of all that was visible of the things and the signs that had been discovered or lodged in them,"38 and as such contained not merely descriptions of the physical anatomy of an animal but also its uses and the stories that had accumulated around it. ${ }^{39}$

\subsection{Mark Dion's Curious Specimens}

Like Fiona Tan, Mark Dion has dedicated his career to exploring the relationship between the collecting of scientific and natural history objects and the processes of accumulating and disseminating knowledge through these collections. Further to this, Dion examines the role that the cultural institutions that present such collections ultimately play in shaping our collective knowledge of science and the history of science. Working within these parameters, Dion has established a reputation by making large-scale interventions into institutional collections, with a particular focus on natural history museum and university collections. He has also been responsible for several major scale permanent public installations, such as Ship in a Bottle (2011) for the Port of Los Angeles Waterfront Enhancement Project, Vertical Garden (2009) in London UK, and Neukom Vivarium (2006) for the Olympic Sculpture Park in Seattle, Washington, an installation which will be discussed in this chapter. Dion has been influenced by artists such as Marcel Broodthaers, Joseph Beuys, Robert Smithson, and Hans Haacke, who were engaged in a practice that came to be known as institutional critique. ${ }^{40}$ Institutional

\footnotetext{
${ }^{38}$ Foucault, Order of Things, 140.

39 Note that my suggestion that Tan's text could be conceived of as of a contemporary imagining of a sixteenth century natural history represents a more literal interpretation than that which I have argued for in the previous chapter of this thesis, wherein I argue that the coded information stored in the Freezerworks database at the Ambrose Monell Cryo-collection at the American Museum of Natural History could also constitute a textual natural history.

${ }^{40}$ In his analysis of the history of conceptual art, Benjamin Buchloh more comprehensively articulated the term "institutional critique" as referring to work that had a history in the ready-made but that also critiqued
} 
critique was characterized by interpretive strategies that utilized both analytical and political positions and that "problematized and critically assessed the soundness of the claims advanced (often tacitly) by art institutions." 41 Although Dion has been influenced by the history of institutional critique, he differentiates himself from the original approach, stating, “As I see it, artists doing institutional critiques of museums tend to fall into two different camps. There are those who see the museum as an irredeemable reservoir of class ideology - the very notion of the museum is corrupt to them. Then there are those who are critical of the museum not because they want to blow it up but because they want to make it a more interesting and effective cultural institution." 42

In his quest to render contemporary museums more "interesting and effective cultural institutions," Dion appropriates and subverts display techniques that reflect his interest in both the sixteenth-century cabinet of curiosities and nineteenth-century glass cabinetry. This approach is a response to what he perceives as the paradox that many contemporary museums face: they exhibit historical objects but are expected to do so using contemporary technologies, often resulting in the loss of historical methods of display in favor of an increased dependence on flashy video and interactive technologies. Although Dion is influenced by ecology and conservation issues in nature, he is equally

the institutions (predominantly museums and galleries) that had a role in the presentation of art. This work also, to a lesser extent, acknowledged established social, economic, and linguistic institutions. He wrote, "What begins to be put into play here... is a critique that operates at the level of the aesthetic 'institution.' It is a recognition that materials and procedures, surfaces and textures, locations and placement are not only sculptural or painterly matter to be dealt with in terms of a phenomenology of visual and cognitive experience or in terms of a structural analysis of the sign... but that they are always already inscribed within the conventions of language and thereby within institutional power and ideological and economic investment." See Benjamin Buchloh, "Conceptual Art 1962 - 1969: From the Aesthetic of Administration to the Critique of Institutions,” October, Vol. 55 (Winter 1990), 136.

\section{1}

Alexander Alberro, "Institutions, Critique, and Institutional Critique," Institutional critique: an anthology of artists' writings, edited by Alexander Alberro and Blake Stimson (Cambridge, Massachusetts: MIT Press, 2009), 3.

42

Mark Dion, "Miwon Kwan in Conversation with Mark Dion," in L.G. Corrin, M. Kwan and N. Bryson, Mark Dion (London: Phaidon), 7-33, as also quoted in Marion Endt, "Beyond Institutional Critique: Mark Dion's surrealist wunderkammer at the Manchester Museum," Museum and Society 5, no. 1 (March 2007), 1. 
concerned with the conservation of museums themselves as historical documents. ${ }^{43}$ All of Dion's institutional projects are characterized by an intense period of research within the collection, often delving into material culture that is rarely seen by the public but that helps to define each collection as a vital entity that is both historical and contemporary.

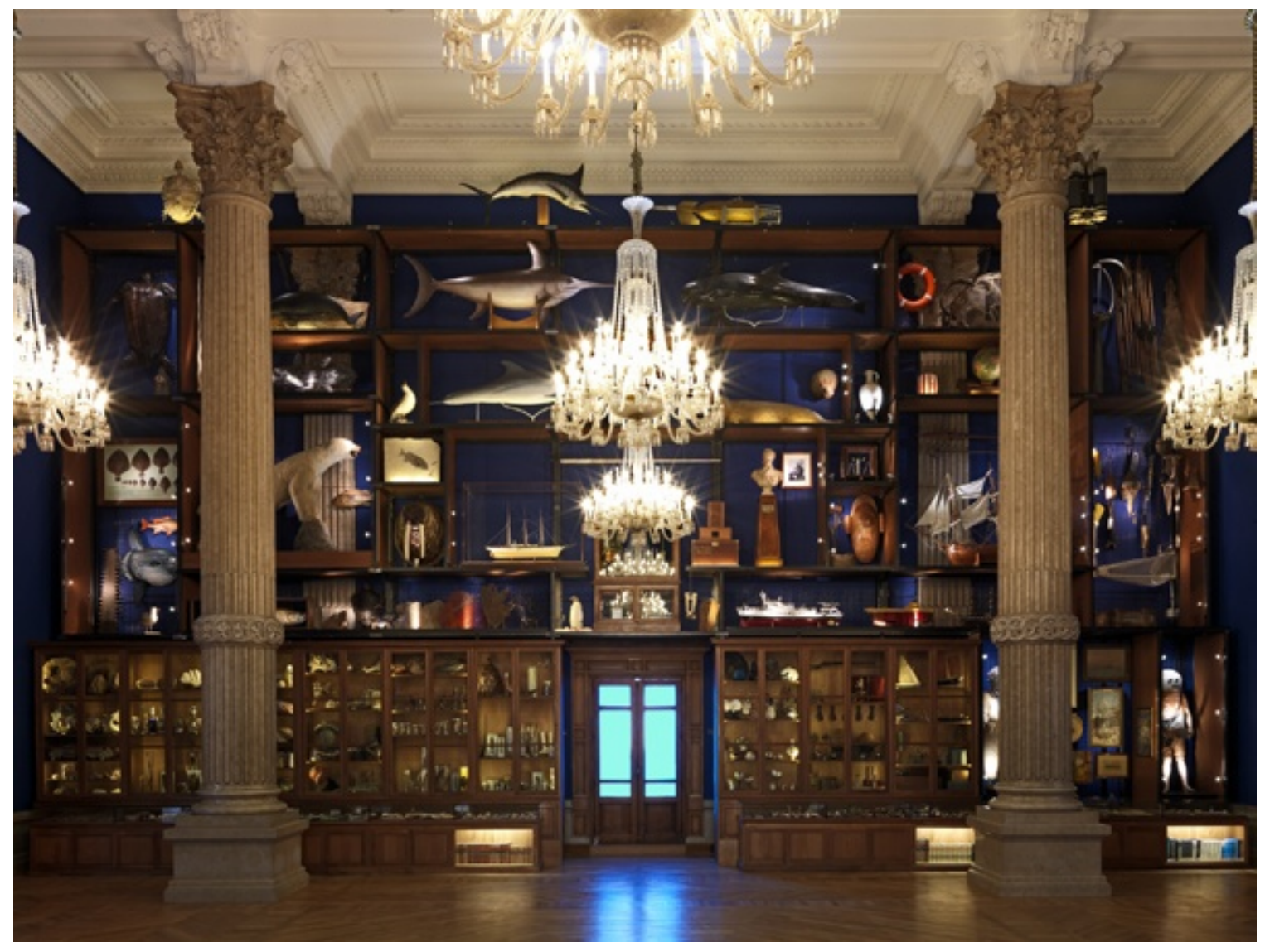

Figure 3.6: Mark Dion, Oceanomania, 2011, Oceanographic Museum of Monaco. Image used with permission from the artist.

Of equal importance to this research is how it is presented to the public. Although the term "cabinet of curiosities" is frequently used to describe Dion's chosen methods of display, many of the cabinets that he incorporates into his installations can be more accurately described as emulating Victorian cabinetry and vitrines. Despite his use of Victorian structures, however, Dion organizes objects culled from museum storage rooms using taxonomies that have more in common with cabinets of curiosity than with

43 Joanna Marsh, "Fieldwork," American Art 23, no. 2 (2009), 40. 
Victorian scientific thought, such as by species in the case of natural history specimens or by discipline or geography in the case of material culture. Rather, objects may be organized according to less scientific relationships: by similitude of form, material, or utility. These multiple taxonomies may be utilized within a single cabinet or vitrine so that, instead of resulting in a cohesive system of classification, it results in a "catalogue of systems. ${ }^{44}$ In all instances, Dion's use of museum objects enforces Alpers' notion of the museum effect, in that each object, including those rarely observed outside of museum storage as well as found objects that Dion has collected elsewhere and incorporated into the installation, becomes an object of visual interest. Even the most banal of Dion's found objects becomes as aesthetically and conceptually significant as the museum artifacts.

A particularly successful example of Dion's approach to museum intervention is Oceanomania: Souvenirs of Mysterious Seas, from the expedition to the aquarium (2011). Exhibited at the Oceanographic Museum of Monaco, the work derives its name from a period of intense fascination with the ocean that arose in the late 1700s and reached its peak during the latter half of the 1800s. The installation was created with the aspiration of being the largest cabinet of curiosities focused on the material culture of the sea in the world. Initially conceived as a response by Dion to the collection of the Oceanographic Museum of Monaco, it expanded to encompass two other venues, an exhibition of the work of twenty contemporary artists, and a retrospective of Dion's past work that related to the marine environment. Although the newly created installation responded to a collection of art and material culture that spanned centuries, Dion's efforts were heavily influenced by two recent maritime events: firstly, the Census of Marine Life (2010) that involved 2700 scientists from 80 countries assessing and documenting marine diversity, and in which 6000 new species were identified; and secondly, the Deep Water Horizon oilrig explosion that caused 4.9 million barrels of crude oil to be leaked into the Gulf of Mexico, the long term effects of which remain unrealized. Dion selected objects from the collection to illuminate the outcomes of these two events. While the Census of

\footnotetext{
${ }^{44}$ Marsh, "Fieldwork," 46.
} 
Marine Life reminds us that between 50 and $80 \%$ of the world's biomass have yet to be identified, environmental tragedies like the Deep Water Horizon spill jeopardize the ocean's inhabitants and will likely have further detrimental effects that will only become apparent only in the fullness of time. Species may become extinct before we have the chance to know that they exist.

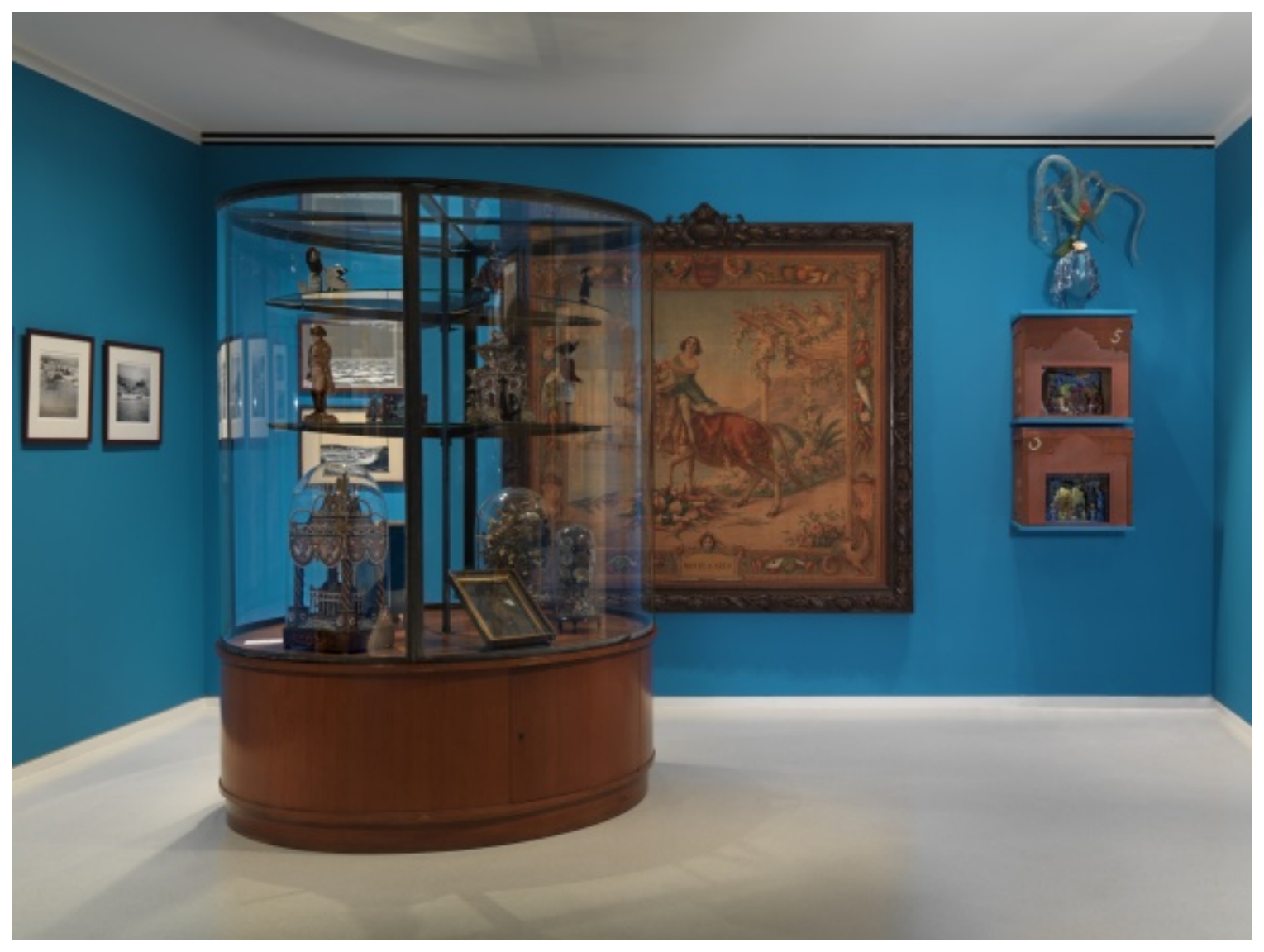

Figure 3.7: Mark Dion, Davy Jones' Locker, 2011, Nouveau Musée National de Monaco. Image used with permission from the artist.

By using objects from all areas of the museum collection - from wet specimens in jars to historical and contemporary examples of material culture relating to the sea - Dion juxtaposes allegories of the sea with imagery that highlights the fragile nature of our current relationship with the ocean environment. For example, the centerpiece of Dion's complex installation includes a massive "cabinet of curiosities" that spans from floor to ceiling. The lower section includes Dion's signature glass-fronted wooden cabinetry that holds all manner of smaller-scale oceanic specimens and museum objects, while the 
upper section reveals specimens of a larger scale, including a polar bear, a swordfish, small porpoises, and sea birds. There are also objects of material culture related to the sea, including several model ships and boats. The overall aesthetic, although characteristic of Dion's oeuvre in general, is here also evocative of the hall of biodiversity at the American Museum of Natural History. The notion of the ocean environment and its inherent fragility at the hand of man is driven home in the section entitled Davy Jones' Locker, a title that takes its name from the expression used to refer to the bottom of sea, or the resting place of drowned mariners. For Davy Jones' Locker, Dion drew from the museum's art collection in order to create a narrative that tells of man's complex and tenuous relationship with the ocean, a relationship that counters death and danger with the spirit of scientific exploration.

Working closely with curators from each department of the museum and allowing them to have input into the selection of objects also allowed Dion to highlight the impact that individuals have on what objects are presented within a museum space and how they are understood. This impact was revelatory to both the public and to the curators themselves:

Dion...separated processes of classification based on aesthetic, historical, or scientific conventions. The curators watched with fascination as the perception of what had once been cloistered relics of variable relevance in the eyes of scholars and specialist were reinvigorated through new interest. The human dimension and subjectivity of the individuals was foregrounded as central to the formation of the museum's ideology, its educational assets, and its knowledge resources. ${ }^{45}$

While engaging in a process that illustrates the subjective nature of how knowledge is constructed within an institution, Dion simultaneously sheds light on the environmental concerns. Although his aims are more broadly critical - addressing the subjective nature

\footnotetext{
45 Sarina Basta and Jackie McAllister, “Exhibition as Expedition, Museum as Object, or Mark Dion's Deep-Sea Maneuvering," Oceanomania [exhibition catalogue], (Monaco: Nouveau Musée Nationale de Monaco, 2011), 158.
} 
of how knowledge is constructed - his goals are not entirely dissimilar from those that curators of natural history hoped to achieve through the display of taxidermic dioramas. In Dion's attempt to "conserve" the museum in its historical form, he raises awareness of the need for environmental conservation. If one looks beyond Dion's well-established aesthetic, the multi-layered nature of the meaning of preservation becomes evident: preservation of specimens, preservation of museum history, and preservation of the environment.

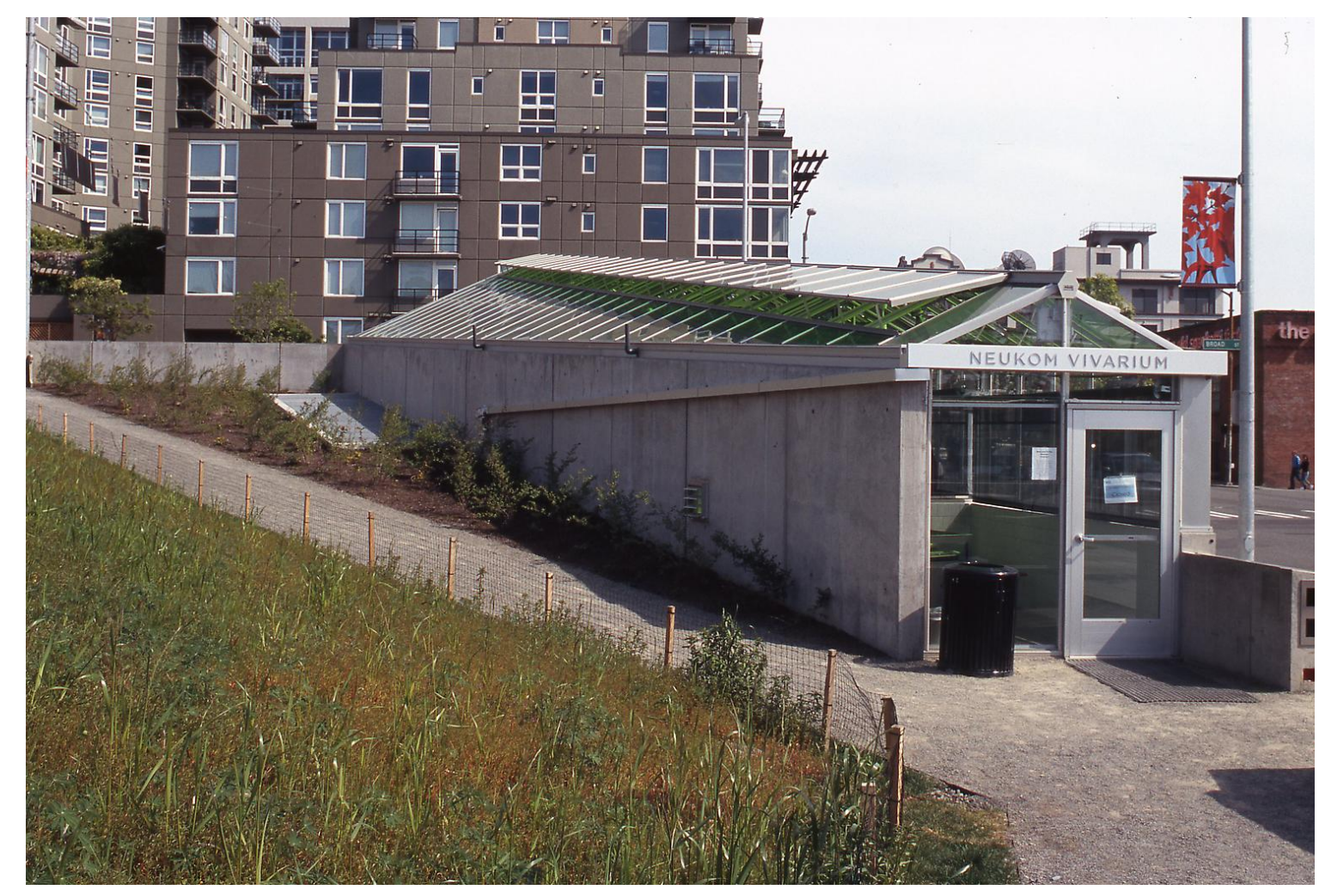

Figure 3.8: Mark Dion, Neukom Vivarium, 2006, Olympic Sculpture Park, Seattle. Image used with permission from the artist.

In contrast to the complexity of Oceanomania that mimics a collection of encyclopedic aspiration, a single preserved specimen dominates Dion's Neukom Vivarium (2006), an interdisciplinary installation consisting of a fallen 60-foot western hemlock tree housed inside an 80-foot greenhouse. The greenhouse is located on the north end of the Seattle seawall, in the Seattle Art Museum's Olympic Sculpture Park, a site formerly occupied by an oil and gas company and which required the removal of 120,000 tons of petroleum-contaminated soil in order to transform it into one of 
downtown Seattle's few green spaces. The area was then covered over with 150,000 cubic meters of clean fill salvaged from the Seattle Art Museum's downtown expansion project. Housed in a purpose built greenhouse that Dion designed, the hemlock resembles an oversized natural history specimen. The greenhouse maintains a strictly monitored set of atmospheric conditions in order to preserve a functioning and evolving ecosystem. The tree, which acts as a nurse log, hosts various microscopic ecosystems consisting of fungi, insects, lichen, and plants, and consequently exists in a sustained state of decay.

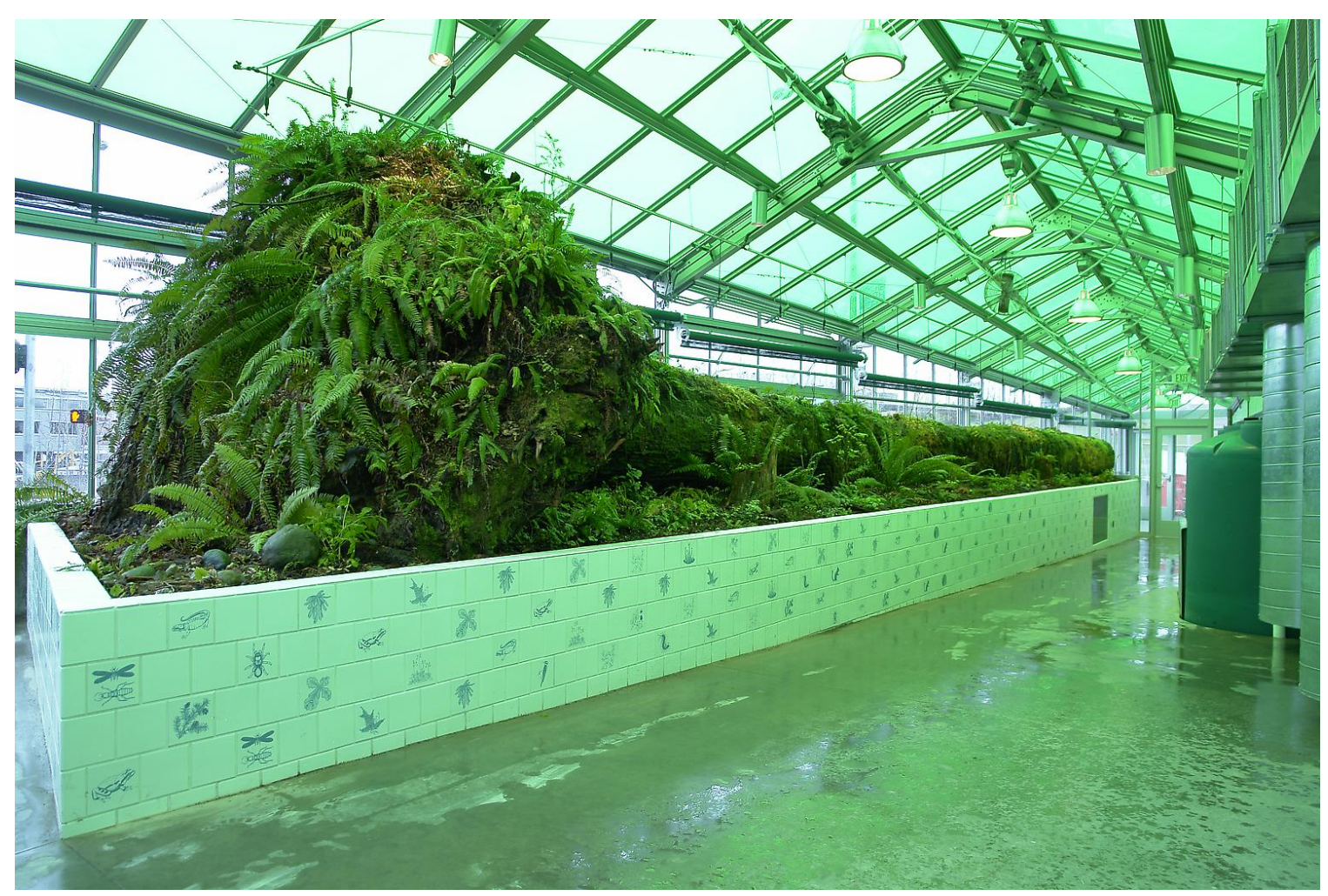

Figure 3.9: Mark Dion, Neukom Vivarium, 2006, Olympic Sculpture Park, Seattle. Image used with permission from the artist.

The greenhouse functions as an enormous museum vitrine that houses a single botanical specimen, but that also houses a microcosm within the macrocosm of the city. Similar to many preserved natural history specimens, the hemlock is presented as a singular object for the contemplation of the viewer. In contrast to the objects held in natural history collections, however, it is not presented in relation to a series of other specimens. It is a solitary specimen maintained in a state of suspended animation, on the precipice between living and dead. Dion describes the project as: 
really not an intensely positive, back-to-nature kind of experience. In some ways, this project is an abomination. We're taking a tree that is an ecosystem - a dead tree, but a living system - and we are re-contextualizing it and taking it to another site. We're putting it in a sort of Sleeping Beauty coffin, a greenhouse we're building around it. And we're pumping it up with a life support system - an incredibly complex system of air, humidity, water, and soil enhancement - to keep it going. All those things are substituting what nature does, emphasizing how, once that's gone, it's incredibly difficult, expensive, and technological to approximate that system - to take this tree and to build the next generation of forests on it. So, this piece is in some way perverse. It shows that, despite all of our technology and money, when we destroy a natural system, it's virtually impossible to get it back. In a sense, we're building a failure. ${ }^{46}$

In response to the fact that the Olympic Sculpture Park was built on reclaimed contaminated land, Dion wanted to show that although an artificial environment can be constructed to house a dynamic and evolving system, it remains an inadequate simulacrum of a natural environment. Despite the fact that the vivarium maintains the temperature and humidity of the watershed from where the log was removed and specially engineered green glass panels filter light to mimic the effects of the forest canopy, one can never truly rebuild or recreate a forest. Although Neukom Vivarium contains living systems, the urge to recreate an exact replica of a natural environment within a glassed-in space echoes the motivation behind museum dioramas of the great natural history museums, whereby animals were hunted, mounted, and displayed in artificial, constructed environments that attempted to present an exact replica of their place of origin.

46 http://www.art21.org/texts/mark-dion/interview-mark-dion-neukom-vivarium 
Dion's greenhouse is a hybrid space ${ }^{47}$ in that it makes reference not only to natural history museums and laboratory research spaces, but also to the history of gardens and greenhouses. The relationship between greenhouses and museum display finds its roots in Joseph Paxton's design for the Crystal Palace, constructed for the 1851 Great Exhibition of the Works of Industry of All Nations in Hyde Park, London. ${ }^{48}$ Paxton was not trained as an architect; instead, his previous experience was working as a gardener for the Duke of Devonshire, where he made innovative use of glass and cast iron to build greenhouses and conservatories at Chatsworth. ${ }^{49}$ This experience allowed him to develop a design for a great exhibition hall made of mass produced identical glass and iron units that could be locked together on site, and later disassembled and reassembled elsewhere. Crystal Palace was six times the size of the great conservatory built at Chatsworth, and housed international exhibitions that stood as a testament to the best of British and international industrial manufacturing, as well as illuminating the colonialist intentions of the British Empire. The exhibitions were multifarious, consisting of mechanical and scientific triumphs of the west, transportation including a full sized steam train, textiles, foods, medical devices, 1500 pieces of Hermann Plouquet's anthropomorphic taxidermy, and works of art that had the unintended consequence of emphasizing the aesthetic divide between art and manufacturing. Amongst these exhibitions was a row of Hyde Park's giant elm trees that were allowed to continue growing undisturbed inside the enormous structure. Paxton's earlier experience with greenhouse design fortuitously allowed the Crystal Palace to be altered through the addition of a transept that would accommodate

\footnotetext{
47 Dion refers to it as "something like a showroom, something like a classroom, and
laboratory." http://www.pbs.org/art21/watch-now/segment-mark-dion-in-ecology

48

After the Great Exhibition, the Crystal Place was deconstructed and reassembled in Sydenham. Some of the exhibits were purchased to form the nucleus of the collection of a new museum, originally known as the Museum of Manufactures, but which came to known as the South Kensington Museum and subsequently renamed the Victoria and Albert Museum. This coincided with the construction of a new building to house the Natural History Museum, which had previously constituted part of the collection of the British Museum.

49 See May Woods and Arete Swartz Warren, Glass Houses: A History of Greenhouses, Orangeries and Conservatories, London: Aurum Press, 1988, for a comprehensive survey of the development of glass structures in garden architecture, particularly chapter 4: "Glass Roofs and Graceful Curves 1780-1850" and chapter 5: "The Victorian Glass House 1850-1920."
} 
the elms without damaging them. This resulted in a structure that allowed for the creation of spectacle while at the same time providing a nurturing space to support specific living organisms. ${ }^{50}$ The glass walls of the building not only allowed light to pass through, but they also allowed for a dissolving of boundaries between interior and exterior, nature and culture: a relationship that was emphasized by the juxtaposition of the enormous elm trees with the manufactured objects.

Like plants in a greenhouse, the Crystal Palace presented objects for refined contemplation. Rachel Teukolsky argues that one of the great concerns over exhibition attendees was that they would behave in an unruly manner unbefitting the venue. "If one of the governing ideologies of the Exhibition was that the wilds of nature could be tamed and utilized by (Western) man, then another version of this ideology was that "the eye" synechdoche for the lustful, unruly body - could be disciplined by the numerous tracts of Exhibition experts. The mode of disciplined looking advocated by such experts was a rational kind of vision associated with science, especially natural history."51 Teukolsky further argues that objects in the exhibition were categorized in a manner in keeping with eighteenth-century naturalists' attempts to categorize nature, and which were intended to be observed and contemplated with a scientific detachment. This type of looking was epitomized by the viewing of objects under glass, particularly as practiced in botany and natural history.

Akin to the experience of visitors to both the Victorian greenhouses and the exhibitions displayed at the 1851 Exhibition that long preceded Dion's Neukom Vivarium, contemporary visitors to Dion's installation are invited to enter a glassed-in space to contemplate an oversized botanical specimen. Mirroring the elms that were housed within the Crystal Palace, Dion's greenhouse supports a hemlock along with its

\footnotetext{
50 Note that this courtesy did not extend beyond the trees. During construction, sparrows began to nest within the structure, and sparrow hawks were brought in to dispatch them. See Patrick Beaver, The Crystal Palace 1851-1936: A Portrait of Victorian Enterprise (London: Hugh Evelyn Limited, 1970), 28. 51 Rachel Teukolsky, "This Sublime Museum: Looking at Art at the Great Exhibition," in Victorian Prism: Refractions of the Crystal Palace, edited by James Buzard, Joseph W. Childers, and Eileen Gillooly (Charlottesville and London: University of Virginia Press, 2007), 87.
} 
parasitic living system. It is a natural object surrounded by a glass and metal structure, which in turn exists within a park surrounded by an urban environment. The Olympic Sculpture Park takes the form of a z-shaped walkway that guides visitors through a variety of landscapes and topographic variations, "a series of microsettings, each a diverse ecological environment of native plantings, ${ }^{, 52}$ and that acts as a means of connection between the urban environment and a newly revitalized waterfront. Although the sculpture park is meant to provide visitors with an enriching cultural experience that merges both urban and natural environments, it is worth noting that the Seattle Art Museum website outlines a number of guidelines for visiting the park. This includes a no touching policy with regards to the artworks, as well as instructions that all visitors must keep to the paths and walkways. Although the space is presented as a park, it nevertheless functions as a disciplinary space in much the same way that nineteenth-century museums did. All visitors are expected to maintain the same social decorum (skateboards and bicycles must be carried or walked through, respectively) as was expected of Victorian visitors to the Crystal Palace.

Upon entering Neukom Vivarium, which is only allowed if specially trained interpreters or "park rangers" are available, visitors encounter a climate-controlled environment created to nurture and sustain the life growing on the fallen log. The ecosystem being nurtured is a result of the symbiotic relationship between the decomposing hemlock specimen and the various organisms and microorganisms that it hosts; consequently, as Lisa Graziose Corrin points out, "this monumental installation defines 'permanence' as a relative state. ${ }^{, 53}$ Further echoing the sensibility of Victorian amateur naturalists, visitors may use magnifying glasses and microscopes, housed in a cabinet designed by Dion, to observe and identify the various organisms living on and in the work. Delft-inspired ceramic tiles illustrated with these organisms surround the structure that supports the hemlock specimen and function as field guides. Although the

\footnotetext{
52 Michael Manfredi and Marion Weiss, Surface/Subsurface (New York: Princeton Architectural Press, 2008), 20.

53 Lisa Graziose Corrin, "Introduction to the Seattle Vivarium," in Field Guide to the Wildlife of Mark Dion's Seattle Vivarium (Seattle: Olympic Sculpture Park [Seattle Art Museum], 2007), 2.
} 
vivarium makes clear reference to the history of greenhouses and museum vitrines, the structure also owes much to the technology behind the incubator, which also keeps living beings alive. "This log represents a tiny fragment of an intricate conglomeration of ecosystem functions, nature's emergent machinery for the sustenance of life - perpetual, ever changing, evolving, and adapting. Inside the Vivarium lies a piece of this life forever changed by its relocation. One log set apart from the rest, enclosed by glass and given a breathing apparatus, must rely on its existing inventory of "parts" - the ferns, the mosses, spores, and microbes - to do what it and all of nature has always done very well: cycle through life and death." 54 The hemlock specimen, like so many other museum specimens before it, is a singular specimen that has been removed from its original context and must stand in for all others of its kind, an embodiment of our flawed knowledge of the need for conservation in conflict with our knowledge that we can never quite achieve it.

\subsection{Exhibiting the Postnatural Specimen}

In contrast to Dion's projects that address the quest to preserve nature, Rich Pell focuses on humankind's desire to alter and control it. The Center for PostNatural History occupies a small, unassuming storefront in Pittsburgh, Pennsylvania. Founded by Pell with biologist and educator Lauren Allen, the Center for PostNatural History was originally conceived as a work of art, but it has since come to function as a legitimate micro-museum that seeks to fill a significant gap that exists in the narrative of nature presented by natural history museums. Natural history museums are dedicated to presenting the grand narrative of evolution through natural selection, a narrative that largely ignores domesticated species that are the result of human driven breeding practices based on artificial selection. Pell came up with the idea to create the Center for PostNatural History while he was researching synthetic biology and noticed that the animals that were most commonly used in that discipline were absent from natural history collections. These excluded organisms fall into the category of the "postnatural," a term applied to anthropogenic interventions into evolution that are both intentional and

\footnotetext{
54 Ivona Kaczynski, “An Ecosystem Like No Other," in Field Guide to the Wildlife of Mark Dion's Seattle Vivarium, (Seattle: Olympic Sculpture Park [Seattle Art Museum], 2007), 10.
} 
heritable, specifically referring to "the purposeful and permanent modification of living species by humans through domestication, genetic engineering, and synthetic biology."55 Because these interventions are a reflection of the intentions of those making the alterations or interventions, the organisms that result from these processes can be regarded as cultural artifacts rather than natural objects. This contrasts with the conception of the natural as represented in natural history museums throughout the world, which focus on an evolutionary model of species that is not a function of human desire or intention.

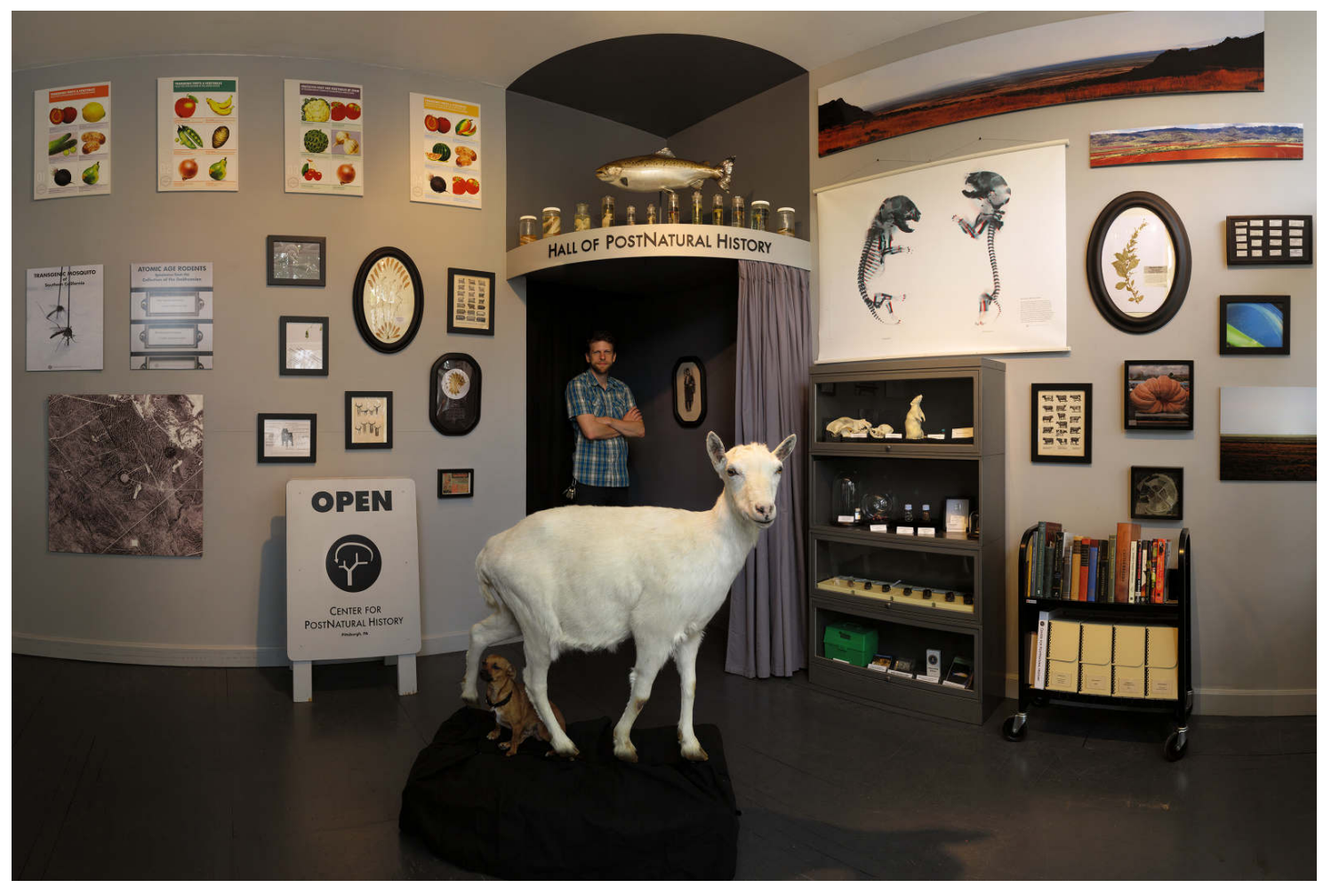

Figure 3.10: Center for PostNatural History, Pittsburgh. Image used with permission from the artist.

Since its inception, the Centre for PostNatural History has developed a collection of preserved organisms bound together by the unifying theme of having been genetically

55 Richard Pell and Lauren B. Allen, "Preface to a Geneology of the PostNatural," in Intercalations 2: Land \& Animal \& Non-Animal, edited by Anna-Sophie Springer \& Etienne Turpin. (Berlin: K. Verlag and the Haus der Kulturen der Welt, 2015), 79. (see also, http://postnatural.org/Explore/Preface-to-aGenealogy-of-the-Postnatural) 
modified through the aforementioned means. The first specimens that they collected were transgenic mosquitos that had been engineered to be resistant to the parasite that causes malaria. The mosquitos were engineered for release into "the wild" with the intention that they would breed with existing native mosquitos and render the population similarly resistant to the parasite and ultimately reduce the frequency of malaria in humans. ${ }^{56}$ Unfortunately Pell later discovered that dermestid beetle larvae had destroyed the specimens. The larvae however were preserved and exhibited, as they had existed on a diet of transgenic organisms.

The collection also holds examples of C57BL6 strains of laboratory mice. Thousands of variations of this strain of mouse exist, but they can all be traced back to a single black female mouse that was purchased from Abbie Lathrop's pet shop in Granby, Massachusetts in $1921 .^{57}$ Dr. C.C. Little, founder of Jackson Laboratories, purchased the mouse, that he named number 57, from Lathrop because her mice had not only already been selectively bred for aesthetic similarities but were beginning to show predispositions that resulted from genetic inbreeding. Little used this mouse to breed other mice that were genetically virtually identical, because he recognized that in scientific research it would be desirable to use subjects that were as genetically standardized as possible. In order for biological research to maintain the level of reproducibility that was expected in other scientific fields, the subject of experimentation would need to be similarly standardized to provide predictable and repeatable results.

\footnotetext{
56 See Uli Beisel, and Christophe Boëte, "The flying public health tool: genetically modified mosquitoes and malaria control," Science as Culture 22, no. 1 (2013), 38-60 for a more complete analysis of the use of mosquitos for malaria control.

57 See David P. Steensma, Robert A. Kyle, and Marc A. Shampo, "Abbie Lathrop, the "mouse woman of Granby": rodent fancier and accidental genetics pioneer," In Mayo Clinic Proceedings, vol. 85, no. 11, p. e83. Mayo Foundation, 2010, and Pell, Richard W., and lauren B. Allen. "Preface to a Geneology of the PostNatural." "Intercalations 2: Land \& Animal \& Non-Animal" Co-edited by Anna-Sophie Springer \& Etienne Turpin. (Berlin: K. Verlag and the Haus der Kulturen der Welt, 2015), 79. (See also, http://postnatural.org/Explore/Preface-to-a-Genealogy-of-the-Postnatural)
} 
The largest specimen held at the Center for PostNatural History is a taxidermied goat named Freckles, one of the original BioSteel ${ }^{\mathrm{TM}}$ goats developed by Canadian corporation Nexia Biotechnologies. ${ }^{58}$ Dr. Jeffrey Turner, professor in the McGill

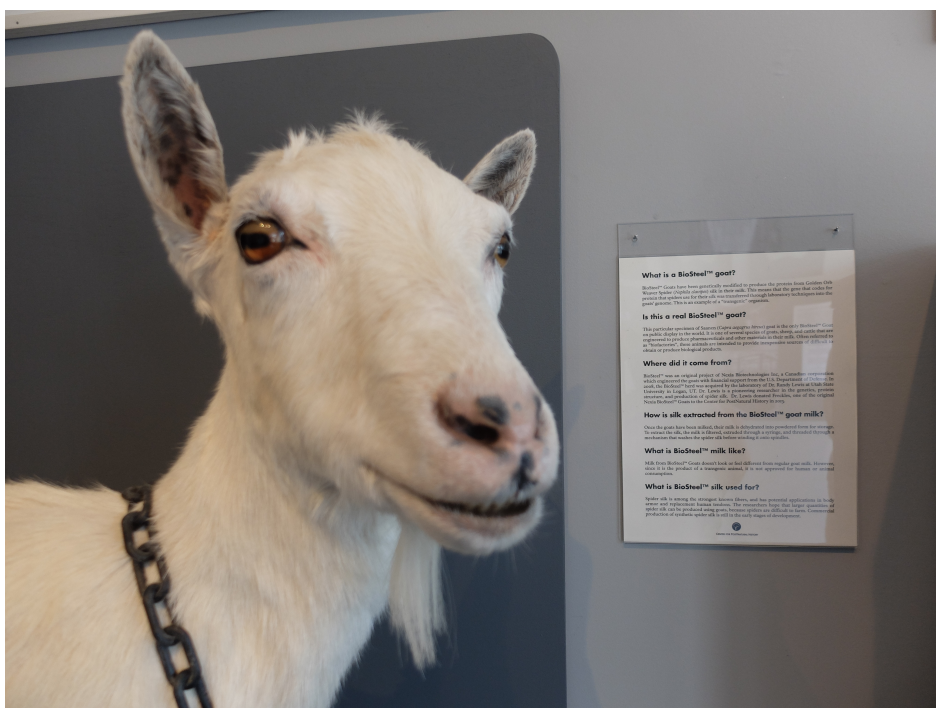

Figure 3.11: BioSteel ${ }^{\mathrm{TM}}$ Goat, Center for PostNatural History, Pittsburgh. Image used with permission from the artist.
Department of Animal Science and founder of Nexia, had hoped to produce goats whose milk would contain spider silk protein that could be harvested, dried, and spun into long threads. These high-tensile threads could then potentially be used in the production of parachutes, bulletproof vests, and sutures in the medical field. The BioSteel ${ }^{\mathrm{TM}}$ goats embody both of the primary defining characteristics of a postnatural organism: the changes to the goats' genome were both intentional and heritable. Firstly, the goats were altered for the purpose of making fibers that were both strong and light and would have commercial applications. Secondly, the changes to the goats' DNA also proved to be permanent in that the genes passed from one generation of goats to the next. Turner reported that, "We're up to three generations. The genes are not being lost and so far we've not detected any adverse effects." ${ }^{, 59}$ Ultimately, Nexia was unable to produce silk of tensile strength comparable to that of an actual spider, and eventually went out of business and divested its assets. Half of the BioSteel ${ }^{\mathrm{TM}}$ goats were transferred to Dr. Randy Lewis of Utah State University, who had provided the initial technology used to clone the spider proteins. Lewis continues to perform research into BioSteel ${ }^{\mathrm{TM}}$ including

\footnotetext{
${ }^{58}$ For further discussion of the methods involved with inserting spider genes into those of a goat, see John C. Avise, "Spider Silk from Goat's Milk," in The Hope, Hype, and Reality of Genetic Engineering (Oxford: Oxford University Press, 2004), 78-80.

59

"Nexia Biotechnologies," http://www.mcgill.ca/files/ott/nexia.pdf, October 2002, accessed July 29, 2015.
} 
in collaboration with artists, ${ }^{60}$ and also donated the body of Freckles the BioSteel ${ }^{\mathrm{TM}}$ goat to the Center for PostNatural History. The other half of the herd was acquired by the US Defense Advanced Research Project Agency (DARPA) and moved to a decommissioned air force base in upstate New York. In addition to the taxidermied goat, the Center for PostNatural History exhibits a miniature diorama, bathed in an eerie orange glow, which shows the BioSteel ${ }^{\mathrm{TM}}$ goats at the air force base. It was developed using images from Google Earth. According to the accompanying text panel the current status of that herd is unknown.

In 2010, Pell undertook a period of research as artist in residence at the Smithsonian National Museum of Natural History, resulting in the photographic series, Atomic Age Rodents (2011). This research revealed that the rodents held in this collection arrived through various paths corresponding to various modes of interspecies relationships between rodents and human. According to Pell, the obsessive organization and classification of organisms by U.S. government employees has resulted in the documentation of a certain aspect of American history as told through the collected skins and skulls of rodent specimens. The collection consists of 40,000 individual specimens, each tagged with collection information, and is housed in a single storage room marked by the unspectacular title, "Division of Mammals: Rodent Range." Pell argues that although the collection has been amassed by researchers as part of the larger project of studying the natural world, "they also provide geographic record of the expanding influence of the United States through trade, diplomacy and military incursion." ${ }^{61}$ By this, Pell means that the method of organization of particular rodents within the collection

\footnotetext{
${ }^{60}$ Lewis has recently been involved in a collaboration with the artist Jalila Essaïdi, creating a piece called Bulletproof Skin in which a piece of bioengineered skin was reinforced with spider silk proteins. Although conceived as an art project, it also exists as part of Lewis's body of research into potential commercial applications of bioengineered spider silk. See "Utah researcher helps artist make bulletproof skin," August 23, 2011, http://www.ctvnews.ca/utah-researcher-helps-artist-make-bulletproof-skin-1.687095, and "Bulletproof Skin," http://jalilaessaidi.com/2-6g-329ms/.

61 Richard Pell, Atomic Age Rodents (Pittsburgh: Centre for PostNatural History, 2013), un-paginated catalogue.
} 
reveals a secondary narrative that may not have been the original intention of the biologists who amassed them.

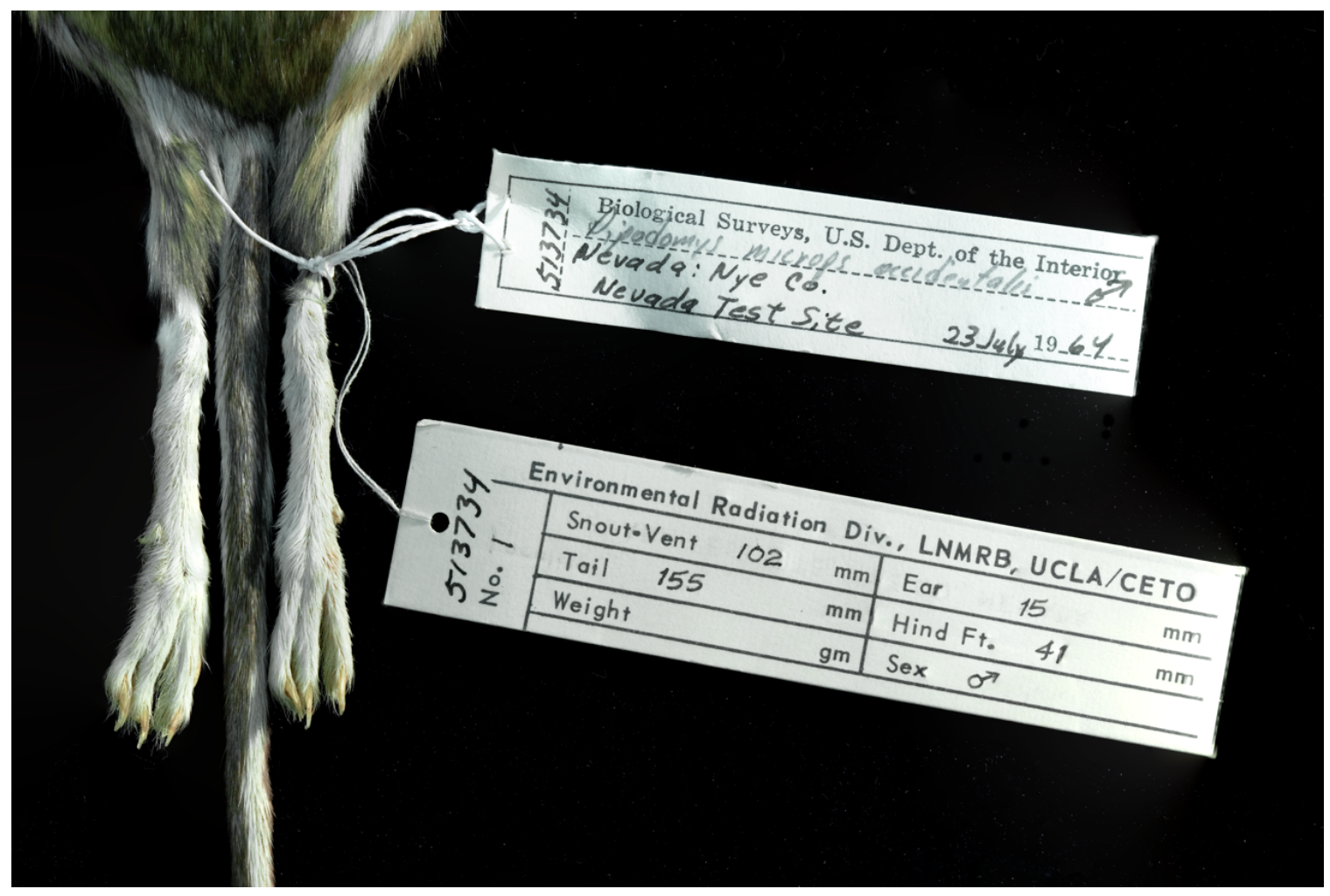

Figure 3.12: Richard Pell, Atomic Age Rodents, 2011, Centre for PostNatural History, Pittsburgh. Image used with permission from the artist.

The majority of the collection is organized in drawers according to the geographical location in which they were collected. However, specimens raised in captivity present a dilemma in that they cannot be classified according to a natural environment in which they were found. These specimens are housed in drawers labeled, "Locality Unknown." The white fur of these rodents differentiates them from the various brown mice that were sourced from natural environments, and betrays their status as lab animals. Many of these mice were used to study the effects of radiation on animals. Their collection tags indicate that they were collected in 1944, prior to the dropping of the first atomic bomb. Pell observed that many of the rodents sourced in the "wild" were collected from localities in which the United States had waged wars, and had been collected by military medics for analysis as potential disease carriers. One specimen that Pell documented had been collected at Tinian Island on August 14, 1945, shortly after the 
United States seized it from Japan. As Pell points out, "Tinian became famous later that same year as the departure point for the Enola Gay bomber for its historic flight to drop the first atomic bomb on Hiroshima." Another specimen that Pell singles out is a rat collected in Nagasaki on October 2, 1945 as a part of the effort to control diseases that might be passed on to humans by rodents during the period following the surrender of Japan and consequent occupation by American forces.

Following World War II, the United States commenced a program of further atomic testing at Bikini Atoll (1946) and Eniwetok Atoll (1975). From these sites, there are numerous rodent specimens that form part of a collection of flora and fauna gathered from the sites both before and after the blasts. This collection also includes feral rats that are likely the descendants of lab rats introduced to the islands for the purpose of testing the cancerous effects of nuclear radiation. The Smithsonian collection also includes a substantial inventory of animals collected from the Nevada Test Site, where the United States government detonated 1,021 nuclear bombs between 1951 and 1952.

What makes this collection of rodent specimens noteworthy is that they are not only a record of any biological aberrations that may have occurred as a result of their exposure to nuclear radiation, but in Pell's estimation they are also the physical evidence of a set of human values, in this case the American desire to exert military prowess and to conduct research into the potential effects that this particular method of military incursion might bring about. They are botched animals of the sort that Baker described, not because they are poorly constructed by human hands, but because they speak of a certain type of human non-human relationship. As Susan M. Pearce tells us, museum collections are made up of the "selected lumps of the physical world to which cultural value has been ascribed. ${ }^{, 62}$ Here Pearce does not limit her definition to objects that have been crafted by human hands, but extends it to include objects in natural history collections, clarifying that "it is the act of selection which turns a part of the natural world into an object and a

\footnotetext{
62 Susan M. Pearce, Museums, Objects, and Collections: A Cultural Study (Washington, D.C.: Smithsonian Institution Press, 1993), 4.
} 
museum piece." ${ }^{63}$ Further to this, Pearce asserts, "collected specimens have become artifacts in that the art of selection turns them into man-made products, and once they have entered our world they become part of the relationships which we construct for them." ${ }^{, 64}$ Natural history specimens take on the status of material culture once they have been removed from their original context, and have been preserved and repositioned within a cultural institution such as a museum or university collection. Material culture requires evaluation in terms of its meaning and significance within a broader context, and each artifact is assessed in terms of its relationship with another and within the collection as a whole. According to Pearce, natural history collections tend to be systematic collections that depend largely upon principles of organization, each artifact being more than just a discrete object but deriving meaning from being one element in a larger set. The emphasis in these collections is on classification, and relationships are generated between the artifacts through seriality. The physical arrangement echoes the systematic nature of the collection, each element being evaluated in relation to the objects surrounding it. Systematic collections also tend to be bound by a set of parameters, and curators are often charged with "filling in the gaps" within those parameters in order to create a more complete collection. In addition, serial display "establishes certain parameters of visual interest, whether those parameters are known to have been intended by the objects' producers or not." ${ }^{, 65}$ In this case we can regard the primary 'producers" of the objects as having been the biologists who collected the specimens, preserved the skins, and arranged them with the drawers, and who likely did not intend for them to become the subjects of "attentive looking" beyond their role of biological specimens. However, by documenting specific specimens from the collection and presenting them in a new context, Pell has also become a producer of this set of objects and positions them as art objects or perhaps more accurately in this case, art subjects: subjects that have become the focus of the intense looking that Alpers associates with the museum effect.

\footnotetext{
63 Pearce, Museums, Objects, and Collections, 5. 
Although already part of the museum collection, the post-atomic rodents were not available for public scrutiny. It was not until they were introduced into a new context that the individual specimens became objects of a visual interest beyond the scientific and their greater cultural value became evident.

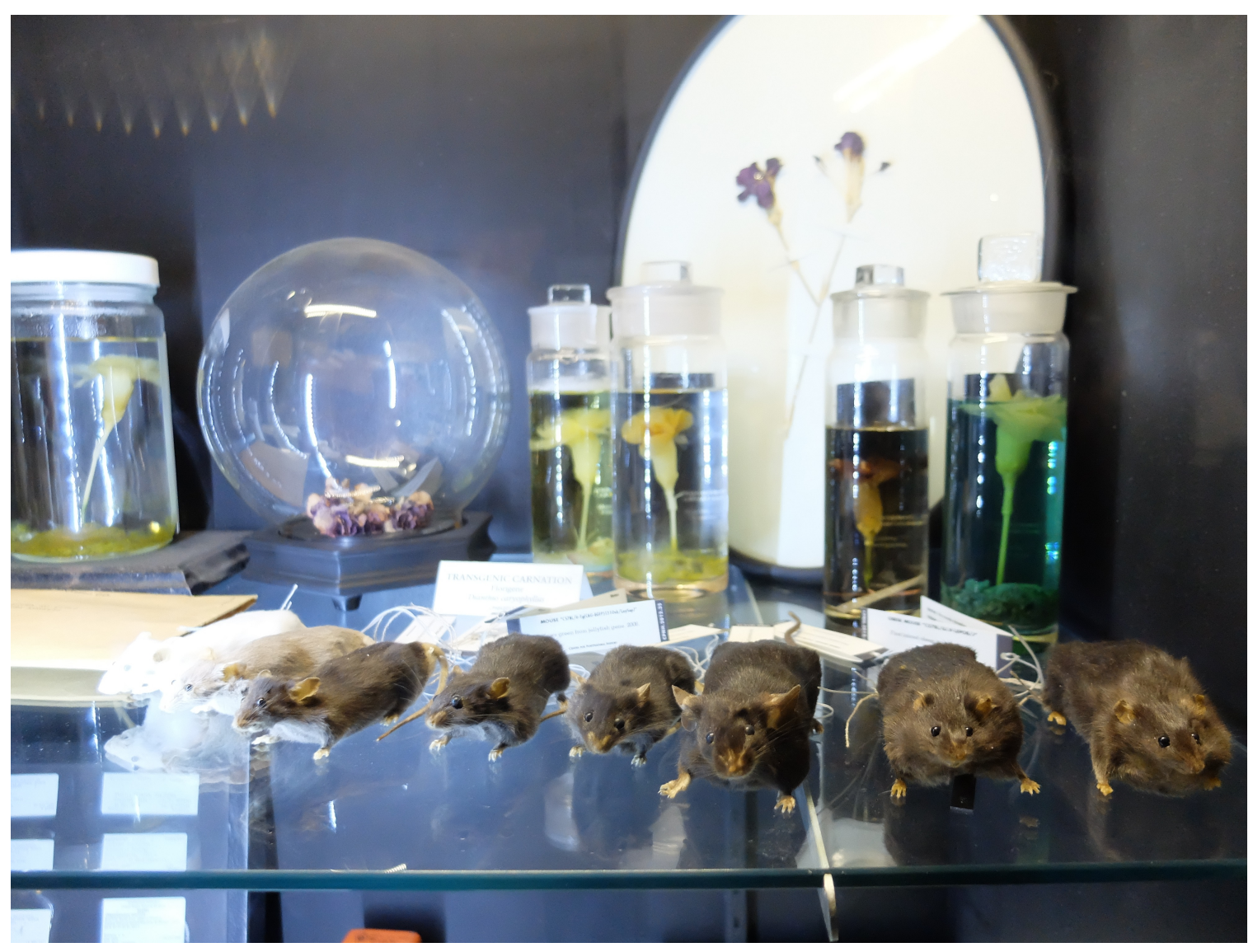

Figure 3.13: Center for PostNatural History, Knock-out Mice, (installation detail).

Within the collection at The Smithsonian National Museum of Natural History, the collection of rodents is but one element within a larger category (small mammals) that is part of an even more comprehensive systematic collection. The arrangement of each rodent specimen, row upon row within banks of storage drawers that are themselves arranged by geographical location, is a function of the method of classification that reflects the systematic nature of the collection. Pearce contrasts systematic collections from what she terms a fetishistic approach to collections and collection making, which is characterized by the desire to collect samples of a particular type of object. I suggest that the collection that comprises Pell's Center for PostNatural History exists somewhat 
paradoxically at the intersection between fetishistic and systematic collections. Pell is engaged in an attempt to collect as many examples as possible of organisms that have been genetically altered as a result of human intervention, yet he also argues that he is trying to fill in a specific gap that exists in natural history museums. Although the Center for PostNatural History may have started out as an art installation, over time it has taken on the status of a micro-museum that has begun to develop a certain amount of credibility within the natural history museum establishment. Despite having engaged in curatorial projects on the subject of the postnatural in collaboration with several international museums of natural history, The Center for PostNatural History maintains a peculiar aura of the fetishistic that is underscored by the methods of presentation that Pell has adopted.

In order to enter the main space, one passes from the brightly illuminated storefront, through a heavy curtain, and into a dimly lit room that contains a number of exhibits behind glass. On the website for the Center for PostNatural History Pell is pictured standing in front of this curtain, striking a pose suggestive of a postnatural reenvisioning of Charles Wilson Peale's self-portrait The Artist in His Museum (1822) in which he draws back a curtain to expose his own collection of taxidermic specimens. Peale amassed a significant natural history collection during his lifetime through a combination of hunting his own specimens and soliciting donations from explorers, prominent naturalists (including Lewis and Clark), and sportsmen who engaged in hunting. A skilled taxidermist as well as artist, Peale preserved and mounted his collected specimens and painted contextual backgrounds to create a series of dioramas for each one. These specimens were then placed within a grid-like series of glass-fronted cabinets. Peale placed great emphasis not only on portraying the specimens as naturalistically as possible, but also on positioning them to reflect the two hierarchical schemes of the Linnaean classification of species and the Great Chain of Being. He arranged his specimens by order, genera, and species in an attempt to gain credibility in the scientific community. In contrast to Peale's collection, the specimens at the Center for Post Natural History fall less comfortably within the Linnaean system and are displayed with more emphasis on the anomalous, almost curious, nature of each object. The specimens and dioramas embedded in the walls at the Center for PostNatural History each tell the story 
of how a particular process of manipulation has rendered a specimen unique from others within its species.

In addition to the illuminated vitrines that contain taxidermied domesticated chickens, preserved lab rats, samples of silk extracted from goats' milk, and the skulls of purebred dogs, there are also dioramas and specimens displayed in glass-fronted alcoves recessed into deeply stained wooden walls, and genetically modified plants that have been pressed and mounted in black oval frames evocative of Victorian mourning souvenirs. These allusions to Victorian display practices appear somewhat anachronistic given the nature of the material being displayed; yet they also highlight the fetishistic quality of the collection. As with the atomic rodents that Pell focused on from the Smithsonian collection, each of the objects in the collection of the Center for PostNatural History was originally a scientific specimen and was not conceived of as an object of visual interest. However, it is their recontextualization through the museum that has enabled them to become the focus of both an aesthetic and an intellectual gaze, and a preserved, genetically modified organism can become conceivable as a work of art.

\subsection{The Bioreactor as Vitrine}

As has been previously discussed, projects carried out by Tissue Culture and Art Project are characterized by the presence of lab-grown biological entities, which means the bioreactor is a correspondingly ubiquitous element. I suggest that the bioreactor serves a similar function to the vitrine in that it separates the contained object from the viewer, and also defines the contained objects as being of a certain class - the semi-living. However, contrary to the disciplinary function that the vitrine exercises over the viewer's gaze, the bioreactor also serves the benevolent purpose of maintaining the tissue cultures in a quasi-living state.

Catts and Zurr routinely position their work within the histories of medicine, art, and public spectacle. One example of an early approach to medical technology that informs their work is the history of neo-natal incubators on public display, a story that 
interweaves science, medicine and spectacle, and that also underlines the ethics of care that is an ongoing concern in Tissue Culture \& Art Project's practice. One of the earliest examples of the use of mechanical incubators to keep premature infants alive took place in the sideshows of Coney Island, but had its roots in the Berlin Exhibition. ${ }^{66}$

At the 1896 Berlin Exhibition, Dr. Martin Couney mounted a display of pre-term infants in specially designed incubators that had been based on those previously used to hatch chickens. Couney had been given premature infants that were not expected to live, thus absolving him from responsibility in the event of any deaths. He had called his Berlin exhibit the Kinderbrutanstalt, or "child hatchery," effectively transforming what may have originally been conceived as a scientific endeavor into a public spectacle. Following a successful display in which many of the children were kept alive, Couney was invited to present a similar exhibition at Luna Park on Coney Island. Couney's display of incubators opened in 1903 and ran until 1943, when Cornell University's New York Hospital opened the city's first neonatal ward. At Luna Park, visitors were charged to view the infants through glass, and observe the feedings, which were often administered through the nose. The exhibition was extremely popular, allowing Couney to care for the infants at no cost to the predominantly poor parents.

Scott Webel argues that these incubators presented an early form of technoscience that blurred the line between public and private spheres, created a cyborgian synthesis between animals and machines, and embodied an aesthetics of display and surveillance. ${ }^{67}$ Of particular interest within the context of this thesis are Webel's arguments surrounding the incubator as a cyborgian extension of the body, and the idea of surveillance of the

\footnotetext{
${ }^{66}$ For further and more extensive discussion of how Catts and Zurr view the public display of neonatal infants in Coney Island sideshows as having impacted notions of the extended body and their own work, see Catts' lecture, "Growing Neolifism," given at The Sanctuary for Independent Media, Troy New York, March 19, 2014, https://www.youtube.com/watch?v=-9nu74yYQ34, (Accessed August 30, 2015); Partial Life, ed. Oron Catts and Ionat Zurr (Open Humanities Press) http://livingbooksaboutlife.org/pdfs/bookarchive/Partiallife.pdf, (Accessed August 30, 2015), and the introduction to Ionat Zurr's doctoral thesis, "Growing Semi-Living Art," (PhD diss., The University of Western Australia, 2008).

${ }^{67}$ Scott Webel, “Kinderbrutanstalt: Leisure Space and the Coney Island Baby Incubators," Text, Practice, Performance V (2003), 3.
} 
neonatal body. Webel informs us that Couney's exhibition was contextualized within images of animal husbandry, and installed in a recreation of a traditional German farmhouse topped with a plaster stork tending to its own young. Consequently, the exhibition relied on a set of images that betrayed the chicken-rearing origins that gave rise to the technology behind the infant incubators: "As a technology of animal husbandry was brought to bear on the human infant, it set off a secret resonance between species. Taken together, the incubator and the baby formed an egg - inanimate matter housing premature life. As spatial technology, incubators performed a mechanization of life-forms that blurred species boundaries." ${ }^{68}$ As Webel further elaborates, Couney's choice of a title that translated to "child hatchery" or "child hatching mechanism" for the Berlin exhibition, in addition to the combined imagery of incubated babies and farming, created a narrative that wove together the relationship between human babies, feathered animals, and machines.

Although it is well documented that the incubators on Coney Island saved the lives of thousands of children, they also existed for the cross purposes of medicine and entertainment in equal measures. Vertical glass viewing panels were installed to replace the original horizontal panels with the express purpose of enabling more efficient viewing by the public. The infants, housed in their cyborgian shells, were consciously positioned as the subjects of a public gaze, exhibited alongside the other sideshow freaks. ${ }^{69}$

Catts suggests that one of the reasons that the incubator babies were so popular among viewers was because they existed outside the realm of cultural understanding of human existence, and that consequently the babies became a liminal entity, not quite human, not quite machine. He argues, "that it was so strange to see these babies in technology, these technological bodies maintaining these babies alive that the only place

\footnotetext{
68 Webel, “Kinderbrutanstalt," 11.

69 Some historians of pediatrics have suggested that it was Couney's blatant showmanship and the juxtaposition with the other residents of the sideshow that slowed the acceptance of neonatal incubators by the medical establishment. See Webel, 3.
} 
they could have been relegated to was the freak show." ${ }^{70}$ Despite Dr. Couney's success at saving the lives of numerous premature infants, the infant incubators provide an example of a technology that was slow to be embraced by the medical establishment. Zurr suggests that the reason for this was that technologically maintained beings "in transition towards not just bare life but also scientific and moral classification, have to be articulated initially via aesthetic rather than scientific modes of presentation."71 It was because of Couney's qualities as a showman that the technology captured the public imagination and became socially accepted prior to being medically approved.

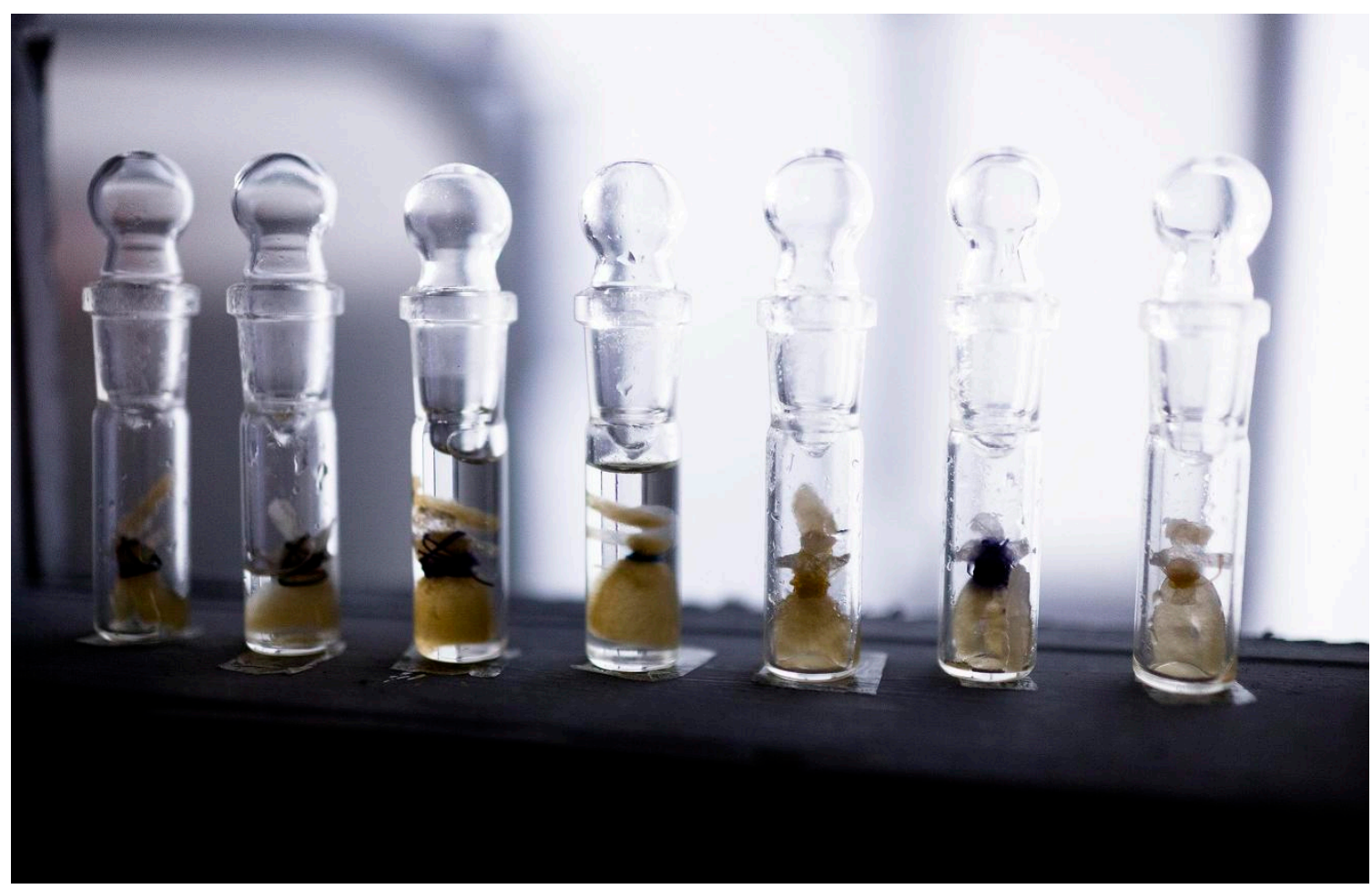

Figure 3.14: Tissue Culture and Art Project, Tissue Culture and (Art)ificial Wombs or Semi-Living Worry Dolls, 2000. Image used with permission from the artists.

Similarly, Tissue Culture and Art Project view their social role as artists, at least in part, as helping to articulate specific advances in the biotechnical sciences in a way

70 Oron Catts, “Growing Neolifism," The Sanctuary for Independent Media, Troy New York, March 19, 2014, https://www.youtube.com/watch?v=-9nu74yYQ34.

71 Ionat Zurr, "Growing Semi-Living Art," (PhD diss., The University of Western Australia, 2008) 
that is thought-provoking and critical. For example, in their work Tissue Culture and Art(ificial) Wombs (2000), sometimes also referred to as Semi-Living Worry Dolls, Tissue Culture and Art Project created a series of tiny figures that served as a visual introduction to the use of tissue engineering for artistic purposes, but also presented a locus onto which people could potentially project their fears about advances in biotechnology. First exhibited at the Ars Electronica Festival 2000, in Linz, Austria, the seven figures echoed the forms of Guatemalan worry dolls, which according to lore are given to children to tell their worries to in the hopes that the dolls will spirit those worries away. The dolls were given alphabetical names to reflect worries and fears about the biotechnical age: Doll A represented the worry of absolute truths and people who think they hold them; Doll B represents the worry of biotechnology; Doll $\mathrm{C}$ represents capitalism and the corporations that drive progress; Doll D stands for demagogy and possible destruction; Doll E represents eugenics and the people who fear they have the right to practice it: Doll $\mathrm{F}$ is the fear of fear itself; $G$ is not a discrete doll, but represents the Genes that are in all seven dolls; and Doll H represents the fear of hope. ${ }^{72}$

The worry dolls were constructed from biodegradable polymers that were seeded with cells from the McCoy cell line. They were cultured in an incubator, and then transferred to a rotating bioreactor that maintained them in microgravity conditions for the duration of the exhibit. Viewers were invited to log on to an affiliated website to leave their worries behind for the dolls. In later remountings of the exhibition, microphones were set up so that viewers could speak directly to the worry dolls and relay their fears. Catts and Zurr initially expected viewers to express worries about biotechnology but were surprised when people approached the dolls from a more personal standpoint, telling them much more private and intimate fears. ${ }^{73}$

\footnotetext{
72 Oron Catts and Ionat Zurr, "Growing Semi-Living Sculptures: The Tissue Culture \&Art Project," Leonardo 35, no. 4 (2002), 368.

73

${ }^{3}$ See interview with Ionat Zurr in conjunction with the exhibit Visceral: The Living Art Experiment, The Science Gallery, Dublin, 2011, https://www.youtube.com/watch?v=cGhyvGJS 3U, accessed September 8, 2015.
} 


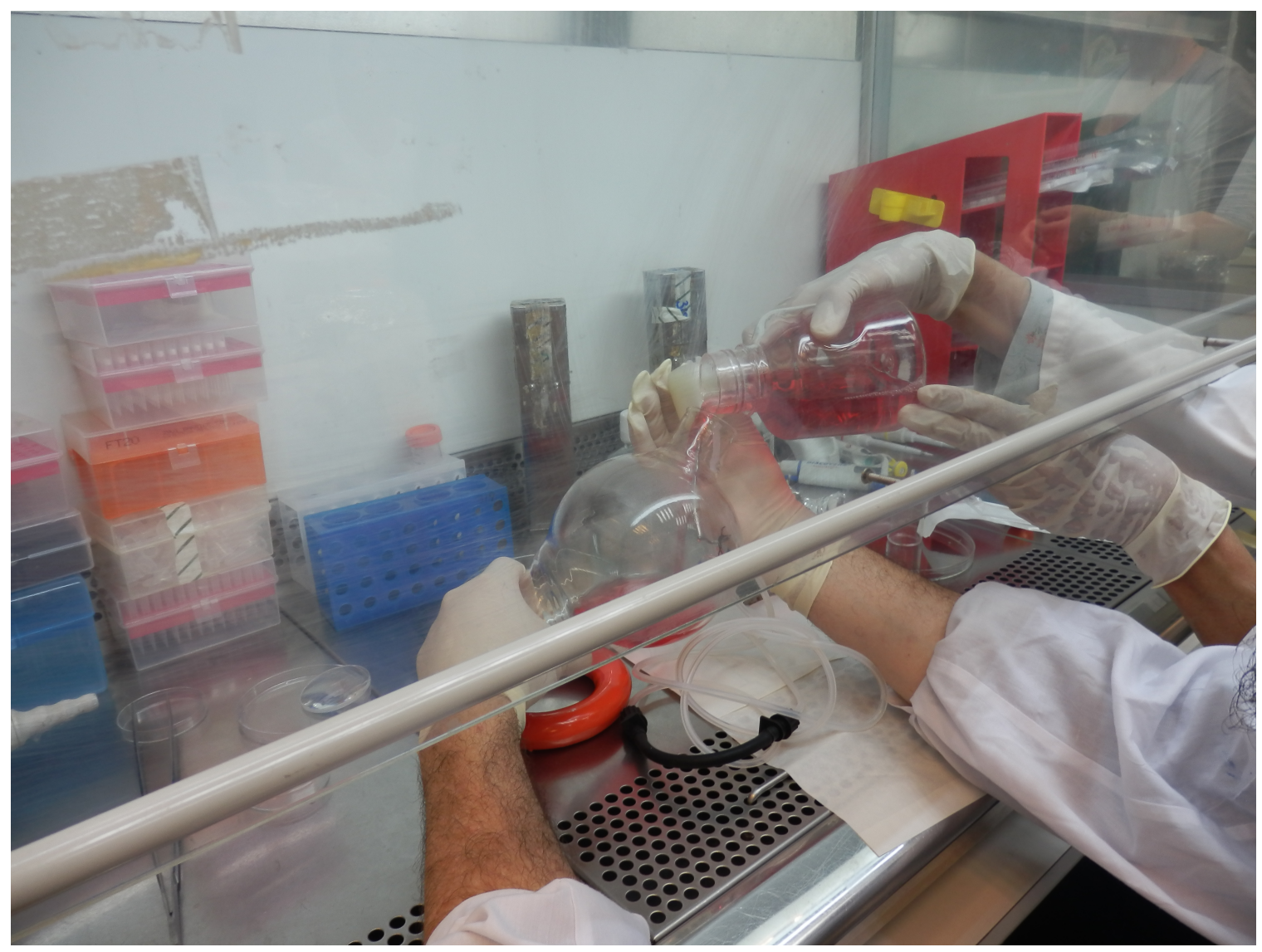

Figure 3.15: Tissue Culture and Art Project, The "feeding ritual." (Tissue cultures are provided with necessary nutrients). Image used with permission from the artists.

The exhibition of Semi-Living Worry Dolls at Ars Electronica was the first example of a tissue cultured work of art being presented in a gallery situation, and as such required an elaborate system of bioreactors to be constructed in the gallery space in order to maintain their existence. In her doctoral dissertation, Zurr writes,

It was the first time we were able to take the Semi-living outside of the laboratory and into the gallery while they were still alive. This meant constructing a fully functioning tissue culture laboratory in the gallery. In installations, TC\&A incorporates the laboratory as part of the installation to present the environment in which semi-living entities can thrive. This also enables us to perform the duties needed to care for the semi-living sculptures while the exhibition is being held, in 
a way that enables the audience to observe and comprehend the commitment and responsibilities that we have towards the living systems we create. ${ }^{74}$

Zurr goes on to elaborate on the level of care required by the semi-livings, including daily "feedings" that consisted of replacing the nutrient solution that maintained the tissue cultures, performed in front of a window for better audience viewing. Here we can observe that, much like Dr. Couney and his incubator-maintained infants, the necessities of care are presented as both ritual and spectacle. It is also clear however, that Catts and Zurr are concerned with the ethics of maintaining these non-sentient semi-living clusters of cells. As with many of Tissue Culture and Art's subsequent projects, the worry dolls could not be maintained indefinitely or brought back to Australia after being exhibited, and as a result were subject to the killing ritual. As Zurr has observed, the act of killing the work of art is not a neutral act. Audience members who have made multiple visits to the exhibition and have confessed their fears to the dolls have found the experience particularly affective. ${ }^{75}$ The killing ritual draws attention to the fragility of life (in both the living and the semi-living) and can be perceived as a compassionate gesture, the "euthanasia of a living being that has no one to care for it." 76 She also observes, "On more than one occasion people from the audience have approached us after the ritual and admitted that initially they did not believe our sculptures were alive until they were killed." 77 This reaction may speak to the disconnect that we form when we view a specimen that has been preserved or otherwise housed behind glass in a museum vitrine, and in this case a bioreactor. Although we may recognize it as something that may be, or may have been, alive, the presence of the vitrine acts as a buffer to our ability to perceive that liveliness. The glass separates the viewer and the object and puts it in a different

\footnotetext{
${ }^{74}$ Zurr, "Growing Semi-Living Art," 66.

${ }^{75}$ Zurr, https://www.youtube.com/watch?v=cGhyvGJS_3U

${ }^{76}$ Zurr, "Growing Semi-Living Art,"126.

${ }^{77}$ Ibid.
} 
ontological class from the living, such that even a cluster of living cells might be perceived as an object.

\subsection{Conclusion}

The works of art discussed here illuminate our perceptions of how certain scientific practices shift over time by drawing our attention to several key ideas, particularly those surrounding the means by which specimens were acquired for museums during the nineteenth century, the conflation of science with spectacle in both the museum and the sideshow, and the degree to which a museum specimen is a crafted object that is as much a function of cultural production as it is derived from nature. These ideas are further highlighted by the appropriation of methods of display drawn from the museum. The museum vitrine provides a means of protection against both the viewer and the environment, thus preserving and extending the life - or afterlife - of the enclosed objects. This function is closely paralleled to that of the bioreactor used in the sciences, and more specifically within the context of my argument, in bioart. Both the vitrine and the bioreactor imply a duty of care. When positioned as objects of knowledge housed behind glass, specimens - be they derived from natural history collections, biotechnology, or otherwise - carry the expectation of scientific neutrality and objectivity. Alberti points out, however, that although museum displays are portrayed as neutral and objective, they are cultural constructs that "are not and never have been representations of incontestable facts." ${ }^{, 78}$ Despite the expectation of scientific neutrality that we assume in science and natural history museums, such experiences are always mediated. Although those who are, or who have been, employed in the crafting of such specimens may have had aspirations of achieving scientific objectivity, artists who reference this category of objects have no such obligations. When viewed within the context of museums, these objects have become naturalized, that is to say they are no

\footnotetext{
78 Samuel J.M.M. Alberti, “Constructing Nature Behind Glass,” Museum and Society 6, no. 2 (Jul. 2008), 79 .
} 
longer "strange,",79 and as museum visitors, one doesn't necessarily question them as anything beyond preserved animals meant to stand in for all others of their species. It is through acts of recontextualization that artists are able to represent museum objects, allowing the viewer to appreciate them for qualities beyond being objects of scientific knowledge. Because these objects have been made "strange" again, viewers are forced to question their own existing assumptions about what constitutes nature, and how methods of display can influence such preconceptions.

79 Alberti, “Constructing Nature," 83. See also, Elizabeth Stephens, "Making Monsters: Bio-Engineering and Visual Arts Practice," Corporeality and Culture: Bodies in Movement, ed. Karin Sellberg, Lena Wånggren, and Kamillea Aghtan (Farnham, Surrey: Ashgate, 2015), 53-66, for further discussion of the object made strange and its connection to wonder in the context of "monsters" as created through bioengineering and visual art practice. 


\section{Chapter 4}

\section{Mutations and Hybrids}

\subsection{Making Sense of Monsters}

From ancient tales of Chimaeras to medieval illustrated bestiaries, and from wonder-inspiring creatures that inhabited early cabinets of curiosity to more current concerns that result from recombinant genetic techniques, there has been an enduring fascination in monstrous creatures that are deformed, anomalous, or somehow defy classification. Following on the deciphering of the genetic code, recent scientific advances such as the cataloguing of the genomes of both human and non-human organisms have led to the perception of DNA as readable and mutable text that can not only be altered as we see fit, but can be combined with that of other life forms to create novel organisms. Correspondingly, the ubiquity of biotechnology in contemporary culture has had ramifications in both the sciences and in visual culture. Following on this newfound ability to alter and create life forms, there is a need to reexamine how we perceive the resulting organisms. Working across materials and techniques ranging from taxidermy to genetic manipulation and primary biological research, there are a number of artists whose work reflects such concerns and preoccupations with mutations and hybrid organisms in various forms. With an increasing sense of the flux and malleability intrinsic to life forms, a number of artists have begun not merely creating work that references biotechnology, but collaborating with scientists and working with the actual technologies associated with genetic engineering. In 1905, H. G. Wells showed great prescience when he wrote, "We overlook only too often the fact that a living being may also be regarded as raw material, as something plastic, something that may be shaped and altered." 1 The notion of the mutability of life has become commonplace, as a growing number of contemporary artists currently work with living material, treating it as a mutable, sculptural and expressive medium. Although contemporary artists have

\footnotetext{
${ }^{1}$ H. G. Wells, "The Limits of Individual Plasticity," H. G. Wells: Early Writings in Science and Science Fiction, ed. R. M. Philmus and D. Y. Hughes (Berkley: University of California Press, 1975), 36-39.
} 
appropriated the techniques and methodologies of the biological sciences to generate new forms of hybrid artwork, much of this work can also be traced back to such historical notions as the Chimaera as well to mermaids and basilisks that were created in the sixteenth and seventeenth centuries and marketed to collectors of curiosities.

The image of the Chimaera, a monstrous beast comprised of elements from a number of other animals, has existed in many cultures throughout history. Subject to various shifts in meaning, it has manifested across a wide spectrum of disciplines, from the visual arts and literature to the sciences. In the $8^{\text {th }}$ century BC, Hesiod described the Chimaera, "who breathed raging fire, a creature fearful, great, swift-footed and strong, who had three heads, one of a grim-eyed lion; in her hinderpart, a dragon; and in her middle, a goat, breathing forth a fearful blast of blazing fire."2 As humankind has gained more knowledge of and control over the natural world, chimeric creatures are no longer the result of fictional imaginings or the constructed offerings of skilled ancient taxidermists; they have become emblematic of advances in contemporary science. In genetics, for example, a chimera refers to a single animal organism with genetically distinct populations of cells from two different zygotes. The term chimera also refers to a virus containing genetic material from other organisms, or to a hybrid protein made by splicing two genes. The combining of the genetic material from one organism with that of another in the hopes of creating something new and beneficial has become part of our collective consciousness.

Here, I will examine how the notion of combinatory organisms has been taken up in the practices of artists working with biological material in various forms, including sculptors working in taxidermy, bio-artists working with living cells and tissues, and artists pushing the boundaries between human and non-human through the altering of their own bodies. Artists working in taxidermy use animal skins that, although no longer a part of a living organism, can still be considered biological material. This material has been taken up as an expressive medium that can be used to create combinatory creatures

\footnotetext{
${ }^{2}$ The Theogeny of Hesiod, ii 319, trans. Hugh G. Evelyn-White, 1914, http://www.sacredtexts.com/cla/hesiod/theogony.htm
} 
that reference similar social issues to those artists working with specimens on a genetic level. Likewise, there are many examples of bio-artists who are treating DNA as interpretable and mutable code by combing genetic fragments of more than one species. Although much of this work addresses contemporary concerns such as genetic engineering, tissue culturing, and regenerative medicine, it also can be paralleled to the practices surrounding the creation of a particular genre of specimen that was popular in sixteenth and seventeenth century cabinets of curiosity.

Monsters, mutations, and anomalies have been a subject of human fascination for centuries. The images of monsters populated illustrated bestiaries during the Renaissance and were later recreated by the merchants and apothecaries who exploited the public interest in nature's aberrations in order to create a market for dried curious specimens. ${ }^{3}$ Rachel Poliquin argues that this trade in the curious resulted in a particular class of historical objects that can be understood through attention to both their "palpable materiality and poetic imagination." ${ }^{4}$ Such objects consist of either disembodied fragments of animal specimens or whole specimens crafted from fragments. She argues that these objects collected during the sixteenth and seventeenth centuries for inclusion in cabinets of curiosity created an enhanced sense of wonder that was the result of particular qualities. Because many of these specimens took the form of fragments, they demanded an intellectual completion on the part of the viewer and that this was how they created a sense of wonder. Citing Greenblatt's description of wonder as "the power of the displayed object to stop the viewer in his or her tracks, to convey an arresting sense of

\footnotetext{
${ }^{3}$ See Paula Findlen, "Inventing Nature: Commerce, Art, and Science in Early Modern Cabinets of Curiosities," Merchants and Marvels: Commerce, Science, and Art in Early Modern Europe, ed. Pamela H. Smith, and Paula Findlen. (New York and London: Routledge, 2002), 297-322, for a discussion of how the interest in curiosities - monsters in particular - created a thriving commerce in fraudulent basilisks, hydras, and dragons.

4

4 Rachel Poliquin, "Botched Animals and Enigmatic Beasts," Curious Collectors, Collected Curiosities: An Interdisciplinary Study, ed. Janelle A. Schwartz and Nhora Lucia Serrano (Newcastle Upon Tyne: Cambridge Scholars Publishing, 2010), 41.
} 
uniqueness, to invoke an exalted attention," result of "enchanted looking" but demands that the act of looking be grounded in the realness of the object. Wonder, she maintains, is the result of a combination of realness and otherworldliness that "hovers between material proof and imaginative possibility."6 The meaning in these objects is derived through a combination of the object's incomplete materiality and the elements invented by a viewer who fills in the missing information to create a complete interpretable whole.

Prior to the advent of reliable methods of preservation, early collections existed under constant threat of decay, with the skins and soft parts of specimens being particularly vulnerable. Because of this, the parts or fragments of animals that were less prone to decay, such as claws, teeth, bones, and horns, were collected more frequently than whole preserved bodies. Sometimes such a fragment or a dried skin was all that could be brought back to Europe and consequently was all that the collector had to go on when attempting to reconstruct an accurate representation of the original whole specimen. Drawing on the notions of similitude between organisms that characterized natural philosophy at the time, collectors extrapolated from this knowledge to imagine what the specimen might have looked like. Without having seen the original animal and with only the skin for example to go on, attempts to create an accurate representation of an animal resulted in the creation of imaginative representations. ${ }^{7}$ It is precisely this type of imaginative leap that Poliquin argues gave early modern specimens their power.

\footnotetext{
5 See Stephen Greenblatt, "Resonance and Wonder," in Exhibition Cultures: the Poetics and Politics of Museum Display, ed. Ivan Karp and Steven D. Lavine (Washington, Smithsonian Institution Press, 1991) 42, cited in Poliquin, "Botched Animals," 41.

6 Poliquin, "Botched Animals," 41.

7 See Poliquin, "Botched Animals," 44, and also Karen Wonders, Habitat Dioramas: Illusions of Wilderness in Museums of Natural History (Uppsala: Acta Universitatis Upsaliensis, 1993), 25: "Without having seen the living animal, it was just as difficult to create a life-like mount as it was to represent the animal in a pictorial image. Progress towards naturalistic representation in mounted animals must therefore be considered both in regard to the technical problems of preservation and in regard to the process of visualization by which the animal form was discovered in art."
} 
Poliquin contrasts her analysis of early modern collecting and exhibiting practices with a description of the high level of skill that characterizes much of contemporary taxidermy. She suggests that it is the perfectly executed taxidermy in certain works of contemporary art that is responsible for a sense of wonder, whereas during the $17^{\text {th }}$ century, an equivalent sense of wonder would have been achieved even through less perfect preservation techniques. Such poorly constructed taxidermy would have resulted in objects that required similar poetic imagination, "While always offering the anticipation of knowledge, some objects prove too opaque to decipher without a little reverie." 8 Although she does not refer to him, Poliquin seems to owe much to Derrida's suggestion that the analysis of certain types of animals requires "poetic thinking." In a discussion of the animals that appear to be one thing but are in fact something else specifically the hedgehogs and flamingos that serve as croquet mallets and balls in Alice's Adventures in Wonderland, Derrida writes, "For thinking concerning the animal, if there is such a thing, derives from poetry. There you have a hypothesis: it is what philosophy has, essentially, had to deprive itself of. That is the difference between philosophical knowledge and poetic thinking." ${ }^{9}$ Similarly, the works of contemporary art that I discuss here, all of which involve the combination of different organisms, result in objects that defy any notion of standardized classification as we have some to know it. I will break my discussion of combinatory organisms into three categories: taxidermic hybrids that combine the skins of more than one type of animal or combine an animal skin with another material; bioart's use of recombinant life forms combined at the molecular level; and human/non-human hybrids in which material from one is inserted into the other. In discussing these combinatory organisms, I would add to the positions outlined by Poliquin and Derrida that the viewer is denied the opportunity to make the imaginative leap that comes from "filling in the gaps" because the artists have already filled in those gaps. As a result we are denied the opportunity to experience reverie, and instead experience discomfort. Such monstrous combinations almost defy our

\footnotetext{
8 Poliquin, "Botched Animals," 44.

9 Jacques Derrida, "The Animal That Therefore I Am (More To Follow)," Critical Inquiry 28, No. 2 (Winter 2002), 377.
} 
imaginations and force us to engage in acts of "reverie" that border on nightmare. Perhaps it is only through the combination of scientific knowledge with poetic imagination that we might reconcile what we see with what we know.

\subsection{Taxidermic Hybrid Constructions}

It has become something of a convention in contemporary artistic taxidermy that the skins of animals need not be used exclusively in the creation of mimetic representations of the original animal, but may also be used as a sculptural and expressive material. As in any other form of mixed media sculpture, the skin of an animal may be used in combination with other materials or with the skins of other species. The majority of this work resonates not only with the ideas of early modern science but also the genetic manipulation now common in contemporary scientific research. It must be acknowledged that there are some artists working in taxidermy whose sculptures are more evocative of a twisted game of exquisite corpse, played out with real corpses. ${ }^{10}$ In general, however, any discussion of taxidermic practices that involves either the alteration of one species or the creation of a new creature through the combination of more than one type of animal skin necessitates contextualization within a greater historic discourse that includes the crafting of fraudulent specimens for the curiosity trade, as well as recombinant technology.

According to Harriet Ritvo, much of the interest in aberrations, freaks, and malformations focused on those things that were curious, but still fit into an ordered conception of the cosmos - those things that "pushed the limits of the natural without threatening to overturn them." ${ }^{11}$ On the other hand there were certain fabled creatures that didn't fit into any sort of order, things that required "not mere modification of

\footnotetext{
${ }^{10}$ Artist Enrique Gomez de Molina creates assemblages from the parts of many different animals, seemingly selected for their beauty: turtle shells, iridescent exotic birds, and small animals with particularly well-marked furs. Although beautiful, these works are controversial in a way that much of the contemporary taxidermy movement is not. Unlike many of his contemporaries, Gomez de Molina does not engage with ethical sourcing of animal skins, and was recently convicted and served prison time for illegal trafficking in endangered and protected species. See "Miami Taxidermist Sentenced for Wildlife Smuggling," http://www.justice.gov/opa/pr/miami-taxidermist-sentenced-wildlife-smuggling 11

Harriet Ritvo, The Platypus and the Mermaid and Other Figments of the Classifying Imagination (Cambridge, Massachusetts: Harvard University Press, 1997), 175.
} 
previously recognized laws but wholesale rewriting."12 These were the types of creatures that Poliquin describes as demanding a more poetic and imaginative approach to their reading. They could not be classified and their existence could not be proven; yet they continued to haunt human consciousness. Ritvo addresses several creatures that existed in the imaginative consciousness during the eighteenth and nineteenth centuries, including the unicorn, the sea serpent, and most significant for this discussion, the mermaid. They were all characterized by a skeptical yet enduring belief in their existence despite the fact that there was no proven physical evidence. This persistence in spite of a lack of physical evidence betrayed not merely a willingness to believe but an ardent desire. It was this desire to believe in creatures that required an extension of imaginative reasoning that helped to create an atmosphere that supported a trade in constructed mermaids.

Invariably, naturalists consulted for their expertise in the matter proved that the mermaids were composed of a combination of simian and fish parts, although this did not dissuade people from viewing such specimens when placed on exhibit. Similarly, there continued to be naturalists who sought explanations, continuing to believe that mermaids might possibly exist. ${ }^{13}$ As Ritvo explains, these creatures that defied classification, "offered a blank text upon which people could inscribe their own beliefs about the organization of the animal kingdom, or, to look at it from a different angle, their reluctance to accept the structures imposed by self-constituted expertise."14

Dubious creatures constructed from the skins of multiple animals are the subjects of the ongoing series of sculptures, Misfits, by German artist Thomas Grünfeld. ${ }^{15}$ He uses

\footnotetext{
12 Ritvo, The Platypus and the Mermaid, 175.

13 See Ritvo as above, pages 181-182, for anecdotes of several naturalists who remained open-minded on the possible existence of mermaids, including William MacLeay and William Swainson who found space in their elaborate system of taxonomic categories "for an as-yet-unknown amphibious primate which might, as MacLeay suggested in 1829, 'explain why there is such a general feeling among mankind of all ages, in favour of the existence of mermaids and may indeed render the past or present existence of amphibious primates probable."”

14 Ritvo, The Platypus and the Mermaid, 186.

15 Some examples Thomas Grünfeld's Misfits can be viewed at http://www.ravishingbeasts.com/fraudulent-animals/2008/10/21/grunfelds-misfits.html
} 
taxidermy to combine elements of two different species, creating new hybrid animals that seem both as evidently fraudulent yet eerily conceivable to contemporary eyes as early mermaids must have looked to early men of science. Unlike many depictions of early mermaid constructions that had a menacing air, Grünfeld's constructions appear rather benign. They do however hint at contemporary genetic practices that have more ominous implications. A lamb has the head of a penguin, delicate bat-wings unfurl from the back of a small fawn, the head and back of a peacock morph into the body of a kangaroo, an ostrich's body in one sculpture supports the head of a cow, and in another it has the head, neck and legs of a giraffe. Grünfeld's new animals also allude to Wolpertinger, the improbable creatures with human attributes that populate the popular Bavarian storytelling tradition of moralistic folk tales. Taxidermic representations of these Wolpertinger could once be found in cabinets of curiosity in southern Germany, and can today still be found in Bavarian museums of folk history. ${ }^{16}$ In referring to Wunderkammern, Grünfeld's work evokes an earlier period of scientific classification and taxonomy, when a different type of code described the order and structure of nature. Although, Grünfeld's work is decidedly rooted in historical tradition, it nevertheless makes clear reference to genetic engineering.

Deborah Sengl also engages in an art practice characterized by the use of hybrid taxidermy that addresses notions of both genetic chimerism and evolution. By creating a series of sculptures in which she stretches the skin of one animal over the corporeal form of its natural predator, Sengl's sculptures examine the use of camouflage or mimicry as a means of survival in predatory creatures. The sculpture The Lioness - As PredatorDisenguises Her Desired Prey (2004) portrays the skin of a zebra seamlessly stretched over the body of a lion. The Wolf - As Predator - Disenguises Her Desired Prey (2003) is a literal embodiment of the wolf in sheep's clothing. With these works, Sengl creates animals that appear equally benign and menacing, simultaneously predator and prey. By

\footnotetext{
16 Jessica Ullrich, "Taxidermic Hybrid Animals in Contemporary Art”, Henry Moore Institute: Online Papers and Proceedings, http://www.henry-moore.org/hmi-journal/homepage/view-by-conference/againstnature/taxidermic-hybrid-animals-in-contemporary-art/page-1
} 
assimilating characteristics of two separate and adversarial animals, these hybrid beasts manifest a highly evolved vision of an exceptionally fortuitous genetic mutation.

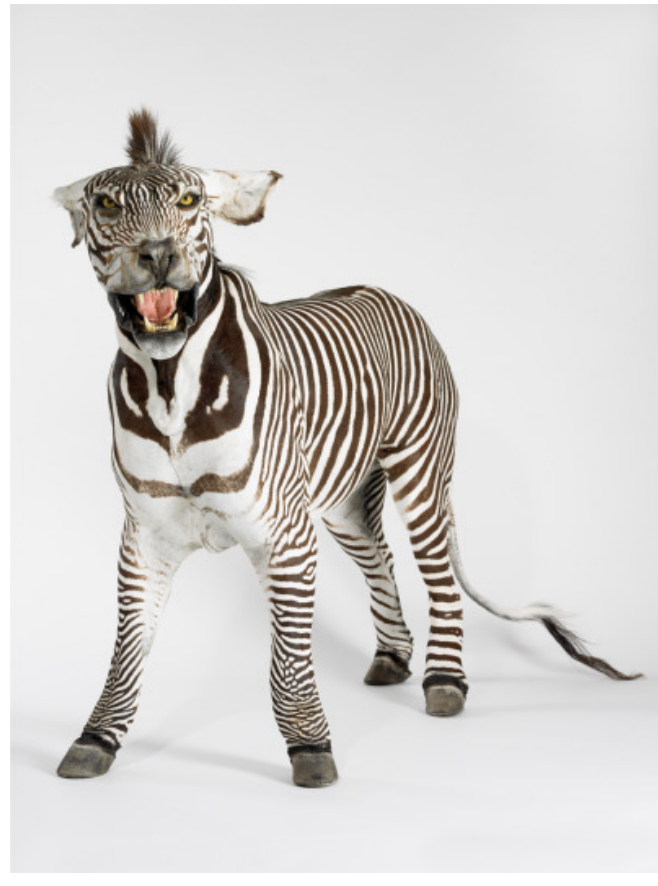

Figure 4.1: Deborah Sengl: The Lioness - As Predator - Disenguises Her Desired Prey (2004). Image used with permission from the artist.
Although similarly well crafted, the work of Thomas Grünfeld appears explicitly artificial when compared to that of Sengl. The seams between one animal and another are demarcated sharply, with little softening to indicate anything other than a collaging together of multiple animals. Although the success of Sengl's work, by contrast, relies on a high level of craftsmanship for its believability, in both cases it is the ability of the artist to look at a skin and envision another creature entirely that creates the impact that Poliquin describes. This skill of looking at one creature and imaging how it might be transformed into something more enigmatic was not lost on early modern naturalists. The trade in curiosities at that time included dried basilisk and dragon specimens that had been crafted from the bodies of rays or lizards. In his 1558 treatise History of Animals, Conrad Gessner described how such acts of fakery were created: "They bend the body, distort the head and mouth, and cut away other parts. They raise up the parts that remain and simulate wings, and invent other parts at will." ${ }^{17}$ As Findlen tells us, "Understanding the possibilities of the ray as a dragon in potential was the first step in appreciating the art of the dragon." ${ }^{, 18}$ Many artists working in taxidermy are able to see the expressive potential in the skins that they use, drawing on a tradition of fakery that is centuries old.

\footnotetext{
${ }^{17}$ Conrad Gessner quoted in Findlen "Inventing Nature," 310.

18 Ibid.
} 


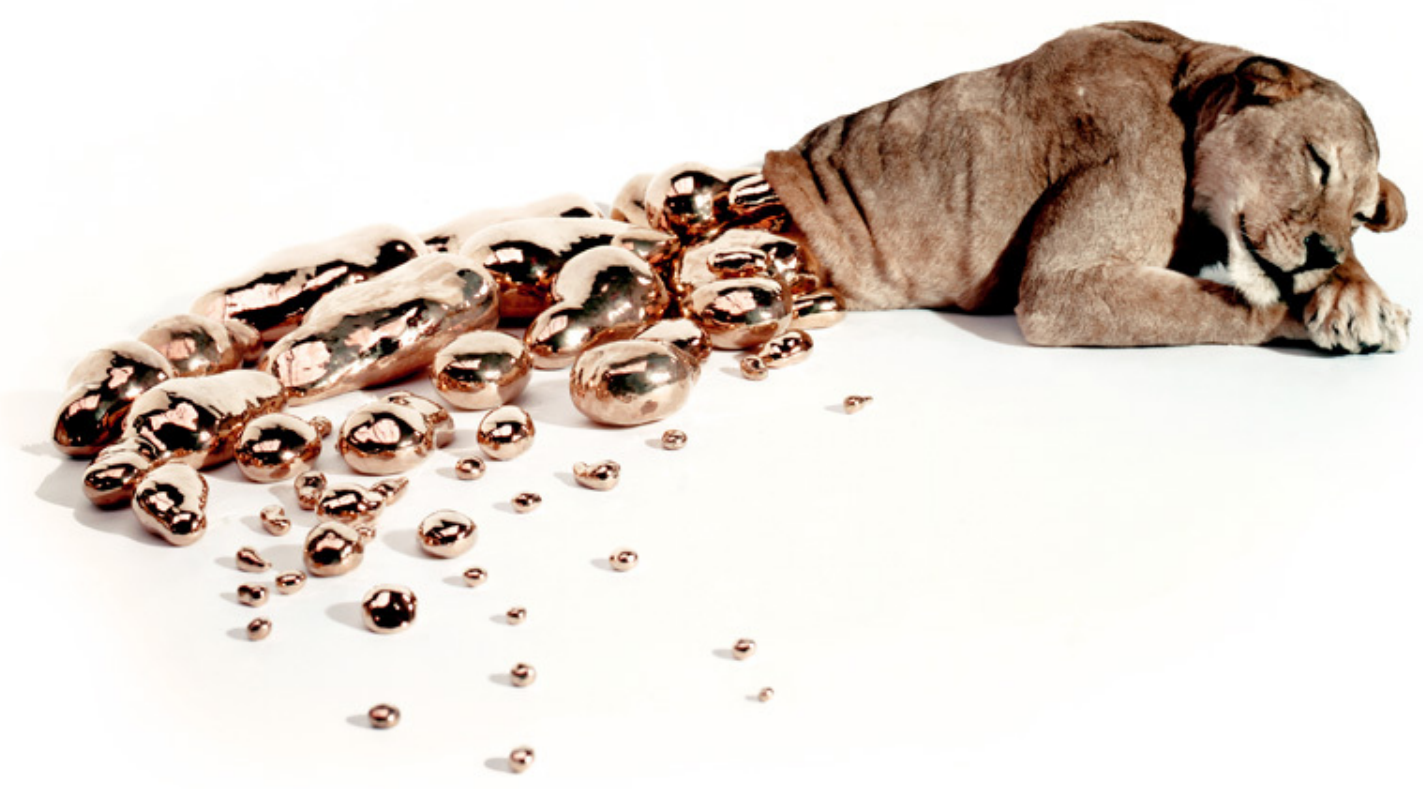

Figure 4.2: Idiots, Ophelia, 2005. Image used with permission from the artists.

The transformative power of the artist to take one animal and make it into something new with a high potential to create affect in the viewer is evident in the work of the Dutch artists known as Idiots. Formerly known as This Work Must Be Designed By Idiots, the duo consists of Afke Golsteijn and Floris Bakker. Poliquin argues that it is the mimetic perfection of Idiots' flawlessly skillful taxidermic techniques that stimulates the poetic imagination of the viewer. I would suggest, however, that it is not merely the mimetic exactitude that brings about this leap in imaginative response, but also the craftedness of the work. Although the work looks exceptionally "real" or so "lifelike" in most of the works made by Idiots, that quality is betrayed by the obvious intervention of the human hand as skin seamlessly dissolves into other materials such as gold, amethyst, fabric or beadwork. In the work Ophelia (2005), which can be construed as a sort of diptych when paired with Geologische Vondst II (2012), the front half of a sleeping lioness appears to dissolve into a pool of golden globules. The hindquarters of the lioness is separated from the front half of its body and appears to have been carved away in 
broad slices, yet these slices reveal neither the viscera of its former existence, nor the materials that betray its construction through the act of taxidermy; rather it reveals crystalline cross sections of luminous amethyst.

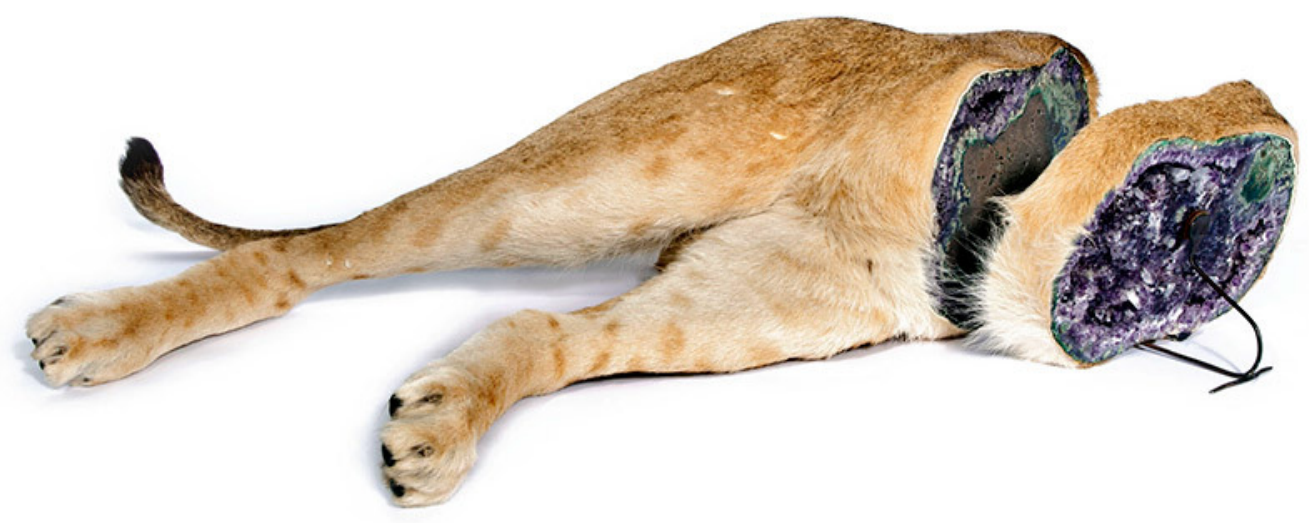

Figure 4.3: Idiots, Geologische Vondst II, 2012. Image used with permission from the artists.

Another work, This Seat is Taken (2007), consists of a taxidermic peacock perched on the arm of an embroidered antique chair. The peacock's tail elides into a mass of black tulle and green fabric that has been richly embellished with glittering beadwork. The feathers of the peacock give way to handcrafted embroidery as ostentatious as the tail feathers that it has largely replaced. These interventions with the bodies of animals create something that is both natural and conspicuously artificial, akin to constructed mermaids, basilisks and dragons, as well as to the mirabilia that were collected at the same time. 


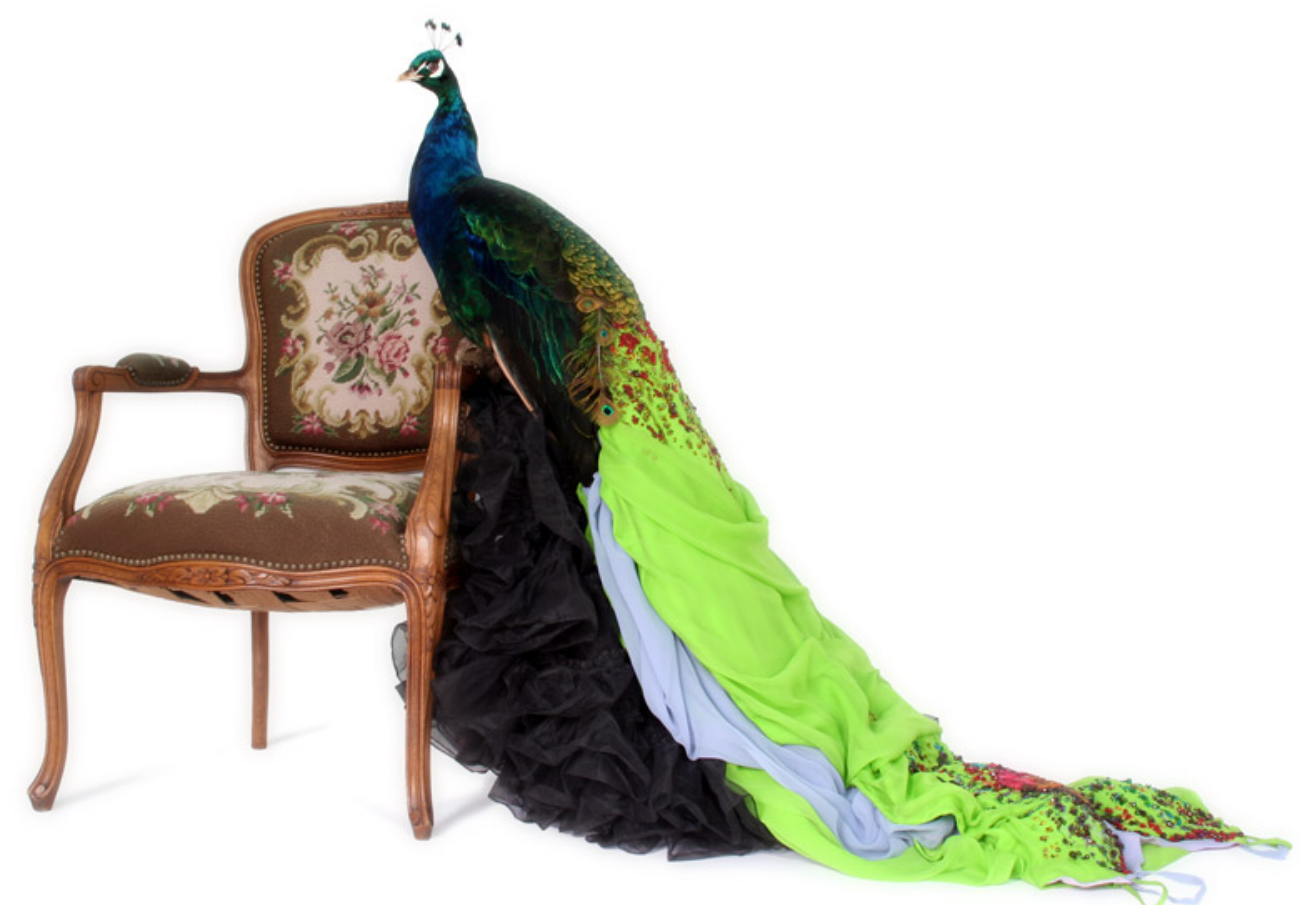

Figure 4.4: Idiots, This Seat is Taken, 2007. Image used with permission from the artists.

The desire to take something already spectacular in its natural form and embellish it even further owes much to the decorative impulses that characterized objects housed in early modern collections, where all forms of artificialia (art), naturalia (nature), and mirabilia (wonders) were exhibited alongside one another. If each item could dazzle and inspire wonder in the viewer individually, then the effect would be even more breathtaking when viewed collectively. The examples of naturalia held within these collections were already exquisite in and of themselves: amethyst crystals, the baroque curves and volutes embodied by nautilus shells, gigantic emeralds, birds of paradise, unicorn horns (narwhal tusks), gryphon claws and eggs (bison horns and ostrich eggs). When these marvelous natural specimens were fused with the craftsmanship of skilled artisans, the objects became more wondrous still, blurring the boundaries between the wonders of art and the wonders of nature. Describing the Baroque impulse towards extravagance and glorified superfluity, Lorraine Daston and Katherine Park write, 
In the case of naturalia, the spiral of virtuosity had already begun before the artisan even touched the object. Naked and natural, the nautilus shell or rhinoceros horn were already marvels, rare and finely wrought. Nature's admirable workmanship was a gauntlet thrown down to the human artisan, who enriched the delicate, pearly shell of the nautilus with still more delicate carvings, burnished its luster with gold, outdid its rarity by adding fabulous figures of dragons, sea serpents, and satyrs, and finally threw in a branch of coral for good measure. Lest the point of the competition between nature and art be lost on spectators, cabinets often displayed ornamented and plain naturalia side by side. In these hybrids art and nature competed rather than collaborated with one another, but in both cases nature tended to merge with art - or rather with artisan. ${ }^{19}$

The specimens crafted by artists wherein an object is extracted from nature and altered through embellishment or is otherwise manipulated through less visible means, through genetic manipulation for example, can be thought of as the mirabilia, the gilded coral or carved nautilus, of our age. They are the wondrous, yet somewhat discomforting, objects that result from human intervention in nature: nature embellished by the human hand. In the case of taxidermy, it is a sensation that would not be possible without virtuosic craftsmanship. $^{20}$

\footnotetext{
${ }^{19}$ Lorraine Daston and Katharine Park, Wonders and the Order of Nature 1150-1750 (New York: Zone Books, 1998), 281. has observed, the current popularity of taxidermy has led to a situation wherein, "The mounting of animals has been popularized to a degree that it has almost become the new knitting. One can take classes to prepare a mouse, rat, or pigeon and - in the tradition of amateurs or the popular taxidermist Walter Potter (1835-1918) - decorate these bodies with beads or lace." Such an increase in popularity has resulted in scores of examples of what Steve Baker would refer to as "Botched Taxidermy." See Petra Lange-Berndt, "A Parasitic Craft: Taxidermy in the Art of Tessa Farmer," The Journal of Modern Craft 7, no. 3 (2014): 267-84.
} 


\subsection{Bioart and the Recombinant Life Form}

In contrast to artists working with taxidermy to create combinatory creatures out of animal skins, there is a new wave of artists harnessing biotechnology, tissue cultures, and regenerative medicine to create new visions of what can constitute a work of art. If artists combining animal skins with other materials can be said to be creating contemporary mirabilia, the same can be said of artists integrating cells and bacteria with bioreactors and other structures in their art practice. Artists who create taxidermic hybrids can be said to reference recombinant technology by varying degrees, but artists working on a molecular level are actively engaged with it.

Netherlands-based artist Paul Perry is one such artist whose work integrates biotechnology with more traditional sculptural forms. In his work Good and Evil on the Long Voyage (1997) Perry fused one of his own white blood cells (lymphocytes) with a cancer cell (myeloma) from a mouse, creating a new cell called a hybridoma. ${ }^{21}$ For the exhibition of the work, the hybridoma was kept alive in a bioreactor placed in an aluminum canoe raised several meters above the ground by scaffolding. The bioreactor could only be viewed in the reflection of a mirror suspended above the canoe. In Good and Evil, Perry explores his interest in the varied discussions surrounding immortality and the possibility of radical life extension. The white blood cell that is normally associated with the "good" illness-fighting qualities of the immune system is conjoined with the "evil" cancer cell in a journey that has the potential to create an eternal replication of the artist's cells. The hybridoma that he created is, in principle, immortal, due to the perpetually replicating cancerous nature of the mouse cell. As long as the culture is kept in a bioreactor, some of his genetic material has the potential to continue living and dividing forever.

Perry describes the metaphorical relationship between conceptual art and biology in terms of genotype (the genetic make-up of an organism) and phenotype (the

\footnotetext{
21 Good and Evil on the Long Voyage was created in collaboration with Dr. Frans Ramaekers and Mr. Wiel Debie from the Department of Molecular Cell Biology and Genetics at the University of Maastricht. It was included in the exhibition Preservations at Bonnefanten Museum Maastricht in 1997.
} 
characteristics of an organism determined by both genetic and environmental factors). He writes,

A cell or organism's genetic constitution or genotype is much more concrete than an image in the imagination, as the genes can be read, measured and rerecorded precisely. In some ways, however, genotype and art concept are similar: Both depend on the corresponding phenotype or genetic expression to get passed on to the next generation. The phenotype is the expression of the genes and art concept made physical in the world as body, entity, or artwork. ${ }^{22}$

In essence, Perry's white blood cell and the mouse's cancer cell constitute the hybridoma's genotype, but it is the positioning of the cell culture within the context of a work of contemporary art that creates its phenotype, giving it meaning beyond that of a biological specimen. Perry's hybridoma is not a mere cluster of replicating cells subject to a dispassionate analysis, but the catalyst for a deeper philosophical investigation. For example, the potential of Perry's hybridoma to infinitely replicate makes reference to both the history of the "immortal" HeLa cells as well as transgenic animals that have been created for cancer research. ${ }^{23}$ The HeLa cell line, despite the ethically questionable circumstances under which it was originally gathered, also embodies the idea of good and evil combined in a journey into the future. It was the aggressive nature of the HeLa cancer cells that quickly ravaged the body of their original host and killed her that has ultimately made them a powerful and ubiquitous research tool in the fight against cancer. Good and Evil also reflects the transhumanist interests in human enhancement and life extension, and calls into question the ethics of medical research on animals to that end, wherein acts of cruelty are perpetrated ostensibly with the aim of the greater good. By combining his own cells with mouse cancer cells, Good and Evil specifically brings to

\footnotetext{
22 Paul Perry, "Good and Evil on the Long Voyage," Signs of Life: Bio Art and Beyond, ed. Eduardo Kac (Cambridge Massachusetts: The MIT Press, 2007), 212.

23

The HeLa cell is an immortal cell line used in medical research, derived from cervical cancer cells from Henrietta Lacks in 1953. Cultured and commercialized without Ms. Lacks' permission, these cells are "immortal" in that they will replicate infinitely under appropriate conditions. Although many strains of HeLa cells exist, they all descended from the original tumor cells removed from Ms. Lacks' cervix.
} 
mind the case of the OncoMouse, the first genetically modified animal to be patented. Patented by Harvard University and marketed by the Du Pont Corporation, the OncoMouse was a transgenic strain of mouse, which had had an activated human oncogene inserted in its genome and was consequently guaranteed to develop a lethal cancerous tumor within a few months of birth. ${ }^{24}$ In 1988, the U.S. Patent and Trademark Office granted a patent to two genetics researchers who assigned it to the trustees of Harvard College, who in turn licensed the patent for commercial development to Du Pont who had an increasing interest in biomedical research, creating a complicated relationship between academic research and commercial industry. ${ }^{25}$

OncoMouse is as well known for having been the first patented animal as for its use in cancer research. Although the patent was granted for OncoMouse in the United States in 1988, it is worth noting that Harvard was not immediately successful upon applying for international patent protection. The patent application was initially denied in Europe, but was later granted in 1992. In Canada the patent application was met with considerable resistance and in 2002 was denied on the grounds that higher organisms

${ }^{24}$ Robert Pollack, Signs of Life (Boston and New York: Houghton Mifflin Company, 1994), 143.

25

Although in 1997, Donna Haraway portrayed the DuPont corporation as having a somewhat benevolent relationship with academia, providing OncoMouse specimens for research at what she described as the reasonable price of $\$ 50$ to $\$ 75$ each, "an amount that could not recoup the original investment even if sales were brisk," (Donna J. Haraway, Modest_Witness @ Second_Millenium, (New York and London: Routledge, 1997), 81) by 2002 there is evidence that DuPont was exercising its intellectual property rights within the academic research community and exerting pressure for researchers to pay licensing fees. DuPont argued that OncoMouse patents covered any transgenic animals predisposed to cancer and was asking institutions to enforce the agreements that had been made. In 2000, DuPont had entered into an agreement with the National Institute of Health in the United States to provide a "free research license" to any NIH research scientist using the OncoMouse for noncommercial studies. However, any scientist using the mouse in drug trials or other commercial research had to pay the licensing fee. Academics were able to use the mice in their research through their affiliated institutions that were expected to comply with and enforce DuPont's terms. This was problematic, since by 1990 it was becoming more common for researchers to develop mice that were prone to developing different strains of cancer. In 2002 Science magazine reported that DuPont was exerting pressure on MIT researcher Tyler Jacks, creator of the $p 53$ knockout mouse (a mouse in which certain genes are eliminated), arguing that MIT was required to sign a licensing agreement with DuPont because " 'any animal with germ line disruptions that is cancer prone' must be licensed for research use under the OncoMouse patent." (Eliot Marshall, "DuPont ups ante on Use of Harvard's OncoMouse," Science 296, no. 5571 (2002), 112.) For further discussion of how commercial industry and academic research have clashed over the development of transgenic organisms in general and the OncoMouse in particular, see Fiona Murray, "The Oncomouse That Roared: Hybrid Exchange Strategies as a Source of Distinction at the Boundary of Overlapping Institututions," American Journal of Sociology 116, no.2 (2010) 341-88. 
cannot be patented. The reasons for the rejection, however, are what make the OncoMouse so compelling. The process by which the OncoMouse was created was outlined in the patent application Harvard College v. Canada:

The respondent applied for a patent on an invention entitled "transgenic animals." According to the application, a cancer-promoting gene ("oncogene") is injected into fertilized mouse eggs as close as possible to the one-cell stage. The eggs are then implanted into a female host mouse and permitted to develop to term. After the offspring of the host mouse are delivered, they are tested for the presence of the oncogene. Those that contain the oncogene are called "founder" mice. Founder mice are mated with mice that have not been genetically altered. Fifty per cent of the offspring will have all of their cells affected by the oncogene, making them suitable for animal carcinogenic studies. ${ }^{26}$

Although the patent examiner accepted the claim for the process, the claim for the product, OncoMouse, was denied on the grounds that a higher life form cannot be patented because it is not a "manufacture" or "composition of matter" within the meaning of "invention" in the Canadian Patent Act. "While a fertilized egg injected with an oncogene may be a mixture of various ingredients, the body of a mouse does not consist of ingredients or substances that have been combined or mixed together by a person. 27 While it was conceded that the process by which the mouse egg bearing the oncogene was created was an invention with great scientific potential, the court found that the mouse that grew from that egg did so as a result of the laws of nature, despite the fact that every cell in the mouse's body was genetically altered. In essence, a higher multi-cellular life form that already exists in nature cannot be regarded as an invention, even if it has been altered through human innovation. Despite OncoMouse's conflicting status that arises from an uneasy meeting of nature and culture, it nevertheless remains a commodity

${ }^{26}$ Harvard College v. Canada (Commissioner of Patents), [2002] 4 SCR 45, 2002 SCC 76 (CanLII), $<\mathrm{http}: / /$ canlii.ca/t/1k9> retrieved on 2015-06-24

27 Ibid. 
for commercial gain. It is a "kind of machine tool for manufacturing other knowledgebuilding instruments in technoscience... a scientific instrument for sale like many other laboratory devices. ${ }^{28}$

Given that in some legal jurisdictions higher life forms cannot be regarded as inventions, one might question the status of works of art that aim to create novel life forms through similar transgenic techniques. This raises the question of whether, in such cases, the work of art supersedes the scientific "invention." Does the creation of a work of art trump scientific innovation as a consequence of artists' privileged position as creators? The ontological significance of such organisms that that been altered through human innovation and that are both novel and reproducible is the subject of W.J.T. Mitchell's article, "The Work of Art in the Age of Biocybernetic Reproduction," in which he examines the impact that such practices have had on works of contemporary art. Couched as a contemporary response to Benjamin's "The Work Of Art in the Age of Mechanical Reproduction," Mitchell questions the effect that developments in both biology and computing have had on the arts and traditional humanistic disciplines, arguing that biocybernetic reproduction has resulted in a destabilizing and corresponding malleability of species identity, an argument that has been similarly addressed by many of the artists discussed here. He responds to Benjamin's argument that mechanical reproduction (print, film, photographs) is the dominant technical determinant of our age with the suggestion that the mechanical reproducibility that defined the modern era has been replaced by biocybernetic reproduction (computing, digital imaging, virtual reality, genetic engineering) as the defining characteristic of the age often termed postmodern. Addressing Benjamin's extension of the definition of a work of art to include the emerging media of his time (photography, cinema, television), Mitchell further extends the definition to include contemporary art that draws upon new reproductive processes. He clarifies, "Reproduction and reproducibility mean something quite different now when the central issues of technology are no longer "mass production" of commodities or "mass reproduction" of identical images but the reproductive processes of biological

28

Haraway, Modest_Witness, 79. 
sciences and the production of infinitely malleable, digitally altered images." ${ }^{29}$ Mitchell's argument also hinges, in part, on the provided etymological definition of biocybernetics:

The word cybernetics comes from the Greek word for the steersman of a boat, and thus suggests a discipline of control and governance... Bios, on the other hand, refers to the sphere of living organisms which are to be subjected to control, but which may in one way or another resist that control, insisting on "a life of their own." Biocybernetics, then, refers not only to the field of control and communication, but to that which eludes control and refuses to communicate. ${ }^{30}$

Consequently, biocybernetics relies on the interplay of human intervention in the form of some type of control, be it the digital alteration of images or the genetic manipulation of life forms, and some level of resistance from that which is being manipulated. One example that Mitchell provides to illustrate this tension is the work of Eduardo Kac. Kac defines himself as a transgenic artist, proposing that,

Transgenic art is a new art form based on the use of genetic engineering techniques to create unique living beings. This can be accomplished by transferring synthetic genes to an organism, by mutating an organism's own genes, or by transferring natural genetic material from one species into another. Molecular genetics allows the artist to engineer the plant and animal genomes and create new life forms. ${ }^{31}$

Although there are superficial thematic similarities between Kac and those artists working with combinatory taxidermic practices, there is a vast difference in the scope of his investigations. Each of the artists discussed here is interested in the plasticity of the physical body. While those working in taxidermy manipulate the actual skins of different

\footnotetext{
${ }^{29}$ W. J. T. Mitchell, "The Work of Art in the Age of Biocybernetic Reproduction," What do Pictures Want: The Lives and Loves of Images (Chicago: University of Chicago Press, 2005), 318.

30 Mitchell, "Biocybernetic Reproduction," 312-13.

31 Eduardo Kac, Telepresence and Bio Art (Ann Arbor: University of Michigan Press, 2005), 236.
} 
animals to create new albeit static life forms, Kac is exploring what goes on beneath the skin. For Kac, the skin is not merely the impermeable barrier that contains and defines the body in space, but is the site of continuous transmutation. By working with transgenic organisms, Kac is examining the mutability of the body on a cellular level. In his essay for the catalogue produced in response to the exhibition The Eighth Day (2000), Edward Lucie-Smith writes,

Kac's work has nothing to do with the hybrid creatures produced by the German artist, Thomas Grünfeld that are related to the mermaids concocted by the oldfashioned showmen from fish married to monkeys. Grünfeld's images are essentially nostalgic - they try to transport us to a world where "wonders" of this sort could be viewed without irony. Kac tries to excite our imaginations by showing us what contemporary science can genuinely do. ${ }^{32}$

Lucie-Smith distances Kac's work from Grünfeld's taxidermic sculptures, rather aligning it with the work of renaissance artists such as Da Vinci and Vesalius, who straddled the divide between art and science. I argue, however, that this distancing is unnecessary as it ignores the connection to the role that curiosity played in stimulating an early scientific interest in the unknown natural world. Although there is an incontrovertible history of charlatanry that is part of the lore of mermaids, basilisks, and dragons, there is also a corresponding history of early scientific enquiry. In many respects, Kac is constructing contemporary interpretations of curiosities. Furthermore, Lucie-Smith ignores the corresponding relationship between science and spectacle that characterized the cabinet of curiosities in early modern science and continues to be evident in both the work of Grünfeld and Kac. Kac's approach to the creation of novel organisms through transgenesis owes much to these traditions, and results in the creation of organisms that require a similarly "poetic" intellectual shift in order to make sense of them.

\footnotetext{
32 Edward Lucie-Smith, "Eduardo Kac and Transgenic Art," The Eighth Day: The Transgenic Art of Eduardo Kac, ed. Sheilah Britton and Dan Collins (Tempe, Arizona: The Institute for Studies in the Arts, 2003), 23.
} 


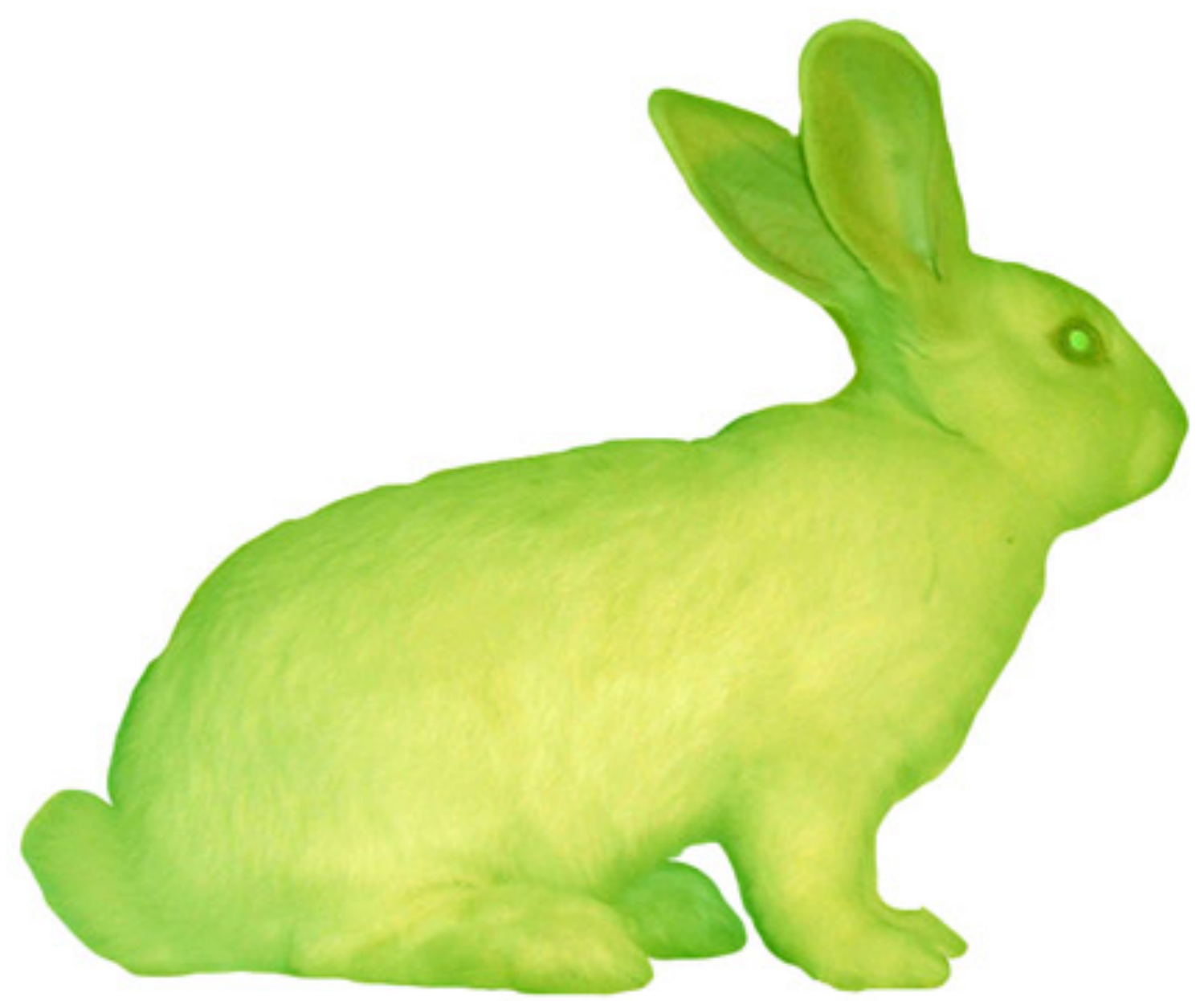

Figure 4.5: Eduardo Kac, GFP Bunny, 2000. Image used with permission from the artist.

Despite the contemporary technology required to create the work GFP Bunny (2000), the resulting animal was very much a curiosity. Kac worked with geneticist Louis-Marie Houdebine to create a rabbit that was genetically modified by the insertion of a gene that codes for green fluorescent protein (GFP) in the hope of creating a rabbit that would fluoresce green under light of a specific wavelength. GFP is derived from the jellyfish Aequorea victoria, the green fluorescence being widely used as a marker to track genetic change in contexts ranging from the identification and location of proteins in embryonic development to determining the infectivity of viruses. ${ }^{33}$ Although

33 Dan Collins, "Tracking Chimeras: The Eighth Day," The Eighth Day: The Transgenic Art of Eduardo $\underline{K a c}$, ed. Sheilah Britton and Dan Collins (Tempe Arizona: The Institute for Studies in the Arts, 2003), 96. 
representations of GFP Bunny, whom Kac named "Alba," depict her as a luridly green rabbit, Mitchell reports that it is only the skin that actually glows and one would have to part her fur and view the skin under a special light in order to perceive any difference from other rabbits. ${ }^{34}$ Kac chose to work with a rabbit due to its historical and symbolic significance in various world cultures. In the Aztec culture, for example, the rabbit is known as Tochtli, the eighth day sign of the Tonalpohualli - the Aztec sacred calendar and was the sign for the date of the earth's creation. GFP Bunny is intended to be a commentary on the history of the domestication of rabbits by humans and the resulting effect of man's intervention as a factor in their evolution. Kac states that GFP Bunny is not merely an exercise in breeding but must be understood as a transgenic artwork. Through the insertion of a gene derived from a jellyfish into a rabbit, Kac not only undermines the notion of genetic purity and reveals the fluidity of the concept of species, but also underlines man's complicity in certain evolutionary changes.

Here I return to Mitchell's premise that the age of biocybernetic reproduction revolves around the role of biological advancements in the recreating of new and improved versions of existing life forms. Recalling Benjamin's assertion that mechanical reproduction leads to a decay in the aura of the original, Mitchell argues that in the case of biocybernetic reproduction the relationship between the copy and the original is reversed, and that the copy is no longer inferior but an improvement or enhancement of the original. ${ }^{35}$ Eduardo Kac, by combining a rabbit with the DNA of a Jellyfish, has created a rabbit that is superior to the original and has created "a copy that has more aureole, if not aura, than its original. ${ }^{, 36}$ Unlike the original rabbit in its unmanipulated form, the newly created rabbit Alba possesses a great auratic quality. Although superficially she resembles any other white rabbit since one can only view her fluorescence by parting her skin and viewing it under an ultraviolet light, she is

\footnotetext{
34 Mitchell, "Biocybernetic Reproduction,” 328.

${ }^{35}$ Ibid., 320.

36 Ibid.
} 
nevertheless subject to the mystique that arises from the narrative that has developed around her. Images of Alba are always depicted as a green bunny, an image that itself has been manipulated. Further, despite Kac's requests to take Alba home to the United States, the lab where she was created refused to release her, intensifying her almost mythical status. There are so few photographs of Alba in existence, with none actually showing her skin glowing, that she is in effect a rabbit who exists purely as a digitally manipulated image. Despite Alba's seemingly mythical quality, at least one attempt has been made to represent her in traditional museum context, although as a rather poor simulation. In the exhibition Darwin's rEvolution (2010) at the Natural History Museum in Vienna, a somewhat disheveled taxidermic hare was exhibited, illuminated by a green light. The hare was exhibited without prior permission from Kac. ${ }^{37}$ The Natural History Museum of Vienna is a UNESCO World Heritage site, and as such is subject to numerous restrictions in terms of what they can change in their displays. By exhibiting a representation of Kac's GFP Bunny curators contrasted the historical collection with the contemporary, in an attempt to show the continued relevance of their existing collection. The greenglowing hare may have been intended as a critique of transgenic organisms, but at the same time it was an attempt to capture public imagination through a provocative image. Elizabeth Stephens argues that Alba's authenticity is suspect and draws attention to the fact that Kac defines GFP Bunny as chimerical only in the cultural sense rather than the scientific sense of containing genetically distinct types of cells. She argues that this statement has received little or no attention and, combined with the fact that there is no independent documentation that proves that the genetic modification occurred, raises suspicion as to whether or not a true GFP bunny was ever created. ${ }^{38}$

In the installation, The Eighth Day (2001), Kac again makes use of live organisms that he has genetically manipulated. Mice, zebra fish, tobacco, and a colony of the

\footnotetext{
${ }^{37}$ This event was described to me by Oron Catts, and an image of the disheveled hare appears in the exhibition catalogue for Darwin's rEvolution. As explained to me by Catts, the curator, perhaps jokingly, justified the act by saying that if artists can appropriate the sciences without prior consultation, then scientists can appropriate the arts.

38 Stephens, "Making Monsters," 60.
} 
amoebae Dictyostelium discoideum, all of which have been genetically altered to include green fluorescent protein, coexist within a specially designed biodome. The colony of amoebae is housed inside a "biobot" that functions as a bioreactor to keep them alive. The biobot is equipped with an internal sensing unit that allows it to move in response to the behavior of the amoebas. The biobot can be regarded as a sort of cyborgian hybrid organism. Housed within the metal robotic body is an organic "brain," amoebas that form a network in the bioreactor, and behave not as individuals but as a larger multicellular organism. Dictyostelium, or slime mold, was selected because of peculiarities that occur in its morphology during its life cycle. The amoebae can exist as individual single-celled organisms, but under the right conditions they can join together into a unified blob that can move as one. When the amoebae move or react in response to external stimuli, the legs of the biobot extend or contract correspondingly. According to Kac,

While fluorescent creatures are being developed in isolation in laboratories, seen collectively in this work for the first time they form the nucleus for a new and emerging synthetic bioluminescent ecosystem. The piece brings together living transgenic life forms and a biological robot (biobot) in an environment enclosed under a clear Plexiglas dome, thus making visible what it would be like if these creatures would in fact coexist in the world at large. ${ }^{39}$
Although the coexistence of so many transgenic organisms at such proximity to one another seems an unlikely scenario, the situation reflects the ubiquity of transgenic organisms in contemporary society. Even more significantly, as Haraway tells us, 'transgenic creatures, which carry genes from 'unrelated' organisms, simultaneously fit into well-established taxonomic and evolutionary discourses and also blast widely understood senses of natural limit. What was distant and unrelated becomes intimate."40 Each of the organisms housed within Kac's biodome is paradoxical because it continues to fit into its original taxonomic position, yet they are all also drawn closer together to

\footnotetext{
39 Eduardo Kac, "Life Transformation - Art Mutation," Signs of Life: Bio Art and Beyond ed. Eduardo Kac (Cambridge Massachusetts: The MIT Press, 2007), 175.

40

Haraway, Modest_Witness, 56.
} 
one another in a newly created techno-scientific taxonomy. The title, The Eighth Day, is an allusion to the book of Genesis in which, we are told, on the seventh day God had finished creating the world, and seeing that all was good, he rested. The Eighth Day suggests that we have reached the point where man is able to create new life forms on his own with little help from God, and these new life forms defy traditional taxonomies as we have come to recognize them.

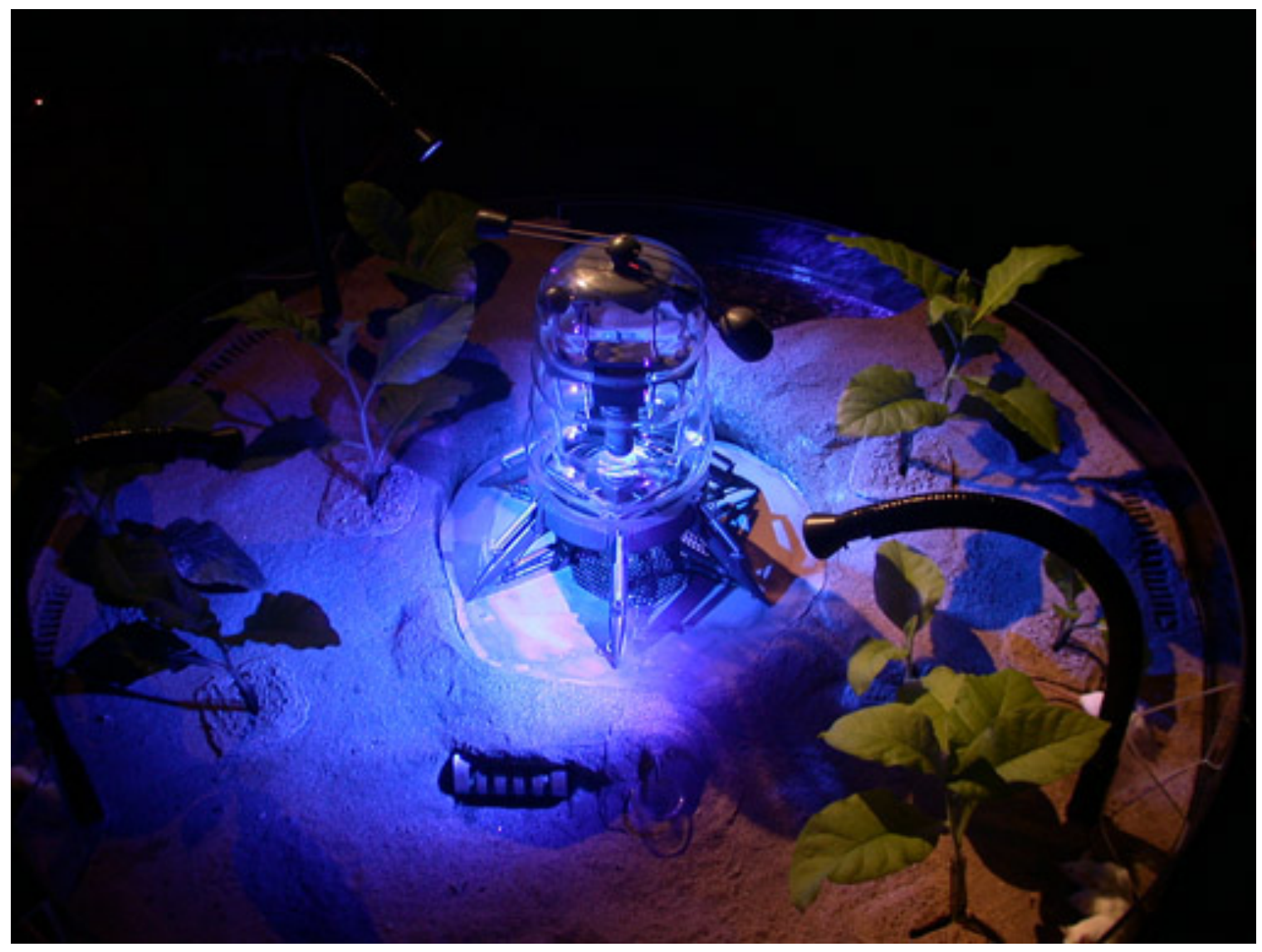

Figure 4.6: Eduardo Kac, The Eighth Day, 2000 (view of biobot). Image used with permission from the artist.

The Eighth Day was not Kac's first work to allude to the book of Genesis. The installation, Genesis (1998-1999) began with the creation of an impossible, synthetic "biblical gene," a gene that Kac created, which does not actually exist in nature. Kac began with the text, "Let man have dominion over the fish of the sea, over the fowl of the air, and over every living thing that moves upon the earth." This sentence, chosen because it implies a divinely sanctioned superiority of humankind over all other 
creatures, was translated into Morse code, chosen because it represents to Kac the dawn of the information age. That code was then converted into base pairs using a conversion principle of Kac's own devising, a code developed expressly for this work. Kac then emailed the sequence to a facility specializing in DNA synthesis, and several weeks later he received a test tube containing millions of copies of the gene. It occurred to Kac, looking at the powdery substance, that "the isolated gene is inert matter and that alone it is destitute of the agency often ascribed to it...By itself the gene cannot do anything because to be meaningful it needs a context." The synthetic "Genesis gene" was inserted into the "context" of an E. coli bacteria ${ }^{42}$ and that bacterial culture was exhibited in a gallery as well as being broadcast over the Internet. Remote viewers could, with the click of a mouse, turn an ultraviolet light on and off, and influence the rate of mutation of the DNA in the bacteria. By choosing to accelerate mutation and alter the sequence of the gene, the viewer was in effect choosing to alter the meaning encoded within the DNA. At the end of the exhibit, the genetic sequence of the bacteria was translated back into Morse code, and then into English, demonstrating how the text encoded in the DNA had been changed. The resulting sentence read, "Let aan have dominion over the fish of the sea and over the fowl of the air and over every living thing that ioves ua eon the earth." Through the melding of the genetic code with cultural codes, the insertion of a synthetic "biblical gene" into the genome of a bacteria, Kac creates a form of recombinant DNA that is simultaneously natural, man-made and divinely ordained. While it can be argued that the "Genesis gene" is merely a series of random bases generated by Kac, and not a true gene in that it does not code for any actual function, I suggest that it nevertheless produces interpretable text, if only metaphorically rather than literally. The original sentence contends that God has granted man dominion over every creature that inhabits the planet, and the alteration of the text confirms that, whether

${ }^{41}$ Kac, Telepresence and Bio Art, 251.

${ }^{42}$ E. coli is commonly used in genetic engineering and research because of its safety, genetic simplicity, rapid growth rate, and ability to both host foreign DNA and reproduce it rapidly. It is worth noting that a simple internet query into the use of $E$. coli in genetic engineering reveals instructions for how to insert green fluorescent protein into $E$. coli targeted at the level of high school science labs, demonstrating the level of acceptance that the creation of simple transgenic organisms has achieved. 
divinely ordained or not, man now has the ability to alter any organism that currently exists. According to Kac, "In the context of the work, the ability to change the sentence is a symbolic gesture: It means that we do not accept its meaning in the form we inherited it, and that new meanings emerge as we seek to change it." ${ }^{43}$ However, by actively, if remotely, interacting with the bacteria and subsequently causing genetic mutations, viewers demonstrate their power to genuinely alter the DNA. Whether we accept the original biblical ordination or not, as a society we are increasingly moving towards a greater level of domination of other life forms. Although the DNA that Kac has created does not occur in nature, the ease with which viewers are able to alter it parallels the relative ease with which scientists are now able to alter and combine the DNA of existing organisms. N. Katherine Hayles connects this ability to render DNA as writable code to the Biblical notion of the Word of God: "In the beginning was the Word and the Word was God," according to the gospel of St. John, which she tells us set the stage for seeing Jesus as the Word incarnate. In the twentieth century, the carnal relation between the flesh and the word "took a new turn when DNA was seen as the 'master code' responsible for writing the flesh." ${ }^{44}$ The ability to use DNA as a method of inscription to write the flesh provides us with enhanced abilities to use the body to transmit information. This is, however, merely the one recent iteration of the idea of flesh as embodiment of knowledge that we can see has taken different forms across different times in history.

As discussed in the previous chapters, Tissue Culture and Art Project, made up of artists Oron Catts, and Ionat Zurr, have been exploring the manipulation of living tissue as a medium for artistic expression since the inception of the group in 1996. Tissue Culture and Art Project engages in the manipulation of living cells as both medium and subject: the work that they create is at times more metaphorically chimeric than that of other artists previously discussed here in that they do not always combine material from

\footnotetext{
${ }^{43}$ Kac, "Life transformation - Art Mutation," 164.

44 N. Katherine Hayles, "Who is in Control Here? Meditating on Eduardo Kac's Transgenic Art," The Eighth Day: The Transgenic Art of Eduardo Kac, ed. Sheilah Britton and Dan Collins (Tempe Arizona: The Institute for Studies in the Arts, 2003), 80.
} 
more than one species. The combinatory status of their work is derived more as a result of an ontological blurring: the practices in which they are engaged are concerned less with the representation of objects and more the creation of new semi-living subjects that require a level of care in order to survive. The process by which the work is achieved is as, if not more, important than the end product. Catts and Zurr write,

We use tissue engineering and stem cell technologies to create semi-living entities. The semi-livings are made of living tissues from complex organisms grown over/into three-dimensional constructed substrates. Our semi-living entities grow in artificial conditions, which imitate body conditions, in bioreactors...the semi-livings are constructed of living and non-living materials, and are new subautonomous entities located at the fuzzy border between the living/non-living, grown/constructed, and object/subject. ${ }^{45}$

The object/subjects that Tissue Culture and Art Project create are, as I have previously argued, an example of the fusing of nature and culture that characterizes the work made by artists working with living cells or tissues. The cells require man-made environments to stay alive, and the removal of that environment spells the end of the tissue culture as a semi-living entity.

In 2000 - 2001, Catts and Zurr were Research Fellows at the Tissue Engineering and Organ Fabrication Laboratory at Harvard Medical School where they were studying the potential for tissue culturing as an expressive artistic medium. Here they were able to work with Dr. Joseph Vacanti and Dr. Charles Vacanti, both transplant surgeons and pioneers in the field of tissue engineering who are perhaps best known in popular culture for creating (along with Robert Langer and Yilin Cao) a mouse with a human ear on its back in 1997, often referred to as the "Earmouse". Despite the appearance of having combined elements of two species, the mouse was not an example of genetic engineering. The mouse that was used was a "nude mouse," a hairless strain of mouse with a genetic

\footnotetext{
45 Oron Catts and Ionat Zurr, "Semi-Living Art,' Signs of Life: Bio Art and Beyond, ed. Eduardo Kac (Cambridge Massachusetts: The MIT Press, 2007), 232.
} 
mutation resulting in the absence of a thymus, and a correspondingly disabled immune system. A biodegradable ear-shaped scaffold was constructed out of a porous polymer similar to the synthetic material used in surgical stitches. The scaffold was then seeded with cartilage cells from a cow, and grafted onto the back of the mouse, between the skin and the muscle layers. Due to the mouse's lack of an immune system, it did not reject the cow cells, and a system of blood vessels grew to support the growth of the cartilage cells. Despite the arresting appearance of the combined image of mouse and human, there was no actual alteration of the mouse's genome to incorporate human DNA. ${ }^{46}$ Although the mouse was created in the continued quest to perfect tissue engineering as a viable medical technique, one of the ways in which it remains enduringly compelling is the result of the showmanship with which the scientists presented their work, as much spectacle as scientific innovation. Cao, for example, is now based in Shanghai, and continues to create mice with human ears on their back. At least one of these mice was created purely for display purposes and is now exhibited in plastinated form at the Shanghai Science and Technology Museum. The Vacantis, who continue to be interested in collaborating with artists and in using tissue culturing in the name of spectacle, recently assisted with Demut Strebe's sculpture Sugababe (2014), in which she claimed to have regrown Van Gogh's ear using cells from one of Van Gogh's direct descendants. $^{47}$

The image of the Earmouse continues to resonate within popular culture and was recently the subject of an exhibition celebrating the $20^{\text {th }}$ anniversary of its creation. The exhibition DeMonstrable (2015), curated by Oron Catts, Jennifer Johung, and Elizabeth Stephens, was presented at the University of Western Australia. The curators position Earmouse within the history of scientific monsters dating back to the Renaissance. The word monster is derived from the Latin monstrare meaning to show or to warn, as monsters were originally understood as omens or signs. As Catts et. al argue, the

\footnotetext{
${ }^{46}$ Karl S. Kruszelninicki, “Great Moments in Science: Mouse with Human Ear,” June 2, 2006, www.abc.net.au/science $/ \mathrm{k} 2 /$ moments $/ \mathrm{s} 1644154 . \mathrm{htm}$

47 See Demut Strebe, “Sugababe, ongoing project," http://diemutstrebe.altervista.org
} 
Earmouse represented both "established fears and a warning about something yet to come: a brave new world in which organs and body parts are grown to measure, and surrealist dreams come alive." ${ }^{48}$ Despite the fact that many of the medical advances promised by the advent of Earmouse have yet to transpire, the image of combined man and mouse continues to provoke debate regarding the contradictory status of such an organism.

While at Harvard furthering their research into tissue culture as an art medium, Tissue Culture and Art Project developed the work Tissue Culture and Art(ificial) Wombs (2000), as discussed in the previous chapter. This work necessitated the creation of the "feeding ritual" in which the tissues are immersed in a nutrient solution. Catts emphasizes that the creation of semi-living art comes with a certain level of responsibility to care, "The Feeding Ritual attempts not only to demystify some of the processes involved in creating semi-living entities but also to emphasize the notion that life that we have created needs care for its survival and is wholly dependent on us to feed and nurture it." ${ }^{49}$ Tissue Art and Culture Project were faced with the same set of moral responsibilities surrounding the care and maintenance of living tissue in their exhibition, Pig Wings (2000-2002). Using techniques similar to those pioneered by Dr. Vacanti, bone marrow stem cells were used to grow pig bone tissue over a substrate, creating three small sculptures referencing different solutions for flight in vertebrates: angel wings, bat wings and the culturally neutral pterosaur wings. Chimeric winged creatures have been portrayed throughout history, with goodness often being indicated by angel wings and evil being evidenced by bat wings. Confronted by the reality that they were not able to stay with the work for the duration of the exhibition, and that not only would the sculptures require being maintained in a bioreactor but would also require a great deal of further care, TC\&A elected to develop a "killing ritual" to bring each installation to a close. The killing is done by removing the semi-living sculptures from their protective

\footnotetext{
48 Oron Catts, Jennifer Johung, and Elizabeth Stephens, DeMonstrable, exhibition catalogue, 3 October - 5 December, 2015, Lawrence Wilson Art Gallery, University of Western Australia, Perth, Australia.

${ }^{49}$ Catts and Zurr, "Semi-Living Art," 237.
} 
environment, and then by encouraging the audience to touch them. The fungi and bacteria in the air and on the hands of the audience are sufficient to contaminate the cells and cause them to die. Despite the implied violence of the ritual, the process is intended to provide viewers with the chance to experience the semi-living entities through touch, and forge a more intimate haptic connection to them. It is intended to remind us not only of the fragility and temporality of the sculptures, but also the responsibility that society has towards the living creatures that are used in laboratories for our own betterment. ${ }^{50}$

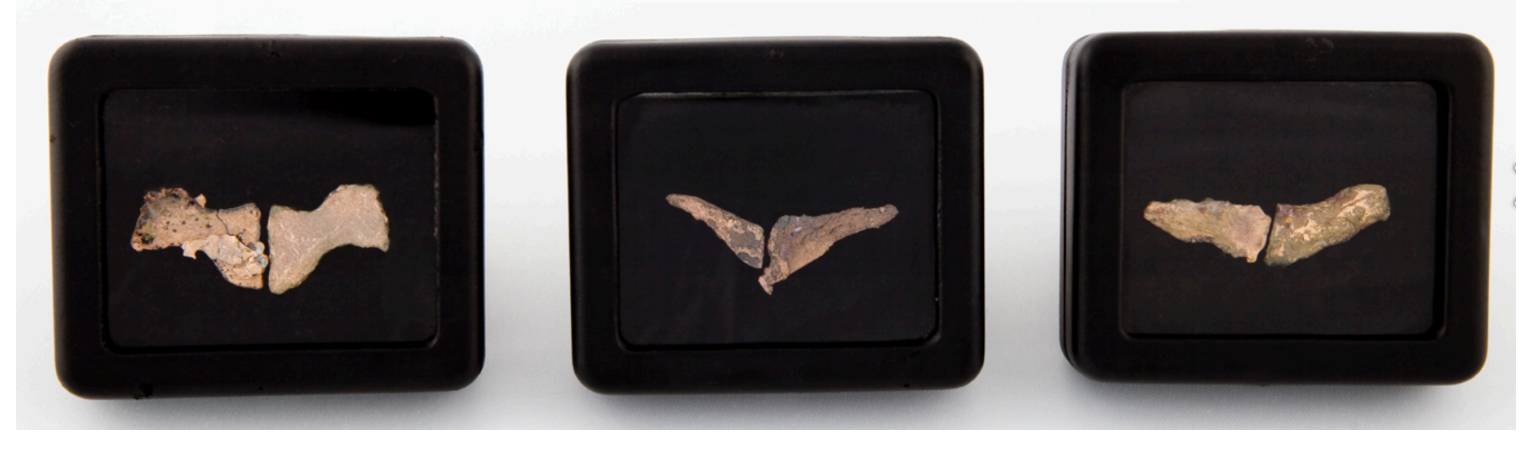

Figure 4.7: Tissue Culture and Art Project. Pig Wings, 2000-02. Image used with permission from the artists.

For TC\&A, human existence and our experience of the being-in-the-world has always been mediated by artificial constructs such as language or technology. The subjects being presented in their work are not experienced through a representational medium, but are experienced directly and without mediation, particularly during the "killing ritual." According to Catts and Zurr,

\footnotetext{
${ }^{50}$ Even when it falls to the curator of an exhibition to shut down the bioreactor that maintains an exhibition of one of TC\&A's installations, it is not taken as a neutral act. In 2008, TC\&A's installation Victimless Leather was exhibited at the Museum of Modern Art in New York as part of the exhibition "Design and the Elastic Mind." The mouse cells that formed the small "leather" jacket that comprised the installation grew with such vigour that they risked overgrowing the bioreactor and clogging the incubation system that kept them alive. It fell to senior curator Paola Antonelli to shut down the bioreactor and "kill" the jacket. However, she ultimately was unable to turn the switch, and called in colleagues from Columbia University to do the deed. Antonelli stated," It generated reactions you wouldn't think you'd have rationally...I really had to think about whether this little coat was alive." See: Carolina A. Miranda, "Weird Science: Biotechnology as Artform," ArtNews, March 18, 2013, http://www.artnews.com/2013/03/18/biotechnology-as-art-form/ (accessed July 7, 2015).
} 
Our work with tissues as material is not intended to be pitiless art but rather to act as a tangible warning sign and a starting point for new broader discourse. The constant questioning of validity of the use of the tissues for artistic ends is in the core of the work itself, it does bring to question the validity of the use of living materials for other human undertakings as well. It is the actual engagement and referral to the technology that makes art reveal the mediation as mediation. ${ }^{51}$

Although it pales in comparison to other works of art that have involved the intentional killing of an animal, ${ }^{52}$ interaction that results from the "killing ritual" nevertheless initiates a questioning of the ethical responsibilities of those working with live and semiliving specimens. As McLuhan put it, “The medium is the message.” Here, TC\&A's use of tissue culturing is inextricably linked with the messages they are putting forth with their various projects. ${ }^{53}$ It is not merely a means to an end. The vulnerability of tissue cultures exposes the conflict between our new increasing knowledge of and ability to manipulate living systems and the ethical dilemmas that are raised by the use of the animals that provide the biological material. The killing of non-sentient, unsustainable, semi-living tissues is in itself not where the ethical dilemma rests, rather it is a potent reminder of the hidden population of lab animals that provides the tissues and cells from which these semi-livings are derived.

\footnotetext{
51 Oron Catts and Ionat Zurr, "The Art of the Semi-living and Partial Life: Extra Ear - 1/4 Scale," www.tca.uwa.edu.au/publication/TheArtoftheSemi-LivingandPartialLife.pdf, 11

52 Helen and Newton Harris's Portable Fish Farm (1971) was the first artwork in North America to involve the intentional killing of an animal, in this case by electrocution. In 1972 Ana Mendieta decapitated a chicken in her performance Untitled (Chicken). More recently, Marco Evaristi in the work Helena \& El Pescador (2000) placed goldfish in blenders connected to electrical outlets. Although he was accused of encouraging people to kill the goldfish, he argues that he was testing gallery-goers sense of right and wrong by putting them in the ethical position of choosing whether or not to turn on the blenders.

53 See also Richard Cavell, "McLuhan and The Body as Medium," Sk-interfaces: Exploding Borders Creating Membranes in Art, Technology, and Society, ed. Jens Hauser (Liverpool: FACT and Liverpool University Press, 2008), 32-41.
} 


\subsection{Human/ Non-Human Hybrids}

As combinatory genetic techniques that utilize different species have become more sophisticated, it is not surprising that these practices have extended towards the creation of human-non-human chimeras, as evidenced in both stem cell research and xenotransplantation. Given that such medical practices have become more commonplace, it necessarily follows that they have also become the subject of both ethical and philosophical debates that have been taken up in both academia and the visual arts. ${ }^{54} \mathrm{As}$ discussed before, Eduardo Kac has devoted a large portion of his practice as an artist to working with transgenic techniques. Although many of his previous works have been confined to working with lower order organisms, Kac enters into the human-non-human chimera debate with his work The Natural History of the Enigma (2009), an exhibition that revolves around a "plantimal" that he created and named "Edunia." "Edunia" is a genetically engineered petunia into which Kac has inserted his own genetic material. The Edunia flower is characterized by pink petals marked with red veining that expresses for a gene isolated from Kac's blood. According to Kac, "The petal pink background, against which the red veins are seen, is evocative of my own pinkish white skin tone. The result of this molecular manipulation is a bloom that creates the living image of human blood rushing through the veins of a flower." 55 The gene expressed by Edunia is responsible for the identification of foreign bodies in the human body, representing Kac's desire to integrate "that which identifies the other that I integrate into the other, thus creating a new kind of self that is partially flower and partially human." ${ }^{56}$ In order to create this work, Kac had one of his own genes isolated from a blood sample, specifically a genetic sequence that is part of his immune system, "the system that distinguishes self from non-

\footnotetext{
54 Just one of many examples of the focus on transgenesis as an emerging subject for ethical debate, in 2003 The American Journal of Bioethics devoted an entire issue to the subject of transgenesis and the crossing of species boundaries (The American Journal of Bioethics, Vol. 3, No. 3, Summer 2003). Much of the issue revolved around Robert and Baylis's article, "Crossing Species Boundaries," and the various articles written in response to it.

55 http://www.ekac.org/nat.hist.enig.html

56 Ibid.
} 
self, i.e., protects against foreign molecules, disease, invaders - anything that is not me. To be more precise, I isolated a protein-coding sequence of my DNA from my Immunoglobulin (IgG) light chain (variable region)." ${ }^{57}$ The resulting human-plant chimera is a reflection of what Kac identifies as the contiguity between life forms, an acknowledgement that in terms of DNA humans are more closely related to plants and other higher life forms than we sometimes like to acknowledge. As in his project $G F P$ Bunny, Kac again disrupts the notion of the purity of species.

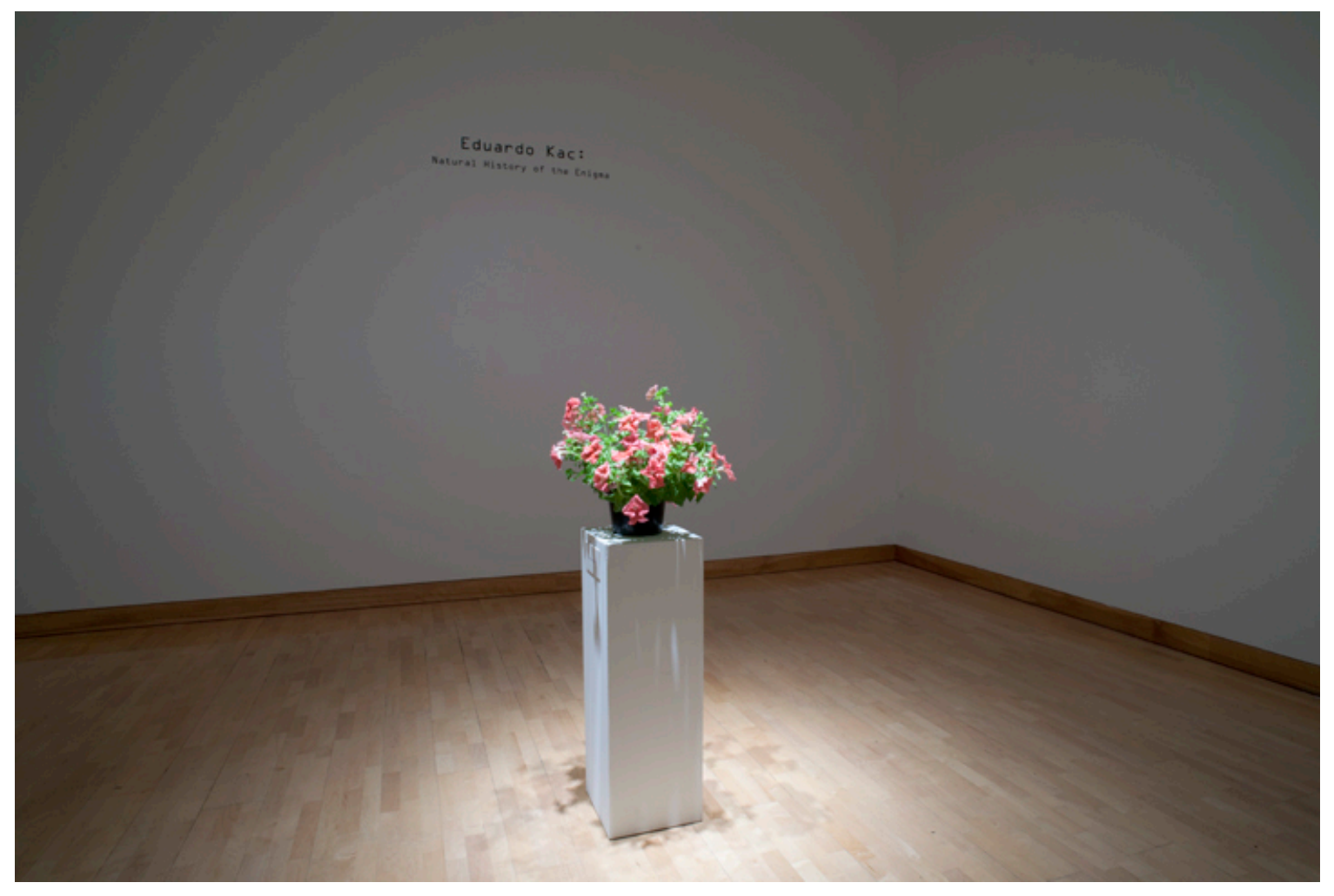

Figure 4.8: Eduardo Kac, The Natural History of the Enigma (installation), 2009. Image used with permission from the artist.

It is this questioning of the idea that distinct boundaries exist between species that forms the basis of Robert and Baylis's argument in their article, "Crossing Species Boundaries." Here, Robert and Baylis dispassionately assert that the notion of a purely differentiated species identity is a flawed rationale for arguing against the morality of

${ }^{57}$ Ibid. 
transgenic manipulation. They argue that the existing belief that species identity is fixed and any transgression of the boundaries that separate species is morally problematic is unsustainable, pointing out that people rarely regard rhododendrons or mules as being particularly monstrous. They posit that the only species that is deemed genuinely "fixed" is the human species, despite the fact that genomic research has shown that humans are more closely related to all other life forms than previously realized. They suggest that this belief is the result of holding humanity to a higher moral standard, and therefore results in a greater sense of repugnance when that humanity is transgressed. Robert and Bayliss suggest that the blurring of species boundaries presents a moral dilemma because,

Human beings attach considerable symbolic importance to classificatory systems and actively shun anomalous practices that threaten cherished conceptual boundaries ... Human-to-animal chimeras, for instance, are neither clearly animal nor clearly human. They obscure the classification system (and concomitant social structure) in such a way as to constitute an unacceptable threat to valuable and valued conceptual, social, and moral boundaries that set human beings apart from all other creatures. ${ }^{58}$

Surely there is some variability in the level of horror that we experience when viewing human-non-human chimeras, depending on whether it is the human or the non-human that is playing host to the other. A work such as Kac's The Natural History of the Enigma creates an ambivalence in the viewer that is the result of the aesthetic response to the undeniably lovely pink and red petunia acting in opposition to the slight repugnance that one feels knowing that that those red veins express the DNA of the artist. One cannot help but imagine the delicate flower pumping human blood through those veins like some sort of malevolent triffid. Do we respond more profoundly when a non-human animal suddenly possesses a characteristic that we identify with humanness than when a human is imbued with an aspect of non-humanness? Perhaps it is our anthropocentrism that allows us to feel less threatened by the idea of the integration of animal elements into the

\footnotetext{
58 Jason Scott Roberts and Françoise Baylis, "Crossing Species Boundaries," The American Journal of Bioethics 3, no. 3 (2003), 7.
} 
human body, through xenotransplantation for example, than by a non-human organism with human characteristics. Perhaps there is also a variability in our response to a hybrid organism depending on the level at which the combining occurs. The physical seaming together of disparate fleshy elements, either in taxidermy or in human xenotransplantation in which the elements retain their original identity, seems less threatening than when one organism truly assimilates something of another at the genetic level.

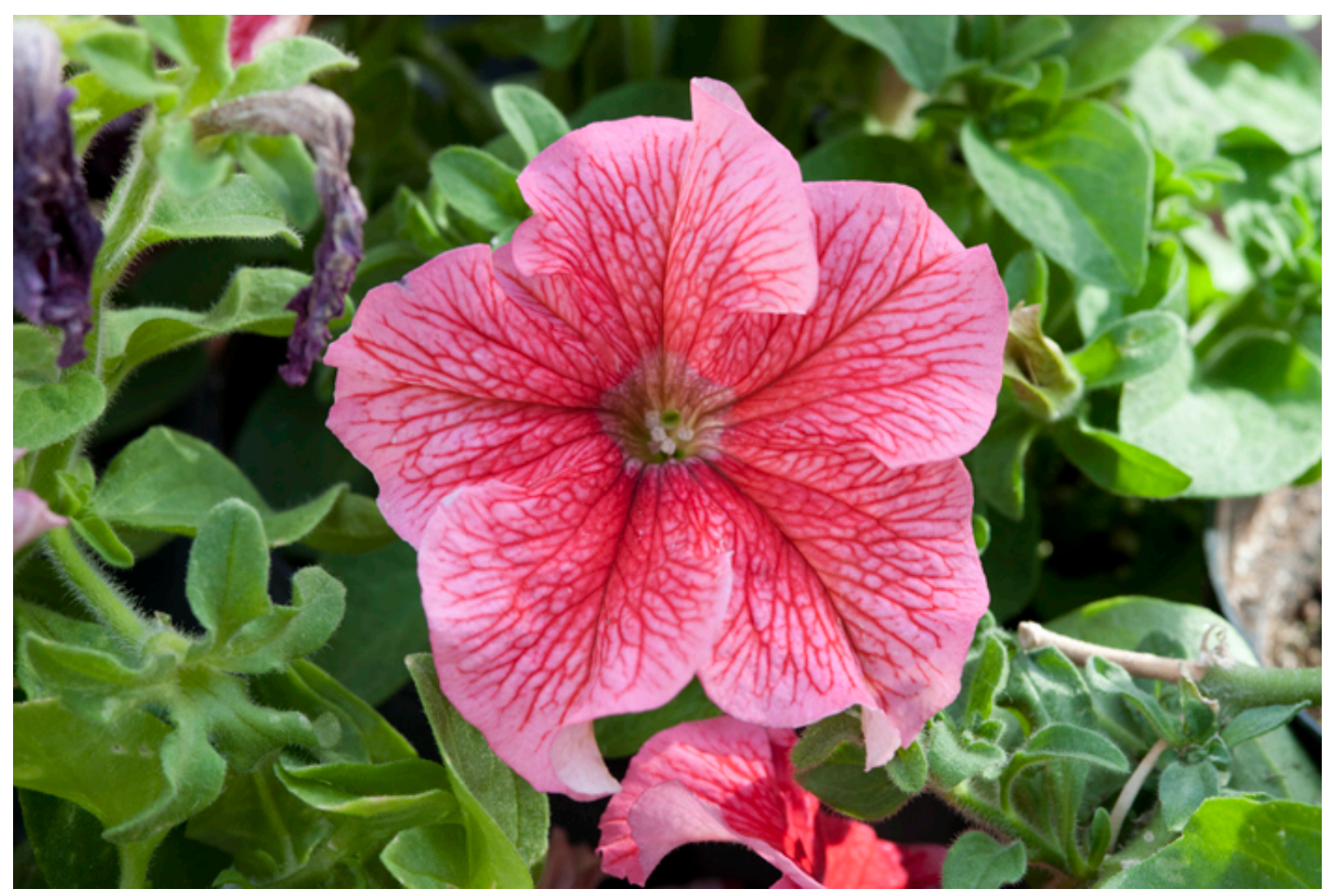

Figure 4.9: Eduardo Kac, The Natural History of the Enigma (detail: "Edunia") 2009. Image used with permission from the artist.

French performance artists Marion Laval-Jeantet and Benoit Mangin have succeeded in transgressing boundaries between species in several of their projects, resulting in varying levels of discomfort for the viewer. Collaborating under the name Art Objet orienté since 1991, their practice focuses on ecology, examining the intersecting spaces of human and animal lives through trans-species relationships, and the questioning of scientific methods and tools. This has resulted in several projects in which they appropriate scientific and medical practices to obscure the boundaries between human 
and non-human subjects. In 1996, they began work in the skin biology laboratories at Cambridge University on a project intended to transgress traditional notions of art mediums, by "proposing a living medium that was none other than the artist in person.",59 They wanted to use skin cultures to create a work of art that was both conceptual and carnal in an attempt to mend the rift between object and image. To create Cultures de Peaux d'Artistes/ Artists' Skin Cultures (1996-1997) they used their own skin tissues to culture a piece of skin. Although they found the idea of creating such a sample to be satisfactory in that it fulfilled both requirements of being cerebral and visceral, the resulting skin sample was disappointingly thin and transparent. In order to overcome this and create something that sufficiently resonated with the ideas of smoothness, thickness, and opaqueness that the viewer would associate with skin, they grafted their human skin culture onto an existing piece of pig dermis. These pieces of trans-gender, trans-species skin were then tattooed with images drawn from the most popular animal tattoos of that time, such as hummingbirds and butterflies. According to Laval-Jeantet, these Artists' Skin Cultures "were the projection of a hybrid world where xeno-transplants would be common currency and the distinctions between living species would be blurred until they finally disappeared altogether," creating a world where humans had evolved to the point where the physical body had fused with its environment, including with animals. ${ }^{60}$

Art Objet orienté pushed the idea of human animal fusion considerably further, and with considerably higher risk, with their performance Que le Cheval Vive en Moi (May the Horse Live in Me) (2011). ${ }^{61}$ In this work, Laval-Jeantet had horse blood injected into her veins, dramatically extending the limits of what it means to be human or animal and blurring the boundaries between species. Through this act, Laval-Jeantet makes a movement towards becoming a hybrid species, enacting a centaur through both

\footnotetext{
59 Marion Laval-Jeantet, “The Fusional Haptics of Art Object orienté," Sk-interfaces: Exploding Borders Creating Membranes in Art, Technology, and Society, ed. Jens Hauser (Liverpool: FACT and Liverpool University Press, 2008), 90. 
the transfusion of blood and the wearing of a specially constructed set of prostheses based on the form of a horse's legs.

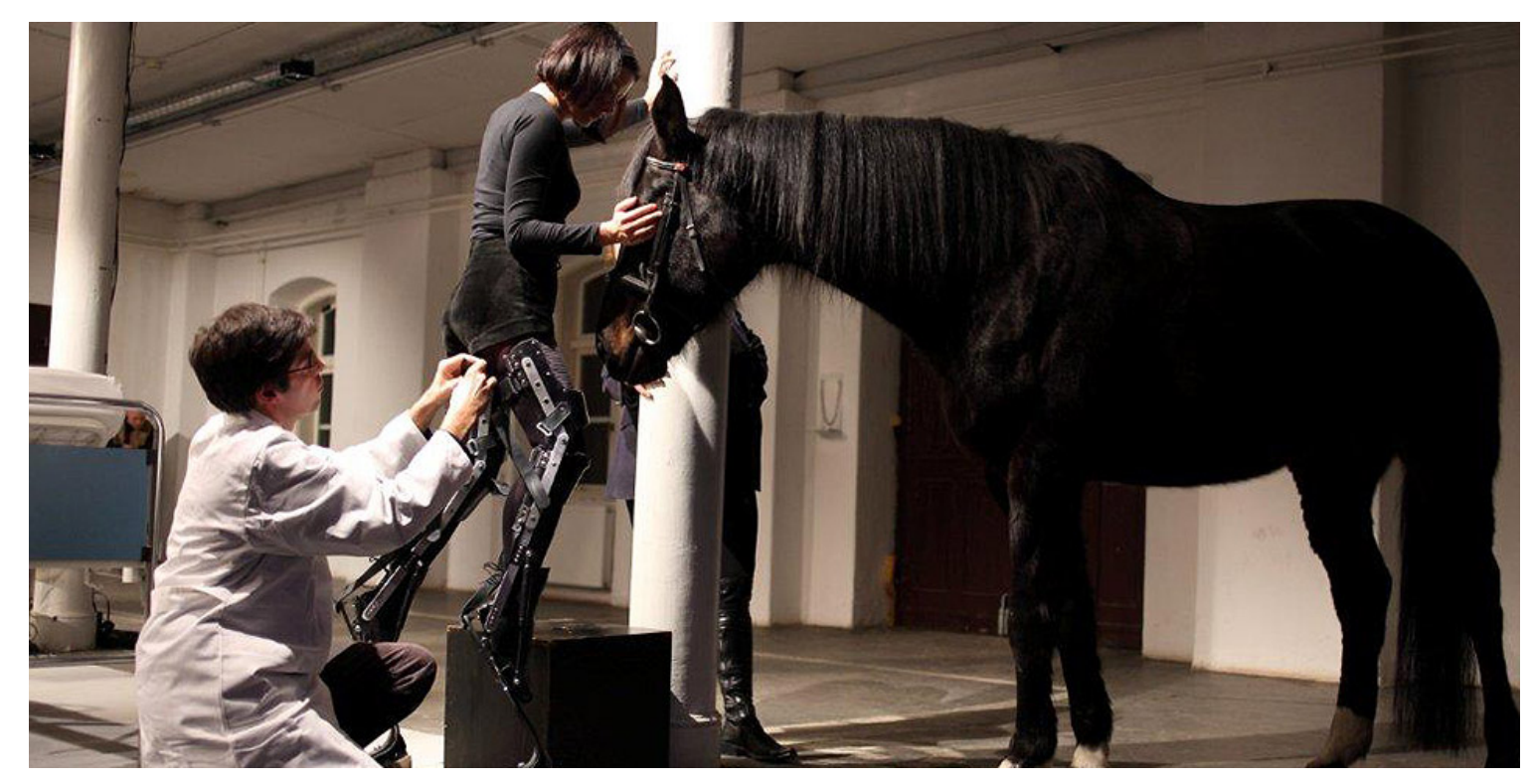

Figure 4.10: Art Objet orienté, Que le Cheval Vive en Moi (May the Horse Live in Me), 2011. Image used with permission from the artists.

In preparation for the performance that took place in a gallery in Ljubljana, Slovenia, Laval-Jeantet underwent a series of experimental transfusions aimed at both acclimatizing her body to the foreign substance and testing for tolerance. In an attempt to build up her body's tolerance for the foreign matter, for the month prior to the performance Laval-Jeantet was injected sequentially with various horse immunoglobulins, the proteins produced by plasma cells that function as antibodies by binding to foreign objects in the body such as bacteria and viruses. By injecting her body with the biological material of another species, the artist was extending the limits of her own immune system and putting herself at risk of anaphylactic shock. However, the fluid had been stripped of "the most cyto-toxic red blood cells, as well as lymphocytes and macrophages," 62 but still contained all other blood cells including the immunoglobulins

\footnotetext{
62 Aleksandra Hirszfield, "May the Horse Live in Me (interview with Art Orienté Objet)", http://artandsciencemeeting.pl/?page id=306\&lang=en (Accessed February 4, 2015)
} 
that Laval-Jeantet perceives as being responsible for transferring information within the body and between organs through their various functions. Having developed a sufficient tolerance to complete the performance, Laval-Jeantet rested on a hospital bed in the gallery, where she received the infusion of horse blood plasma containing the full spectrum of horse immunoglobulins. It was predicted that the horse immunoglobulins would not be rejected by Laval-Jeantet's immune system, and could enter her bloodstream and bind to the proteins in her body, and could potentially have an effect on all of her bodily functions. After the transfusion, she was helped into a pair of specially constructed horse-leg prostheses as a horse was led into the gallery. The artist and the horse then walked slowly together around the gallery, in constant contact with one another, and in an act of shared experience. After receiving the blood transfusions, LavalJeantet states that she found that she had not only achieved a metaphorical state of centaur-like hybridity, she had also developed nervous responses sympathetic to those of the horse:

I could sleep no longer than one hour at a time then I woke up for another hour and then fell asleep for another short period of time. My nights were totally fragmented, I had an absurdly strong appetite, and when someone knocked my arm I used to panic. In spite of that I felt incredibly strong...I was talking to immunology doctors about it, and particularly with one immunologist who specializes in horses. To him it was obvious that all my reactions which have not been entirely of a psychological nature were very much typical of a horse. ${ }^{63}$

Laval-Jeantet has expanded on her interest in having a shared experience with another animal and has actually integrated elements of that animal into her own body, and consequently that shared experience required accepting the physiological effects that may give her insight into how it might feel to be a horse. Although there is already medical precedent for combining matter from another species with the human body in the form of xenotransplantation, for example the use of pig heart valves to replace damaged human

\footnotetext{
${ }^{63}$ Hirszfield, "May the Horse Live in Me" http://artandsciencemeeting.pl/?page id=306\&lang=en (Accessed February 4, 2015)
} 
heart valves, such processes are intended to serve a purely utilitarian medical purpose rather than to create a sensorial interspecies event. Art Objet orienté's project not only raises questions of empathy as embodied in our relationships with animals, but also reflects aspects of our own humanity, specifically a desire for human enhancement at whatever cost. Julian Savulascu expands on the notion of human-animal chimeras, arguing that the fusing of human and animal through the acts of human-animal transgenesis is not monstrous but rather an expression of our humanity. Although Savulescu is referring to the inserting of genes from other animals into the human genome, and creating a truly chimeric being in which the animal's genes resonate in every cell of the human body rather than merely inserting a piece of tissue, he believes that the desire to enhance the human body for the better is part of our nature. This desire, whether it was what Laval-Jeantet consciously desired or not, is reflected in her fascination with feelings of enhanced sensitivity and sleeplessness that she attributes to her incorporation of the horse serum. Savalescu argues that it is not DNA that separates humans from animals, but humankind's capacity for reason, the capacity to engage in complex social relationships, the capacity to display sympathy and empathy, and the capacity to have faith. He argues that,

If our humanity is located, at least in part, in our practical rationality...then there are two ways in which our humanity can be either promoted or threatened ... Actions that are the reflection of our practical rationality express our humanity. When we act according to what we have good reason to do, we express our humanity. So whether creating transgenic human beings or chimeras is an expression of our humanity or a threat to it turns on whether we have good reason to radically alter our genome. ${ }^{64}$

He goes on to give several examples of theoretical combinations that might enhance or be detrimental to human abilities, but ultimately his argument rests on the notion that,

\footnotetext{
64 Julian Savalescu, "Human-Animal Transgenesis and Chimeras Might be an Expression of Our Humanity," The American Journal of Bioethics 3, no. 3 (2003), 24.
} 
Bringing animals closer to human beings to share their genes might paradoxically improve our humanity, what is essentially human. Humanity until this point has been a story of evolution for the survival genes - survival and reproduction. Now we are entering a new phase of human evolution - evolution under reason - where human beings are masters of their destiny. ${ }^{65}$

\subsection{Conclusion}

Greenblatt remarks that "wounded artifacts" are compelling not only because they are "witnesses to the violence of history" but also because they betray the "signs of use, marks of the human touch" 66 that have brought about their condition as flawed, altered, and inherently resonant objects. Greenblatt was no doubt thinking of museum artifacts rather than manipulated organisms, and likely saw the marks of use as a positive and evocative characteristic. However, such an observation is applicable to much of the work discussed in this dissertation, particularly that which is discussed in this chapter and the previous one. These "objects of nature," despite having taken on a more and more flexible set of defining characteristics as my argument has progressed, in all cases continue to bear the marks of human intervention, and as such have been subject to a certain level of violence against their beings. From the hunting and preserving of animals to the harvesting of bovine fetal serum to grow a coin-sized blob of sheep tissue, to injecting horse serum into a human body, they all have resulted in some form of what Steve Baker refers to as "botched taxidermy." As explained earlier, botched taxidermy does not necessarily refer only to taxidermy, but may refer to human interspecies relationships in a broader sense. In each case, the altered organism has become a clearer reflection of the human desire to control the environment and the things in it, than of the nature of the organism itself. For example, as N. Katherine Hayles suggests in reference to Eduardo Kac's The Eighth Day, “GFP can be understood as the mark of the human on

\footnotetext{
65 Savalascu, "Human-Animal Transgenesis," 24.

66 Greenblatt, "Resonance and Wonder," 44.
} 
the fish, mice, tobacco plants, and amoebae inhabiting the dome." ${ }^{67}$ Each organism, trapped inside the purpose built bio-dome, glows under an ultraviolet light and betrays the otherwise invisible evidence of human intervention into its make-up. If we return to W. J. T. Mitchell's suggestion that in biotechnology the relationship between the copy and the original is reversed, and that the copy is no longer inferior but an enhancement of the original, it demands that one question the hubris of such a statement when applied to living organisms. The objects described in this chapter can indeed be described as the mirabilia of the modern age, but one might also remember that the materials once frequently used to create such wonderful objects, notably blood coral and nautilus shells, are now all too rare. The ongoing desire to manipulate and otherwise control nature speaks to a level of anthropocentrism that is not without consequences.

${ }^{67}$ Hayles, "Who is in Control Here?" 79. 


\section{Conclusion}

In this dissertation, my objective has been to examine how our cultural understanding of a natural history specimen has been impacted by the changing perception of life as a result of advances in biotechnology. These advances include, but are not limited to: the use of tissue culturing to grow new body parts, which sometimes requires the use of another animal body to act as a host organism, for example a mouse used to support a human ear-shaped scaffold; the use of genetic modification to insert the genes of one organism into the genome of another, effectively creating a new combinatory organism, ranging from inserting human genetic material into a flower to spider genes into a goat's genome so that it can express spider silk in its milk; and the movement in natural history museums towards storing genetic material gathered from their historical collections as an insurance policy against the potential loss of endangered species. I have further sought to determine how the impact of such biotechnological advances has been addressed in the practices of artists, ranging from those who engage in primary biological field research to those appropriating techniques that require laboratory equipment, those engaged in the museum practices of preservation and display, and finally, those engaged in traditional art fields such as painting. In all cases the common element is the focus on biological material, from cells to complete animal bodies, as an expressive medium with the potential for mutation.

I came to this line of inquiry by a somewhat serendipitous route. In the early stages of my doctoral program I experienced the crisis that no doubt plagues every graduate student. I had several areas of research that I was genuinely passionate about: taxidermy, bioart, museum collections in general, and natural history collections in particular, but I couldn't narrow my intended field to just one of these topics. Having done previous research on cabinets of curiosity during my master's degree, I sensed that they might be connected, but I couldn't establish the precise links. I had the opportunity to discuss the matter with Oron Catts of Tissue Culture and Art Project, who described his works NoArk and Odd NeoLifism, explaining that he believed that the turn towards new scientific practices was generating a new class of organisms that exceeded the limits of conventional taxonomy. Our ensuing conversation over the following days helped me 
to sort out how I wanted to proceed and became the catalyst for this dissertation. I have since realized that my difficulties stemmed from the lack of existing literature that addresses this specific set of interrelations. The best examples of work that directly addresses the questions that I wanted to ask are works of art rather than scholarship, such as NoArk and Odd NeoLifism, and Rich Pell's Center for PostNatural History, which, as described above, began as an art installation but has since evolved into a micro-museum that mounts exhibitions and collaborates with museums of natural history internationally. The Center for PostNatural History is described as being "dedicated to the advancement of knowledge of the complex interplay between culture, nature, and biotechnology,"1 and focuses on organisms that have been altered through such human-driven processes as selective breeding or genetic manipulation. In both of these cases I have made connections between the scientifically altered organism and the crafted nature of the natural history specimen, drawing attention not only to the historical precedents that have roots in early examples of fraudulent chimeras in cabinets of curiosity but also to the established practices of preservation and display utilized in all museums that result in a recategorization of objects of nature to objects of culture.

Given that it is well established that the natural history specimens collected and ordered by museums function as sites of knowledge, I have tried to determine whether organisms altered though human intervention can serve a similar function. As illustrated by the Center for PostNatural History, such organisms have been largely ignored by the museums of natural history as collecting institutions. Perhaps these organisms should not be assigned a place in the natural order because they are not completely natural, however, as I and others before me have argued, the preserved specimens of natural history collections are similarly hybrid due to the processes required for their preservation and display. Despite their tenuous position in the context of natural history, postnatural history specimens have become sites of knowledge that reflect how humankind now interacts with the non-human natural world, just as natural history specimens and curiosities did in centuries past. The knowledge of every episteme, to use the Foucauldian

\footnotetext{
1 "Introduction to PostNatural History," http://www.postnatural.org/Introduction-to-PostNatural-History-1.
} 
term, is reflected in its collected objects, and the Center for Postnatural History is as accurate a reflection of knowledge of the current state of humankind's relationship with nature as any museum of natural history, if not more so. Indeed, the application of biotechnology to an organism further obscures the illusion of the natural, including examples where the alteration has been made at the molecular level and the organism appears superficially unchanged. The effect is of course even more apparent in cases where the organism has been visibly altered. Extending this premise into the field of contemporary art made me question how artists working with mutable and mutating living specimens help us to understand the impact of biotechnology on the natural world, and how these specimens become the locus for that acquired knowledge.

My contribution to this field is to develop a scholarly analysis of the propositions initiated by Tissue Culture and Art Project's NoArk and Odd Neolifism and Rich Pell's Center for PostNatural History, and to situate these discussions within a broader discourse of contemporary art. In order to determine the epistemological value of these new classes of specimen, as well as to map the terrain in which I position my argument, I have drawn on scholarship from several fields that circumscribe the issues at play in the works of art discussed here. These fields include: the history of natural history museums, material culture inclusive of taxidermy, DNA taxonomy, and art-science collaboration. In each of these areas there have been certain texts that have proven instrumental to my understanding of the field and to establishing my argument. However, given the broad nature of such material and in the interest of not reiterating what I have already argued any more than is necessary, I will limit my discussion to the most influential texts.

I have positioned my argument within the discourse of history using Michel Foucault's The Order of Things and Hooper-Greenhill's Museums and the Shaping of Knowledge, both of which examine how language and systems of classification shaped perceptions of the world and the influence this has on the formation of the museum. In his analysis of the development of the natural sciences from the sixteenth to nineteenth centuries, Foucault examines the evolution of modes of thinking, understanding, and constructing knowledge (and consequently scientific thinking) during the three periods that he terms epistemes: the Renaissance, Classical, and Modern. Most significant for my 
research is his focus on how the Classical episteme heralded a new focus on language, as well as the concern for establishing a system of taxonomy. The naming of things was crucial to the development of a universal science of order, which in turn became a form of knowing, defining, and structuring the natural world. Hooper-Greenhill expands upon Foucault's work by analyzing how his ideas about representation, language, and knowledge manifest in three case studies of the museum's evolution as a construct throughout the Renaissance, the Classical, and the Modern epistemes. Extending this argument, I suggest that we may be on the verge of a new episteme as a consequence of introducing new categories into the order of nature through genetic modification and selective breeding.

In order to understand the mechanisms that drive the shift from "object of nature" to "object of knowledge," I have examined the role of interior and exterior research spaces in the construction of knowledge. In chapter one, Fieldwork, Laboratories, and the Construction of Knowledge, I discussed how the binary of interior and exterior spaces of scientific research, the laboratory and the field respectively, is subject to hierarchies of knowledge that are complicated by the introduction of artists within those spaces. As these spaces are traditionally occupied by scientists, the presence of artists can be alien. What is the impact and potential outcome of artists occupying these spaces? Field research has a historical connection to amateur naturalists and thus may provide an easier point of entry for artists, although as Cornelia Hesse-Honegger's case indicates, this is not necessarily the case. Although field research also has a history of employing "citizen scientists" to help gather data, this is not the case in laboratory research, which continues to be predominantly occupied by specialists in the field. Consequently, the laboratory maintains a barrier between itself and the non-specialist public. This is still the case in research laboratories affiliated with natural history museums as well as in other research institutions. Although some science and natural history museums make attempts to involve visitors in a more interactive and embodied way, there remains a sense of separation between museum exhibitions and what is happening "behind the scenes." Certain museums have tried particularly hard to break down these hierarchies, and have used the arts as a tool to make science more accessible and palatable. However, artists 
should not merely be seen as a means to achieving such an end. As free agents, artists can do much more than this by being socially engaged, posing difficult questions, and criticizing any potentially negative impacts of scientific practices on both the environment and society.

Returning to the importance of language in chapter two, Disrupting the Language of Classification, I investigated what constitutes a natural history specimen in a culture that routinely alters organisms, either through genetic manipulation or tissue culturing. Extending Oron Catt's argument that these practices have led to the creation of new unclassifiable organisms, I revisited Francis Bacon's proposal for a natural language to see if it might offer a viable model for a new form of classification that would address both the backward-looking chimeric nature of many of these organisms as well as their future-oriented nature as cryogenically stored museum specimens. The unclassifiable chimeric blobs of semi-living tissue created by Tissue Culture and Art Project stand in contrast to the work of Gemma Anderson, who employs traditional methods of drawing and printmaking to explore morphological relationships between specimens across different phylogenic kingdoms. By examining these two contrasting modes of classification, one based in biotechnology, the other in morphological observation, I concluded that although we may have entered a period that demands new forms of language to respond to new types of organisms, abandoning old methods of classification presents risks. While DNA barcoding is both conceptually fascinating and offers speed and efficiency, it also threatens to eclipse the more nuanced observational skills required in traditional taxonomy. Here, I drew on Rebecca Ellis's criticism of DNA barcoding as a means of classifying and cataloguing museum specimens, in both her article "Rethinking the Value of Biological Specimens: laboratories, museums, and the Barcoding of Life Initiative," and Waterton, Ellis, and Wynne's book Barcoding Nature: Shifting cultures of taxonomy in an age of biodiversity loss. Ellis provides a critical perspective on the impact of current technology on classifying and preserving natural history museum specimens through the Barcoding of Life Initiative (now Database). Ellis argues that museum specimens by virtue of being held in collections and connected to their own respective object biographies are the sites of evolving potential readings as scientific, epistemic objects. The reduction of these specimens to mere DNA code effectively shuts 
down potential future readings as objects within the larger social constructs of both the museum and the discourse surrounding it. In response to this, I contend that DNA barcoding is not necessarily a dead end, but instead offers biological and biographical information encrypted within a symbol in a manner that evokes Bacon's idea of a natural language. Furthermore, I suggest that although DNA taxonomy offers speed and efficiency at the potential expense of traditional morphological taxonomy, it might hold potential value for creating a nomenclature for unclassifiable "chimeric blobs."

In chapter three Of Vitrines and Bioreactors: Museums and Methods of Preservation and Display, I explored the nature of the relationships between various methods of display, from vitrines to greenhouses to bioreactors. In each case the emphasis was on glass as a device that protects and reveals its contents, while at the same time acting as a disciplinary barrier between the viewer and those objects. I concluded that the bioreactor that houses and maintains the matter created by bioartists functions in much the same way as the museum vitrine. In both examples the display mechanisms embody two functions that are seemingly incompatible: they both protect and maintain their contents, while at the same time offering up their contents as a publicly consumable spectacle. I argue that these various classes of newly created organisms can be compared to the idea of the preserved specimen as material culture, as described in Samuel J.M.M. Alberti's article, "Constructing Nature Behind Glass."2 The notion that nature can be rendered an object of material and visual culture can be applied to ontological descriptions of the semi-living tissue-cultures created by Tissue Culture and Art Project, preserved museum specimens, taxidermy (both museum specimens and works of art), and all modified organisms, both genetically and physiologically. In response to Alberti's question, "what of the bird skin, the pinned beetle, the organ in a jar, the dried plant, the fossil, the quartz fragment and frozen DNA? Are they, too, material culture?"3 I would

\footnotetext{
2 Alberti, "Constructing Nature Behind Glass," 73-97.

3 Alberti, "Constructing Nature," 81.
} 
answer yes, as are the various works of art discussed here. All are carefully crafted and meticulously preserved.

In the fourth and final chapter, Mutations and Hybrids, I further expanded on the idea of the natural history specimen as a combination of nature and culture by considering organisms that are constructed from the combined elements of more than one species. Here, I attempted to determine the ontology of composite creatures created by artists, through works of taxidermy as well as through different forms of bioart practice. To my mind, one of the most influential texts for articulating the nature of art-science collaboration as applied to animal skins, cells, and tissues is W.J.T. Mitchell's "The Work of Art in the Age of Biocybernetic Reproduction.” Here he argues that biocybernetic reproduction has had a destabilizing effect on species identity. Of particular relevance to my argument is his definition of the term reproducibility, which he extends to reproductive processes. I argue that Mitchell's definition of reproducibility can be applied in the case of alterations made to living organisms at the genetic level, including organisms that have been altered by bioartists and those exhibited in the Center for PostNatural History. These changes happen at the genetic level and are thus heritable and repeatable. As is the case with much of the material discussed throughout the dissertation, I have suggested that the resulting work can be described as the mirabilia of the modern age. In each case some object or material derived from nature has been worked by the hands of the artist to create a new hybrid creature, either superficially, as in the case of taxidermy, or in a more permanent, heritable or - to quote Mitchell - reproducible way.

If we extend the metaphor of the mirabilia of the modern age, we might equally imagine the work presented here as a contemporary cabinet of curiosities. HooperGreenhill has written that the collector of the seventeenth century cabinets "assembled a representative collection of meaningful objects, to display or present this assemblage in such a way that the ordering of the material both represented and demonstrated the knowing of the world."4 The owner of the cabinet, through the process of ordering and

\footnotetext{
${ }^{4}$ Hooper-Greenhill, "Museums and the Shaping of Knowledge," 82.
} 
arranging the collected objects, came to understand his own place in that order. I contend that it is through the presentation, representation, and manipulation of the artifacts of our techno-scientific society that the artist has become the ordering subject who shows us our place within that world. 


\section{Bibliography}

Alberro, Alexander. "Institutions, Critique, and Institutional Critique." In Institutional critique: an anthology of artists' writings, edited by Alexander Alberro and Blake Stimson, 2-19. Cambridge, Massachusetts: MIT Press, 2009.

Alberti, Samuel J.M.M. "Constructing Nature Behind Glass." Museum and Society 6, no. 2 (July 2008): 73-97.

---. The Afterlives of Animals, edited by. Samuel J. M. M. Alberti. Charlottesville and London: University of Virginia Press: 2011.

Aloi, Giovanni and Cornelia Hesse-Honegger. "Cornelia Hesse-Honegger: Heteroptera," Antennae: The Journal of Nature in Visual Culture 11 (Autumn 2009): 29-36.

Alpers, Svetlana. "The Museum as a Way of Seeing." In Exhibiting Cultures: The Poetics and Politics of Museum Display, edited by Ivan Karp and Steven D. Levine, 2532. Washington and London: Smithsonian Institution Press, 1991.

Anderson, Gemma. "Endangered: A Study of Morphological Drawing in Zoological Taxonomy." Leonardo 47, no. 3 (2014): 232-239.

Anderson, Lloyd. "On the Nature of Interactions." In Artists in Labs: Networking in the Margins, edited by Jill Scott, 23-33. Vienna: Springer-Verlag / Wien, 2010.

Appadurai, Arjun. "Commodities and the politics of value." in Interpreting objects and collections (1994): 76-91.

Avise, John C. The Hope, Hype, and Reality of Genetic Engineering. Oxford: Oxford University Press, 2004.

Bacon, Francis. The New Organon, in The Works of Francis Bacon. Vol. IV, edited by James Spedding. London: Longman and Co., 1860.

---. Advancement of Learning, in Essays, Advancement of Learning, New Atlantis, and Other Pieces, edited by. Richard Foster Jones, New York: The Odyssey Press, 1937.

Baker, Steve. The Postmodern Animal. London: Reaktion Books, 2000.

Ballengée, Brandon. "Ecological Understanding through Transdisciplinary Art and Participatory Biology." PhD diss., University of Plymouth, 2014.

Baker, Steve. “Something's Gone Wrong Again.” Antennae 7 (Autumn 2008): 4-9.

Basta, Sarina and Jackie McAllister. "Exhibition as Expedition, Museum as Object, or Mark Dion's Deep-Sea Maneuvering." Oceanomania [exhibition catalogue]. Monaco: Nouveau Musée Nationale de Monaco, 2011, 147-160.

Beisel, Uli and Christophe Boëte. "The flying public health tool: genetically modified mosquitoes and malaria control." Science as Culture 22, no. 1 (2013), 38-60.

Beaver, Patrick. The Crystal Palace 1851-1936: A Portrait of Victorian Enterprise. London: Hugh Evelyn Limited, 1970.

Bennett, Tony. “The Exhibitionary Complex,” New Formations 4 (Spring 2008): 73-102. 
Brenna, Brita. "The Frames of Specimens: Glass Cases in Bergen Museum Around 1900." In Animals on Display: The Creaturely in Museums, Zoos, and Natural History, edited by Liv Emma Thorsen, Karen A Rader, and Adam Dodd, 37-57. University Park, Pennsylvania: The Pennsylvania State University Press, 2013.

---. "Nature and Texts in Glass Cases: the vitrine as a tool for textualizing nature." Nordic Journal of Technology Studies 3, no 1 (2014): 46-51.

Buchloh, Benjamin. "Conceptual Art 1962 - 1969: From the Aesthetic of Administration to the Critique of Institutions." October, 55 (Winter 1990), 105-143.

Byatt, Lucy. "Introduction." nanoq: flat out and bluesome, A Cultural Life of Polar Bears. 13-19. Snæbjörnsdóttir/Wilson. [Exhibition catalogue], (Spike Island Gallery, Bristol: Black Dog Publishing, 2006.

Catts, Oron and Ionat Zurr. "Growing Semi-Living Sculptures: The Tissue Culture \&Art Project.” Leonardo 35, no. 4 (2002): 365-370.

---. “Ingestion/Disembodied Cuisine,” Cabinet Magazine 16 (2004/2005), http://www.cabinetmagazine.org/issues/16/catts_zurr.php

---. "Semi-Living Art.” Signs of Life: Bio Art and Beyond. Edited by Eduardo Kac, 231248. Cambridge Massachusetts: The MIT Press, 2007.

---. “The Ethics of Experiential Engagement with the Manipulation of Life," Tactical Biopolitics: Art, Activism, and Technoscience. Edited by Beatriz De Costa and Kavita Philip, 126-142. Cambridge, Massachusetts and London, England: MIT Press, 2008.

---. "The Art of the Semi-living and Partial Life: Extra Ear - 1/4 Scale." www.tca.uwa.edu.au/publication/TheArtoftheSemi-LivingandPartialLife.pdf

Catts, Oron and Gary Cass. "Labs Shut Open: A Biotech Hands-on Workshop for Artists." Tactical Biopolitics: Art, Activism, and Technoscience, edited by Beatriz De Costa and Kavita Philip, 143-156. Cambridge, Massachusetts and London, England: MIT Press, 2008.

Catts, Oron. "Growing Neolifism." (Lecture at The Sanctuary for Independent Media in Troy NY, March 19, 2014). https://www.youtube.com/watch?v=-9nu74yYQ34

Catts, Oron, Jennifer Johung, and Elizabeth Stephens. DeMonstrable, [exhibition catalogue] 3 October - 5 December 2015. Lawrence Wilson Art Gallery, University of Western Australia, Perth, Australia.

Chipperfield, John. "Jonah the giant blue whale still in one piece." Oxford Mail, May 14, 2007.

http://www.oxfordmail.co.uk/news/community/memorylane/1395817.Jonah the giant_blue_whale_still_in_one_piece_?ref=arc

Clarke, A. G. "The Frozen Ark Project: the role of zoos and aquariums in preserving the genetic material of threatened animals." International Zoo Yearbook 43 (2009): 224. 
Clifford, James. "On Collecting Art and Culture." Predicament of Culture: Twentieth Century Ethnography, Literature, and Art. Cambridge: Harvard University Press, 1988. 215-29.

Collins, Dan. "Tracking Chimeras: The Eighth Day." The Eighth Day: The Transgenic Art of Eduardo Kac, edited by Sheilah Britton and Dan Collins, 96-102. Tempe Arizona: The Institute for Studies in the Arts, 2003.

Cook, Harold J. "Time's Bodies: Crafting the Preparation and Preservation of Naturalia." Merchants and Marvels: Commerce, Science, and Art in Early Modern Europe, edited by Pamela H. Smith, and Paula Findlen, 223-247. New York and London: Routledge, 2002.

Corrin, Lisa Graziose, Miwon Kwan and Norman Bryson, "Miwon Kwan in Conversation with Mark Dion." 7-33. Mark Dion: The Natural History of the Museum. London: Phaidon, 2007.

Corrin, Lisa Graziose. "Introduction to the Seattle Vivarium." in Field Guide to the Wildlife of Mark Dion's Seattle Vivarium. Seattle: Olympic Sculpture Park [Seattle Art Museum], 2007.

Cummings, Laura. "Fiona Tan: Depot review - mementoes from the deep." The Guardian, July 19, 2015, http://www.theguardian.com/artanddesign/2015/jul/17/fiona-tan-depot-reviewbaltic-mementoes-from-the-deep.

Daston, Lorraine and Katharine Park. Wonders and the Order of Nature 1150-1750. New York: Zone Books, 1998.

Daston, Lorraine and Peter Galison. Objectivity. New York: Zone Books, 2007.

De Menezes, Marta. “The Artificial Natural: Manipulating Butterfly Wings for Artistic Purposes." Leonardo 36, No. 1 (2003): 29-32.

---. "The Laboratory as Art Studio." The Aesthetics of Care? The artistic, social and scientific implications of the use of biological/medical technologies for artistic purpose, edited by Oron Catts, 53-58. Perth: SymbioticA, School of Anatomy and Human Biology, University of Western Australia, 2002.

Derrida, Jacques. "The Animal That Therefore I Am (More To Follow)." Critical Inquiry 28, no. 2 (2002): 369-418.

Draganov, Marian, Marianna Murdjeva, and Teodora Michailova-Topalska. "McCoy and McCoy-plovdiv Cell Lines in Experimental And Diagnostic Practice - Past, Present, and Perspectives." Journal of Culture Collections 4, no. 1 (2005): 3-16.

Dunn, Rob. Every Living Thing. New York, London, Toronto and Sydney: Smithsonian Books, HarperCollins, 2010.

Ede, Siân. "The Scientist's Mind: The Artist's Temperament." Strange and Charmed: Science and the Contemporary Visual Arts, edited by Sian Ede and A. S. Byatt, 28-49. London: Calouste Gulbenkian Foundation, 2000. 
Edwards, Charlotte. "Man vs Burger.” Evening Standard. August 7, 2013. http://www.standard.co.uk/lifestyle/foodanddrink/man-vs-burger-8749749.html

Ellis, Rebecca. "Rethinking the Value of Biological Specimens: laboratories, museums, and the Barcoding of Life Initiative." Museum and Society 6 no. 2 (2008): 172191.

Endt, Marion. “Beyond Institutional Critique: Mark Dion's surrealist wunderkammer at the Manchester Museum.” Museum and Society 5, no. 1 (March 2007), 1-14.

Essaïdi, Jalia. "Exploring Boundaries by Piercing Barriers.” http://jalilaessaidi.com/2-6g$329 \mathrm{~ms} /$.

Findlen, Paula. "Inventing Nature: Commerce, Art, and Science in Early Modern Cabinet of Curiosities." Merchants and Marvels: Commerce, Science, and Art in Early Modern Europe, edited by Pamela H. Smith, and Paula Findlen, 297-322. New York and London: Routledge, 2002.

Foucault, Michel. “Of Other Spaces.” Diacritics 16, No 1, (Spring 1986): 22-27.

---. The Order of Things. London and New York: Routledge, 2006.

Glauser, Andrea. "Formative Encounters: Laboratory Life and Artistic Practice." Artists in Labs: Networking in the Margins, edited by Jill Scott, 12-22. Vienna: SpringerVerlag / Wien, 2010.

Gosden, Chris and Yvonne Marshall. "The cultural biography of objects." World archaeology 31, no. 2 (1999): 169-178.

Greenblatt, Stephen. "Resonance and Wonder" in Exhibition Cultures: the Poetics and Politics of Museum Display, edited by Ivan Karp and Steven D. Lavine, 42-56. Washington: Smithsonian Institution Press, 1991.

Gregory, Helen. "The Souvenir And The Collection: Taxidermy, Photography and the Archetype of the Colonial Hunter in the Exhibition nanoq: flat out and bluesome." Museums, Marginality and the Mainstream. (2012): 33-48. http://docslide.us/documents/museums-marginality-and-the-mainstream.html

Gregory, Helen and Anthony Purdy. "Present Signs, Dead Things: Indexical Authenticity and Taxidermy's Nonabsent Animal." Configurations 23, no. 1 (2015): 61-92.

Hanner, Robert, Angélique Corthals, and Rob DeSalle. "Biodiversity, Conservation, and Genetic Resources in Modern Museums and Herbarium Collections." Conservation Genetics in the Age of Genomics, edited by George Amato, Oliver Ryder, Howard Rosenblaum, and Rob DeSalle, 115-123. New York: Columbia University Press, 2009.

Haraway, Donna J."Teddy Bear Patriarchy: Taxidermy in the Garden of Eden, New York City, 1908-36." Primate Visions: Gender, Race, and Nature in the World of Modern Science. New York: Routledge, 1989.

---. Modest_Witness@Second_Millenium. New York and London: Routledge, 1997.

Hayles, N. Katherine. "Who is in Control Here? Meditating on Eduardo Kac's Transgenic Art." The Eighth Day: The Transgenic Art of Eduardo Kac, edited by 
Sheilah Britton and Dan Collins, 79-86. Tempe Arizona: The Institute for Studies in the Arts, 2003.

Hébert, Paul D. N., Alina Cywinska, Shelley L. Ball, and Jeremy R. deWard. "Biological Identification through DNA Barcodes." Biological Sciences 270, no. 1512 (Feb. 7, 2003): 313-321.

Hébert, Paul D. N. and T Ryan Gregory. "The Promise of DNA Barcoding for Taxonomy.” Systematic Biology 54, no. 5 (Oct., 2005): 852-859.

Henning, Michelle. "Skins of the Real: Taxidermy and Photography." nanoq: flat out and bluesome, A Cultural Life of Polar Bears. 136-147. Snæbjörnsdóttir/Wilson, [Exhibition catalogue]. Spike Island Gallery, Bristol: Black Dog Publishing, 2006.

---. Museums, Media, and Cultural Theory. Maidenhead, Berkshire: Open University Press, 2006.

Hesse-Honegger, Cornelia and Peter Walliman. "Malformation of the True Bug (Heteroptera): a Phenotype Field Study on the Possible Influence of Artificial Low-Level Radioactivity." Chemistry and Biodiversity 5 (2008), 499-539.

Hirszfield, Aleksandra. "May the Horse Live in Me (interview with Art Orienté Objet)." http://artandsciencemeeting.pl/?page id=306\&lang=en

Hooper-Greenhill, Eilean. Museums and the Shaping of Knowledge. London: Routledge, 1992.

Hunter, Michael. "The Cabinet Institutionalized: The Royal Society's 'Repository' and its Background." in The Origins of Museums: The Cabinet of Curiosities in Sixteenth- and Seventeenth-Century Europe, edited by Oliver Impey and Arthur MacGregor, 159-168. Oxford: Clarendon Press, 1985.

Jha, Alok. "First lab-grown hamburger gets full marks for "mouth feel."” The Guardian. August 6, 2013. https://www.theguardian.com/science/2013/aug/05/world-firstsynthetic-hamburger-mouth-feel,

Jordanova, Ludmilla. "Objects of Knowledge: A historical Perspective on Museums." The New Museology, edited by Peter Vergo, 22-40. London: Reaktion Books, 1989.

Kac, Eduardo. Telepresence and Bio Art. Ann Arbor: University of Michigan Press, 2005.

---. "Life Transformation - Art Mutation." Signs of Life: Bio Art and Beyond, edited by Eduardo Kac, 163-184. Cambridge Massachusetts: The MIT Press, 2007.

Kaczynski, Ivona. "An Ecosystem Like No Other." in Field Guide to the Wildlife of Mark Dion's Seattle Vivarium, Seattle: Olympic Sculpture Park [Seattle Art Museum], 2007.

Karl S. Kruszelninicki. "Great Moments in Science: Mouse with Human Ear.” June 2, 2006. www.abc.net.au/science/k2/moments/s1644154.htm 
Kohler, Robert H. Landscapes and Labscapes: Exploring the Lab-Field Border in Biology. Chicago: University of Chicago Press, 2002.

Kopytoff, Igor. "The cultural biography of things: commoditization as process." The social life of things: Commodities in cultural perspective 68 (1986): 70-73.

Lange-Berndt, Petra. "A Parasitic Craft: Taxidermy in the Art of Tessa Farmer." The Journal of Modern Craft 7, no. 3 (2014): 267-284.

Latour, Bruno and Steve Woolgar. Laboratory Life: The Construction of Scientific Facts. Princeton, New Jersey: Princeton University Press, 1979.

Laval-Jeantet, Marion. “The Fusional Haptics of Art Object orienté.” Sk-interfaces: Exploding Borders - Creating Membranes in Art, Technology, and Society, edited by Jens Hauser, 90-95. Liverpool: FACT and Liverpool University Press, 2008.

Lord, Beth. "Foucault's Museum: Difference, Representation, and Genealogy," Museum and Society 4, Issue 1 (March 2006): 1-14.

Losonky, Michael. "Leibiz's Academic Language of Thought." Journal of the History of Philosophy 30, no. 4. (October 1992): 523-543.

Lucie-Smith, Edward. "Eduardo Kac and Transgenic Art." The Eighth Day: The Transgenic Art of Eduardo Kac, edited by Sheilah Britton and Dan Collins, 2026. Tempe Arizona: The Institute for Studies in the Arts, 2003.

Manfredi, Michael and Marion Weiss. Surface/Subsurface. New York: Princeton Architectural Press, 2008.

Marsh, Joanna. "Fieldwork.” American Art 23, no. 2 (2009), 32-53.

Marshall, Eliot. "DuPont ups ante on Use of Harvard's OncoMouse.” Science 296, no. 5571 (2002): 112.

Mitchell, W. J. T. "The Work of Art in the Age of Biocybernetic Reproduction." What do Pictures Want: The Lives and Loves of Images. Chicago: University of Chicago Press, 2005. 309-335

Murray, Fiona. "The Oncomouse That Roared: Hybrid Exchange Strategies as a Source of Distinction at the Boundary of Overlapping Institututions." American Journal of Sociology 116, no.2 (2010): 341-388.

Outram, Dorinda, "New Spaces in Natural History." Cultures of Natural History, edited by N. Jardine, J.A. Secord, and E.C. Spary, 249 -265. Cambridge and New York: Cambridge University Press, 1996.

Park, Katherine and Lorraine Daston. "Unnatural Conceptions: The Study of Monsters in Sixteenth- and Seventeenth-Century France and England." Past \& Present 92, (August 1981): 20.

Pearce Susan M. Museums, Objects, and Collections: A Cultural Study. Washington, D.C.: Smithsonian Institution Press, 1993.

Pell, Richard and Lauren B. Allen. "Preface to a Geneology of the PostNatural." Intercalations 2: Land \& Animal \& Non-Animal, edited by Anna-Sophie Springer 
\& Etienne Turpin, 75-100. Berlin: K. Verlag and the Haus der Kulturen der Welt, 2015.

Pell, Richard. Atomic Age Rodents. Pittsburgh: The Center for PostNatural History, 2013.

Perry, Paul. "Good and Evil on the Long Voyage." Signs of Life: Bio Art and Beyond, edited by Eduardo Kac, 211-214. Cambridge Massachusetts: The MIT Press, 2007.

Poliquin, Rachel. "The Matter and Meaning of Museum Taxidermy." Museum and Society 6, no. 2 (2008): 123-134.

---. "Botched Animals and Enigmatic Beasts." Curious Collectors, Collected Curiosities: An Interdisciplinary Study, edited by Janelle A. Schwartz and Nhora Lucia Serrano, 40-50. Newcastle Upon Tyne: Cambridge Scholars Publishing, 2010.

---. The Breathless Zoo: Taxidermy and the Culture of Longing. University Park, Pennsylvania: The Pennsylvania State University Press, 2012.

Pollack, Robert. Signs of Life. Boston and New York: Houghton Mifflin Company, 1994.

Putnam, James. Art and Artifact: The Museum as Medium. New York: Thames \& Hudson, 2001.

Raffles, Hugh. Insectopedia. New York: Vintage Books, 2011.

Reodica, Julia. "Test Tube Gods and Microscopic Monsters.” The Aesthetics of Care? The artistic, social and scientific implications of the use of biological/medical technologies for artistic purposes, edited by Oron Catts, 46-51. Perth, Australia: SymbioticA, School of Anatomy and Human Biology, University of Western Australia, 2002.

Ritvo, Harriet. The Platypus and the Mermaid and Other Figments of the Classifying Imagination. Cambridge, Massachusetts: Harvard University Press, 1997.

Roberts, Jason Scott and Francoise Baylis, "Crossing Species Boundaries," The American Journal of Bioethics 3, no. 3 (2003): 1-13.

Ryan, James R. Picturing Empire: Photography and the Visualization of the British Empire. London: Reaktion Books, 1997.

Savalescu, Julian. "Human-Animal Transgenesis and Chimeras Might be an Expression of Our Humanity." The American Journal of Bioethics 3, no. 3 (2003): 22-25.

Shearer, Rhonda Roland and Stephen J. Gould. "Of Two Minds and One Nature." Science 286. no. 5442 (5 November 1999): 1093.

Simon, Jonathan. "The Theatre of Anatomy: The Anatomical Preparations of Honoré Fragonard." Eighteenth Century Studies 36, no.1 (2002): 63-79.

Singer, Thomas C. "Hieroglyphs, Real Characters, and the Idea of Natural Language in English Seventeenth Century Thought", Journal of The History of Ideas, Vol. 50, No. 1 (1989): 49-70.

Skloot, Rebecca. The Immortal Life of Henrietta Lacks. New York: Crown Publishing Group, 2010. 
Slaughter, Mary M., Universal Languages and Scientific Taxonomy in the Seventeenth Century. Cambridge: Cambridge University Press, 1982.

Star, Susan Leigh. "Craft vs. Commodity, Mess vs. Transcendence: How the Right Tool Became the Wrong One in the Case of Taxidermy and Natural History." The Right Tools for the Job, edited by Adele E. Clarke and Joan H. Fujimura, 257286. Princeton, New Jersey: Princeton University Press, 1992.

Steensma, David P., Robert A. Kyle, and Marc A. Shampo. "Abbie Lathrop, the "mouse woman of Granby": rodent fancier and accidental genetics pioneer." In Mayo Clinic Proceedings 85, no. 11. Mayo Foundation (2010), e83.

Stephens, Elizabeth. "World's first Lab-grown burger? Don't forget the first semi-living steak.” Science Alert. August 13, 2013. http://www.sciencealert.com/worlds-firstlab-grown-burger-dont-forget-the-semi-living-steak

---. "Making Monsters: Bio-Engineering and Visual Arts Practice." In Corporeality and Culture: Bodies in Movement. Edited by Karin Sellberg, Lena Wånggren, and Kamillea Aghtan, 53-66. Farnham, Surrey: Ashgate, 2015.

Teukolsky, Rachel. "This Sublime Museum: Looking at Art at the Great Exhibition." Victorian Prism: Refractions of the Crystal Palace, edited by James Buzard, Joseph W. Childers, and Eileen Gillooly, 84-100. Charlottesville and London: University of Virginia Press, 2007.

The Theogeny of Hesiod, ii 319, Trans. Hugh G. Evelyn-White, 1914. http://www.sacredtexts.com/cla/hesiod/theogony.htm

Ullrich, Jessica. "Taxidermic Hybrid Animals in Contemporary Art." Henry Moore Institute: Online Papers and Proceedings. http://www.henry-moore.org/hmijournal/homepage/view-by-conference/against-nature/taxidermic-hybrid-animalsin-contemporary-art/page-1

Van Valen, Leigh and Virginia C. Maiorana. "HeLa, a new microbial species." Evolutionary Theory and Review 10 (1991): 71-74.

Warner, Marina, Dorothy Cross, Tom Cross. "Medusae." Experiment: conversations in art and science. Edited by Bergit Arends and Davina Thackara, 16-61. London: the Wellcome Trust, 2003.

Waterton, Claire, Rebecca Ellis, and Brian Wynne. Barcoding Nature: Shifting Cultures of Taxonomy in an Age of Biodiversity Loss. London and New York: Routledge, 2014.

Welchman, John C. "Introduction." In Sculpture and the Vitrine, edited by John C. Welchman, 1-22. Farnham Surrey: Ashgate Publishing, 2013.

Wells, H. G. "The Limits of Individual Plasticity." H. G. Wells: Early Writings in Science and Science Fiction, edited by R. M. Philmus and D. Y. Hughes, 36-39. Berkley: University of California Press, 1975.

Will, Kipling W., Brent D. Mishler, and Quentin D. Wheeler. "The Perils of DNA Barcoding and the Need for Integrative Taxonomy." Systematic Biology 54, no. 5 (Oct., 2005): 844-851. 
Wonders, Karen. Habitat Dioramas: Illusions of Wilderness in Museums of Natural History. Uppsala: Acta Universitatis Upsaliensis, 1993.

Woods, May and Arete Swartz Warren. Glass Houses: A History of Greenhouses, Orangeries and Conservatories. London: Aurum Press, 1988.

Zurr, Ionat. "Growing Semi-Living Art." PhD diss. The University of Western Australia, 2008. 


\section{Curriculum Vitae}

\section{HELEN GREGORY}

\section{EDUCATION}

University of Western Ontario

$\mathrm{PhD}$ (Art and Visual Culture)

2011-2016

Memorial University

MPhil (Humanities)

2008-2011

Concordia University

BFA

1989-1993

\section{HONOURS AND AWARDS}

Graduate Thesis Research Award

Faculty of Arts and Humanities, University of Western Ontario 2015

Canada Graduate Scholarship

Social Sciences and Humanities Research Council of Canada

2012-2015

Ontario Graduate Scholarship, Doctoral (declined)

2012

Western Graduate Research Scholarship

University of Western Ontario

2011-2012

President's Entrance Scholarship

Faculty of Arts and Humanities, University of Western Ontario

2011

Graduate Research Travel Grant

Department of Fine Arts, University of Western Ontario

2013, 2014, 2015 


\section{PUBLICATIONS}

Gregory, Helen. "The Souvenir And The Collection: Taxidermy, Photography and the Archetype of the Colonial Hunter in the Exhibition nanoq: flat out and bluesome." Museums, Marginality and the Mainstream. (2012): 33-48.

Gregory, Helen and Anthony Purdy. "Present Signs, Dead Things: Indexical Authenticity and Taxidermy's Nonabsent Animal." Configurations 23, no. 1 (2015): 61-92.

\section{CONFERENCES}

"Curious Instances and Chimeric Blobs: Disrupting definitions of natural history specimens through contemporary art practice," Association of Art Historians Conference, University Of East Anglia, Norwich, United Kingdom, April 9-11, 2015

"Curious Instances and Chimeric Blobs: Disrupting definitions of natural history specimens through contemporary art practice," "Curiosity 2.0" Conference, Kulturstiftung des Bundes, Dresden, Germany, January 16-17, 2015

"A Meeting of Nature and Culture: expanding definitions of natural history specimens through contemporary art practices," University Art Association of Canada Conference, Toronto, Ontario, October 23-26, 2014

"A Meeting of Nature and Culture: expanding definitions of natural history specimens through contemporary art practices," Society for Literature, Science, and the Arts Conference: "Fluid," Dallas, Texas, October 9-12, 2014

"The Skin of the Animal: Authenticity and the Uncanny in Contemporary Taxidermy," University Art Association of Canada Conference, Banff, Alberta, October 17-19, 2013

"The Unintentional Museum: Mark Dion's Archaeological Digs and the Aesthetics of Garbage," Society for Literature, Science, and the Arts Conference: "The PostNatural," University of Notre Dame, South Bend, Indiana, October 3-6, 2013

"The Souvenir and the Collection: Taxidermy and Photography in the Exhibition nanoq: flat out and bluesome," Department of Art History and Communications Conference: "The Tangible," McGill, Montreal, Québec, April 26, 2012

"Unrequited Death," (artist's lecture), Canadian Museum of Nature, Ottawa, Ontario, June 2012 
"Transgenesis and the Chimera in Contemporary Art," Department of Art Graduate Symposium "Experimental Cutures: Mergers of Art and Science," University of Toronto, Toronto, Ontario, January 27, 2012

"Unrequited Death," (artist's lecture), The Rooms Provincial Art Gallery, St. John's Newfoundland, February 3, 2010

"Anatomy Lessons: Écorchés, Wax Anatomical Models, and the Grotesque Body," Humanities Department Colloquium "Words in Edgewise," Eastern Edge Gallery, St. John's Newfoundland, October 14, 2010

"Exquisite Corpse: Contiguity and Meaning in the Work of Cornelia Parker," Humanities Department Conference "Mediating the Aesthetic," Memorial University, St. Johns, Newfoundland, September 21, 2008

\section{PROFESSIONAL EXPERIENCE}

Graduate Teaching Assistant, University of Western Ontario

VAH1045 Collecting Art and Culture (art history), Winter 2015

Graduate Teaching Assistant, University of Western Ontario

VAH1041 Art and Power (art history), Fall 2013

Instructor of Record, University of Western Ontario

VAH1053 Picturing Science (art history), Fall 2012

Graduate Teaching Assistant, University of Western Ontario

VAS3380 Art Criticism (studio), Fall 2011-Winter 2012

Artist in Residence

Canadian Museum of Nature, May-June, 2012

\section{SELECTED EXHIBITIONS - SOLO}

Specimen, Concourse Gallery, John Labatt Visual Arts Centre, University of Western Ontario, London, Ontario, 2013

Unrequited Death, The Canadian Museum of Nature, Ottawa, Ontario, 2012

Unrequited Death, The Rooms Provincial Art Gallery, St. John's, Newfoundland, 2009

Desiccate, Gallery Page and Strange, Halifax, Nova Scotia, 2006 


\section{SELECTED EXHIBITIONS - GROUP}

Make/Shift, artLAB, University of Western Ontario, London Ontario, 2012

25 for 25, Mary March Provincial Museum (a division of The Rooms), Grand FallsWindsor, Newfoundland, 2012

Animal Kingdom, Beaverbrook Art Gallery, Fredericton, New Brunswick, 2010-11

Seven Artists/Seven Residencies, Sir Wilfred Grenfell College Art Gallery, Corner Brook, Newfoundland, 2009

Marion McCain Atlantic Art Exhibition, Beaverbrook Art Gallery, Fredericton, New Brunswick, 2007 and 2004

Pulp Fictions, Confederation Centre for the Arts, Charlottetown, Prince Edward Island, 2003

“What's That You're Reading?” Galérie Articule, Montréal, Quebec, 2001

Bookmarks, AKA Gallery, Saskatoon, Saskatchewan, 1999

\section{COLLECTIONS}

National Gallery of Canada, Ottawa, Ontario

Victoria and Albert Museum, London, UK

National Library of Canada, Ottawa, Ontario

The Rooms Provincial Art Gallery, St. John's, Newfoundland

Beaverbrook Art Gallery, Fredericton, New Brunswick

La Collection Loto-Quebec, Montreal, Quebec

Government of Newfoundland and Labrador

City of St. John's Civic Art Collection, St. John's, Newfoundland 